\title{
ZOOTAXA
}

5002

\section{Revision of Tomosvaryella Aczél (Diptera: Pipunculidae) in the Middle East, with description of 19 new species}

\footnotetext{
BEHNAM MOTAMEDINIA ${ }^{1,2 *}$, JEFFREY H. SKEVINGTON ${ }^{1,3}$ \& SCOTT KELSO ${ }^{1,4}$

${ }^{I}$ Canadian National Collection of Insects, Arachnids and Nematodes, Agriculture and Agri-Food Canada, 960 Carling Avenue, Ottawa, ON K1A 0C6, Canada.

${ }_{2}^{2}$ Plant Protection Research Department, South Khorasan Agricultural and Natural Resources Research and Education Center, AREEO, Birjand, Iran

${ }^{3}$ Carleton University, Biology Department, 207 Nesbitt Biology Building, 1125 Colonel By Drive, Ottawa, ON K1S 5B6, Canada ="jhskevington@gmail.com; 으ttps://orcid.org/0000-0002-1445-9870

4 ”scott.kelso@canada.ca; @ ittps://orcid.org/0000-0001-5559-9477

"Corresponding author. =" bmoetamedi@yahoo.com; @ https://orcid.org/0000-0002-6697-4030
}

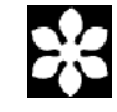

Magnolia Press

Auckland, New Zealand 
BEHNAM MOTAMEDINIA, JEFFREY H. SKEVINGTON \& SCOTT KELSO

Revision of Tomosvaryella Aczél (Diptera: Pipunculidae) in the Middle East, with description of 19 new species

(Zootaxa 5002)

103 pp.; $30 \mathrm{~cm}$.

16 Jul. 2021

ISBN 978-1-77688-302-8 (paperback)

ISBN 978-1-77688-303-5 (Online edition)

FIRST PUBLISHED IN 2021 BY

Magnolia Press

P.O. Box 41-383

Auckland 1041

New Zealand

e-mail: magnolia@mapress.com

https://www.mapress.com/j/zt

(C) 2021 Her Majesty the Queen in Right of Canada, as represented by the Minister of Agriculture and AgriFood Canada.

ISSN 1175-5326 (Print edition)

ISSN 1175-5334 (Online edition) 


\section{Table of Contents}

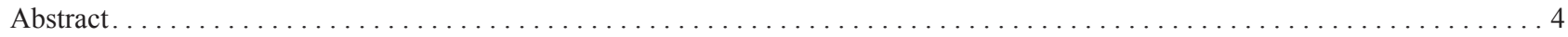

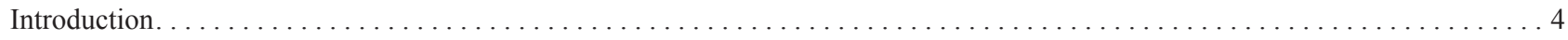

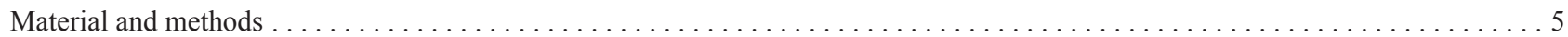

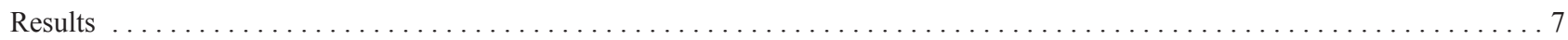

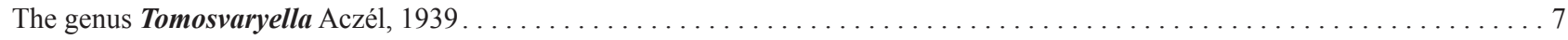

Key to males of the Middle Eastern species of Tomosvaryella ${ }^{*} \ldots \ldots \ldots \ldots \ldots \ldots \ldots \ldots \ldots \ldots \ldots \ldots \ldots \ldots \ldots$

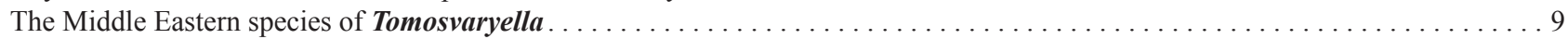

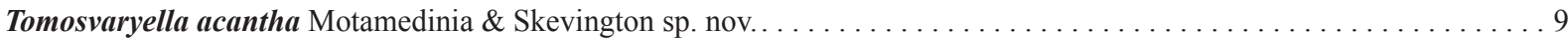

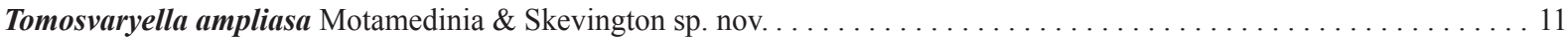

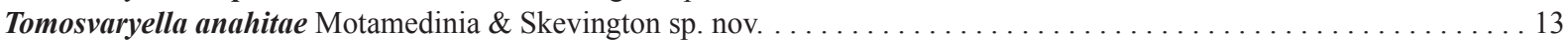

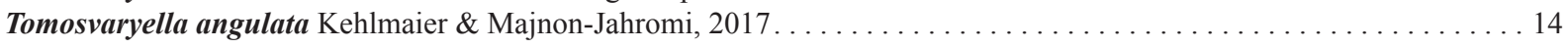

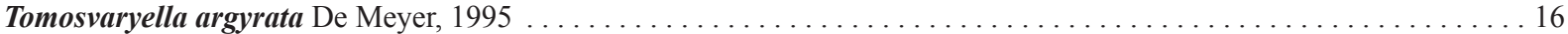

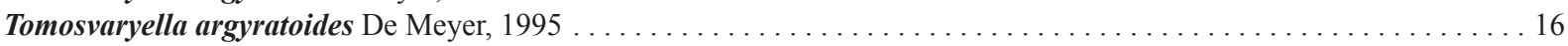

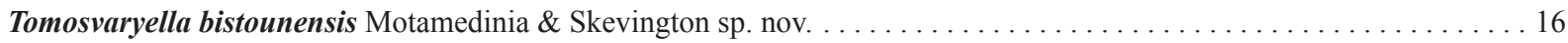

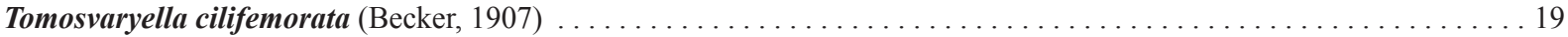

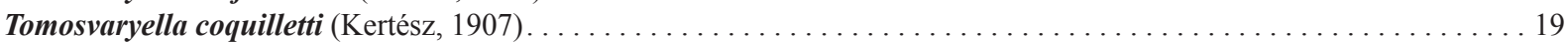

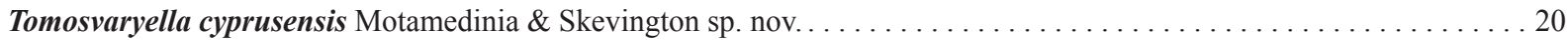

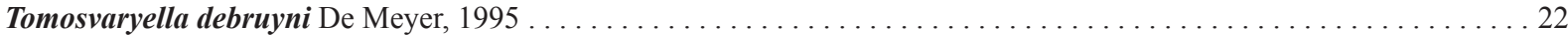

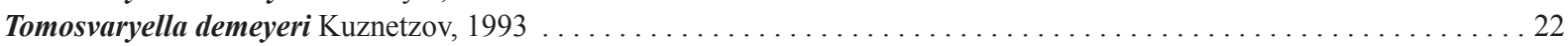

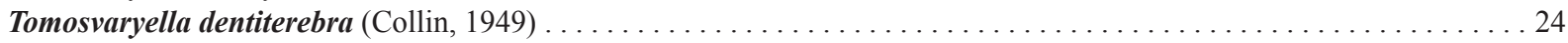

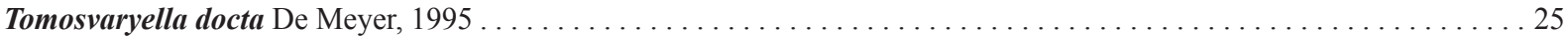

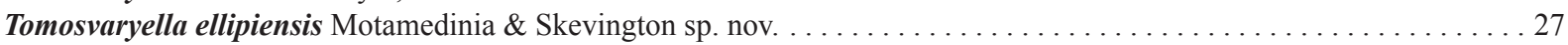

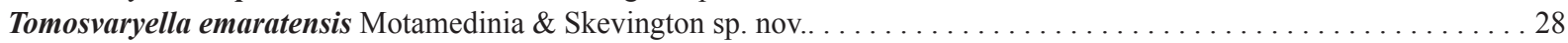

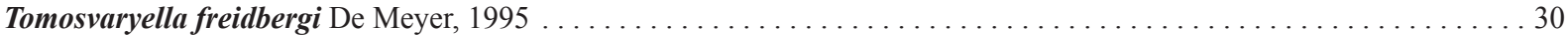

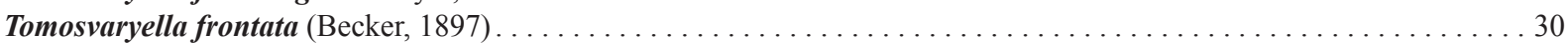

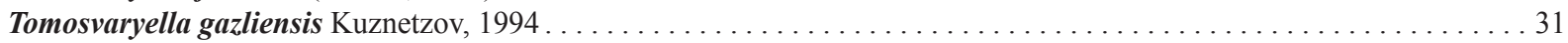

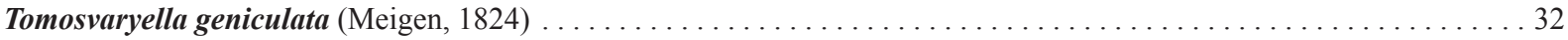

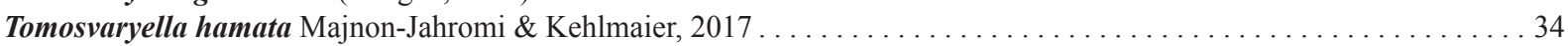

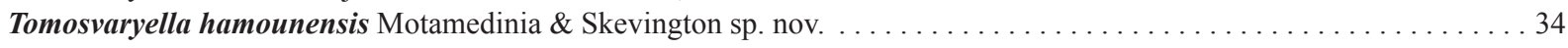

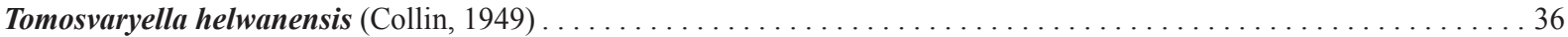

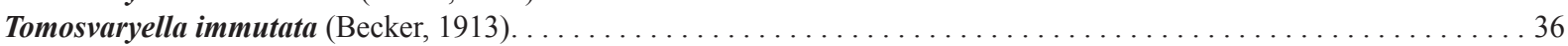

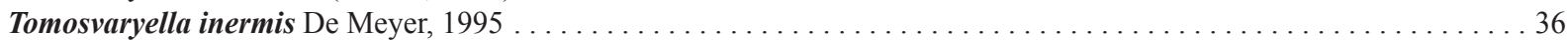

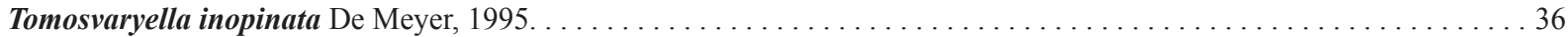

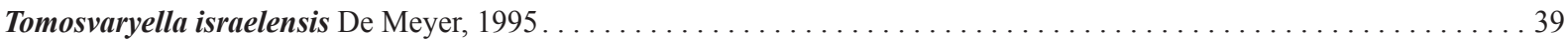

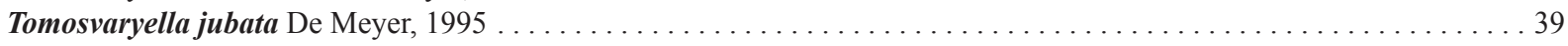

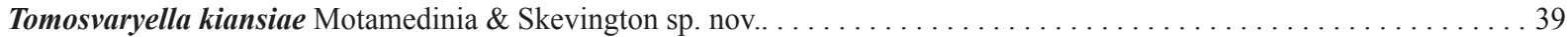

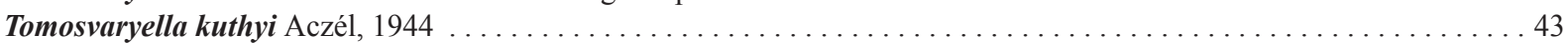

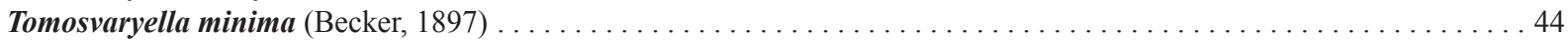

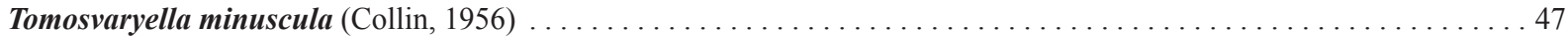

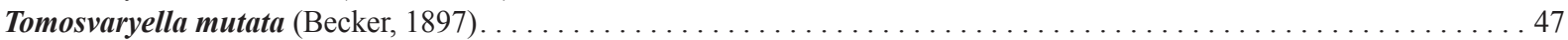

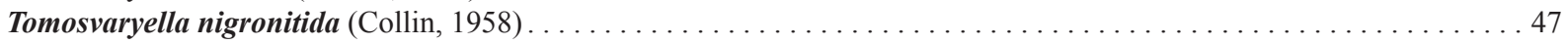

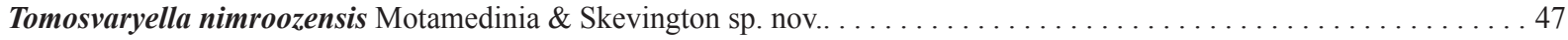

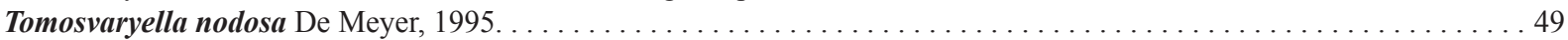

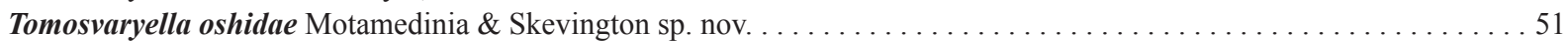

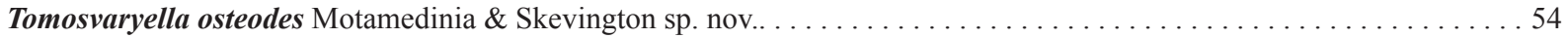

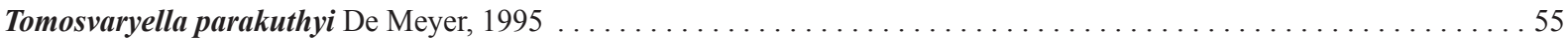

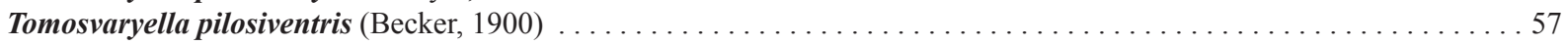

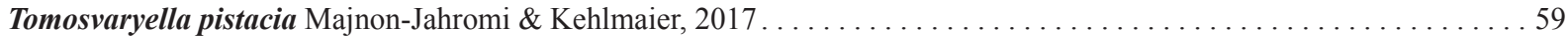

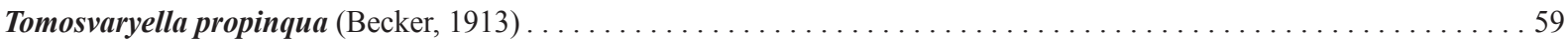

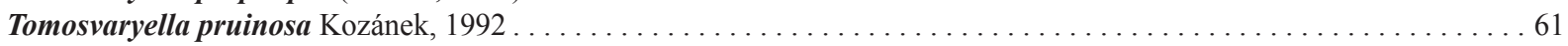

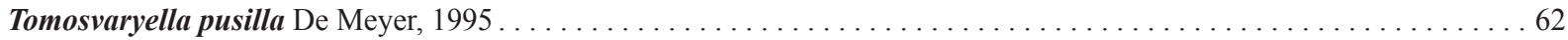

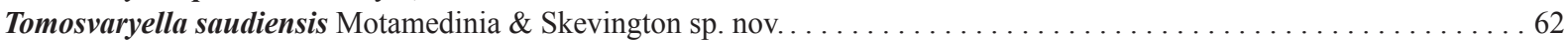

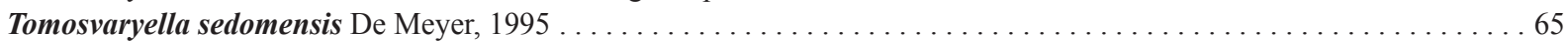

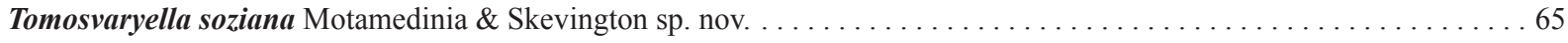

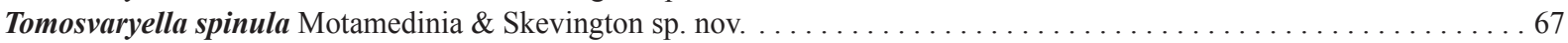

Tomosvaryella subsylvatica Kazerani, Khaghaninia \& Kehlmaier, $2017 \ldots \ldots \ldots \ldots \ldots \ldots \ldots \ldots \ldots \ldots \ldots \ldots \ldots$

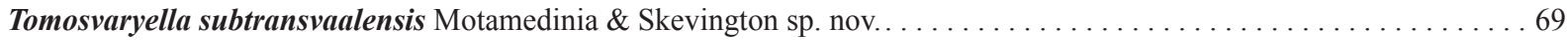

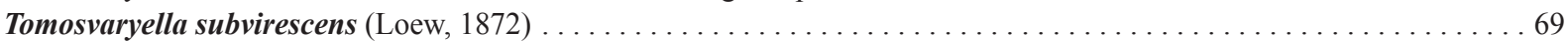

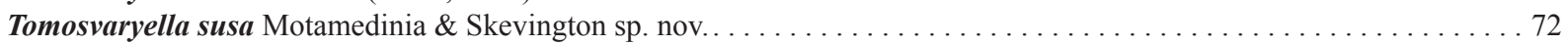

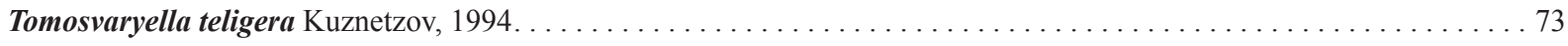

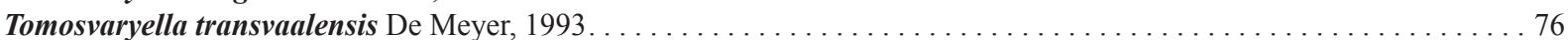

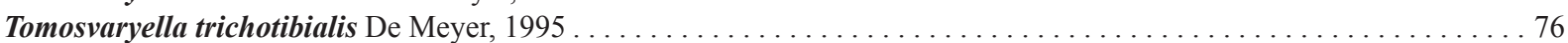




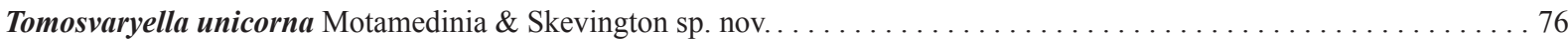

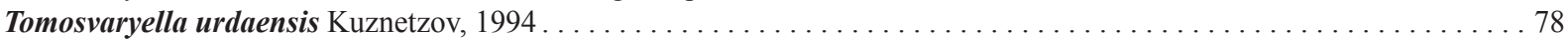

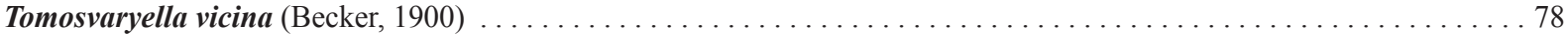

Tomosvaryella yemenensis Motamedinia \& Skevington sp. nov. $\ldots \ldots \ldots \ldots \ldots \ldots \ldots \ldots \ldots \ldots \ldots \ldots \ldots \ldots$

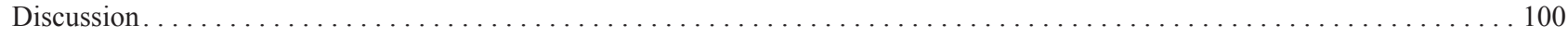

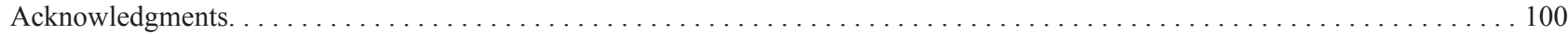

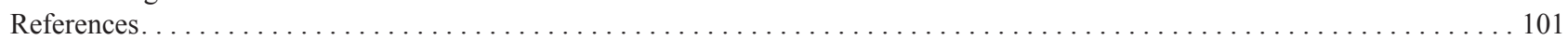

\begin{abstract}
The genus Tomosvaryella Aczél, 1939 is revised from the Middle East. Fifty-nine species are recorded and 19 of these are new to science: T. acantha Motamedinia \& Skevington sp. nov., T. ampliasa Motamedinia \& Skevington sp. nov., T. anahitae Motamedinia \& Skevington sp. nov., T. bistounensis Motamedinia \& Skevington sp. nov., T. cyprusensis Motamedinia \& Skevington sp. nov., T. ellipiensis Motamedinia \& Skevington sp. nov., T. emaratensis Motamedinia \& Skevington sp. nov., T. hamounensis Motamedinia \& Skevington sp. nov., T. kiansiae Motamedinia \& Skevington sp. nov., T. nimroozensis Motamedinia \& Skevington sp. nov., T. oshidae Motamedinia \& Skevington sp. nov., T. osteodes Motamedinia \& Skevington sp. nov., T. saudiensis Motamedinia \& Skevington sp. nov., T. soziana Motamedinia \& Skevington sp. nov., T. spinula Motamedinia \& Skevington sp. nov., T. subtransvaalensis Motamedinia \& Skevington sp. nov., T. susa Motamedinia \& Skevington sp. nov., T. unicorna Motamedinia \& Skevington sp. nov. and T. yemenensis Motamedinia \& Skevington sp. nov. are described and illustrated based on sequence information from the mitochondrial COI barcoding gene and morphological parameters. DNA barcodes are provided for 37 of the 59 species. Descriptions of new species, diagnoses, distribution maps and an illustrated key for all species are provided.
\end{abstract}

Key words: big-headed flies, COI, distribution map, DNA barcoding, identification key, mini barcode protocol, west Palaearctic

\title{
Introduction
}

Tomosvaryella Aczél, 1939 is a genus of parasitoid flies placed within the tribe Tomosvaryellini (Diptera: Pipunculidae: Pipunculinae). This cosmopolitan genus, with 284 described species, contains small to medium-sized species (1.5-4.6 $\mathrm{mm}$ ) found in many regions in the world (Skevington, 2020). Most pipunculid species are found in mesic habitats, but Tomosvaryella are most diverse in grasslands, deserts and other dry areas (Jeff Skevington's personal observation). Rafael \& De Meyer (1992) hypothesized that Tomosvaryella is closely related to Dorylomorpha Aczél, 1939 within the tribe Tomosvaryellini which can be separated from other tribes by the lack of pterostigma on wings. Most Tomosvaryella species can be differentiated from Dorylomorpha by the position of cross-vein r-m, which is near the middle of discal cell.

Recent taxonomic treatments of Tomosvaryella have focused on different regions and described some new species to science, i.e. one new species from central and western Europe (Földvári \& De Meyer 1999), three from the Mediterranean Basin (Kehlmaier et al. 2019), four from Iran (Kazerani et al. 2017; Majnon-Jahromi et al. 2017a, b), 16 from the Afrotropical Region (De Meyer 1993), 19 from the Neotropical Region (Ale-Rocha \& Rafael 1995; Ale-Rocha 1996; Ramos-Pastrana \& Rafael 2021) and three from Fiji (Skevington \& Földvári 2007).

The Tomosvaryella fauna of the Middle East [here defined as the area including Bahrain, Cyprus, Iran, Iraq, Israel, Jordan, Kuwait, Lebanon, Oman, Palestine, Qatar, Saudi Arabia, Syria, Turkey, United Arab Emirates, and Yemen] includes 38 previously reported species (Skevington 2020), but many more are expected in this ecologically diverse and extensive area.

The purpose of this paper is to update our knowledge of Middle Eastern Tomosvaryella and to provide a single point of reference for future work on this genus in the region. The taxonomy is explored using a combination of morphological characters and DNA barcoding and an identification key to males is provided. 


\section{Material and methods}

Morphological study. This study is based on the examination of all available material from the following collections: CNC (Canadian National Collection of Insects, Arachnids and Nematodes), EAD (Environment Agency of Abu Dhabi, United Arab Emirates), HMIM (Hayk Mirzayans Insect Museum, Insect Taxonomy Research Department, Iranian Research Institute of Plant Protection, Tehran, Iran), TAU (Tel Aviv University, Israel) and USNM (National Museum of Natural History, Washington, DC, USA).

The specimens were collected with Malaise traps, funnel Malaise traps, sweep net, pan traps and light traps based on the label data. All specimens are labelled with a unique reference number from the CNC database (e.g., Jeff_Skevington_Specimen12345 and CNC_Diptera12345, abbreviated as JSS12345 and CNCD12345 respectively) and can be accessed at https://cnc.agr.gc.ca/. Specimens from traps were collected into $60 \%-90 \%$ ethanol, serial dehydrated into absolute ethanol, then dried by critical-point drying (CPD) and pointed. Male genitalia were separated from the abdomen and stored in microvials containing glycerin after clearing in hot lactic acid (85\%) at $100^{\circ} \mathrm{C}$ for $30-240$ minutes. For some darker genitalia, terminalia were treated with $10 \% \mathrm{KOH}$ at $100^{\circ} \mathrm{C}$ for $10-120$ minutes then neutralized in glacial acetic acid for 5 minutes. Terminalia were washed with ethanol before placing them into glycerin. All examined males were included in the type series of new species and female specimens were included if DNA data corroborated their linkage with sequenced males.

Morphological features were examined using Leica MZ16 and M80 stereomicroscopes with an ocular micrometer. Stacked external character photographs were taken using a Leica DFC450 camera with a $0.6 \times$ lens on a Leica M205C stereomicroscope. Final images were merged using the image-stacking software ZereneStacker (Littlefield 2018). The genitalia characters were imaged using a Leica DM5500B microscope equipped with a Leica DMC4500 module connected to a personal computer running the Leica Application Suite software (https://www.leica-microsystems.com), which includes an Auto-Montage module that combines multiple layers of photographs into a single fully focused image. All photos were subsequently modified using Adobe Photoshop CS3 ${ }^{\circledR}$ imaging software.

The morphological terminology follows Skevington (2002) and Kehlmaier (2005), with the following abbreviations being used throughout the paper: $\mathrm{LF}: \mathrm{WF}=$ length of flagellum to its width; LW:MWW=length of wing to maximum width of wing; LS:LTC=length of pterostigma to length of third costal segment; LTC:LFC=length of third costal segment to length of fourth costal segment; LT35:W5=length tergite 3-5 to maximum width of tergite 5; WT5:LT5=width of tergite 5 to length of tergite 5; T5R:T5L=length of right margin of tergite 5 to length of left margin of tergite 5; LT35:WS8=length tergite 3-5 to width of syntergosternite 8; LS8:HS8=length syntergosternite 8 to its height; MLE:MWE=maximum length of epandrium to maximum width of epandrium (viewed dorsally); LP:LB=length of piercer to length of base (viewed laterally); LDP:LPP=length of distal part of piercer to length of proximal part of piercer (viewed laterally). The genitalia terminology used in this study is shown in Fig. 1. SimpleMappr (Shorthouse, 2010) was used to create the species distribution maps.

Molecular study. Total genomic DNA was non-destructively extracted from two legs, or whole specimens (dried or in alcohol) using the DNeasy Blood \& Tissue Kit (Qiagen Inc., Santa Clara, CA, USA) following the manufacturer's protocol. Following extraction, specimens were critical-point dried and deposited as vouchers in all aforementioned collections.

For DNA barcoding, a $658 \mathrm{bp}$ fragment of the 5' end of the mitochondrial coding gene cytochrome oxidase subunit I (COI) was amplified using the primer pair LCO1490 and COI-Dipt-2183R, as previously described by Gibson et al. (2011). In some cases, initial attempts to amplify the full COI barcode failed, presumably due to the degradation of the DNA. In these cases, a COI mini-barcode protocol was employed in order to amplify a 214bp fragment (COI-Fx-C), located at the 3'-end of the COI barcode region, for species identification (Motamedinia et al. 2019). In the case of putative new species, efforts were made to amplify the 5 '-end and middle COI mini-barcode fragments (COI-Fx-A and COI-Fx-B respectively) that, when combined, provide a complete COI barcode sequence. Oligonucleotides (primers) used in this study are listed in Table 1. PCR amplifications were carried out in $25 \mu \mathrm{l}$ volumes, including $15.7 \mu \mathrm{l} \mathrm{ddH}_{2} \mathrm{O}, 2.5 \mu \mathrm{l} 10 \mathrm{X}$ Ex Taq PCR buffer (containing $20 \mathrm{mM} \mathrm{MgCl}_{2}$ ), $0.65 \mu \mathrm{l} 25$ $\mathrm{mM} \mathrm{MgCl}{ }_{2}, 1 \mu \mathrm{l}$ of each $10 \mu \mathrm{M}$ primer, $2 \mu 10 \mathrm{mM}$ dNTPs, $0.15 \mu \mathrm{l}$ Ex Taq HS DNA polymerase (TaKaRa Bio USA, Madison, WI, USA), and $2 \mu$ total DNA. Amplification cycles were performed on an Eppendorf ep Gradient S Mastercycler (Eppendorf AG, Hamburg, Germany). All PCR and sequencing reactions were performed with the following thermal cycler conditions: $94^{\circ} \mathrm{C}$ for 3 mins for 1 cycle, $94^{\circ} \mathrm{C}$ for $45 \mathrm{secs}, 45^{\circ} \mathrm{C}$ for $45 \mathrm{secs}, 72^{\circ} \mathrm{C}$ for $1 \mathrm{~min}$ for 45 cycles, $72^{\circ} \mathrm{C}$ for 5 mins for 1 cycle, followed by an unlimited step at $10^{\circ} \mathrm{C}$. Employing these standard PCR 


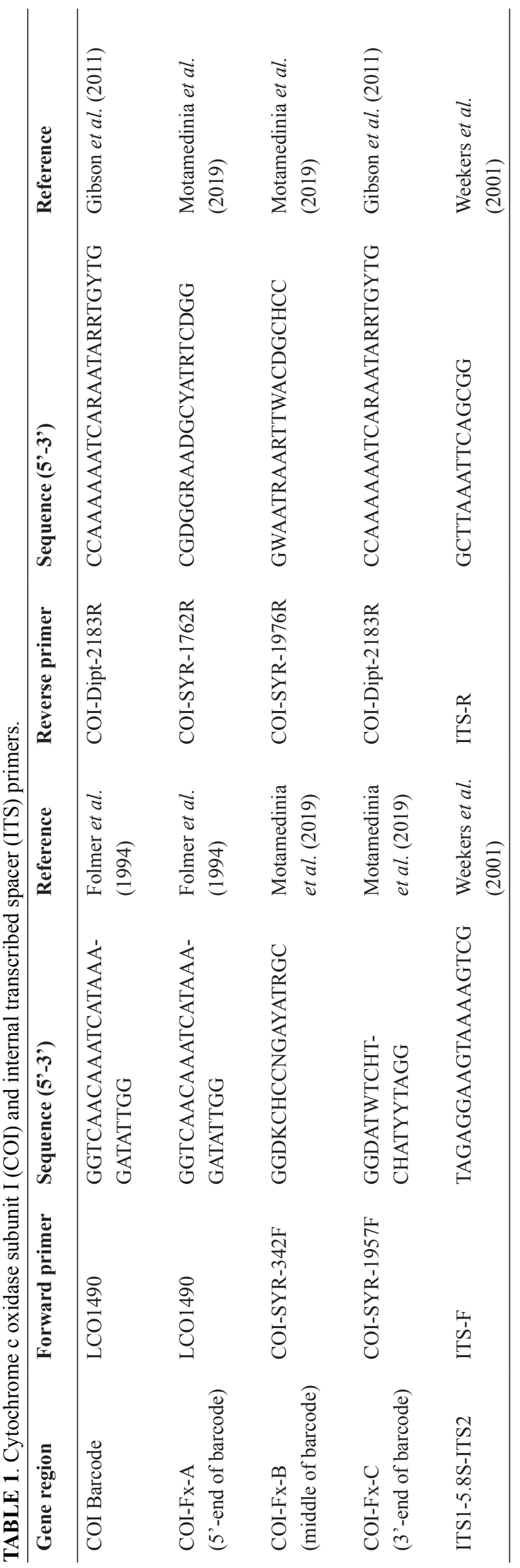


thermalcycler conditions for the ABI BigDye Terminator sequencing reactions is much more successful at sequencing a broad range of Diptera across a few dozen molecular markers and scores of oligos. Amplification products were visualized on 1\% agarose electrophoresis gels and purified using either E-Gel CloneWell Agarose Gels $0.8 \%$ (Invitrogen ${ }^{\mathrm{TM}}$, Carlsbad, CA, USA) for full barcode amplicons, or the enzymatic ExoSAP-IT clean-up protocol (USB Corp., Cleveland, OH, USA) for the mini-barcode amplicons. Bidirectional sequencing reactions with the original PCR primers were carried out in $10 \mu \mathrm{l}$ volumes, using the ABI BigDye Terminator v3.1 Cycle Sequencing kit (PE Applied Biosystems, Foster City, CA, USA), purified using the ABI ethanol/EDTA/sodium acetate precipitation protocol (https://assets.thermofisher.com/TFS-Assets/LSG/manuals/cms_041276.pdf), and analyzed on an ABI 3500xl Genetic Analyzer (PE Applied Biosystems, Foster City, CA, USA) at CNC.

Sequencing of $394 \mathrm{bp}-483 \mathrm{bp}$ of the ribosomal internal transcribed spacer (ITS2) region was carried out for several putative new species, where the morphological evidence suggested the specimens were unique species, but the COI barcode sequences were overlapping with similar species. The ITS2 region was amplified using oligonucleotides ITS-F and ITS-R as previously described by Weekers et al. (2001). PCR and sequencing reactions were carried out as described above for COI barcodes, except the annealing temperature used for PCR reactions was $50^{\circ} \mathrm{C}$.

All sequence chromatograms were edited and contigs formed using Sequencher 5.4.6 (Gene Codes Corp., Ann Arbor, MI, USA). Resulting contigs were hand-aligned using Mesquite 3.6 (Maddison \& Maddison 2018). Uncorrected pairwise genetic distances (p-distance) were calculated with MEGA7 (Kumar et al. 2016). The final COI dataset was $658 \mathrm{bp}$ long and contained 468 sequences of 50 species, of which 366 sequences were taken from GenBank (see Supplementary Table 1). Sequence accession numbers issued by GenBank (GB) are provided for each species in Table 2.

\section{Results}

\section{The genus Tomosvaryella Aczél, 1939}

Type species: Pipunculus sylvaticus Meigen, 1824, by original designation.

Diagnosis: Small to medium-sized species $(1.5-4.6 \mathrm{~mm})$, ground abdomen color metallic blue (Skevington \& Földvári 2007) to usually black, dorsocentral rows of hairs on prescutum and scutum with longer hairs anteriorly (Fig. $68 \mathrm{~A}-\mathrm{B}$ ), third costal section of wing very short, pterostigma absent, cross-vein r-m usually close to middle of discal cell (rarely more basal) (Fig. 68B,D) (Rafael \& De Meyer 1992).

Distribution: Cosmopolitan except Antarctica (Skevington 2020).

\section{Key to males of the Middle Eastern species of Tomosvaryella*}

*Three species are not included in the key. Tomosvaryella immutata (Becker, 1913) and T. nigronitida (Collin, 1958) are only known from females. Tomosvaryella propinqua (Becker, 1913) is known only from the syntype series which was not available for our examination.

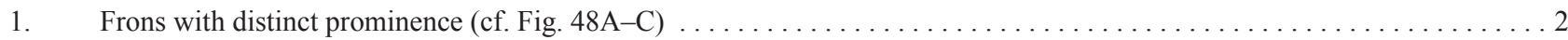

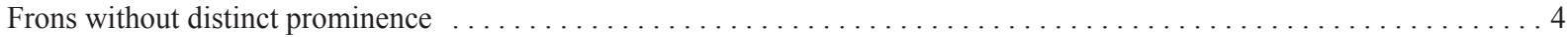

2. Surstyli elongated in dorsal view, about twice the length of epandrium; rectangular-shaped (Fig. $43 \mathrm{~A}$ ) . . T. unicorna sp. nov.

- $\quad$ Surstyli not elongated in dorsal view, about as long as epandrium; triangular-shaped $\ldots \ldots \ldots \ldots \ldots \ldots \ldots \ldots \ldots$

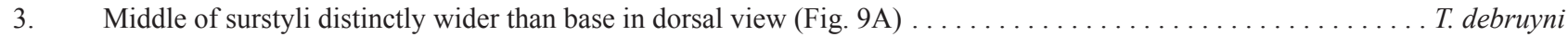
Middle of surstyli as wide as base in dorsal view (Fig. 41A) $\ldots \ldots \ldots \ldots \ldots \ldots \ldots \ldots \ldots \ldots \ldots$. $\ldots \ldots$ teligera Hind femur with distinct ventrobasal protuberance (see Kehlmaier \& Majnon-Jahromi, 2014: page 33, fig. 6) ... T. demeyeri

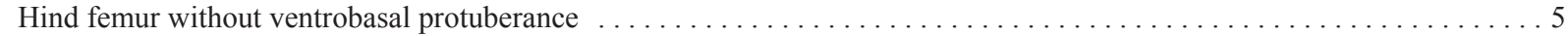

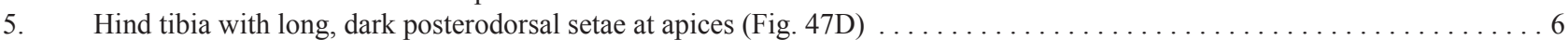

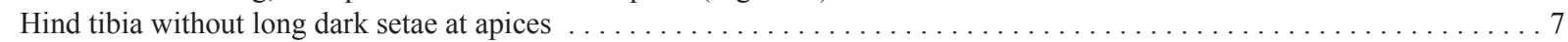

6. Surstyli with apicoventral triangular projection in lateral view (Fig. 45D-E) . . . . . . . . . . T. yemenensis sp. nov. Surstyli without apicoventral triangular projection in lateral view (see De Meyer, 1955: page 317, fig. 22b, c) .........

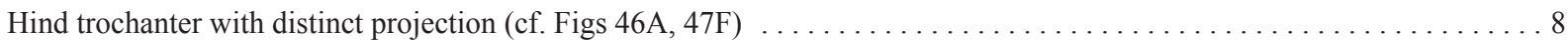

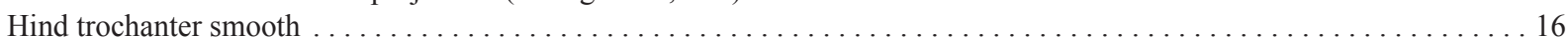




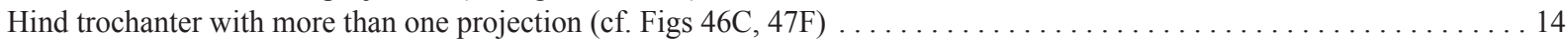

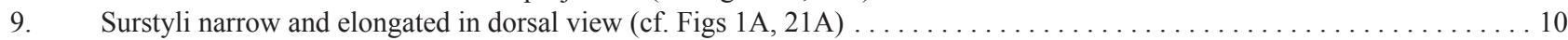

Surstyli different shape (not elongated) in dorsal view (cf. Figs 17A, 26A) $\ldots \ldots \ldots \ldots \ldots \ldots \ldots \ldots \ldots \ldots \ldots \ldots$

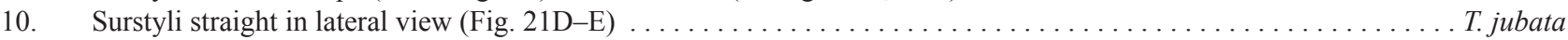

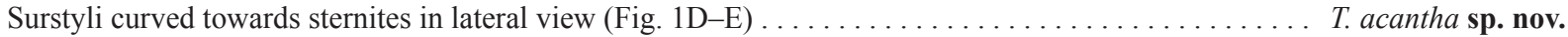

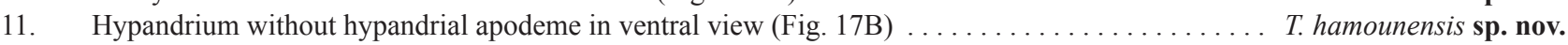

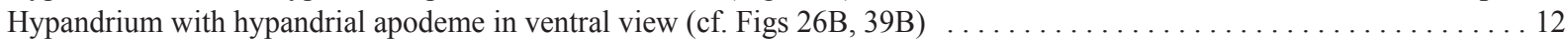

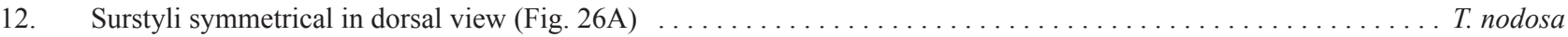

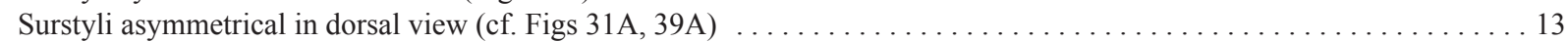

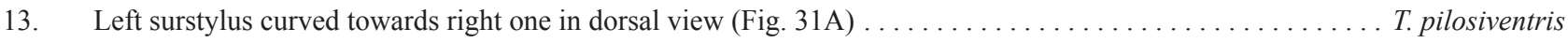

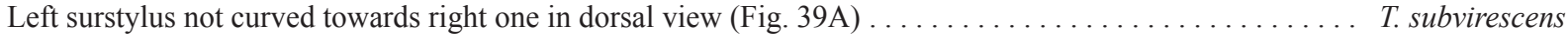

14. Surstyli very narrow in dorsal view (see Kazerani et al. 2017: page 5, fig. 3B) . . . . . . . . . . . . . . T. subsylvatica

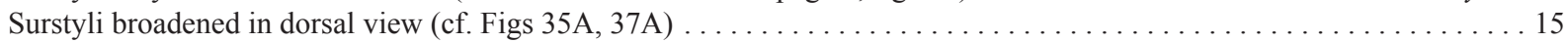

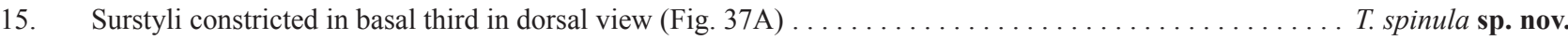

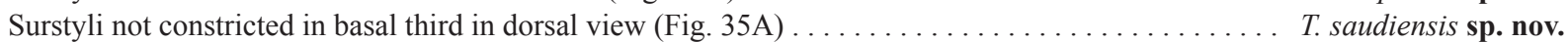

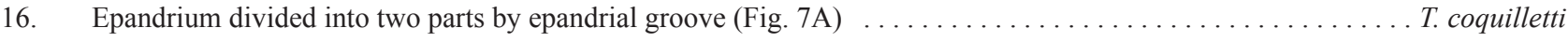

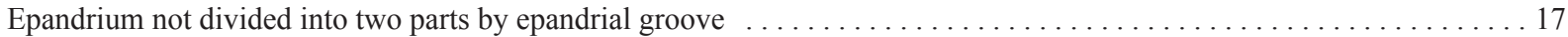

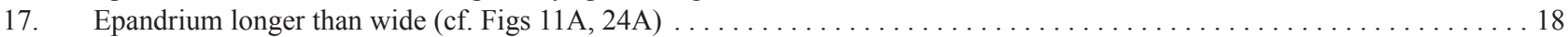

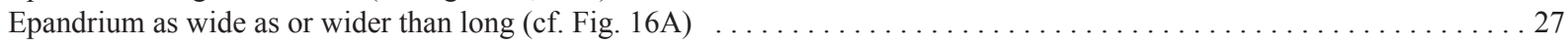

18. Right surstylus not curved towards left surstylus in dorsal view (Fig. 11A) $\ldots \ldots \ldots \ldots \ldots \ldots \ldots$. . . . . . . . . . . . . . . . . . . Right surstylus curved (or bent) towards left surstylus in dorsal view (cf. Fig. 24A) $\ldots \ldots \ldots \ldots \ldots \ldots \ldots \ldots$

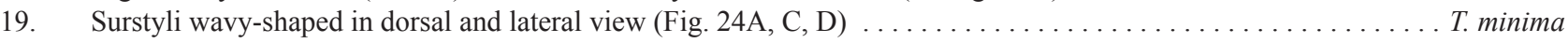

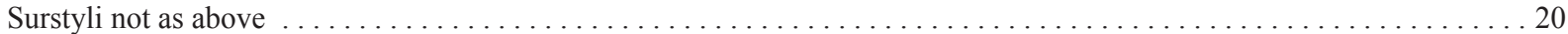

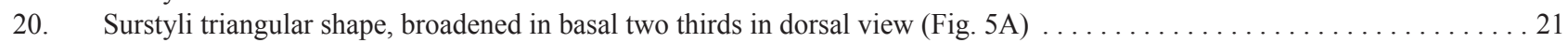

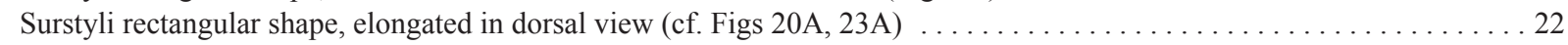

21. Hind femur ventrally with long setae (see De Meyer, 1995: page 299, fig. 9b) .................. Hind femur ventrally without long setae $\ldots \ldots \ldots \ldots \ldots \ldots \ldots \ldots \ldots \ldots \ldots \ldots \ldots \ldots \ldots \ldots \ldots \ldots \ldots \ldots$. argyratoides

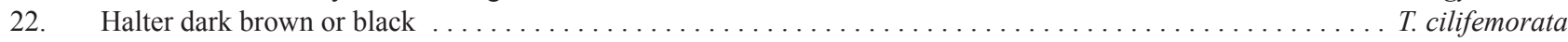

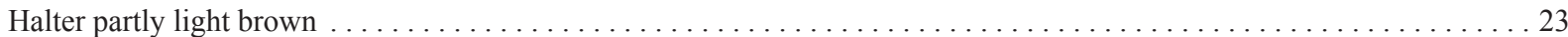

23. Both surstyli straight in lateral view (Fig. $8 \mathrm{D}-\mathrm{E}) \ldots \ldots \ldots \ldots \ldots \ldots \ldots \ldots \ldots \ldots \ldots \ldots \ldots$. cyprusensis $\mathbf{s p .}$ nov.

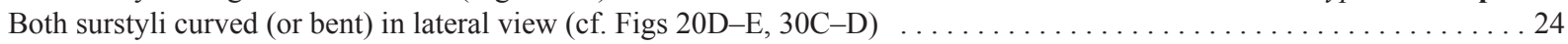

24. Left surstylus straight at dorsomedial margin in lateral view (Fig. 30C) $\ldots \ldots \ldots \ldots \ldots \ldots \ldots \ldots \ldots$..... parakuthyi Left surstylus curved at dorsomedial margin in lateral view (cf. Figs $14 \mathrm{D}, 20 \mathrm{D}, 23 \mathrm{C}$.) $\ldots \ldots \ldots \ldots \ldots \ldots \ldots \ldots$

25. Phallic guide with three distinct spine-like setae dorsally before the apex in lateral view (Fig. 14D-E) ........ T. freidbergi Phallic guide without spine-like setae dorsally in lateral view (cf. Figs 20D-E, 23C-D) $\ldots \ldots \ldots \ldots \ldots \ldots \ldots \ldots$

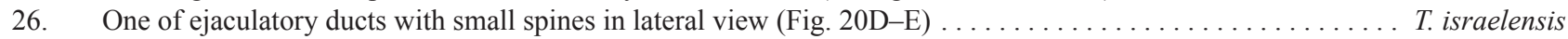

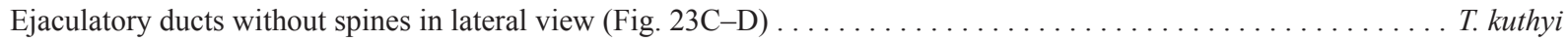

27. Phallic guide divided in lateral view (see Földvári \& De Meyer, 1999: page 314, fig. 13E-F) ........... T. minuscula

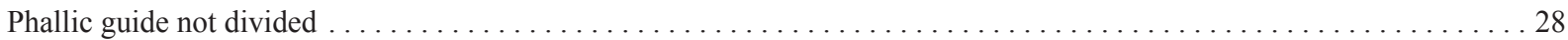

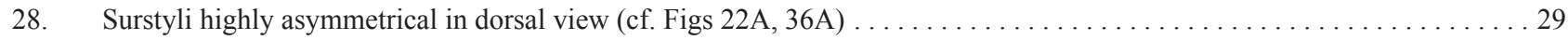

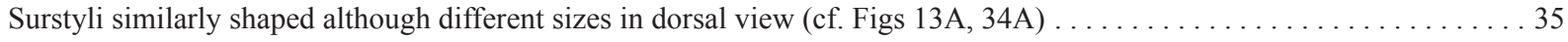

29. Left surstylus with ventromedial triangular-shaped projection in lateral view (Fig. 36D) ............... T. soziana sp. nov. Left surstylus without ventromedial triangular-shaped projection in lateral view (cf. Figs 10D, 22C) $\ldots \ldots \ldots \ldots$

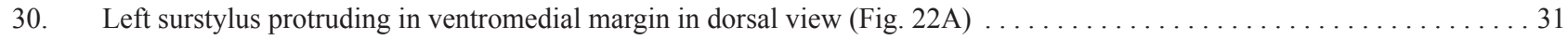

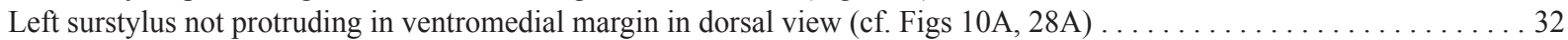

31. Right surstylus smaller than left one in dorsal view (see De Meyer, 1995: page 315, fig. 21) . . . . . .

Right surstylus as long as left one in dorsal view (Fig. 22A) . .

32. Right surstylus straight in dorsal view (Fig. 10A) $\ldots \ldots \ldots \ldots \ldots \ldots \ldots \ldots \ldots \ldots \ldots$ dentiterebra

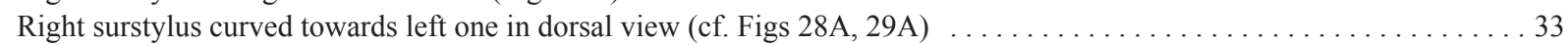

33. Right surstylus wider than left one basally in dorsal view (Fig. 28A) $\ldots \ldots \ldots \ldots \ldots \ldots \ldots \ldots \ldots$. oshidae sp. nov.

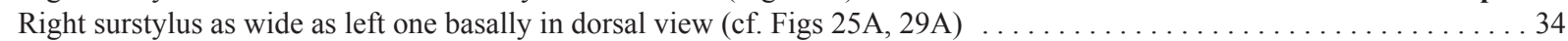

34. Left surstylus constricted in middle in dorsal view (Fig. 25A); both surstyli bent in middle in lateral view (Fig. 25E-F) .... .

T. nimroozensis sp. nov. Left surstylus not constricted in middle in dorsal view (Fig. 29A), both surstyli bent in apical third in lateral view (Fig. 29D-

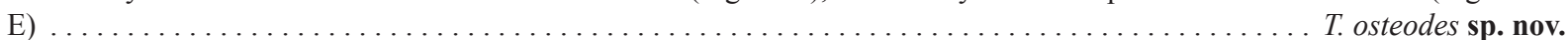

35. Surstyli elongated in dorsal view (length more than twice the width of base) (cf. Figs 13A, 34A) $\ldots \ldots \ldots \ldots \ldots \ldots$ Surstyli shortened in dorsal view (length less than twice the width of base) (cf. Figs 12A, 15A) $\ldots \ldots \ldots \ldots \ldots \ldots$

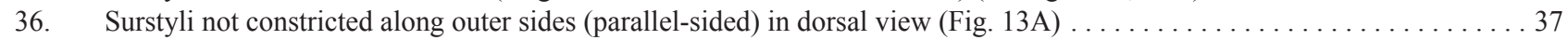

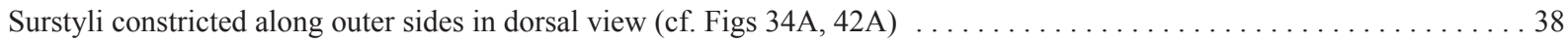

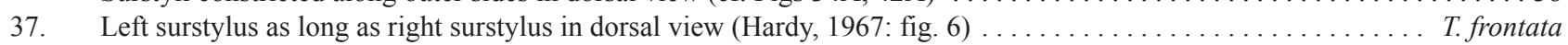

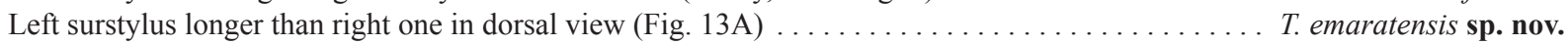

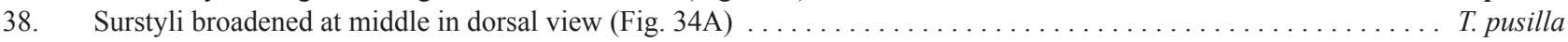
Surstyli not broadened at middle in dorsal view (cf. Figs 16A, 42A) . . . . . . . . . . . . . . . . . 39 
39. Left surstylus strictly bent towards sternites apically in lateral view (Fig. 16D) ................ T. geniculata

- $\quad$ Left surstylus curved towards sternites in middle in lateral view (cf. Figs 32D, 38D, 42D) $\ldots \ldots \ldots \ldots \ldots$

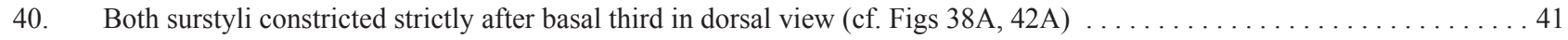

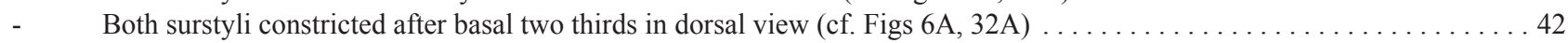

41. Surstyli with tips expanded medially in dorsal (Fig. 42D), hypandrium with hypandrial apodeme in ventral view (Fig. 42B) . ..... transvaalensis

Surstyli with tips swollen and knob-like in dorsal view (Fig. 38D), hypandrium without hypandrial apodeme in ventral view

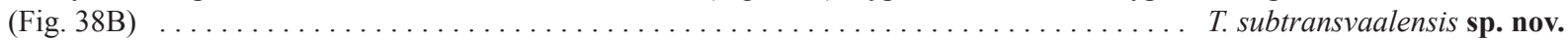

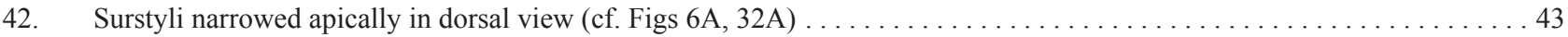

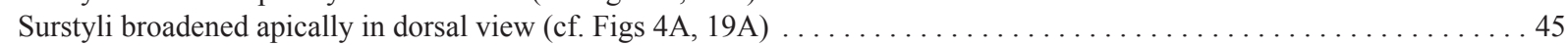

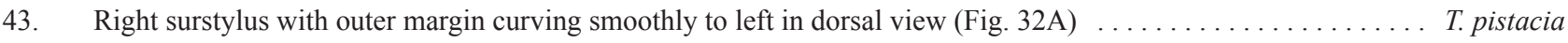

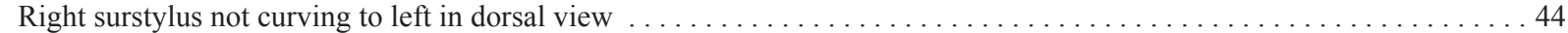

44. One of ejaculatory ducts with three distinct spines in lateral view (Fig. 6F) . . . . . . . . . . . T. bistounensis sp. nov. One of ejaculatory ducts with small teeth in lateral view (see Földvári \& De Meyer, 1999: page 316, fig. 15D) ... . T. mutata

45. Surstyli much longer than epandrium in dorsal view, pinched and narrowed in middle (Fig. 4A) . . ......... T. angulata Surstyli short, similar in length to the epandrium in dorsal view (Fig. 19A) . . . . . . . . . . . . . . T. inopinata

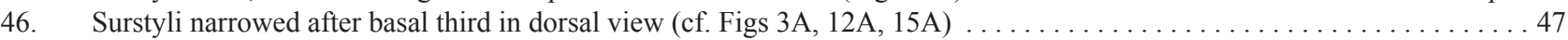

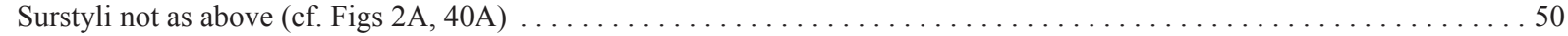

47. Surstyli stubby and without a projection in lateral view (Fig. $3 \mathrm{C}-\mathrm{D}) \ldots \ldots \ldots \ldots \ldots \ldots \ldots \ldots \ldots$. . . . anahitae sp. nov.

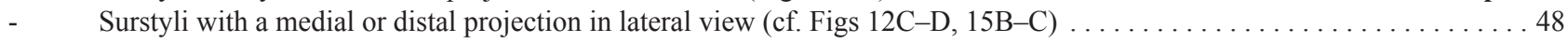

48. Surstyli conspicuously broadened and roundish in lateral view (see Majnon-Jahromi et al. 2017a: page 3, fig. 1A, C) .......

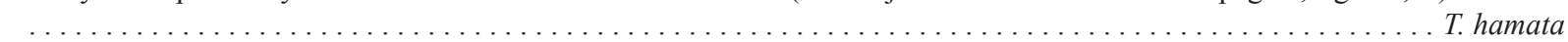

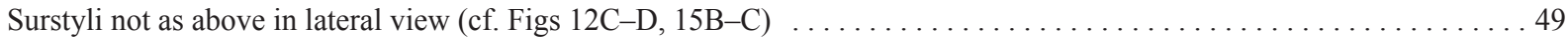

49. Surstyli with ventral medial protuberance in lateral view (Fig. 12C-D); phallic guide curved towards surstyli with a pair of

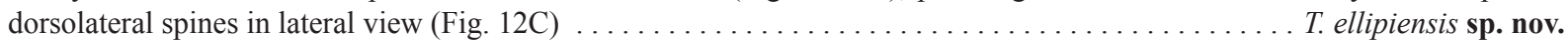
Surstyli with ventral distal protuberance in lateral view (Fig. 15B-C); phallic guide straight without a pair of dorsolateral spines

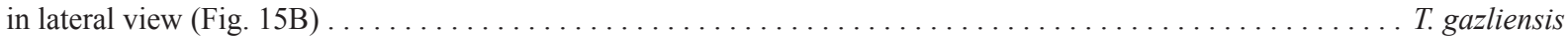

50. Both surstyli with large dorsomedial lobe in lateral view (Fig. 44E-F) $\ldots \ldots \ldots \ldots \ldots \ldots \ldots \ldots \ldots$. . . . . . . . . . . . . . . . .

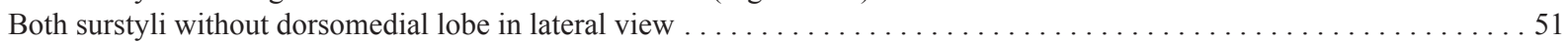

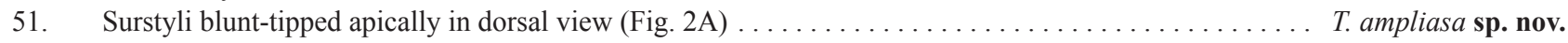

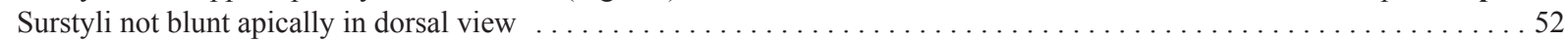

52. Surstyli nearly straight ventrally in lateral view (Fig. 40C-D) $\ldots \ldots \ldots \ldots \ldots \ldots \ldots \ldots \ldots \ldots \ldots \ldots$. susa sp. nov.

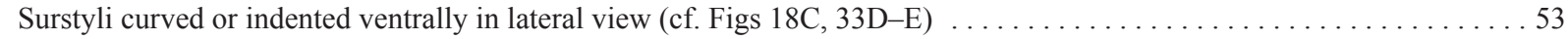

53. Surstyli with dorsobasal triangular-shaped projection in dorsal view (see Majnon-Jahromi et al. 2017b: page 499, fig. 19) ...

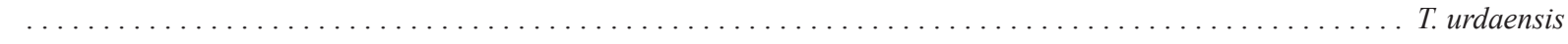

Surstyli without dorsobasal triangular-shaped projection in dorsal view (cf. Figs 18A, 33A) .............. 54

54. Surstyli straight (not curved towards each other) in dorsal view (see Kehlmaier et al. 2019: page 52, fig. 8B) . T. helwanensis

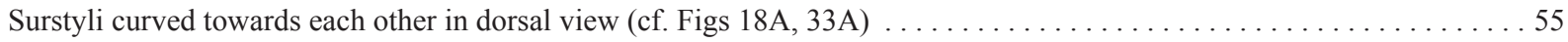

55. Hypandrium about as wide as long and with distinct hypandrial apodeme in ventral view (Fig. 33B); surstyli bulging ventro-

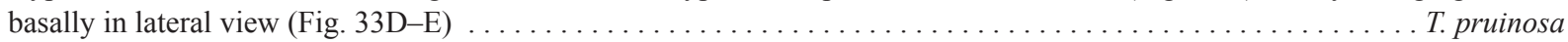
Hypandrium much longer than wide and without hypandrial apodeme in ventral view (Fig. 18B); surstyli only slightly swollen

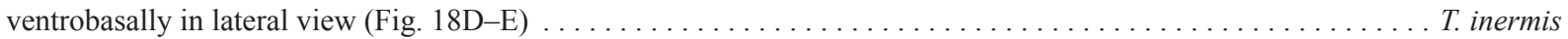

\section{The Middle Eastern species of Tomosvaryella}

Based on morphology and DNA barcoding, the present paper introduces 19 new species and presents the association of males and females of four species, Tomosvaryella ampliasa sp. nov., T. emaratensis sp. nov., T. oshidae $\mathbf{s p .}$ nov., T. soziana sp. nov., for the first time. Sequence data from COI and ITS2 are provided for 102 Middle Eastern Tomosvaryella specimens of 36 species and for six specimens of three species, respectively (Table 2).

\section{Tomosvaryella acantha Motamedinia \& Skevington sp. nov.}

Figs 1A-E, 46A, 49, 65A-B

Diagnosis: This species can be recognized by the distinctive thorn-like projection on the hind trochanter (Fig. 46A); surstyli slender and curved towards each other in dorsal view (Fig. 1A), with a small projection at the base in lateral view (Fig. 1D-E three small ejaculatory ducts, one with some teeth in basal half (Fig. 1D-E); phallic guide with a downward projection before apex in lateral view (Fig. 1D-E). Based on the shape of the surstyli and phallus, this species is related to T. sylvatica (Meigen, 1824) (Földvári \& De Meyer 1999: fig. 3A-D), T. subsylvatica Kazerani, Khaghaninia \& Kehlmaier, 2017 (Kazerani et al. 2017: fig. 3A-D) and T. littoralis (Becker, 1897) (Földvári \& De 
Meyer 1999: fig. 2A-D). It differs by the distinct thorn-like projection (not spines) of the hind trochanter (Fig. 46A). Tomosvaryella sylvatica, T. subsylvatica and T. littoralis (Fig. 46B) have several spines on the hind trochanters.

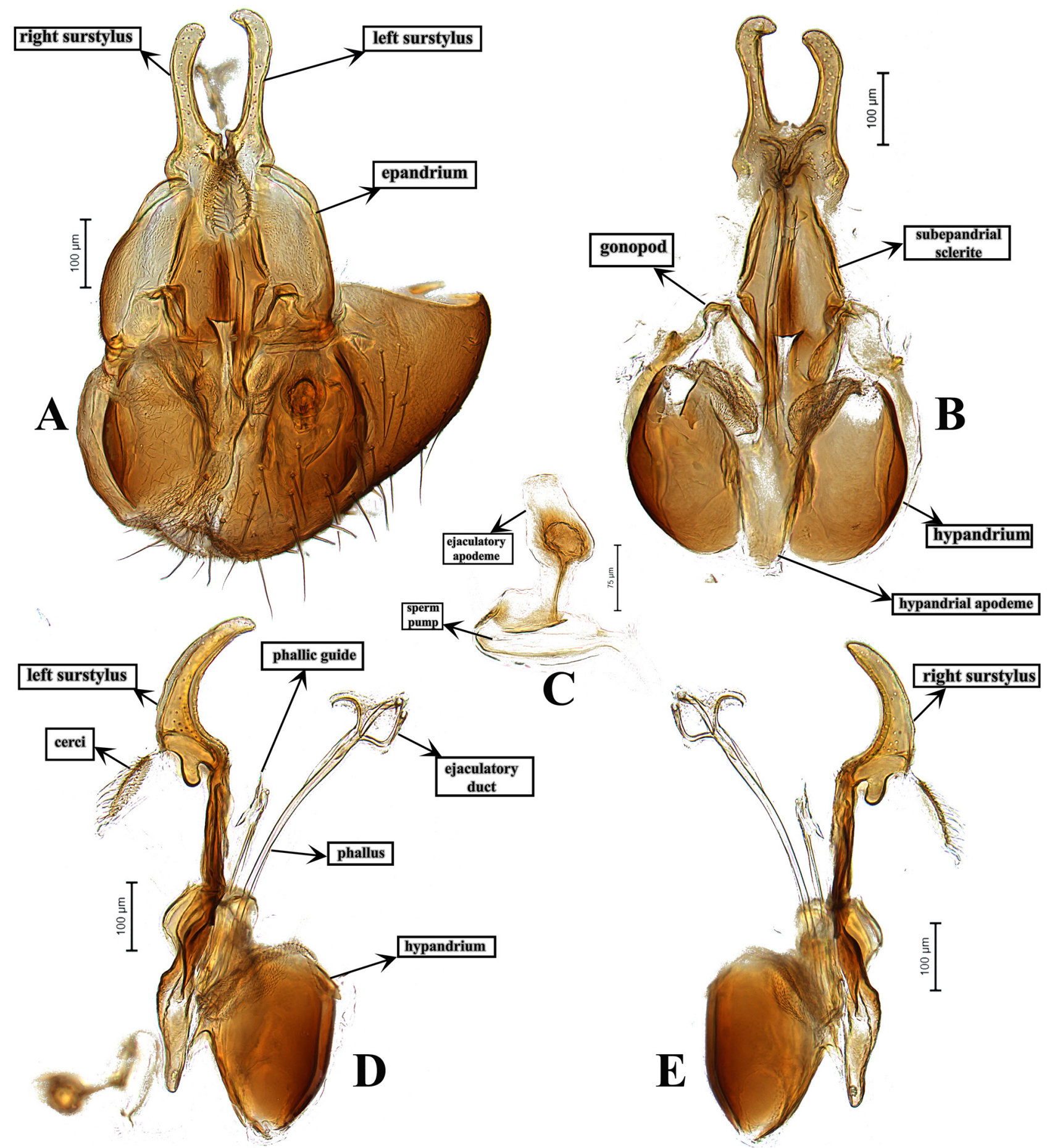

FIGURE 1. Male genitalia of Tomosvaryella acantha sp. nov., holotype (JSS51689, TAU) A) dorsal view, B) ventral view, C) ejaculatory apodeme, D, E) lateral view.

Description: MALE: Body length (excluding antennae): $2.85 \mathrm{~mm}$. Head. Scape, pedicel dark. Flagellum brown. Eyes meeting for a distance of 6-7 facets. Frons silver-gray pollinose. Vertex black, lacking pollinosity. Occiput dark with scattered short black setae. Thorax. Postpronotal lobe light yellow, gray pollinose without setae along upper margin. Prescutum and scutum black, prescutum slightly shining, scutum with a row of long supra-alar setae (up to $0.11 \mathrm{~mm}$ ) and uniseriate rows of long intra-alar setae (up to $0.09 \mathrm{~mm}$ ). Scutellum black, light-brown pollinose, with up to 18 thin setae along posterior margin (up to $0.11 \mathrm{~mm}$ ). Subscutellum and pleura dark brown, silver-gray pollinose. Wing. Length: $3.5 \mathrm{~mm}$. LW: $\mathrm{MWW}=3.5$. Wing almost entirely covered with microtrichia. 
Cross-vein r-m reaching cell $\mathrm{dm}$ at the middle. $\mathrm{M}_{1}$ moderately undulating in middle. Halter length: $0.37 \mathrm{~mm}$. Whitish, dark at base. Legs. Dark but narrowly yellow at apex of femora and base of tibiae, gray pollinose. Mid coxa with 3-4 anterior setae. Hind trochanter with a distinct thorn-like projection (not spine) (Fig. 46A). Hind femur with two rows of long setae on anterior and two rows on posterior side. Hind femur with 1-2 wrinkled indentations in basal quarter. Tibiae with two rows of short setae on anterior and three rows on posterior side. Hind tibia with 1-2 wrinkled indentations in the middle. Tarsi light brown, gray pollinose. Claws white in basal half. Abdomen. Ground color dark brown. Tergite 1 entirely gray pollinose with 8-9 brown long lateral setae (up to $0.16 \mathrm{~mm}$ ). Tergites $2-5$ with scattered yellowish setae (up to $0.08 \mathrm{~mm}$ ). Sternites light brown laterally and dark brown centrally, gray pollinose. Syntergosternite 8 with scattered long dark setae. Genitalia. Genital capsule in dorsal view: epandrium and surstyli brown, gray pollinose. Epandrium wider than long (MLE:MWE = 0.72). Surstyli rather symmetrical, elongated and slender, slightly curved to each other at apical third (Fig. 1A). Genital capsule in ventral view: gonopods small and wide, equal in height, hypandrium broad, subepandrial sclerite wide basically (Fig. 1B). Genital capsule in lateral view: both surstyli gently curved to sternite, with a small projection in basal towards hypandrium (Figs 1D-E). Phallic guide long, pointed apically with a small projection pointed towards hypandrium (Fig. 1D-E); phallus with three small ejaculatory ducts, one bearing some saw-like teeth in basal half (Fig. 1D-E). Ejaculatory apodeme tube-like, bent, with a bulb in its middle (Fig. 1C). FEMALE: unknown.

Etymology: The specific name is derived from the Latin word 'acantha', meaning thorn, referring to thorn-like projection on its hind trochanter.

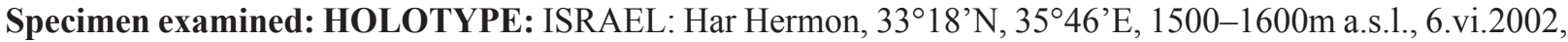

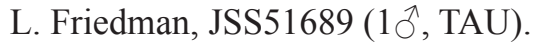

Distribution: Israel (Fig. 49).

Notes: Based on the DNA barcode, this species is genetically most similar to T. sylvatica (4.6\% pairwise divergence) (Supplementary Table 1).

\section{Tomosvaryella ampliasa Motamedinia \& Skevington sp. nov.} Figs 2A-E, 27A, 49, 65C-D

Diagnosis: This species can be recognized by the shape of surstyli, which are rectangular-shaped and flatted apically in dorsal view (Fig. 2A), and almost straight in lateral view (Fig. 2D-E); right gonopod with a long projection in ventral view (Fig. 2B); wide subepandrial sclerite basally in ventral view (Fig. 2B); wide gonopods in ventral view (Fig. 2B); three small ejaculatory ducts, one with some teeth in basal half (Fig. 2D). Based on genitalia characters, this species is close to T. susa sp. nov. and T. helwanensis (Collin, 1949). It differs from T. susa (Fig. 40A-D) in the different shape of the surstyli at the apex in dorsal view, flattened (not rounded) and from T. helwanensis (Kehlmaier et al. 2019: Fig. 8) in the different shape of the surstyli in dorsal view, rectangular shaped (Fig. 2A); with a broad and short phallic guide in lateral view (Figs 2D-E).

Description: MALE: Body length (excluding antennae): $2.8 \mathrm{~mm}$. Head. Scape dark, pedicel dark brown, flagellum light brown; pedicel with three short upper setae; flagellum tapering (LF: $\mathrm{WF}=4.0)$; arista brown with a dark spot near the base. Eyes meeting for a distance of 5-7 facets. Frons silver-gray pollinose. Vertex black, lacking pollinosity. Occiput dark and gray pollinose. Thorax. Postpronotal lobe light yellow, gray pollinose with $2-4$ small setae along the upper margin (up to $0.04 \mathrm{~mm}$ ). Prescutum and scutum black, with a row of supra-alar setae and uniseriate rows of intra-alar setae. Scutellum black, silver-gray pollinose, with about 14-18 thin setae along posterior margin (up to $0.08 \mathrm{~mm}$ ). Subscutellum and pleura dark brown. Wing. Length: 2.1-2.4 mm. LW: MWW = 2.5. Wing almost entirely covered with microtrichia. Cross-vein $\mathrm{r}-\mathrm{m}$ reaching cell $\mathrm{dm}$ at the middle. $\mathrm{M}_{1}$ strongly undulating in middle. Halter length: $0.4 \mathrm{~mm}$. Whitish, narrowly light brown at base. Legs. Dark brown but narrowly yellow at apex of femora, tibiae and tarsi. Trochanters and Femora partly gray pollinose. Trochanters smooth. Mid and hind femora bearing two rows of dark, peg-like anteroventral spines in apical one third. Fore, mid and hind femora with 1-2 wrinkled indentations in basal quarter. Tibiae with two rows of short setae on anterior and three rows on posterior side. Hind tibia with 1-2 wrinkled indentations in the middle. Tarsi yellowish, gray pollinose. Pulvilli shorter than distitarsi. Claws white with black tips. Abdomen. Ground color dark brown. Tergite 1 entirely gray pollinose with 12-16 yellowish long lateral setae (up to $0.2 \mathrm{~mm}$ ). Tergites $1-5$ with scattered yellowish setae (up to $0.08 \mathrm{~mm}$ ). Sternites light brown laterally and dark brown centrally, gray pollinose. Syntergosternite 8 dark, gray pollinose. Viewed laterally, higher than long (LS8:HS8 $=0.8$ ). Membranous area absent. Genitalia. Genital capsule in dorsal view: epandrium and surstyli brown, gray pollinose. Epandrium wider than long (MLE:MWE $=0.8$ ). Surstyli rather 
symmetrical, rectangular-shaped, slightly curved to each other at apex, rather flatted apically (Fig. 2A). Genital capsule in ventral view: gonopods wide, large and slightly equal in height, right wider than left one with elongated projection, subepandrial sclerite wide basally, phallic guide strong, slightly straight (Fig. 2B). Genital capsule in lateral view: surstyli longer than wide, slightly straight, rounded at apex (Figs 2D-E). Phallic guide strong, pointed apically (Fig. 2D); phallus with three small ejaculatory ducts, one bearing some saw-like teeth in basal half (Fig. 2D). Ejaculatory apodeme tube-like, bent, with a bulb in its middle (Fig. 2C).

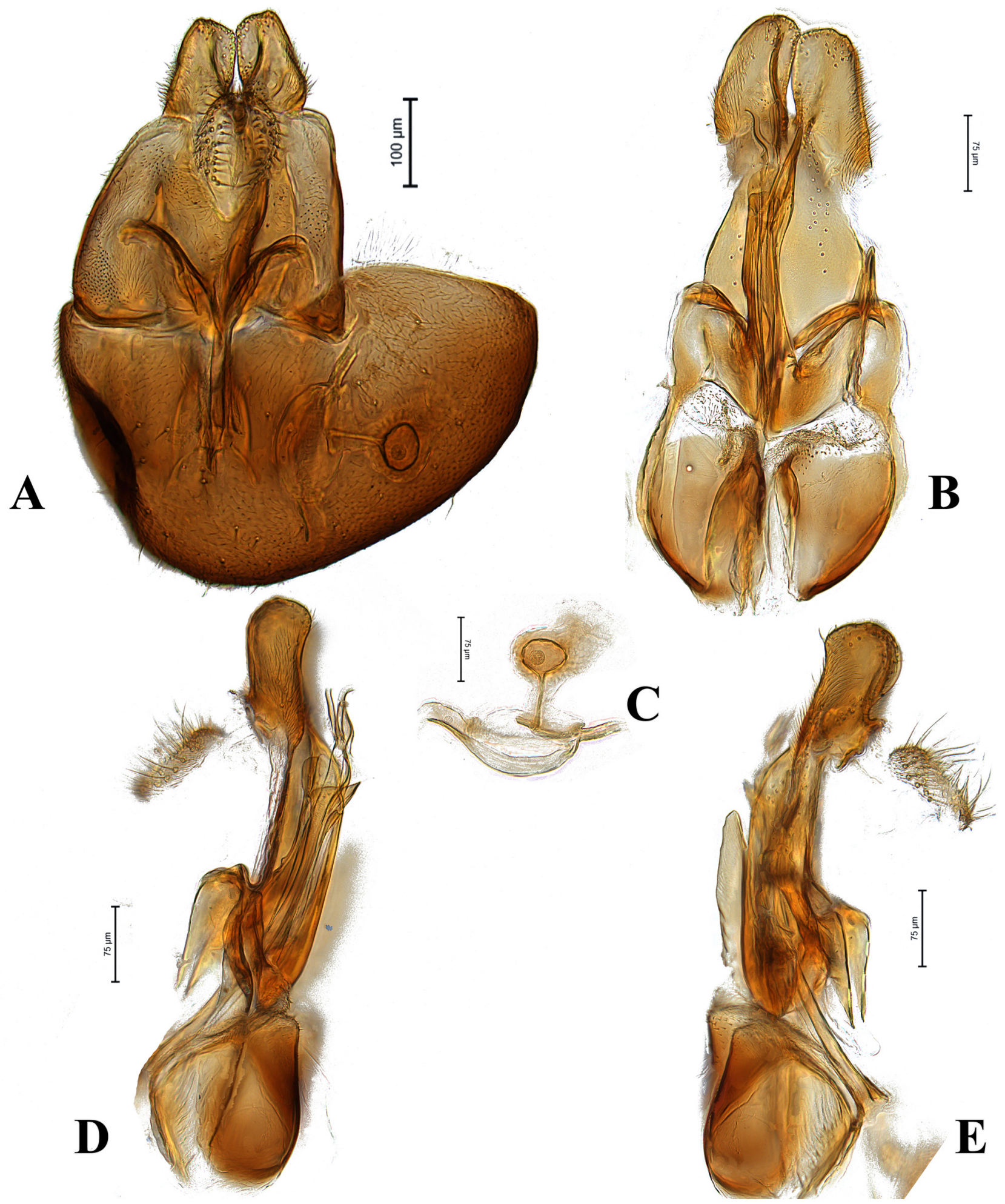

FIGURE 2. Male genitalia of Tomosvaryella ampliasa sp. nov., holotype (JSS51800, TAU) A) dorsal view, B) ventral view, C) ejaculatory apodeme, D, E) lateral view. 
FEMALE: Body length (excluding antennae): $3.2 \mathrm{~mm}$. Head. Eyes separated; with enlarged frontal facets. Frons gray pollinose in lower half. Occiput gray pollinose with scattered light brown setae near ocelli. Thorax. As in male. Wing. Length: $2.75 \mathrm{~mm}$. LW:MWW = 2.08. Legs. As in males except for longer setae on distitarsi. Abdomen. As in males. Ovipositor. Base of ovipositor dark brown with some gray pollinosity. Viewed laterally (Fig. 27A), piercer straight. $\mathrm{LP}: \mathrm{LB}=1.6$. LDP:LPP $=1.9$.

Etymology: The specific epithet ampliasa is derived from the Latin "amplias", which means widened or extended, referring to the extended gonopods.

Specimens examined: HOLOTYPE: ISRAEL: Hofit, 32²3’N $3^{\circ} 4^{\circ} 52^{\prime} \mathrm{E}, 21.1 x .1994$, F. Kaplan \& A. Freid-

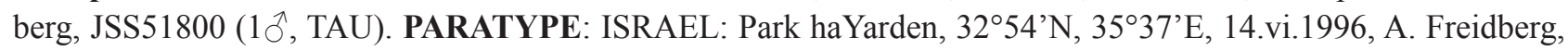
JSS43959 (1 1 , TAU).

Distribution: Israel (Fig. 49)

Note: DNA barcodes of this species are closest to T. susa sp. nov., differing by $0.8 \%$ pairwise divergence. Male and female were both sequenced and are genetically identical (Supplementary Table 1).

\section{Tomosvaryella anahitae Motamedinia \& Skevington sp. nov.}

Figs 3A-D, 49, 65E-F

Diagnosis: This species can be recognized by the shape of surstyli, triangular-shaped in dorsal view (Fig. 3A), broadened at the middle in lateral view (Fig. 3C-D); right gonopod with a small finger-like projection in ventral view (Fig. 3B); three long ejaculatory ducts, two with small teeth in basal third in lateral view (Fig. 3C-D) (similar to those of T. trichotibialis De Meyer, 1995).

Description: MALE: Body length (excluding antennae): $4.1 \mathrm{~mm}$. Head. Scape, pedicel and arista brown. Scape and pedicel without setae; flagellum light brown, gray pollinose and long tapering, distinctly paler than pedicel (LF:WF = 5.0). Eyes meeting for a distance of 14-15 facets. Frons silver-gray pollinose; vertex shining; occiput lacking pollinosity in upper third with scattered light brown setae. Thorax. Postpronotal lobe light brown with pale setae along the upper margin (up to $0.03 \mathrm{~mm}$ ). Prescutum and scutum black, silver-gray pollinose; supra-alar area dark brown and shining, scutum with scattered setae at anterior supra-alar area. Scutellum black, silver-gray pollinose, without setae along posterior margin. Subscutellum black, pleura dark brown. Wing. Wing length: $3.7 \mathrm{~mm}$. LW:MWW $=7.5$. Wing almost entirely covered with microtrichia. $M_{1}$ strongly undulating in middle. Halter length: $0.42 \mathrm{~mm}$. Brown to yellowish, narrowly black at base. Legs. Coxae and trochanters black, gray pollinose, hind trochanter with scattered short pale setae. Femora dark brown with narrow yellow apices, silver pollinose and 5-8 ventral spines toward apex. All femora with one wrinkled indentation in basal. Tibiae light brown at base, gray pollinose, with two rows of short black setae on anterior and three rows on posterior side. Hind tibia with two wrinkled indentations in middle. Tibiae without distal spines. Tarsi dark. Abdomen. Ground color dark brown, tergite 1 silver pollinose, tergite 2 with weak silver pollinose on anterior corner, tergites $2-5$ with scattered brown setae. Sternites white-yellow laterally with dark mid-line centrally, gray pollinose. Genitalia. Genital capsule in dorsal view: epandrium and surstyli light brown, epandrium longer than wide (MLE:MWE $=0.5$ ). Surstyli almost symmetrical, both triangular-shaped and longer than wide (Fig. 3A). Genital capsule in ventral view: gonopods equal in height, right with a small finger-like projection; subepandrial sclerite rectangular-shaped (Fig. 3B). Genital capsule in lateral view: both surstyli broadened medially, slightly straight ventrally (Fig. 3C-D); phallus trifid, with three long straight ejaculatory ducts, two with small teeth in basal third (Fig. 3C-D); phallic guide small, pointed, slightly bent toward surstyli (Fig. 3C-D). FEMALE: unknown.

Etymology: The specific epithet refers to Anahita, the old Persian form of the name of an Iranian goddess who rules water, crops and fertility.

Specimen examined: HOLOTYPE: IRAN: Kermanshah: Sarpolezahab, $34^{\circ} 28^{\prime} \mathrm{N}, 45^{\circ} 49^{\prime} \mathrm{E}, 546 \mathrm{~m}$ a.s.l., 1.vii.2015, M. Zardouei, Malaise trap, JSS51946 (1 $\overbrace{}^{\lambda}$, CNC).

Distribution: Iran (Fig. 49).

Note: Based on DNA barcoding, this species is closest to T. hamata, differing by $2.5-3.1 \%$ (pairwise divergence) (Supplementary Table 1). 

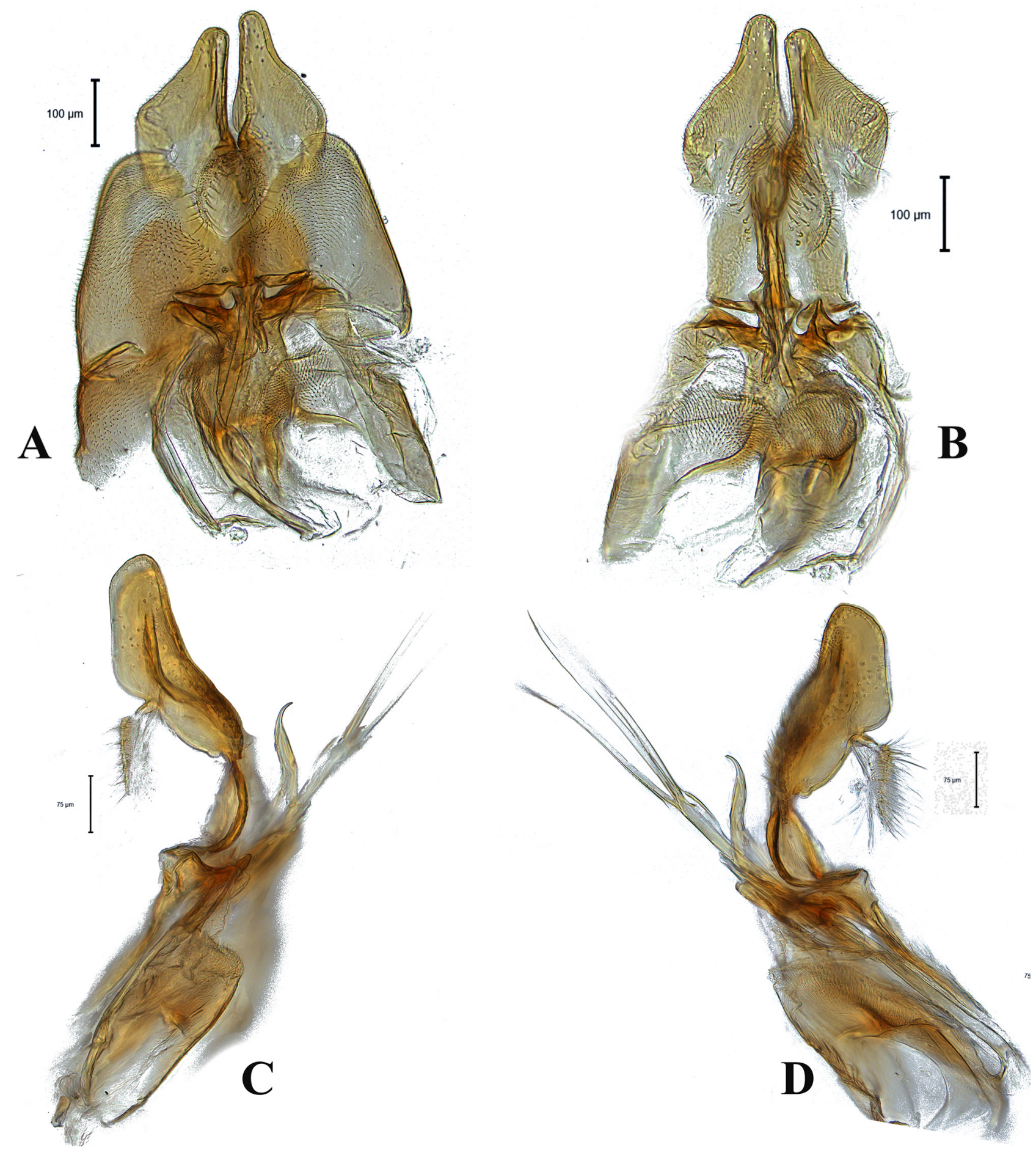

FIGURE 3. Male genitalia of Tomosvaryella anahitae sp. nov., holotype (JSS51946, CNC) A) dorsal view, B) ventral view, C, D) lateral view.

\section{Tomosvaryella angulata Kehlmaier \& Majnon-Jahromi, 2017}

Figs 4A-E, 50

Diagnosis: This species can be recognized by the shape of surstyli, both apically knobbed in dorsal view (Fig. 4A) and bent strictly towards the abdominal sternites in lateral view (Fig. 4D-E); phallus trifid and unequal, one with tooth-like projections in basal half (Fig. 4D-E); phallic guide short and broad (Fig. 4D-E); gonopods slightly unequal in height, left is slightly higher than right (Fig. 4B). The female is described and illustrated in Majnon-Jahromi et al. (2017b). 


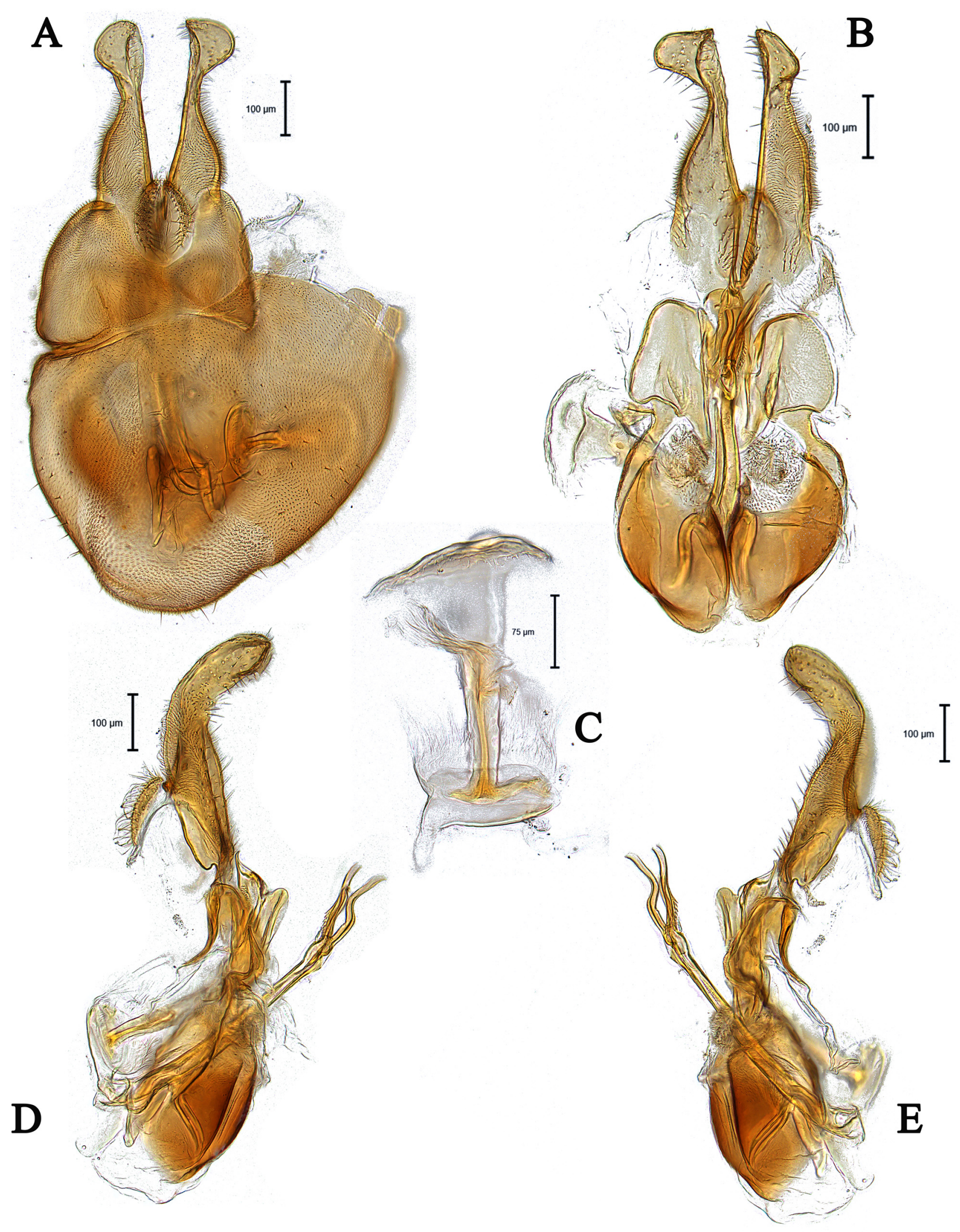

FIGURE 4. Male genitalia of Tomosvaryella angulata (JSS52275, CNC) A) dorsal view, B) ventral view, C) ejaculatory apodeme, D, E) lateral view.

Specimens examined: IRAN: Sistan \& Baluchestan: Saravan, 27²5’N, 62 $17^{\prime}$ E, 12.v.2013, F. Hamzavi,

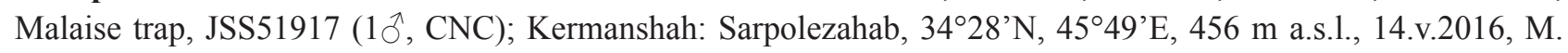




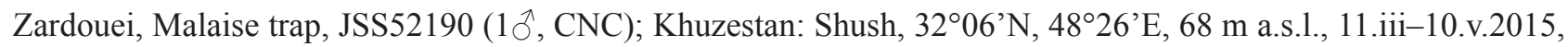
E. Gilasian, Malaise trap, JSS52192 (19, CNC); UNITED ARAB EMIRATES: Barqa Al Suqoor Protected Area, $23^{\circ} 59^{\prime} \mathrm{N}, 52^{\circ} 40^{\prime} \mathrm{E}, 29 . \mathrm{iii} .2018$, A. Saji \& A. van Harten, Malaise trap, JSS52275 (10^, CNC).

Distribution: Iran, United Arab Emirates (Skevington 2020) (Fig. 50).

Note: Based on DNA barcoding, this species is most similar to T. pseudophanes (Perkins, 1905), differing by $8.3 \%$ (pairwise divergence). Intraspecific variation ranges from 0.1 to $3.2 \%$ (Supplementary Table 1).

\section{Tomosvaryella argyrata De Meyer, 1995}

Fig. 50

Diagnosis: Following De Meyer (1995), this species can be recognized by the shape of surstyli, broadened at base and gradually tapering toward apices in dorsal view, both surstyli slightly curved towards abdominal sternites in lateral view (De Meyer, 1995: fig. 9a); epandrium longer than wide, phallic guide slender and long in lateral view, hind femur ventrally with long pale setae (De Meyer, 1995: fig. 9b). Based on the shape of surstyli in dorsal view, this species is similar to T. pistacia Majnon-Jahromi \& Kehlmaier in Majnon-Jahromi et al. 2017b (Fig. 32A) and T. argyratoides De Meyer, 1995 (Fig. 5A). It differs from both species by having long pale setae on the hind femur. Moreover, Tomosvaryella pistacia has wider epandrium and its surstyli are more angulate in lateral view (Fig. 32A, $\mathrm{D}, \mathrm{E})$.

Distribution: Iran, Israel (Skevington 2020) (Fig. 50).

\section{Tomosvaryella argyratoides De Meyer, 1995}

Figs $5 \mathrm{~A}-\mathrm{D}, 50$

Diagnosis: This species can be recognized by the shape of surstyli, broadened at the base and gradually tapering toward apices in dorsal view, both surstyli not curved to the abdominal sternites in lateral view (Fig. 5A); epandrium longer than wide (Fig. 5A); gonopods equal, triangular-shaped with a small projection bent towards phallic guide in ventral view (Fig.5B). This species is closely related to T. argyrata and T. pistacia. See diagnosis of T. argyrata for more details.

Specimens examined: IRAN: South Khorasan: Mohammadieh, 3252'N, 5901'ㄹ, 1419 m a.s.1., 5-23.ix.2016, B. Motamedinia, Malaise trap, JSS52026 (10, CNC); ISRAEL: Arava Valley, nr Hazeva, Shizaf Nature Res. side channel of Waddi Shahak, $30^{\circ} 45^{\prime} \mathrm{N}, 35^{\circ} 15^{\prime} \mathrm{E},-116 \mathrm{~m}$ a.s.l., 16.iv.1995, M. E. Irwin, Malaise trap, JSS52059 (1 ${ }^{\jmath}$,

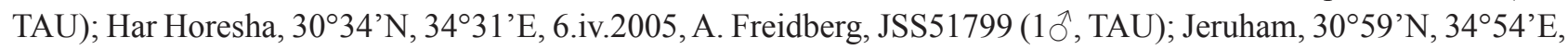

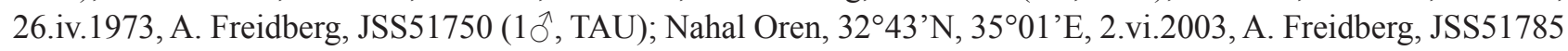

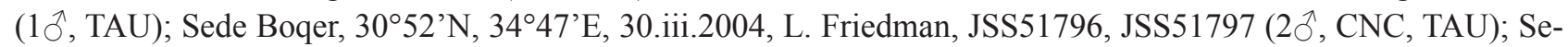
dom, $31^{\circ} 05^{`} \mathrm{~N}, 35^{\circ} 22^{\prime} \mathrm{E}$, 13.iii.1994, A. Freidberg, JSS51702 (10, TAU).

Distribution: Iran, Israel, Spain (Skevington 2020) (Fig. 50).

Note: Based on DNA barcodes, this species is most similar to T. gazliensis Kuznetzov, 1994, differing by 5.05\% (pairwise divergence) (Supplementary Table 1).

\section{Tomosvaryella bistounensis Motamedinia \& Skevington sp. nov.}

Figs 6A-F, 51, 66A-B

Diagnosis: This species can be recognized by the shape of surstyli in dorsal view, broad at base and elongated; both surstyli bent toward sternites in lateral view (Fig. 6A); phallus with three ejaculatory ducts, one with three spines in lateral view (Fig. 6F). Other species that have such distinct spines are T. israelensis De Meyer, 1995 (Fig. 20D-E), T. jubata De Meyer, 1995 (Fig. 221D), T. minuscula (Collin, 1956) (Földvári \& De Meyer, 1999: fig. 13E-F) and T. sedomensis De Meyer, 1995 (De Meyer, 1995: fig. 21f). On the basis of genitalia characters, this species is close to Tomosvaryella cilifemorata (Becker, 1907) (Földvári \& De Meyer, 1999: fig. 11A-E; Kehlmaier et al. 2019: fig. 6A) and Tomosvaryella mutata (Földvári \& De Meyer, 1999: fig. 15A-D). It differs by the shape of surstyli in lateral view and having three distinct spines on one of ejaculatory ducts (Figs 6F). 


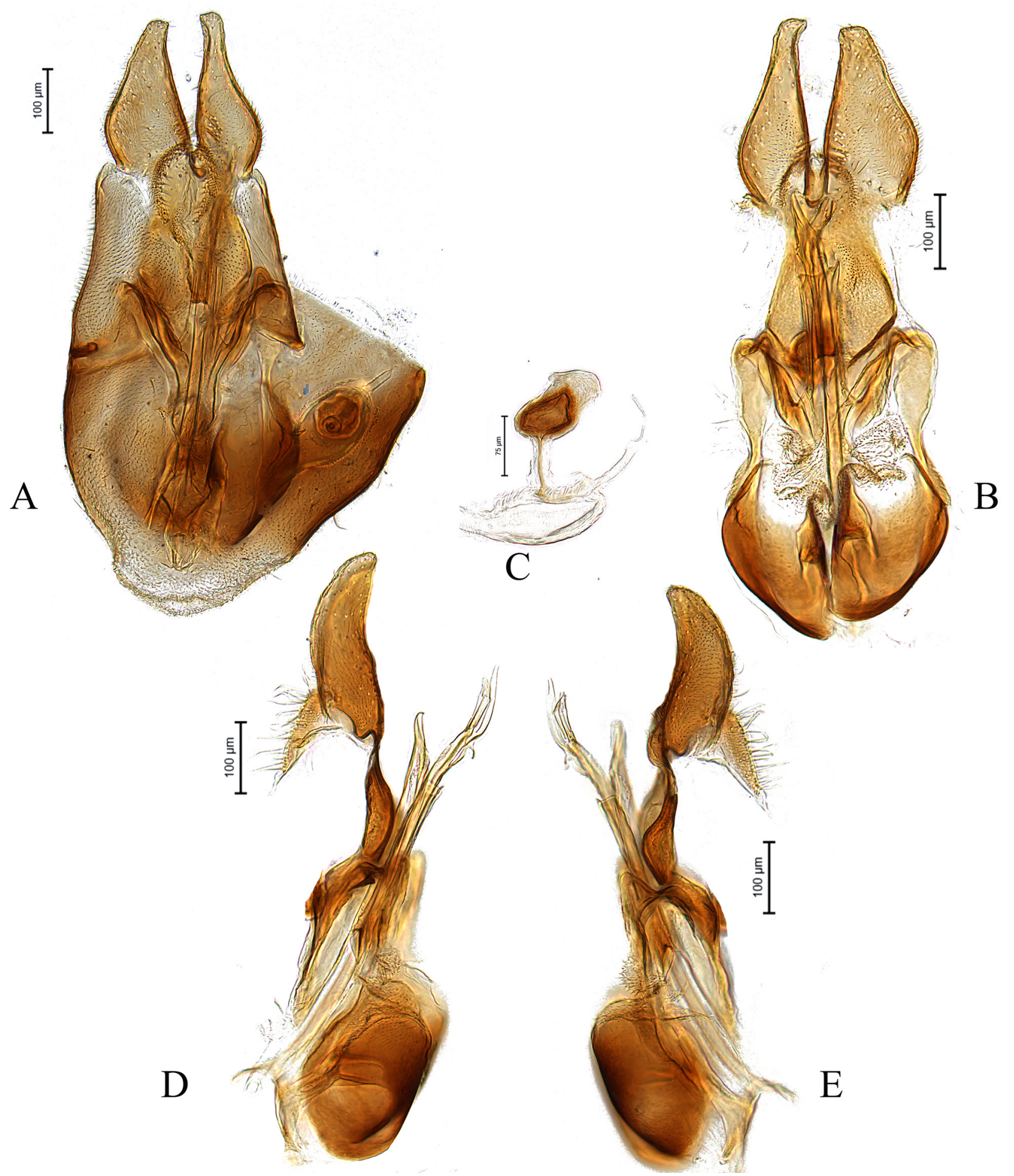

FIGURE 5. Male genitalia of Tomosvaryella argyratoides (JSS51796, CNC) A) dorsal view, B) ventral view, C) ejaculatory apodeme, D, E) lateral view.

Description: MALE: Body length (excluding antennae): $3.6 \mathrm{~mm}(\mathrm{n}=5)$. Head. Scape, pedicel, arista dark. Pedicel with a pair of dorsal setae; flagellum light brown, gray pollinose and tapering, distinctly paler than pedicel $(\mathrm{LF}: \mathrm{WF}=3.0)$. Eyes meeting for a distance of seven facets. Frons silver-gray pollinose. Occiput dark, gray pollinose. Thorax. Postpronotal lobe light brown with 2-3 pale setae along the upper margin (up to $0.03 \mathrm{~mm}$ ). Prescutum and scutum black, prescutum silver-gray pollinose and scutum light brown pollinose, with scattered setae at anterior supra-alar area and uniseriate rows of intra-alar setae. Scutellum black, silver-gray pollinose, with 1-2 thin short setae along posterior margin (up to $0.03 \mathrm{~mm}$ ). Subscutellum and pleura black. Wing. Wing length: $2.5 \mathrm{~mm}$., 
LW:MWW $=2.7$. Wing almost entirely covered with microtrichia. $M_{1}$ strongly undulating in middle. Halter length: $0.33 \mathrm{~mm}$. Brown to yellowish, narrowly black at base. Legs. Coxae black, trochanters dark brown, smooth. Femora dark brown with narrow yellow apices, silver pollinose. Mid and hind femora with one or two wrinkled indentations in basal. Tibiae brown at base, gray pollinose, with two rows of short brown setae on anterior and three rows on posterior side. Tibiae without distal spines, mid and hind tibiae with one or two wrinkled indentations in middle.

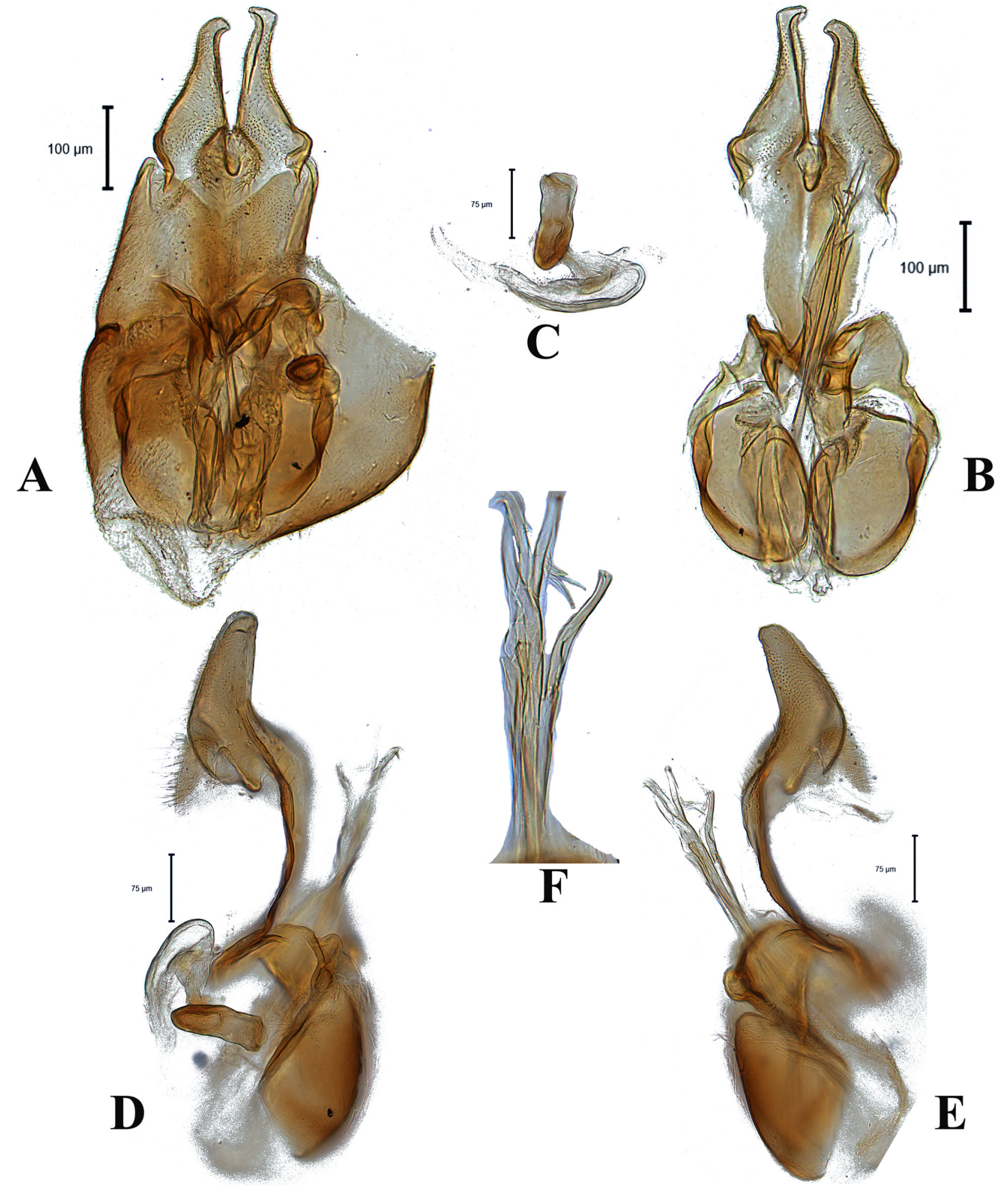

FIGURE 6. Male genitalia of Tomosvaryella bistounensis sp. nov., holotype (JSS51939, CNC) A) dorsal view, B) ventral view, C) ejaculatory apodeme, D, E) lateral view, F) phallus in lateral view. 
Tarsi light brown, distitarsi brown. Abdomen. Ground color dark, tergite 1 silver gray pollinose, tergites $2-5$ brown pollinose with scattered short dark setae. Tergite 5 asymmetrical, T5R:T5L=1.2. Membranous area present. Sternites brown laterally and dark centrally, gray pollinose. Genitalia. Genital capsule in dorsal view: epandrium and surstyli brown, gray pollinose. Surstyli elongated, almost symmetrical, with a broad base and inward bent tips, left surstylus slightly longer (Fig. 6A). Genital capsule in ventral view: gonopods equal in height, right slightly broader than left one (Fig. 6B); genital capsule in lateral view: both surstyli broad at base and bent toward sternites (Fig. 6D-E); phallus with three ejaculatory ducts, one with three long spines towards phallic guide (Fig. 6F); ejaculatory apodeme tube-like, bent, with a bulb in its middle (Fig. 6C). FEMALE: unknown.

Etymology: The specific epithet refers to Bistoun, an archaeological site in Kermanshah from where the specimens have been collected.

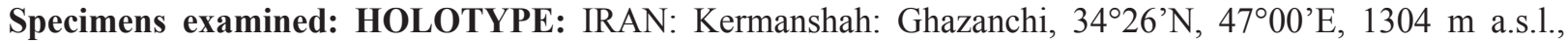

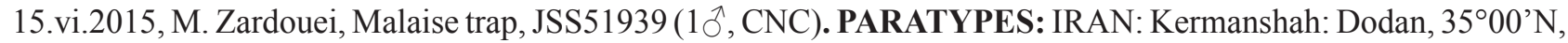

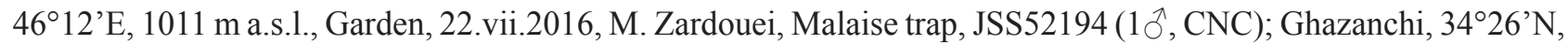

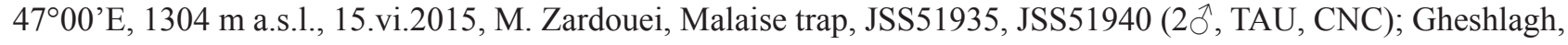
$34^{\circ} 56^{\prime} \mathrm{N}, 4^{\circ} 27^{\prime} \mathrm{E}, 1533 \mathrm{~m}$ a.s.1., 1.vi.2015, M. Zardouei, Malaise trap, JSS51950 (10 $\left.{ }^{\lambda}, \mathrm{CNC}\right)$.

Distribution: Iran (Fig. 51).

Notes: Based on DNA barcodes, this species is closest to T. minuscula (Collin, 1956), differing by $0.9 \%$ (pairwise divergence) (Supplementary Table 1). It is possible that these are a single species with polymorphic genitalia, so future genetic and ecological work are required to confirm their taxonomic status.

\section{Tomosvaryella cilifemorata (Becker, 1907)}

Fig. 49

Diagnosis: Following Földvári \& De Meyer (1999), this species can be recognized by the elongated surstyli in dorsal view, broadened at base, both surstyli normally curved in lateral view; epandrium longer than wide; phallus with three ejaculatory ducts, one with saw-like teeth; long hair on hind femur; black halter (Földvári \& De Meyer, 1999: fig. 11A-E; Kehlmaier et al. 2019: fig. 6A).

Distribution: Austria, Bulgaria, Cyprus, France, Germany, Greece, Hungary, Italy, Morocco, Spain, Switzerland, Tunisia (Földvári \& De Meyer, 1999; Kehlmaier et al. 2019; Skevington 2020) (Fig. 49).

\section{Tomosvaryella coquilletti (Kertész, 1907)}

Figs 7A-E, 52

Pipunculus coquilletti Kertész, 1907.—syn. Hardy (1943): p. 159.

Diagnosis: This species can be recognized by the shape of epandrium in dorsal view, divided into two parts by an epandrial groove (Fig.7A); broad subepandrial sclerite in ventral view (Fig. 7B); phallus trifid, with three wavy ejaculatory ducts (Fig. 7D-E); small and slender phallic guide in lateral view (Fig. 7E); gonopods equal in height (Fig. 7B).

Specimens examined: IRAN: Kermanshah: Ghazanchi, $34^{\circ} 26^{\prime} \mathrm{N}, 47^{\circ} 00^{\prime} \mathrm{E}, 1304 \mathrm{~m}$ a.s.1., 1.vii.2015, M. Zard-

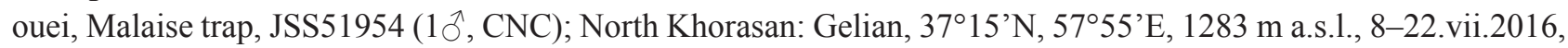

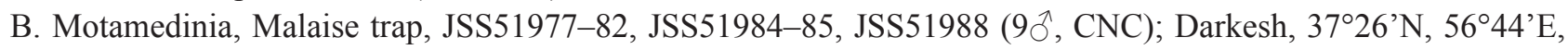
23.vii.2016, B. Motamedinia, sweep net, JSS52036 (1ㅇ, CNC); Razavi Khorasan: Sheikhha, 36 $36^{\circ}$ 'N, $59^{\circ} 11^{\prime} \mathrm{E}$, 1169 m a.s.l., 22.v-6.vi.2016, B. Motamedinia, Malaise trap, JSS51864 (1 $\left.0^{\wedge}, \mathrm{CNC}\right)$; Torqabeh, $36^{\circ} 18^{\prime} \mathrm{N}, 5^{\circ} 22^{\prime} \mathrm{E}$, 1296 m a.s.l., 25.vi-9.vii.2016, B. Motamedinia, Malaise trap, JSS51850, JSS51858-9 (3 ${ }^{2}$, CNC, TAU, USNM);

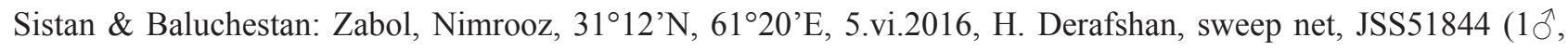
$\mathrm{CNC}$ ).

Distribution: Bulgaria, Canada, Czech Republic, Egypt, Finland, France, Greece, Hungary, Iran, Latvia, Portugal, Romania, Slovakia, Spain, Switzerland, Ukraine, United States (Skevington 2020) (Fig. 52).

Note: DNA barcodes of this species are genetically most similar to T. parakuthyi, differing by $10.3 \%$ (pairwise divergence) (Supplementary Table 1). 

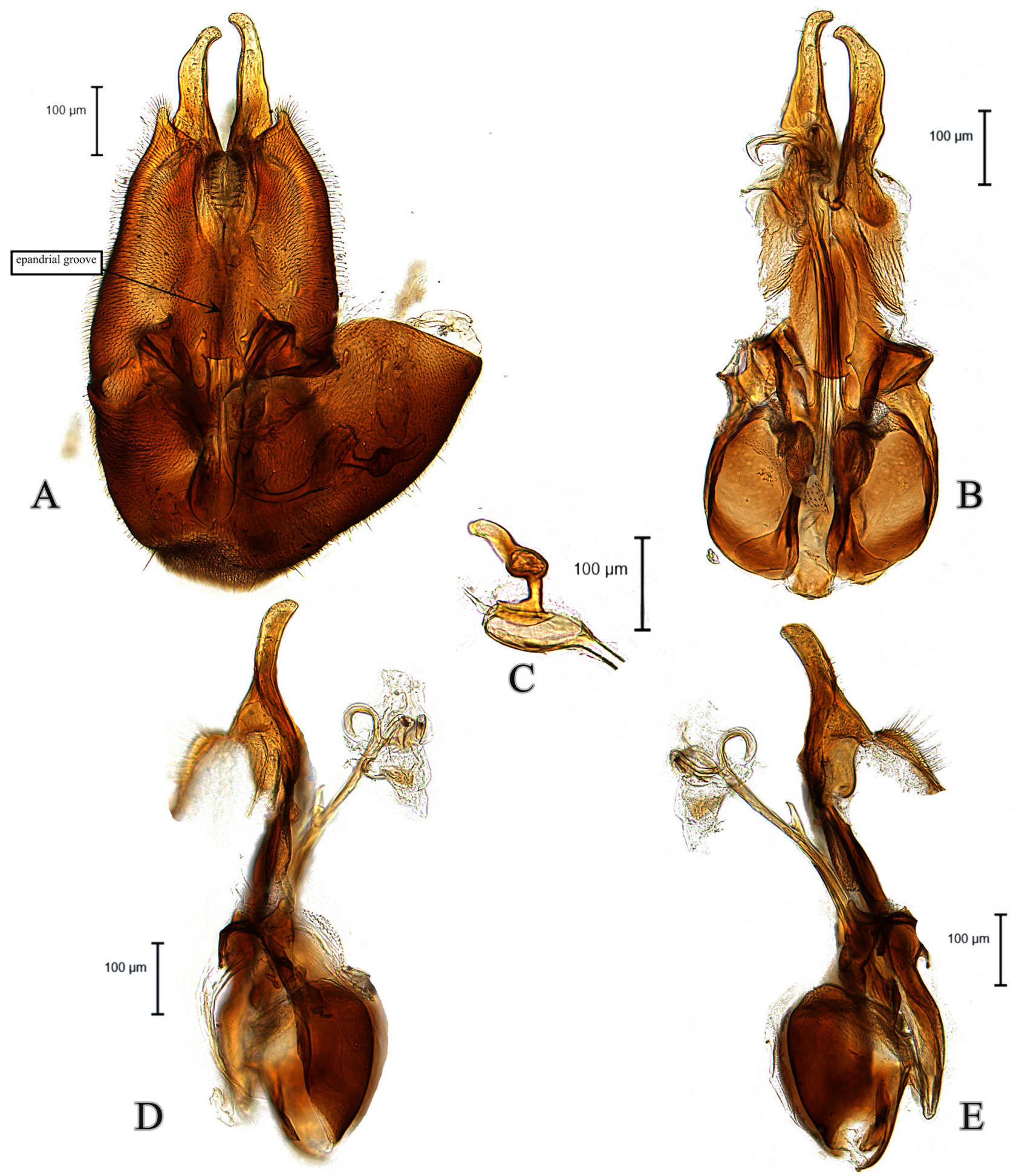

FIGURE 7. Male genitalia of Tomosvaryella coquilletti (JSS51859, USNM) A) dorsal view, B) ventral view, C) ejaculatory apodeme, D, E) lateral view.

\section{Tomosvaryella cyprusensis Motamedinia \& Skevington sp. nov.}

Figs $8 \mathrm{~A}-\mathrm{E}, 50,66 \mathrm{C}-\mathrm{D}$

Diagnosis: This species can be recognized by the shape of surstyli in lateral view, elongated and straight (Fig. 8DE); epandrium longer than wide in dorsal view (Fig. 8A); left gonopod higher than right one in ventral view (Fig. 
8B). Based on the shape of surstyli in dorsal view, this species resembles species in the kuthyi group (Tomosvaryella freidbergi De Meyer, 1995, T. hispanica De Meyer, 1997, T. israelensis De Meyer, 1995, T. kuthyi Aczél, 1944, T. parakuthyi De Meyer, 1995). It differs by the straight surstyli in lateral view (Fig. 8D-E).
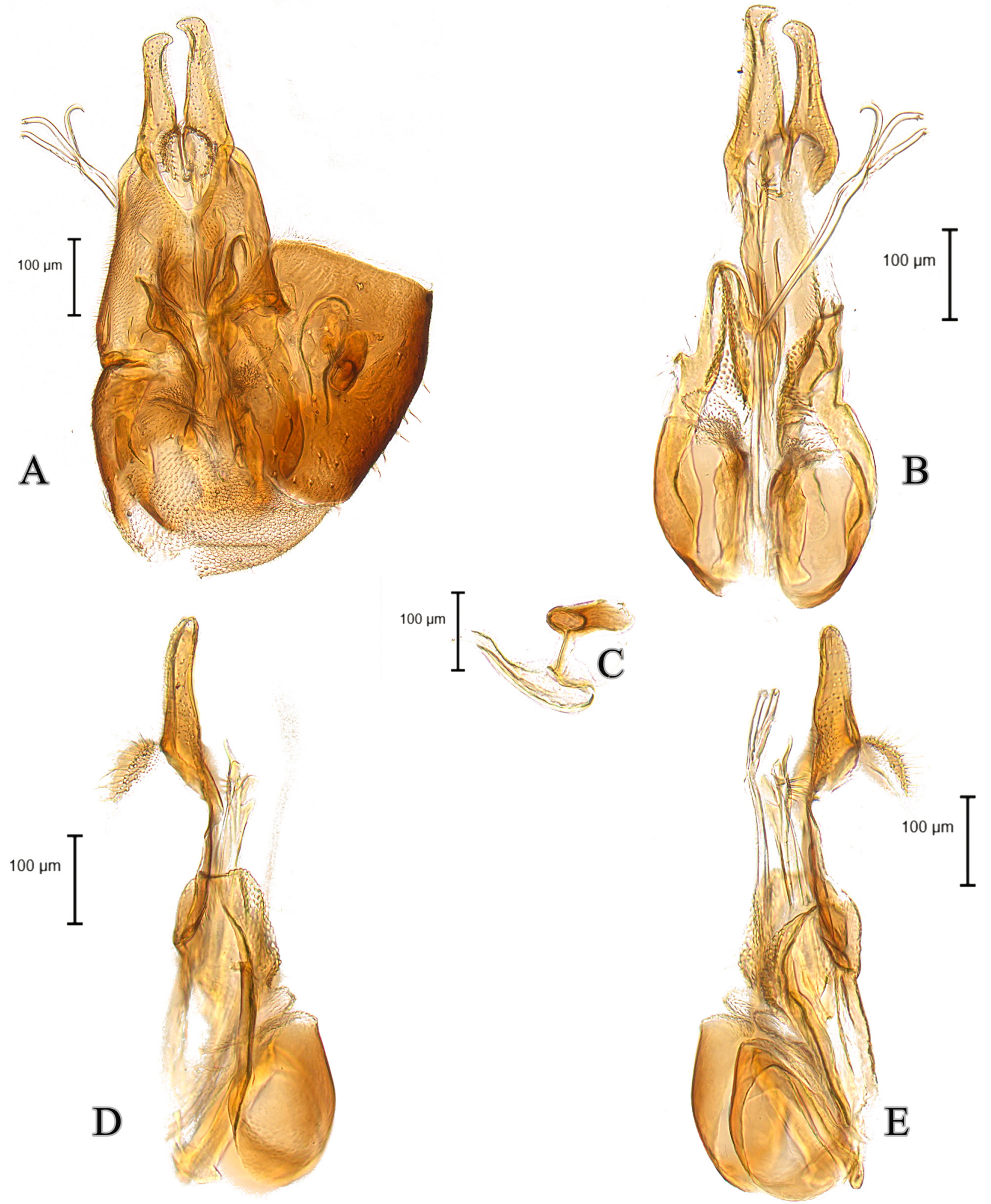

FIGURE 8. Male genitalia of Tomosvaryella cyprusensis sp. nov., holotype (JSS52302, CNC) A) dorsal view, B) ventral view, C) ejaculatory apodeme, D, E) lateral view. 
Description: MALE: Body length (excluding antennae): $2.5 \mathrm{~mm}$. Head. Scape, pedicel and arista dark brown, flagellum light brown. Pedicel with three short, pale upper setae; flagellum tapering and gray white pollinose (LF: $\mathrm{WF}=2.6$ ). Eyes meeting for a distance of 5-6 facets. Frons dark silver-gray pollinose. Vertex black, lacking pollinosity. Occiput dark and gray pollinose. Thorax. Postpronotal lobe light yellow, gray pollinose with 6-7 yellowish setae along the upper margin (up to $0.08 \mathrm{~mm}$ ). Prescutum, scutum, scutellum black. Scutum with two uniseriate rows of conspicuous intra-alar setae and two uniseriate rows of dorsocentral setae. Postalar callus with two dark setae. Scutellum gray pollinose without setae along lateral margin. Subscutellum black, gray pollinose. Pleura dark, gray pollinose. Wing. Length: $2.2 \mathrm{~mm}$. LW:MWW $=3.05$. Wing almost entirely covered with microtrichia. Crossvein $\mathrm{r}-\mathrm{m}$ reaches $\mathrm{dm}$ at the middle. $\mathrm{M}_{1}$ moderately undulating in middle. Halter length: $0.37 \mathrm{~mm}$. Whitish, brown at base. Legs. Coxae dark, gray pollinose. Mid coxa with three dark anterior setae. Trochanters dark, gray pollinose, smooth. Femora dark brown, gray pollinose. All femora with 1-2 wrinkled indentations at base. Tibiae brown but light brown in basal half, with two ventral rows of short setae on anterior and three rows on posterior side. Hind tibia with two wrinkled indentations in middle. Tarsi brown with scattered brown setae at anterior margin. Pulvilli yellow. Claws light brown with black tips. Abdomen. Ground color dark brown. Tergite 1 densely gray pollinose, with 6-8 brown lateral setae (up to $0.13 \mathrm{~mm}$ ). Tergites 2 densely gray pollinose in anterior margin. Genitalia. Genital capsule in dorsal view: epandrium and surstyli light brown, gray pollinose. Epandrium longer than wide (MLE:MWE = 1.33). Surstyli rather symmetrical. Both surstyli elongated, left longer than right one (Fig. 8A). Both surstyli bent towards each other apically (Fig. 8A). Genital capsule in ventral view: gonopods unequal in height, left is higher than right one (Fig. 8B). Subepandrial sclerite elongated (Fig. 8B). Genital capsule in lateral view: both surstyli long and straight, slightly broader at base (Fig. 8D-E). Phallic guide strong with distinct patch of setae dorsally before apex (Fig. 8D-E), phallus with three small ejaculatory ducts, one with some small teeth in basal half (Fig. 8B). Ejaculatory apodeme tube-like, bent, with a bulb in its middle (Fig. 8C). FEMALE: unknown.

Etymology: The specific epithet refers to Cyprus, from where the specimens have been collected.

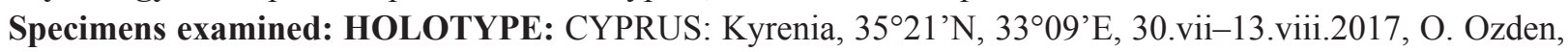

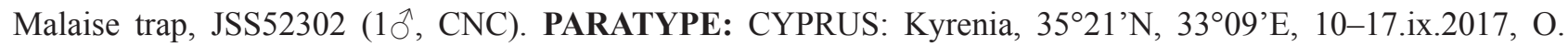
Ozden, Malaise trap, JSS52349 (1乃, CNC).

Distribution: Cyprus (Fig. 50).

\section{Tomosvaryella debruyni De Meyer, 1995}

Figs 9A-D, 48A, 52

Diagnosis: This species can be recognized by the horn-like projection in middle of frons (Fig. 48A); epandrium wider than long in dorsal view (Fig. 9A); surstyli broadened in the middle and gradually tapering toward apices in dorsal view (Fig. 9A); both surstyli slightly curved in lateral view (Fig. 9C-D); phallus trifid, with three wavy ejaculatory ducts, one with teeth-like projections in basal half in lateral view (Fig. 9C-D); small and broad phallic guide (Fig. 9C); gonopods equal in height in ventral view (Fig. 9B).

Specimens examined: ISRAEL [PALESTINE on the label]: Beth Hakerem, Jerusalem, $31^{\circ} 46^{\prime} \mathrm{N}, 35^{\circ} 12^{\prime} \mathrm{E}$,

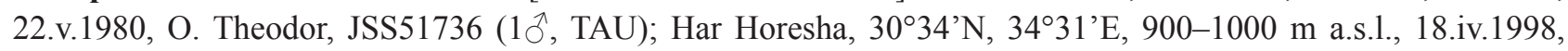
JSS51716 (1へ, CNC).

Distribution: Israel, Morocco, Tajikistan (Skevington 2020) (Fig. 52).

Note: Based on DNA barcodes, this species is closest to T. ellipiensis sp. nov., differing by $6.4 \%$ (pairwise divergence) (Supplementary Table 1).

\section{Tomosvaryella demeyeri Kuznetzov, 1993}

Fig. 49

Diagnosis: Following Kuznetzov (1993), this species can be recognized by the distinct ventrobasal protuberance of hind femur, bearing some distinct spines (Kuznetzov, 1993: fig. 13; Kehlmaier \& Majnon-Jahromi, 2014: fig. 6); syntergosternite 8 with longitudinal suture in dorsal view (Kuznetzov, 1993: fig. 9); epandrium longer than wide (Kuznetzov, 1993: Fig. 18; Kehlmaier \& Majnon-Jahromi, 2014: fig. 4); surstyli short, broadened in the middle and 
gradually tapering toward apices in dorsal view (Kuznetzov, 1993: fig. 18; Kehlmaier \& Majnon-Jahromi, 2015: fig. 4); hypandrium with a distinct constriction after basal quarter (Kehlmaier \& Majnon-Jahromi, 2015: fig. 3).

Distribution: Egypt, Iran (Kuznetzov, 1993; Kehlmaier \& Majnon Jahromi, 2015; Skevington 2020) (Fig. 49).
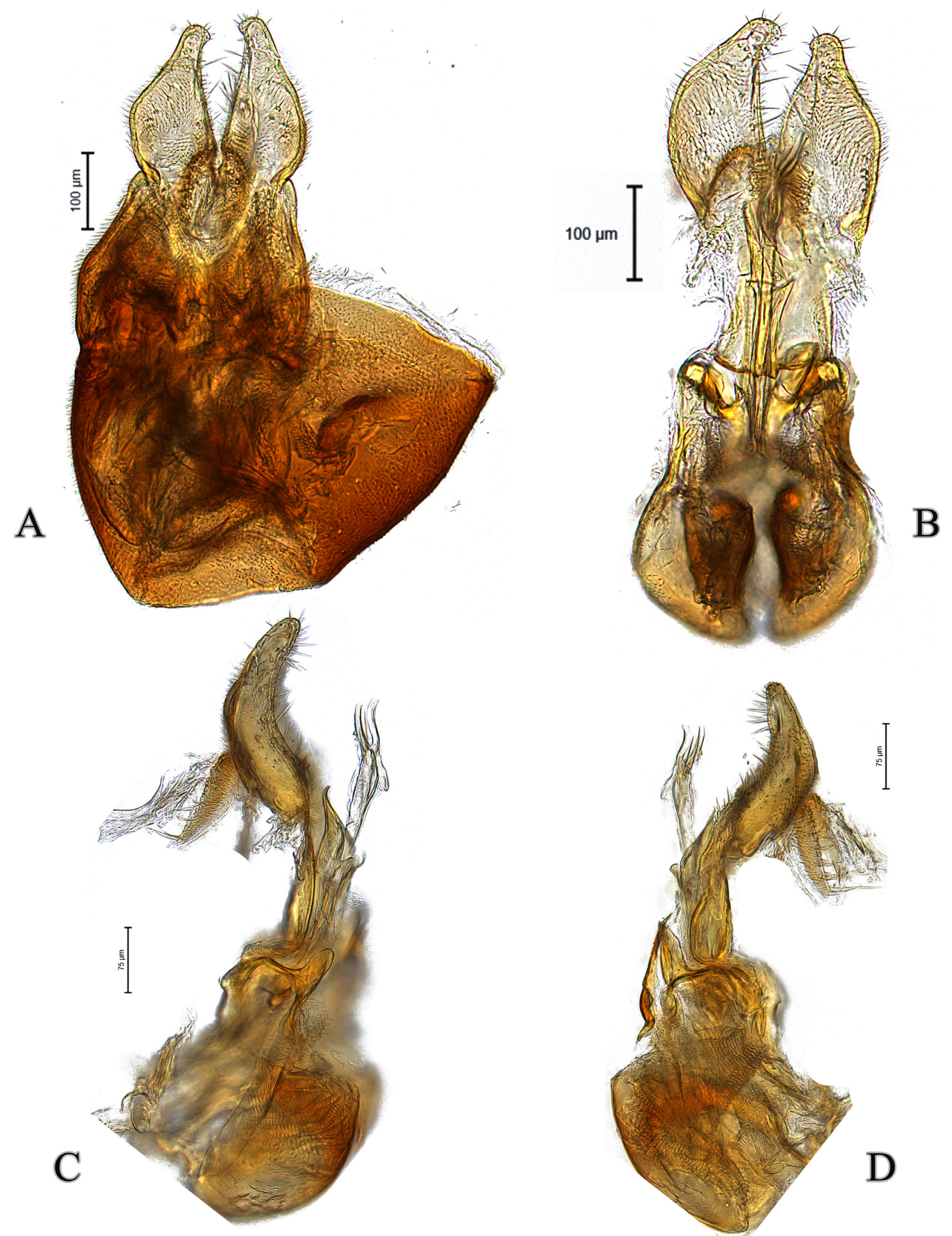

FIGURE 9. Male genitalia of Tomosvaryella debruyni (JSS51736, TAU) A) dorsal view, B) ventral view, C, D) lateral view. 


\section{Tomosvaryella dentiterebra (Collin, 1949)}

Figs $10 \mathrm{~A}-\mathrm{E}, 49$

Diagnosis: This species can be recognized by the asymmetrical shape of surstyli in dorsal view, left surstylus broadened apically and constricted medially, right surstylus broader than left one basally (Fig. 10A); epandrium wider than long in dorsal view (Fig. 10A); gonopods unequal in height, left is higher than right one in ventral view (Fig. 10B); phallus trifid, with three wavy ejaculatory ducts, one with tooth-like projections in basal half in lateral view (Fig. 10D-E). Based on the shape of the surstyli in dorsal view, it is closely related to T. angolensis De Meyer, 1993 and T. forchhammeri De Meyer, 1993. It differs from these species by the shape of the left surstylus in dorsal view, constricted in the middle (Fig. 10A).
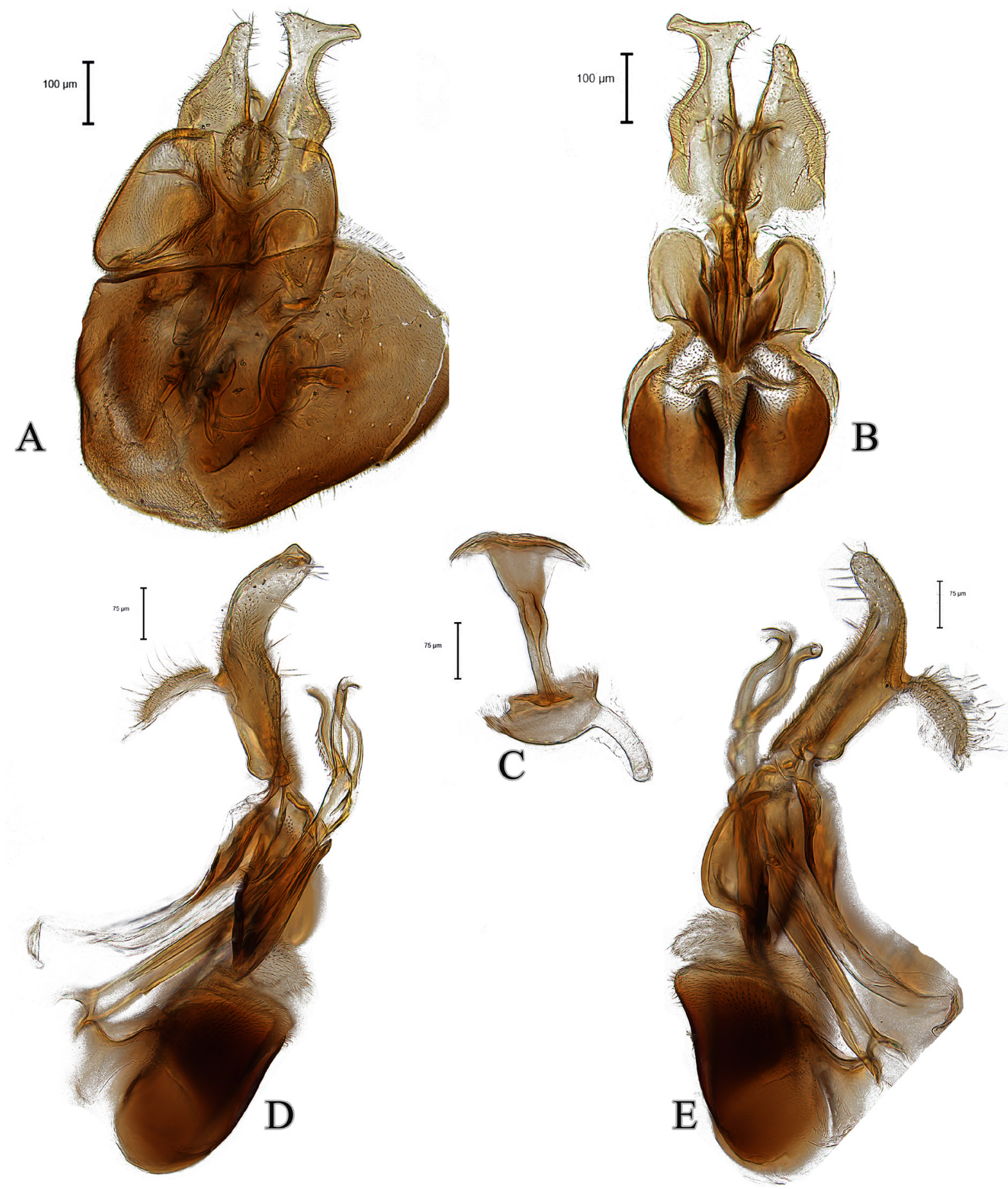

FIGURE 10. Male genitalia of Tomosvaryella dentiterebra (CNCD159901, EAD) A) dorsal view, B) ventral view, C) ejaculatory apodeme, D, E) lateral view. 
Specimens examined: UNITED ARAB EMIRATES: Bithnah, $25^{\circ} 06^{\prime} \mathrm{N}, 56^{\circ} 08^{\prime} \mathrm{E}, 12$.viii-9.ix.2006, A. van Harten, Malaise trap, CNCD160279 (1 $0^{\wedge}$, CNC); Sharjah Desert Park, $25^{\circ} 10^{\prime} \mathrm{N}, 55^{\circ} 25^{\prime} \mathrm{E}$, 4-8.xii.2004, A. van Harten, pan trap, CNCD4277 (1 $\left.{ }^{\top}, \mathrm{CNC}\right)$; Um al-Quwain, $25^{\circ} 19^{\prime} \mathrm{N}, 55^{\circ} 19^{\prime} \mathrm{E}, 23-26 . v i .2008$, A. van Harten, pan trap, JSS52251 (1 $0^{\wedge}$, CNC); Wadi Bih dam, $25^{\circ} 48^{\prime} \mathrm{N}, 56^{\circ} 04^{\prime} \mathrm{E}, 21-30 . i v .2008$, A. van Harten, light trap, JSS52243

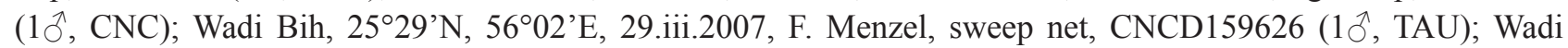

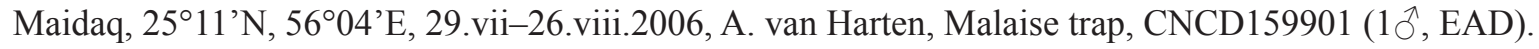

Distribution: Egypt, Iran, United Arab Emirates (Skevington 2020) (Fig. 49).

\section{Tomosvaryella docta De Meyer, 1995}

Figs $11 \mathrm{~A}-\mathrm{F}, 52$

Diagnosis: This species can be recognized by the shape of surstyli in dorsal view, both broadened in basal half; right surstylus narrowed moderately in in apical half, left surstylus narrowed abruptly in apical half (Fig. 11A); epandrium longer than wide (Fig. 11A); subepandrial sclerite wide at the base in ventral view (Fig. 11B); gonopods with an unequal projection, right is farther than left one (Fig. 11B); phallus trifid, one with some small teeth-like projections in lateral view (Fig. 11F).

Specimens examined: IRAN: Khuzestan: Shush, $32^{\circ} 06^{\prime} \mathrm{N}$, $48^{\circ} 26^{\prime} \mathrm{E}, 55 \mathrm{~m}$ a.s.1., 29-31.viii.2013, M. Parchami-Araghi, Malaise trap, JSS52189 (1 9 , CNC); Sistan \& Baluchestan: Daman, 27²4’N, 6049’E, 2-12.vii.2016, H. Davari, Malaise trap, JSS51822 (1 ${ }^{\top}$, CNC); Saravan, $27^{\circ} 25^{\prime}$ N, $62^{\circ} 17^{\prime}$ E, 17.x.2016, F. Hamzavi, sweep net, JSS51827 (1, CNC); Zabol, Dostmohammad, $31^{\circ} 09^{\prime} \mathrm{N}, 61^{\circ} 43^{\prime} \mathrm{E}, 470 \mathrm{~m}$ a.s.l., 29.vi.2016, M. Enaiatnia, Malaise trap, JSS51933 (1ㅇ, CNC); Zabol, $31^{\circ} 03^{\prime} \mathrm{N}, 61^{\circ} 22^{\prime} \mathrm{E}, 480 \mathrm{~m}$ a.s.l., 10.vii.2016, M. Enaiatnia, Malaise trap, JSS51860 (1 $\left.\widehat{\partial}^{\wedge}, \mathrm{CNC}\right) ; 31^{\circ} 02^{\prime} \mathrm{N}, 61^{\circ} 32^{\prime} \mathrm{E}, 470 \mathrm{~m}$ a.s.1., 2.ix.2016, M. Enaiatnia, Malaise trap, JSS51907 (1우,

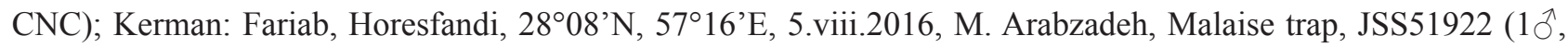

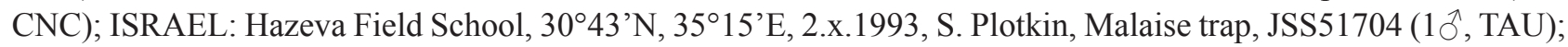

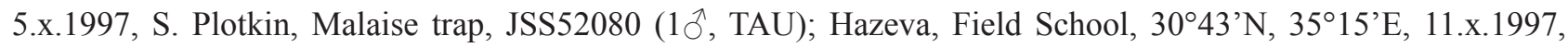

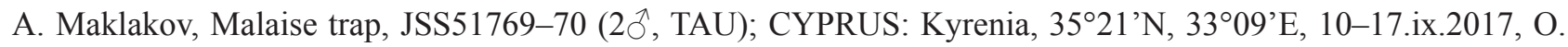
Ozden, Malaise trap, JSS52344 (1ð, CNC); 16-30.vii.2017, O. Ozden, Malaise trap, JSS52325, JSS52355 (2 ${ }^{\lambda}$, CNC); 24.ix-1.x.2017, O. Ozden, Malaise trap, JSS52354 (10, CNC); 30.vii-13.viii.2017, O. Ozden, Malaise trap, JSS52366 (1へ̂, CNC); 9-16.vii.2017, O. Ozden, Malaise trap, JSS52330 (1ð̊, CNC); UNITED ARAB EMIRATES: Abu Dhabi: Al Wathba Wetland Reserve, $24^{\circ} 15^{\prime} \mathrm{N}, 5^{\circ} 37^{\prime} \mathrm{E}$, i.2015, A. Saji \& A. van Harten, Malaise trap, CNC470746 (1ð, CNC); ii.2015, A. Saji \& A. van Harten, Malaise trap, CNC470512, CNC470572 (2ð, USNM); iii.2015, A. Saji \& A. van Harten, Malaise trap, CNC470645, CNC470654, CNC470679-80 (4ð, CNC); iv.2013, A. Saji \& A. van Harten, Malaise trap, CNC470729 (1ð̄, CNC); iv.2015, A. Saji \& A. van Harten, Malaise trap, CNC470808 (1§, CNC); ix.2013, A. Saji \& A. van Harten, Malaise trap, CNC465503, CNC470708-10, CNC470713, CNC470716 (6 ${ }^{\lambda}$, CNC); xi.2013, A. Saji \& A. van Harten, Malaise trap, CNC470721, CNC470725, CNC470728 (3 $\left.{ }^{\wedge}, \mathrm{CNC}\right)$; Al Bida'a Protected Area, $23^{\circ} 36^{\prime} \mathrm{N}, 53^{\circ} 58^{\prime} \mathrm{E}, 29 . x .2018$, A. Saji \& A. van Harten, Malaise

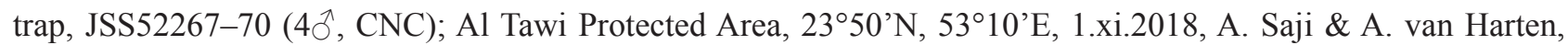

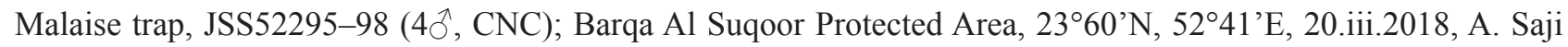
\& A. van Harten, Malaise trap, JSS52260 (10, CNC); 29.x.2018, A. Saji \& A. van Harten, Malaise trap, JSS52282 (10, CNC); Wadi Wurayah farm, $25^{\circ} 14^{\prime} \mathrm{N}, 56^{\circ} 11^{\prime} \mathrm{E}, 17-24 . i i i .2009$, A. van Harten, Malaise trap, CNCD137123 (10ิ, CNC); 19.iv-19.v.2009, A. van Harten, Malaise trap, CNCD137544 (10ิ, CNC); 31.v-14.vi.2009, A. van

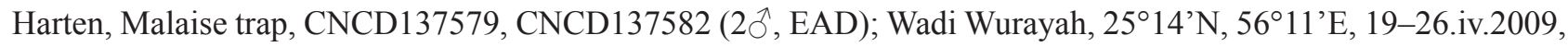
A. van Harten, Malaise trap, CNCD160581 (1§, EAD).

Distribution: Cyprus, Egypt, Iran, Israel, Spain, United Arab Emirates (Skevington 2020) (Fig. 52).

Note: DNA barcodes of this species are genetically most similar to $T$. gazliensis, differing by $7.4 \%$ (pairwise divergence) (Supplementary Table 1). 

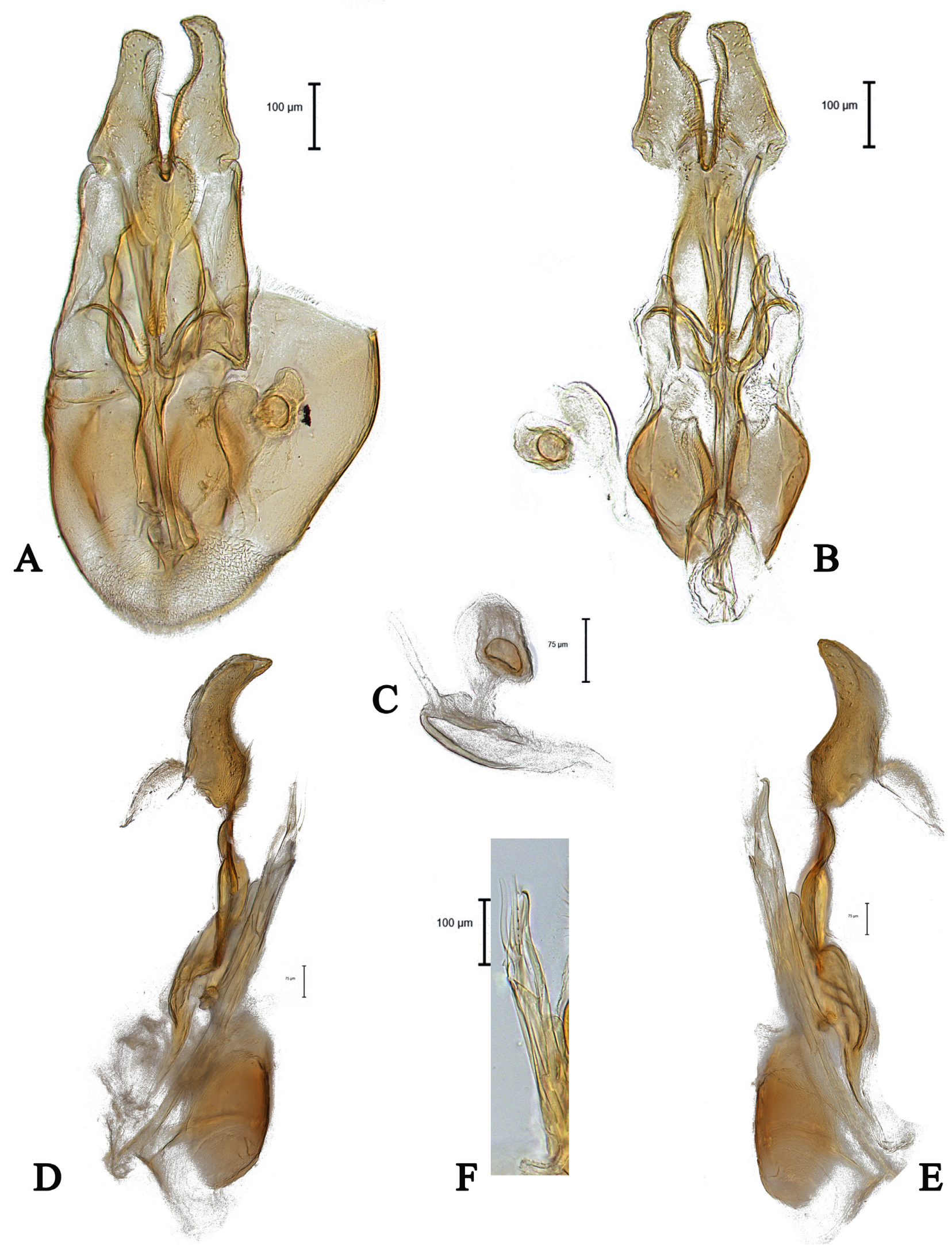

FIGURE 11. Male genitalia of Tomosvaryella docta (CNCD137579, EAD) A) dorsal view, B) ventral view, C) ejaculatory apodeme, D, E) lateral view, F) phallus and phallic guide in lateral view. 


\section{Tomosvaryella ellipiensis Motamedinia \& Skevington sp. nov.}

Figs $12 \mathrm{~A}-\mathrm{D}, 53,66 \mathrm{E}-\mathrm{F}$

Diagnosis: This species can be recognized by the shape of epandrium in dorsal view, expanded towards the left side (Fig. 12A); small surstyli with a ventromedial projection in lateral view (Fig. 12C-D); phallic guide curved towards surstyli, with a pair of dorsolateral spines in lateral view (Fig. 12C).
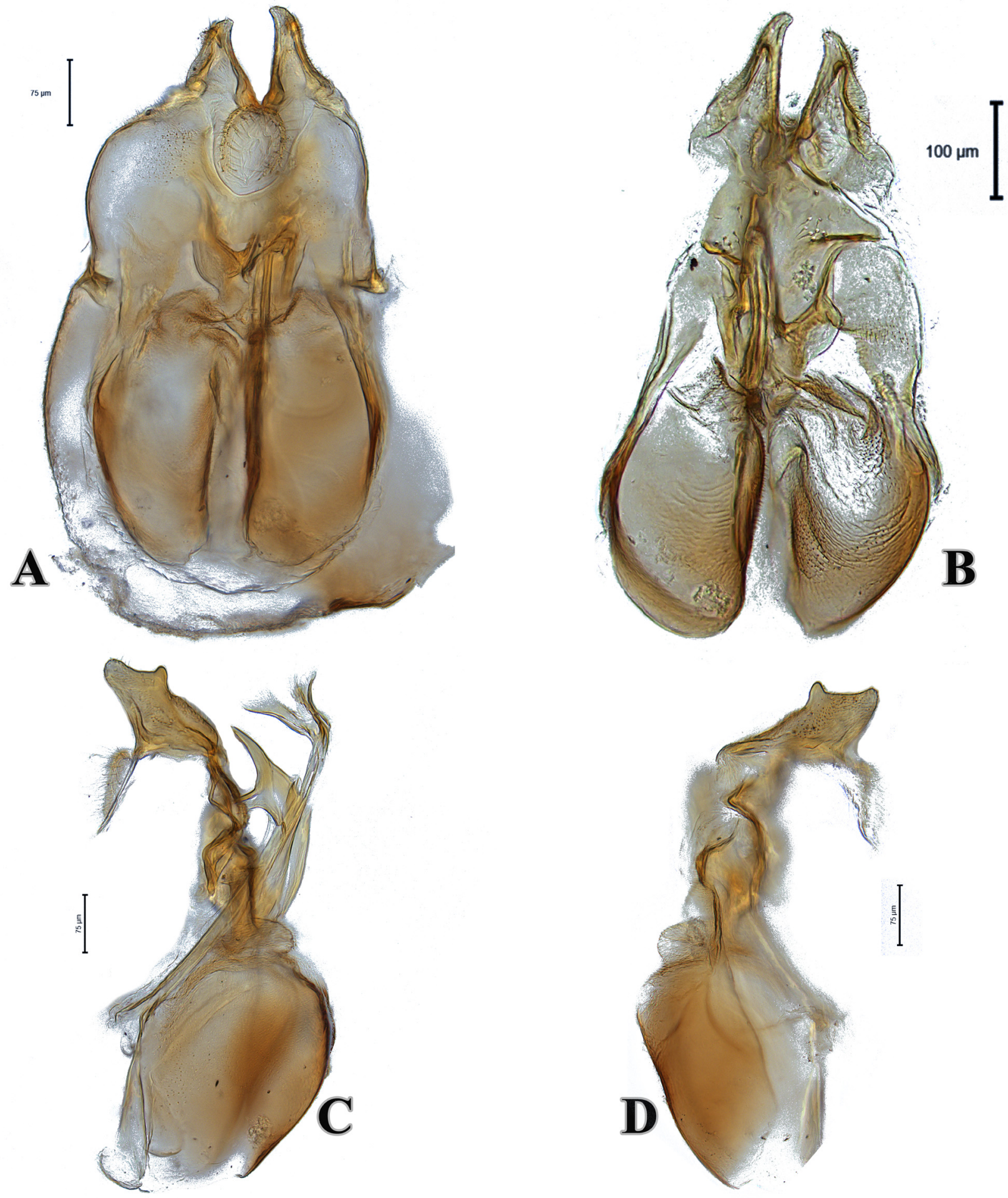

FIGURE 12. Male genitalia of Tomosvaryella ellipiensis sp. nov., holotype (JSS51945, CNC) A) dorsal view, B) ventral view, C) ejaculatory apodeme, D, E) lateral view. 
Description: MALE: Body length (excluding antennae): $2.6 \mathrm{~mm}$. Head. Scape, pedicel, arista dark brown, flagellum brown; scape and pedicel without setae; flagellum tapering $(\mathrm{LF}: \mathrm{WF}=3.0)$. Eyes meeting for a distance of 7-8 facets. Frons silver-gray pollinose. Vertex black, lacking pollinosity. Occiput dark and gray pollinose. Thorax. Postpronotal lobe light yellow, gray pollinose with 2-3 small pale setae along the upper margin (up to $0.02 \mathrm{~mm}$ ). Prescutum and scutum black, with uniseriate rows of intra-alar setae. Scutellum black, silver-gray pollinose, without bristle. Subscutellum and pleura dark brown, gray pollinose. Wing. Length: $2.5 \mathrm{~mm}$. LW:MWW = 2.6. Wing almost entirely covered with microtrichia. Cross-vein $\mathrm{r}-\mathrm{m}$ reaching cell $\mathrm{dm}$ at the middle. $\mathrm{M}_{1}$ strongly undulating in middle. Halter length: $0.28 \mathrm{~mm}$. Whitish, narrowly light brown at base. Legs. Dark brown but narrowly yellow at base of tibiae and all tarsal segments except distitarsi. Trochanters smooth. Femora partly gray pollinose, hind femur shining in posterior. Hind femur bearing two rows of dark, peg-like anteroventral spines in apical one third. Fore, mid and hind femora with 1-2 wrinkled indentations in basal quarter. Tibiae with two rows of short setae on anterior and three rows on posterior side. Hind tibia with 1-2 wrinkled indentations in the middle. Tarsi light brown, gray pollinose. Pulvilli shorter than distitarsi. Claws white with black tips. Abdomen. Ground color dark brown. Tergite 1 entirely gray pollinose with 3-4 yellowish short lateral setae (up to $0.05 \mathrm{~mm}$ ). Tergites $1-5$ with scattered yellowish setae (up to $0.05 \mathrm{~mm}$ ). Sternites brown laterally and dark centrally, gray pollinose. Genitalia. Genital capsule in dorsal view: epandrium and surstyli brown, gray pollinose. Epandrium wider than long (MLE:MWE $=0.5$ ), expanded towards left side (Fig. 12A). Surstyli small, rather symmetrical, triangular-shaped, slightly curved to each other at apex (Fig. 12A). Genital capsule in ventral view: gonopods large and slightly equal in height, subepandrial sclerite wide basically (Fig. 12B). Genital capsule in lateral view: both surstyli small with ventromedial projection (12 C-D); phallic guide broad at base, curved towards surstyli, with two small dorsolateral spines at basal half(Fig. 12C); phallus with three small ejaculatory ducts, one broader than other (Fig. 12C). FEMALE: unknown.

Etymology: The specific epithet refers to Ellipi, the historical name of Kermanshah, from where the holotype has been collected.

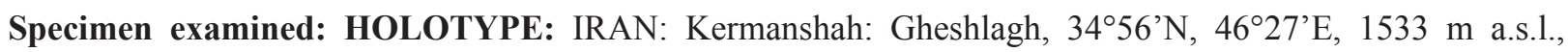
1.vii.2015, M. Zardouei, Malaise trap, JSS51945 (1ðð, CNC).

Distribution: Iran (Fig. 53).

Note: Based on DNA barcodes, T. ellipiensis sp. nov. is genetically most similar to T. teligera (5.6\% pairwise divergence).

\section{Tomosvaryella emaratensis Motamedinia \& Skevington sp. nov.}

Figs 13A-D, 27E, 51, 67A-B

Diagnosis: This species can be recognized by the rectangular shape of both surstyli in dorsal view (Fig. 13A); long gonopods; sclerotized hypandrium with long hypandrial apodeme and a pair of membranous sheaths in the middle in ventral view (Fig. 13D); straight phallic guide with a few distinct dorsolateral spines in lateral and ventral view (Fig. 13B-D). Based on the shape of the surstyli, this species is closely related to kuthyi group (Tomosvaryella cyprusensis sp. nov., T. freidbergi, T. hispanica, T. israelensis, T. kuthyi, T. parakuthyi). It differs by the round syntergosternite 8 in dorsal view (Fig. 13A), long gonopods in ventral view (Fig. 13D) and a few dorsolateral spines on phallic guide in lateral and ventral view (Fig. 13B-D).

Description. MALE: Body length: 2.2-2.9 mm. Head. Frons silver-gray pollinose. Eyes meeting for a distance of four facets. Pedicel with a pair of dorsal setae; flagellum tapering (LF:WF =1.9-2.1), distinctly paler. Thorax. Postpronotal lobe pale, gray pollinose with about 2-3 postpronotal gray setae along upper margin. Prescutum and scutum black, silver-gray pollinose, with uniseriate dorsocentral row of brown setae and some distinct patches of long supra-alar hairs behind postpronotal lobes. Scutellum black, silver-gray pollinose with 8-10 dark brown setae along the upper margin (up to $0.02 \mathrm{~mm}$ ). Subscutellum black and pleura brown. Wings. Wing length: 2.3-2.5 $\mathrm{mm}$. LW:MWW $=2.6-3.0$. Wing almost entirely covered with microtrichia. Cross-vein $\mathrm{r}-\mathrm{m}$ reaching cell $\mathrm{dm}$ at the middle. Halter length: $0.3 \mathrm{~mm}$. Yellow, narrowly brown at base. Legs. Legs dark brown, narrowly yellow at apex of femora, base of tibiae and tarsi. Hind trochanter with a patch of dark brown bristle in the middle. Femora with posteroventral row of black spines and anteroventrally with a row of spines on apical third. Tibiae with two rows of short brown setae on anterior and three rows on posterior side. Pulvilli shorter than distitarsi. Claws white with black tips. Abdomen. Ground color of abdomen dark, gray pollinose; tergite 1 with 3-4 dark lateral setae in both sides, tergites normally covered with distinct bristly brown setae. Sternite brown, lighter than tergites, gray pollinose; syn- 
tergosternite 8 dark brown with scattered brown setae, membranous area large, enlarged towards tip of abdomen and occupying more than half the width of syntergosternite 8. Epandrium darker than surstyli, higher than long (LS8: HS8 = 0.7-0.8); Genitalia. Genital capsule in dorsal view: surstyli rather symmetrical, rectangular-shaped. Left surstylus slightly larger and wider than right one (Fig. 13A). Genital capsule in ventral view: gonopods unequal and long, left slightly higher than right one; lobes of hypandrium sclerotized, with a pair of membranous sheaths covered by small hairs in the middle of hypandrium and with long hypandrial apodeme (Fig. 13D). Genital capsule in lateral view: left surstylus bent towards sternite in apical third, right surstylus gently curved toward sternite (Fig. 13B-C); phallus straight and trifid. Phallic guide straight with few (2-3) short spines laterally (Fig. 13B-C). Ejaculatory apodeme tube-like, bent, with a bulb in its middle (Fig. 13D).
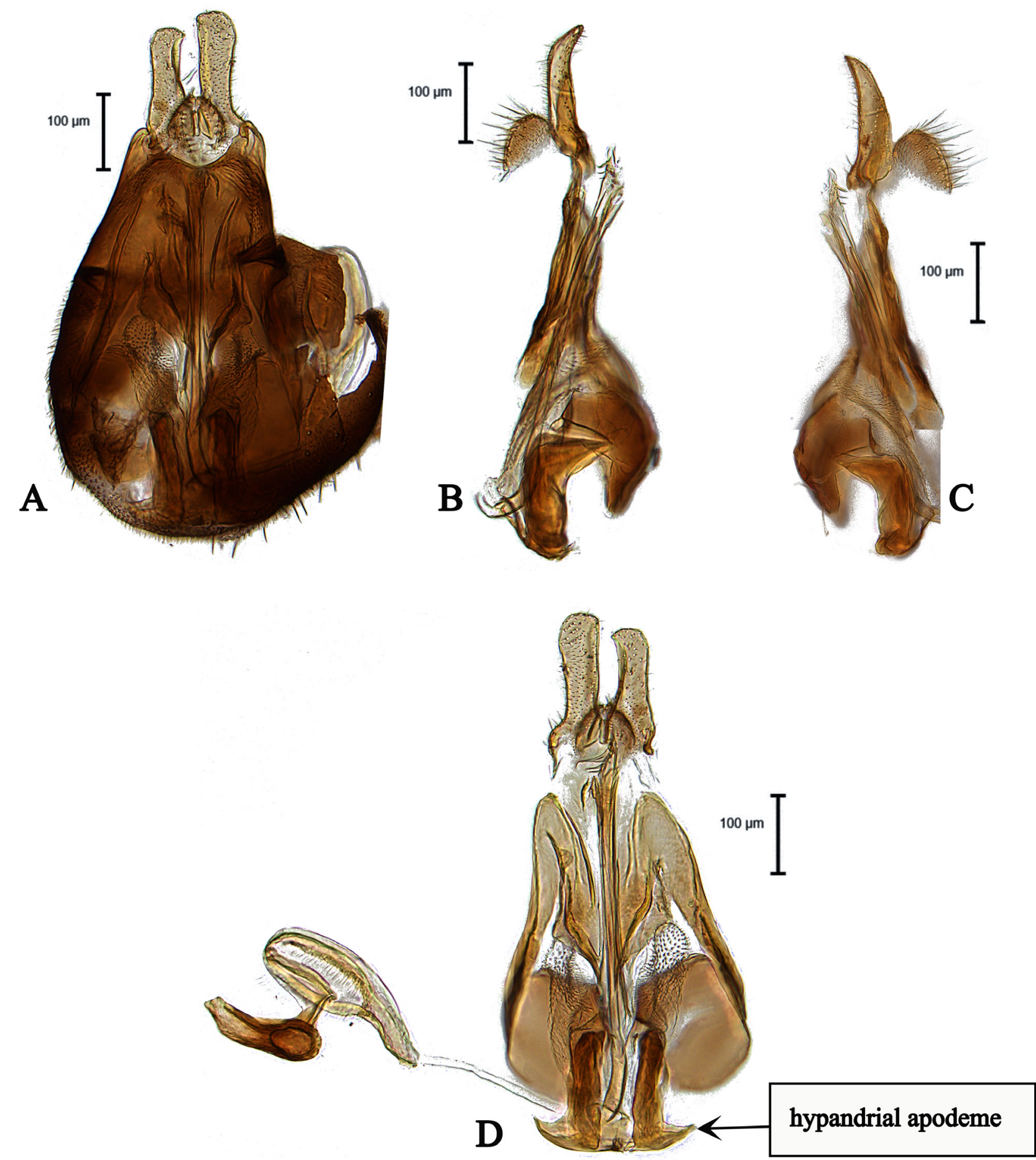

FIGURE 13. Male genitalia of Tomosvaryella emaratensis sp. nov., holotype (CNCD137568, CNC) A) dorsal view, B, C) lateral view, D) ventral view. 
FEMALE: Body length: $2.0 \mathrm{~mm}$. Frons dark, widened in middle. Occiput gray pollinose. Eyes separated, with enlarged frontal facets. Long tapering flagellum. Scutum gray pollinose with two row dorsocentral setae and uniseriate rows of supra-alar setae. Wing length: 1.9-2.0 mm. LW:MWW $=2.1-2.2$. Femora with posteroventral row of black spines and anteroventrally with a row of spines on apical third. Pulvilli smaller than distitarsi. Tergites 1-6 with scattered brown and black setae. Tergite 8 brown, rounded, gray pollinose, distal part of piercer straight and long (Fig. 27E). LP:LB = 1.9-2.1. LDP:LPP = 1.8-2.0.

Etymology: The specific epithet refers to the Emirates, from where the specimens have been collected.

Specimens examined: HOLOTYPE: UNITED ARAB EMIRATES: Wadi Wurayah farm, $25^{\circ} 23^{\prime} \mathrm{N}, 5^{\circ} 19^{\prime} \mathrm{E}$, 31.v.-14.vi.2009, Malaise trap, A. van Harten, CNCD137568 (1 $\hat{\jmath}^{\wedge}$, CNC); PARATYPES: UNITED ARAB EMIR-

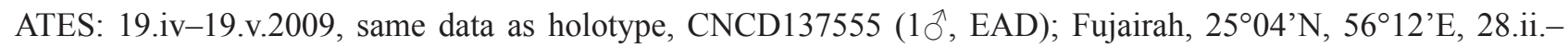

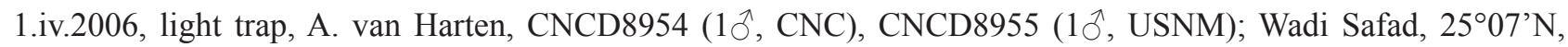
56¹' 'E, 20.xii.2005-2.i.2006, light trap, A. van Harten, CNCD8976 (10, CNC); 19.iv-18.v.2009, same data as holotype, CNCD137556 (1, CNC).

Distribution: United Arab Emirates (Fig. 51).

Note: Based on DNA barcodes, Tomosvaryella emaratensis sp. nov. is genetically most similar to T. minuscula, differing by $2.2 \%$ (pairwise divergence). The male and female sequenced differ by $0.5 \%$ (Supplementary Table 1 ).

\section{Tomosvaryella freidbergi De Meyer, 1995}

Figs 14A-E, 54

Diagnosis: This species can be recognized by the slender shape of surstyli in dorsal view (Fig. 14A); both surstyli straight in basal half, gently bent in apical half in lateral view (Fig. 14D-E); epandrium longer than wide (Fig. 14A); gonopods equal in height (Fig. 14B). Based on the shape of genitalia, this species is part of the kuthyi species group (Tomosvaryella emaratensis sp. nov., T. cyprusensis sp. nov., T. hispanica, T. israelensis, T. kuthyi and T. parakuthyi). It differs from these species by the shape of surstyli in lateral view, slender, slightly straight in basal half and being bent in apical half (De Meyer, 1995: fig. 13a-c; Földvári \& De Meyer, 1999: fig. 10A-D). See diagnosis of $T$. emaratensis sp. nov. and T. cyprusensis sp. nov. for more details.

Specimens examined: HOLOTYPE: ISRAEL: Mt. Hermon, $33^{\circ} 25^{\prime} \mathrm{N}, 35^{\circ} 51^{\prime} \mathrm{E}, 2000 \mathrm{~m}$ a.s.l., 1.vii.1986,

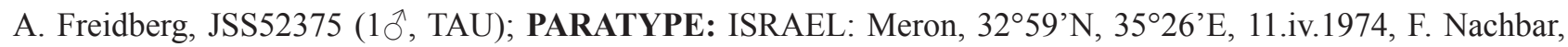

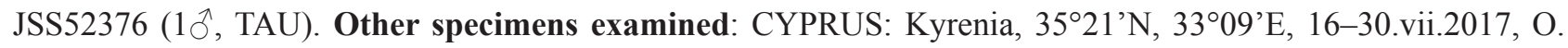

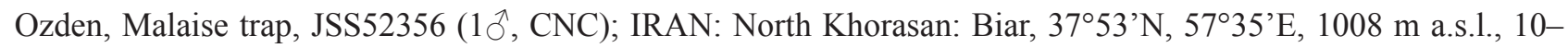
24.vi.2016, B. Motamedinia, Malaise trap; JSS52018 (1 $\left.\mathrm{O}^{\top}, \mathrm{CNC}\right)$; Chenaran village, $37^{\circ} 27^{\prime} \mathrm{N}, 5^{\circ} 36^{\prime} \mathrm{E}, 1300 \mathrm{~m}$ a.s.1.,

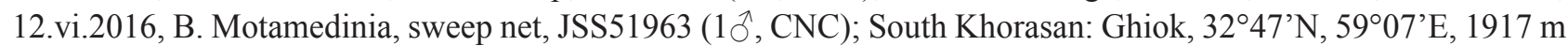
a.s.1., 9.vi.2016, B. Motamedinia, sweep net, JSS52000 (1 ${ }^{\top}$, CNC); Kermanshah: Dodan, $35^{\circ} 00^{\prime} \mathrm{N}, 46^{\circ} 12^{\prime} \mathrm{E}, 1011$

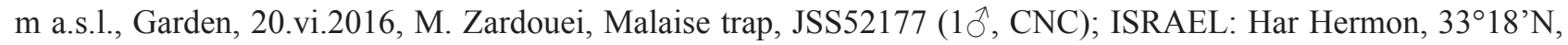

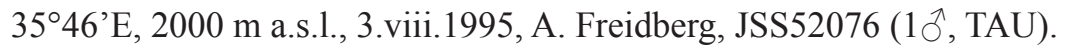

Distribution: Czech Republic Egypt, France, Greece, Hungary, Iran, Israel, Italy, Kyrgyz Republic, Portugal, Spain, Syria, Turkey (Skevington 2020) (Fig. 54).

Notes: DNA barcodes of T. freidbergi are identical to those of $T$. kuthyi (0.0-1.5\% pairwise divergence). The terminalia of these species differ a little by the shape of left surstylus, so this is likely a case of recently-diverged species or ancestral hybridisation. It is possible that these are a single species with polymorphic genitalia, so future genetic work is warranted.

\section{Tomosvaryella frontata (Becker, 1897)}

Fig. 51

Diagnosis. Following Hardy (1967), this species can be recognized by syntergosternite 8, wider than long, without membranous area; epandrium wider than long; symmetrical surstyli, slightly rectangular-shaped, almost twice as wide as long, blunt at apices (Hardy, 1967: fig. 6).

Distribution: Egypt, France, Israel, Italy, Malta, Morocco, Palestine, Romania, Spain, Tunisia (Skevington 2020) (Fig. 51). 
Note: This species has been reared from Tamarix leafhopper, Opsius stactogalus Fieber, 1866, in France (Hardy, 1967).
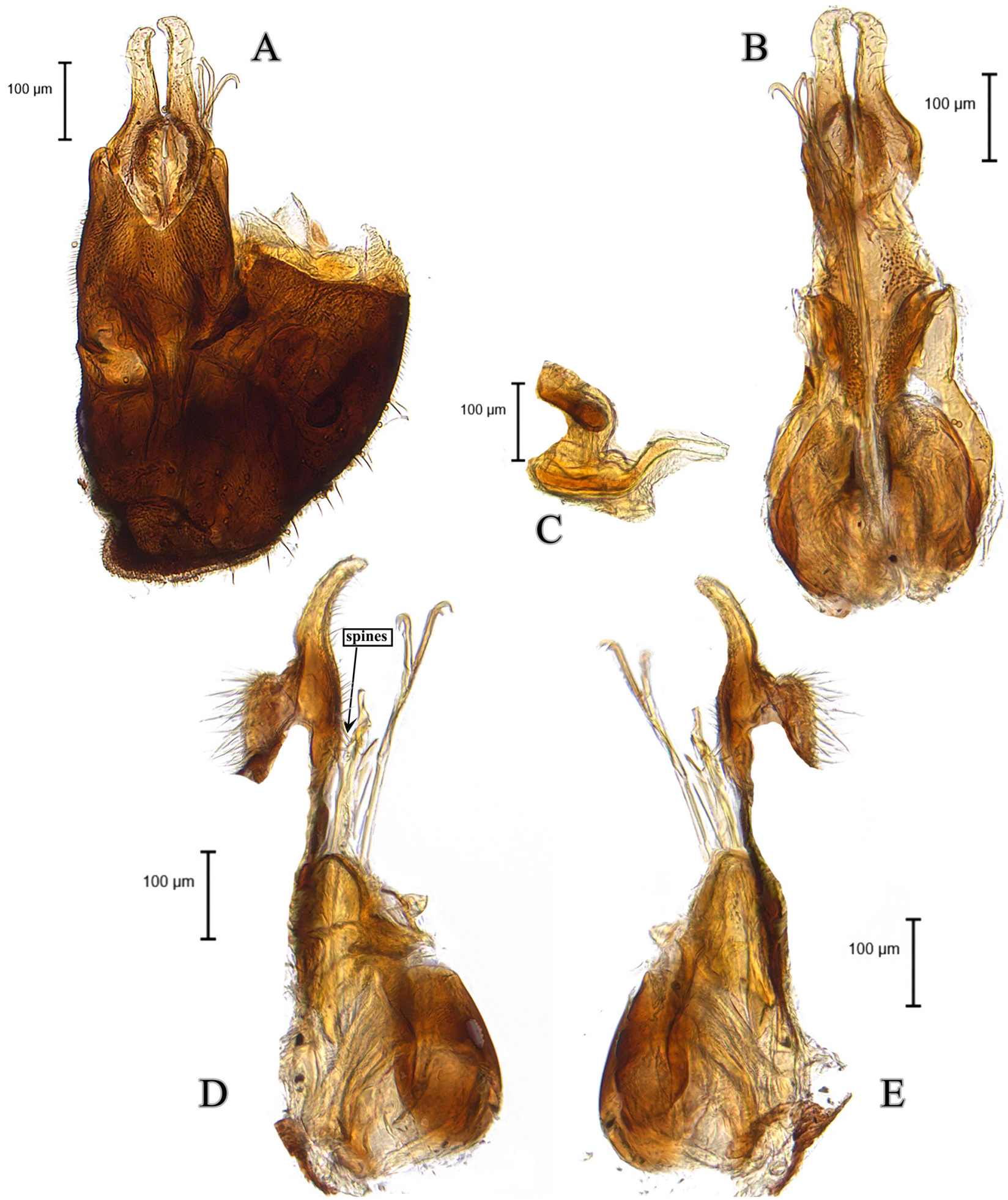

FIGURE 14. Male genitalia of Tomosvaryella freidbergi, holotype (JSS52376, TAU) A) dorsal view, B) ventral view, C) ejaculatory apodeme, D, E) lateral view.

\section{Tomosvaryella gazliensis Kuznetzov, 1994}

Figs $15 \mathrm{~A}-\mathrm{D}, 51$

Diagnosis: This species can be recognized by the shape of surstyli in lateral view, rounded apically, with a distinct 
posteroventral projection before its apex (Fig. 15B-C); epandrium wider than long in dorsal view (Fig. 15A); gonopods equally in height in ventral view (Fig. 15D); subepandrial sclerite small, basically wide in ventral view (Fig. 15D). Based on the shape of genitalia, this species resembles T. urdaensis Kuznetzov, 1994. It differs by the shape of surstyli in dorsal view. Base of surstyli in T. urdaensis is broader and more angulated (Majnon-Jahromi et al. 2017b: fig. 19).

Specimens examined: IRAN: Sistan \& Baluchestan: Saravan, $27^{\circ} 25^{\prime} \mathrm{N}, 62^{\circ} 17^{\prime} \mathrm{E}, 8 . x i .2016$, F. Hamzavi, pan trap, JSS51918 (10, CNC).

Distribution: Iran, Uzbekistan (Skevington 2020) (Fig. 51).

Note: Tomosvaryella gazliensis and T. urdaensis Kuznetzov, 1994, share identical COI barcode ( $0.0 \%$ pairwise divergence) (Supplementary Table 1). In addition, the terminalia of these species are rather similar so future work is required to clarify if they are a single species with polymorphic genitalia or different species.
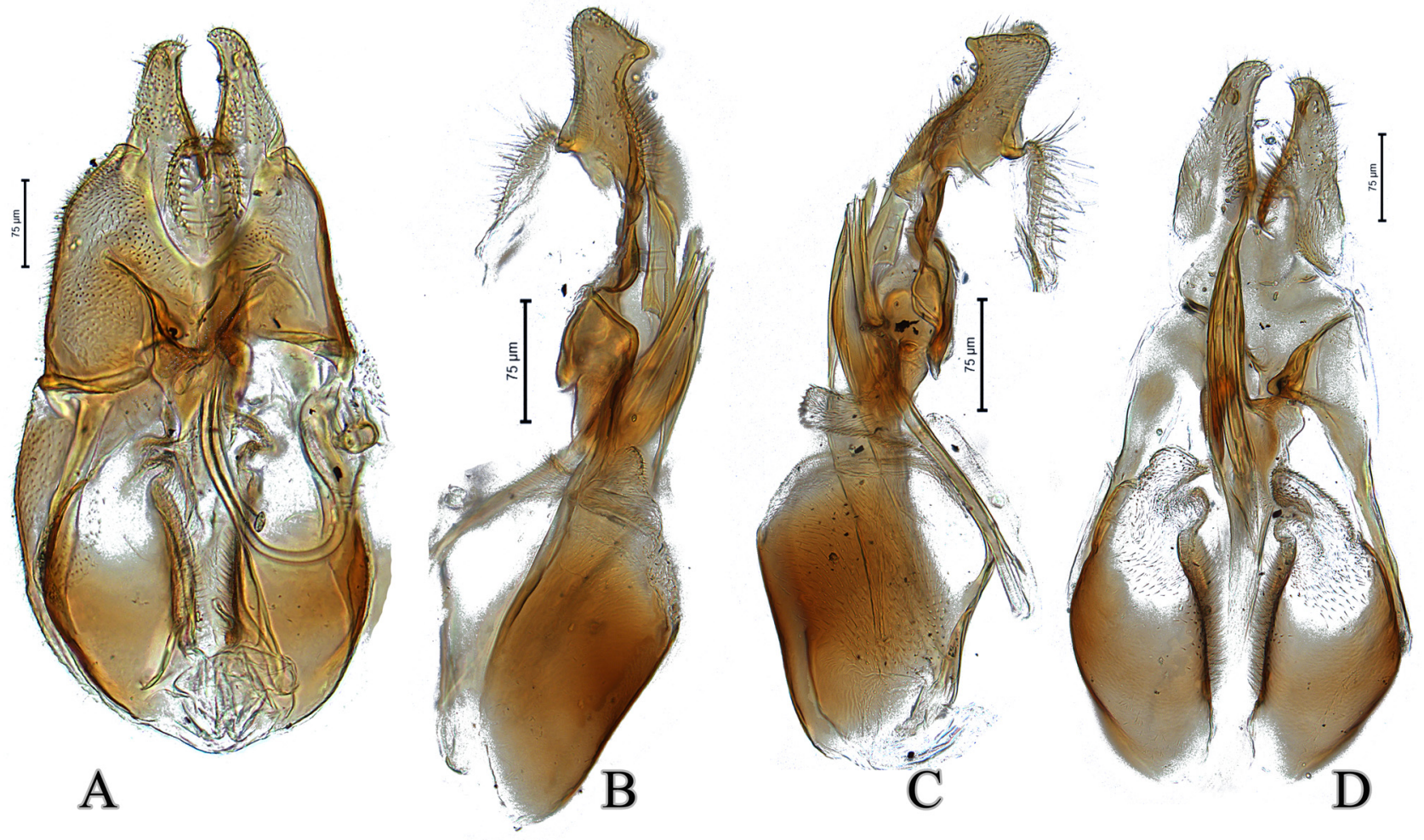

FIGURE 15. Male genitalia of Tomosvaryella gazliensis (JSS51918, CNC) A) dorsal view, B, C) lateral view, D) ventral view.

\section{Tomosvaryella geniculata (Meigen, 1824)}

Figs $16 \mathrm{~A}-\mathrm{E}, 53$

Pipunculus geniculatus Meigen, 1824.—syn. Földvári \& De Meyer (1999): p. 331.

Diagnosis: This species can be recognized by the shape of surstyli in dorsal view, both surstyli slightly rectangular shaped, broader at the base and tips (Fig. 16A), tip of both surstyli flattened apically in lateral view (Fig. 16D-E); epandrium wider than long (Fig. 16A); phallus trifid, one of ejaculatory ducts bearing some small spines in lateral view (Fig. 16E); gonopods equal in height (Fig. 16B).

Specimens examined: IRAN: Kermanshah: Ghazanchi, $34^{\circ} 26^{\prime} \mathrm{N}, 47^{\circ} 00^{\prime} \mathrm{E}, 1304 \mathrm{~m}$ a.s.1., 20.vi.2016, M. Zard-

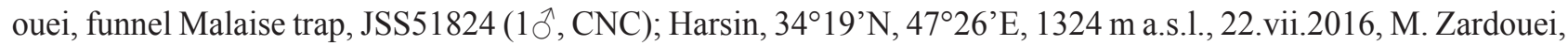

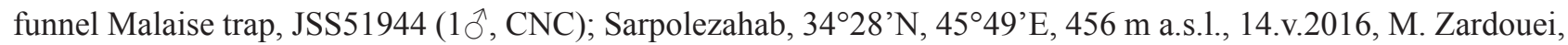

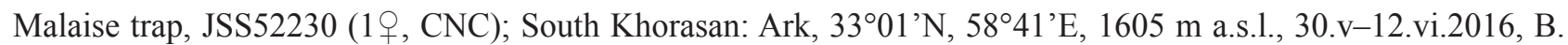

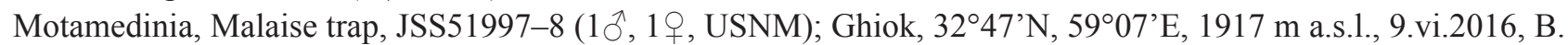

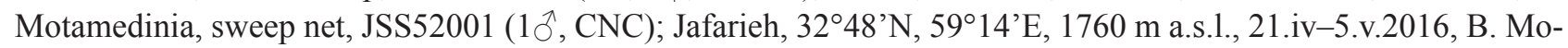
tamedinia, Malaise trap, JSS52007 (1ㅇ, CNC); Mohammadieh, 32 ${ }^{\circ} 52^{\prime} \mathrm{N}, 59^{\circ} 01^{\prime} \mathrm{E}, 1419 \mathrm{~m}$ a.s.1., 14-30.vii.2016, 
B. Motamedinia, funnel Malaise trap, JSS52051 (1 $\hat{\jmath}$, CNC); 3-17.vii.2016, B. Motamedinia, Malaise trap; funnel Malaise trap, JSS52041-2, JSS52045-6, JSS52048, JSS51966-7, JSS51968-72 (11へ̂,1ㅇ, CNC); 5-23.ix.2016, B. Motamedinia, Malaise trap, JSS52025 (1 ${ }^{`}$, CNC); ISRAEL: Nahal Eshharim, 30²8’ N, 34³5’ E, 790 m a.s.l., 2.v.1995, I. Yarom, Malaise trap, JSS51791 (10ิ, TAU).

Distribution: Austria, Belgium, Bulgaria, Croatia, Cyprus, Czech Republic, Denmark, Finland, France, Greece, Germany, Great Britain, Hungary, Iran Israel, Italy, Latvia, Macedonia, Mongolia, Morocco, Netherlands, Poland, Portugal, Romania, Russia, Slovakia, Spain, Sweden, Switzerland (Skevington 2020) (Fig. 53).

Note: This species is genetically most similar to T. emaratensis sp. nov., differing by $9.7 \%$ (pairwise divergence) (Supplementary Table 1).

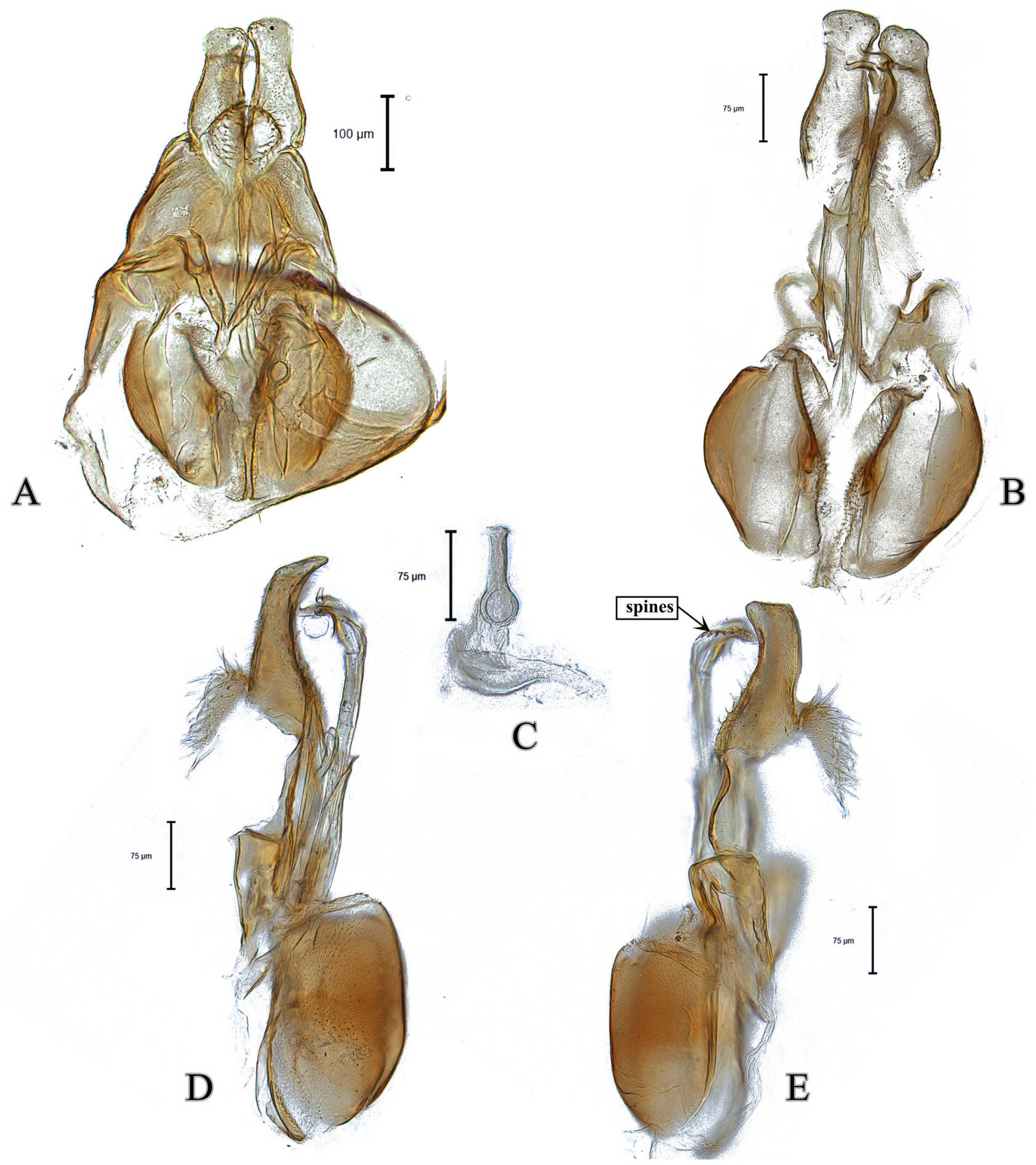

FIGURE 16. Male genitalia of Tomosvaryella geniculata (JSS51944, CNC) A) dorsal view, B) ventral view, C) ejaculatory apodeme, D, E) lateral view. 


\section{Tomosvaryella hamata Majnon-Jahromi \& Kehlmaier, 2017}

Fig. 51

Diagnosis: Following Majnon-Jahromi et al. (2017b), this species can be recognized by the shape of surstyli in lateral view, both cleaver-shaped; epandrium wider than long in dorsal view; phallic guide enlarged apically in lateral view; phallus trifid, with a small hook at the base of ejaculatory ducts (Majnon-Jahromi et al. 2017b: fig. 1A-D).

Distribution: Iran (Majnon-Jahromi et al. 2017b; Skevington 2020) (Fig. 51).

\section{Tomosvaryella hamounensis Motamedinia \& Skevington sp. nov.} Figs 17A-E, 27J, 47B, 51, 67C-D

Diagnosis: This species can be recognized by the shape of surstyli in dorsal view, symmetrical, broadened apically (Fig 17A), both surstyli rather rectangular-shaped in lateral view (Fig. 17 D-E); epandrium wider than long (Fig. 17A); hind trochanter expanded apically with a small projection (Fig. 47B). Based on the shape of surstyli in dorsal view, this species resembles T. nodosa and T. pruinosa. It differs by having broader surstyli apically and lacking a hypandrial apodeme (Fig 17B). Additionally, the hind trochanter of T. pruinosa lacks the small projection found in T. hamounensis sp. nov. (Fig. 47B) and T. nodosa (Fig. 47C).

Description: MALE: Body length (excluding antennae): $2.5-2.7 \mathrm{~mm}(\mathrm{n}=11)$. Head. Scape dark, pedicel and flagellum brown, arista light brown. Flagellum long tapering and gray-white pollinose (LF:WF $=5.0$ ). Eyes meeting for a distance of 10-12 facets. Frons dark silver-gray pollinose. Vertex black, lacking pollinosity, bearing an elevated ocellar triangle. Occiput dark and gray pollinose. Thorax. Postpronotal lobe light yellow, gray pollinose with 3-5 yellowish setae along the upper margin (up to $0.03 \mathrm{~mm}$ ). Prescutum, Scutum, Scutellum black. Scutum with two short uniseriate rows of intra-alar setae and two uniseriate rows of dorsocentral setae. Scutellum gray pollinose with 8-10 thin short setae along lateral margin (up to $0.01 \mathrm{~mm}$ ). Subscutellum black, gray pollinose. Pleura brown. Wing. Length: 2.2-2.8 mm. LW:MWW $=1.6$. Wing almost entirely covered with microtrichia. Cross-vein $\mathrm{r}-\mathrm{m}$ reaches $\mathrm{dm}$ at the middle. $\mathrm{M}_{1}$ moderately undulating in middle. Halter length: $0.33 \mathrm{~mm}$. Whitish, narrowly brown at base. Legs. Coxae brown, gray pollinose. Mid coxa with two or three short dark anterior setae. Trochanters brown, gray pollinose. Hind trochanter broader apically with small projection with some short setae (Fig. 47B). Femora brown with light brown apices, gray pollinose. All femora with one wrinkled indentations at base. Tibiae light brown but darker in middle, with two ventral rows of short setae on anterior and three rows on posterior side. Hind tibia with 1-2 wrinkled indentations in middle. Tarsi light brown with scattered brown setae at anterior margin. Pulvilli yellow. Claws light brown with black tips. Abdomen. Ground color brown. Tergite 1 densely gray pollinose, with 3-5 brown lateral setae (up to $0.08 \mathrm{~mm}$ ). Tergite $2-5$ gray pollinose, with scattered brown setae. Genitalia. Genital capsule in dorsal view: epandrium and surstyli light brown. Epandrium wider than long (MLE:MWE = 0.54). Surstyli rather small and symmetrical. Both surstyli broadened at the middle, with an inner small projection at apex (Fig. 17A). Genital capsule in ventral view: gonopods rather equal in height (Fig. 17B). Subepandrial sclerite small and triangular-shaped (Fig. 17B). Genital capsule in lateral view: both surstyli rather rectangular shape, left surstylus with small ventroapical projection and right surstylus with ventrobasal projection (Fig. 17D-E). Phallic guide strong, phallus with three ejaculatory ducts. Ejaculatory apodeme tube-like, bent, with a bulb in its middle (Fig. 17C).

FEMALE: Body length: $2.6-2.7 \mathrm{~mm}(\mathrm{n}=5)$. Frons gray polllinose, widened in middle. Occiput gray pollinose. Eyes separated. Long tapering flagellum $(\mathrm{LF}: \mathrm{WF}=3.5)$. Scutum gray pollinose with two row dorsocentral setae. Pleura dark brown, silver-gray pollinose. Wing length: 1.9-2.0 mm. LW:MWW $=2.1-2.3$. Fore femur bearing two smaller anteroventral spines in basal third, hind femur with 1-2 wrinkled indentations in basal. Pulvilli smaller than distitarsi. Tergites 1-6 with scattered gray pollinose. Tergite 8 brown, rounded, gray pollinose, distal part of piercer straight (Fig. 27J). LP:LB = 1.3-1.4. LDP:LPP = 2.8-2.9.

Etymology. The specific epithet refers to Hamoun, the region where the specimens have been collected.

Specimens examined: HOLOTYPE: IRAN: Sistan \& Baluchestan: Zabol, 31 ${ }^{\circ} 02^{\prime} \mathrm{N}, 61^{\circ} 32^{\prime} \mathrm{E}, 470 \mathrm{~m}$ a.s.1.,

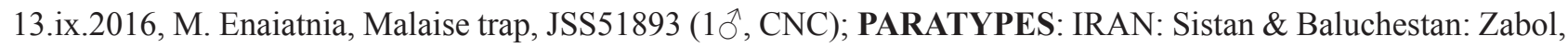
$31^{\circ} 02^{\prime} \mathrm{N}, 61^{\circ} 32^{\prime} \mathrm{E}, 13 . i x .2016$, M. Enaiatnia, Malaise trap, JSS51894-5 (2 ${ }^{\top}$, TAU, USNM); 2.ix.2016, M. Enaiatnia, Malaise trap, JSS51896 (1, CNC); 31 ${ }^{\circ} 03^{\prime} \mathrm{N}, 61^{\circ} 22^{\prime} \mathrm{E}, 7 . i v .2016$, M. Enaiatnia, Malaise trap, JSS51816-7, 
JSS52164, JSS52169 (4^̊, CNC); 2-13.ix.2016, M. Enaiatnia, funnel Malaise trap, JSS52166, JSS52156, JSS52178 (3ㅇ, CNC); 6.x.2016, M. Enaiatnia, Malaise trap, JSS52170 (1 $q$, CNC).

Distribution: Iran (Fig. 51).

Note: Based on DNA barcodes, T. hamounensis sp. nov. is most similar to T. pruinosa, differing by 5.7 \% (pairwise divergence) (Supplementary Table 1).
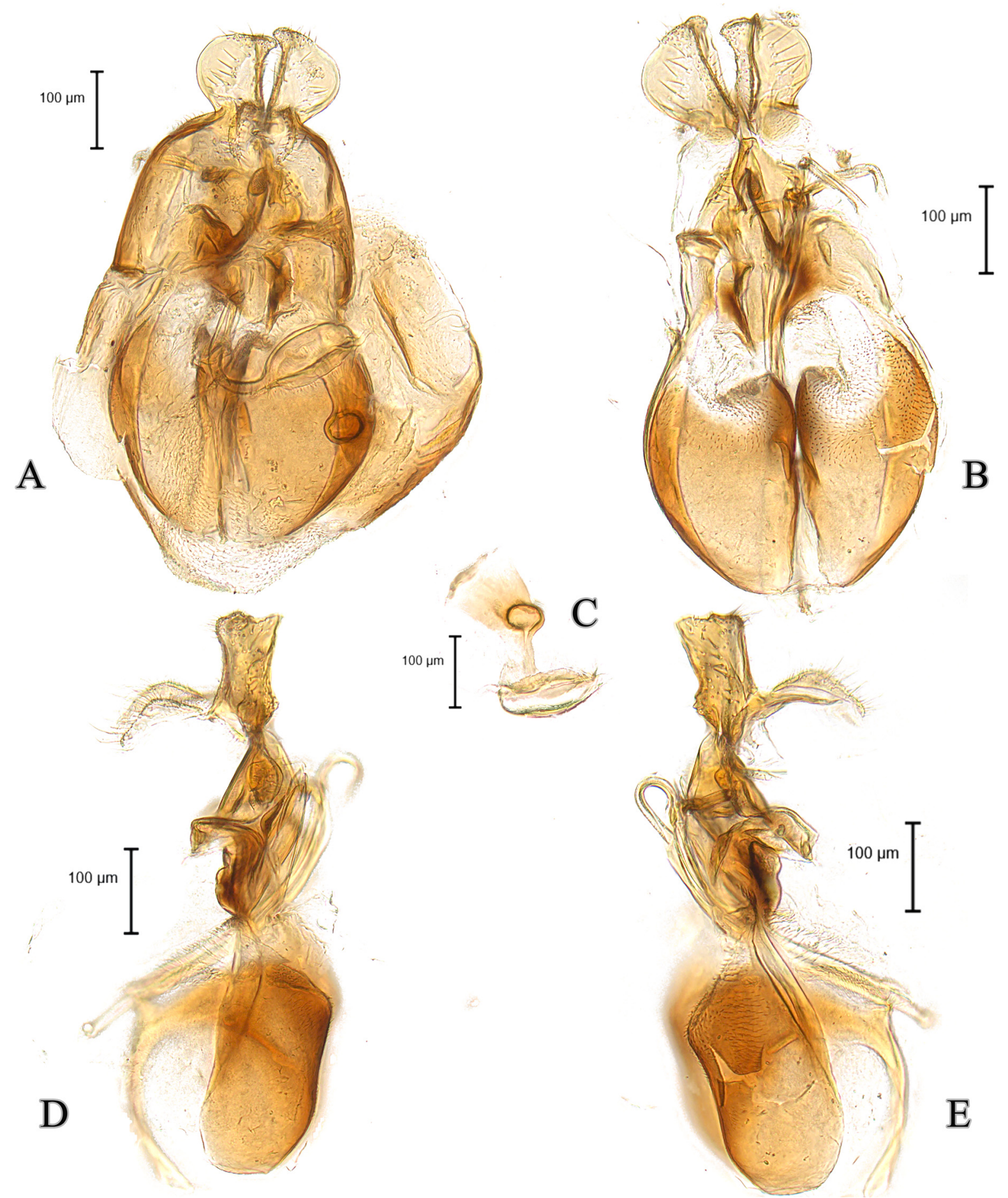

FIGURE 17. Male genitalia of Tomosvaryella hamounensis sp. nov., paratype (JSS51894, TAU) A) dorsal view, B) ventral view, C) ejaculatory apodeme, D, E) lateral view. 


\section{Tomosvaryella helwanensis (Collin, 1949)}

Fig. 53

Diagnosis: Following Kehlmaier et al. (2019), this species can be recognized by the symmetrical surstyli in dorsal view, broadened at the base, both surstyli slightly bean-shaped in lateral view; epandrium wider than long; phallus trifid, one of ejaculatory duct with small spines; phallic guide bent towards surstyli in lateral view (Kehlmaier et al. 2019: fig. 8A-D).

Distribution: Egypt, Israel (Kehlamier et al. 2019; Skevington 2020) (Fig. 53).

\section{Tomosvaryella immutata (Becker, 1913)}

Fig. 49

Distribution: Iran (Skevington 2020) (Fig. 49).

Notes. The female of this species was described by Becker (1913) and the male has not been described or illustrated so far. The type specimen is currently on loan to Sergey Kuznetzov and unavailable (Kehlmaier \& MajnonJahromi, 2014).

\section{Tomosvaryella inermis De Meyer, 1995}

Figs 18A-E, 55

Diagnosis: This species can be recognized by its small epandrium, wider than long (Fig. 18A); both surstyli beanshaped, with an inner small projection shortly before apex in dorsal view (Fig. 18A); phallus with four ejaculatory ducts in lateral view (Fig. 18C-D); equal gonopods in ventral view (Fig. 18B).

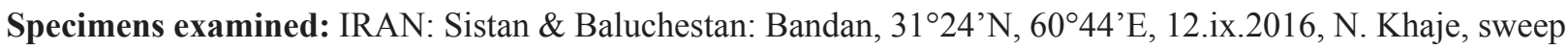
net, JSS51825 (1 ${ }^{\jmath}$, CNC); ISRAEL: 5km S Qiryat Gat, Phillip Farm, $31^{\circ} 31^{\prime} \mathrm{N}, 34^{\circ} 47^{\prime} \mathrm{E}, 12 . x .2004$, A. Freid-

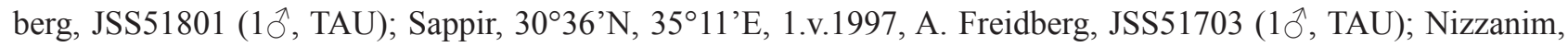

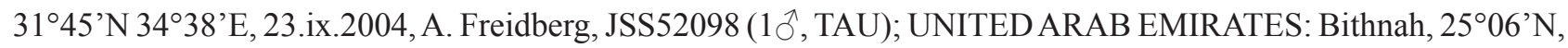
56 08'E, 12.viii-9.ix.2006, A. van Harten, Malaise trap, CNCD160273-8 (5 $\left.{ }^{\circ}, \mathrm{CNC}\right) ; 19 . \mathrm{x}-16 . x \mathrm{i}$ 2006, A. van

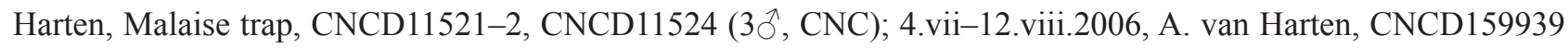
(1 ${ }^{\top}$, USNM); Wadi Bih dam, $25^{\circ} 48^{\prime} \mathrm{N}, 56^{\circ} 04^{\prime} \mathrm{E}, 19-25.1 i .2009$, A. van Harten, Malaise trap, JSS52253, JSS52258

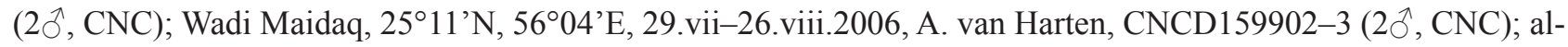

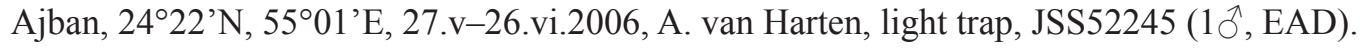

Distribution: Greece, Iran, Israel, Syria, United Arab Emirates (De Meyer, 1995; Kehlmaier et al. 2019; Skevington 2020) (Fig. 55).

\section{Tomosvaryella inopinata De Meyer, 1995}

Figs 19A-E, 56

Diagnosis: This species is related to T. oligoseta De Meyer, 1993 from Botswana (South Africa). Both have rather symmetrical surstyli in dorsal view, broadened at base and apically, constricted at middle (Fig. 19A); epandrium wider than long (Fig. 19A). It slightly differs by the shape of surstyli in dorsal view, the bristling of the phallus and lateral setae in tergite 1 , being completely reduced in T. oligoseta.

Specimens examined: ISRAEL: Nahal Oren, $32^{\circ} 43^{\prime} \mathrm{N}, 35^{\circ} 01^{\prime} \mathrm{E}, 25 . v i i .2002$, A. Freidberg, JSS52071 (1 $\widehat{O}^{\wedge}$,

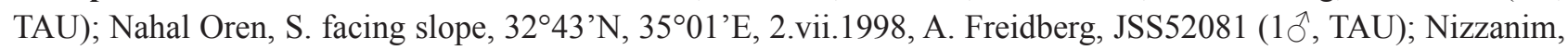
A. Dunes, $31^{\circ} 43^{\prime} \mathrm{N}, 34^{\circ} 38^{\prime} \mathrm{E}, 6 . \mathrm{iv} .2009$, A. Freidberg, JSS52068-9 (20, TAU); UNITED ARAB EMIRATES: Wadi

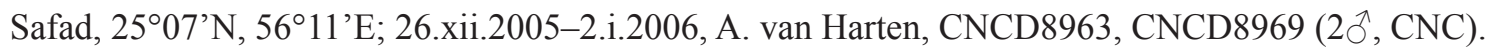

Distribution: Egypt, Israel (Skevington 2020) (Fig. 56).

Note: T. inopinata is genetically similar to T. dentiterebra, differing by $3.9 \%$ (pairwise divergence) (Supplementary Table 1). 

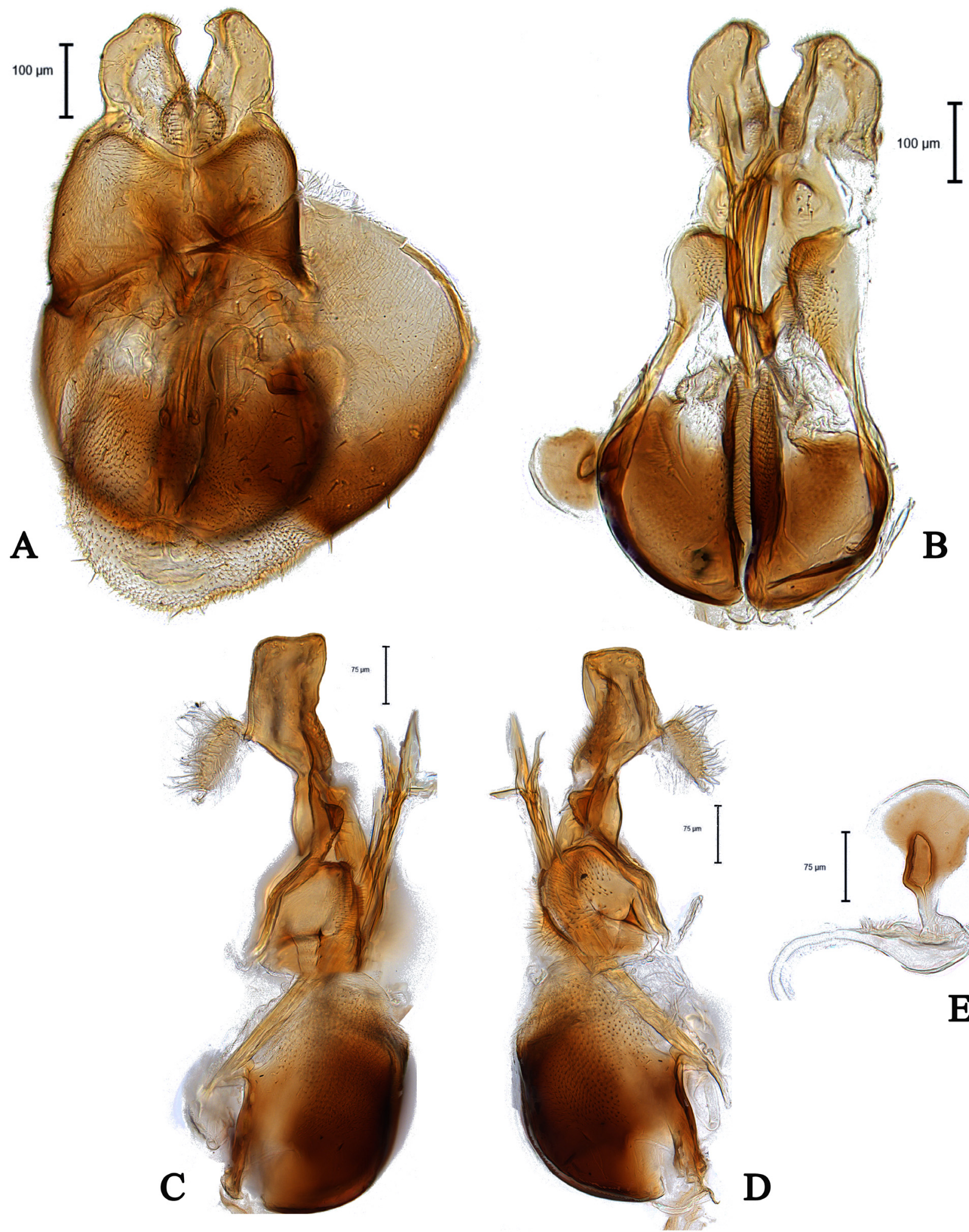

FIGURE 18. Male genitalia of Tomosvaryella inermis (JSS52253, CNC) A) dorsal view, B) ventral view, C, D) lateral view, E) ejaculatory apodeme 

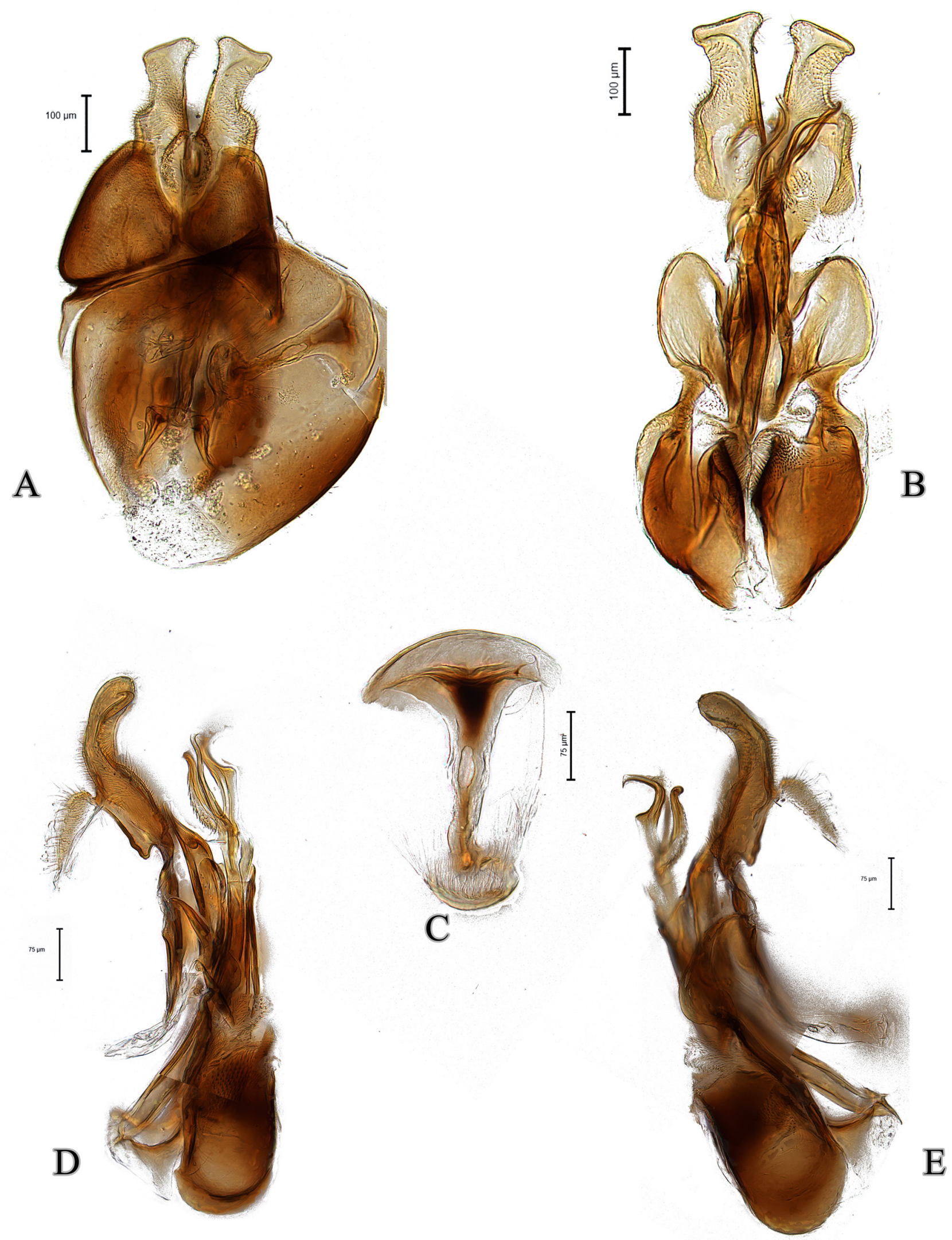

FIGURE 19. Male genitalia of Tomosvaryella inopinata (JSS8963, CNC) A) dorsal view, B) ventral view, C) ejaculatory apodeme, D, E) lateral view. 


\section{Tomosvaryella israelensis De Meyer, 1995}

Figs 20A-E, 55

Diagnosis: Based on the shape of the surstyli in dorsal view, this species is related to the kuthyi species group (Tomosvaryella emaratensis sp. nov. T. cyprusensis sp. nov., T. freidbergi, T. hispanica, T. kuthyi and T. parakuthyi). It differs from these species by the shape of the surstyli in lateral view, broadened, being normally curved (Fig. 20D-E). This species also can be recognized by the shape of phallus, with three ejaculatory ducts, one with more than eight small spines in basal two thirds in lateral view (Fig. 20D-E); epandrium longer than wide (Fig. 20A), gonopods equal in height (Fig. 20B). See diagnosis of T. emaratensis sp. nov. and T. cyprusensis sp. nov. for more details.

Specimens examined: HOLOTYPE: ISRAEL: Kfar Shamai, 32 $2^{\circ} 57^{\prime} \mathrm{N}, 35^{\circ} 27^{\prime} \mathrm{E}$, 30.ix.1975. A. Freidberg,

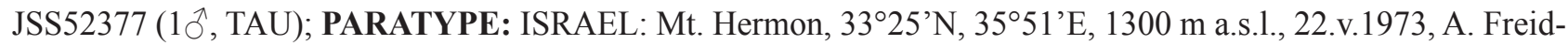
berg, JSS52378 (10̄, CNC).

Distribution: Czech Republic, Greece, Hungary, Iran, Israel, Italy, Romania, Slovakia, Syria (Skevington 2020) (Fig. 55).

\section{Tomosvaryella jubata De Meyer, 1995}

Figs 21A-E, 47A, 53

Diagnosis: This species can be recognized by the small epandrium, wider than long (Fig. 21A); both surstyli rather straight in lateral view (Fig. 21D-E); phallus with three ejaculatory ducts, one with some long spines towards surstyli in lateral view (Fig. 21D); subepandrial sclerite long, both sides with about seven setae apically (Fig. 21B); gonopods broad, equal in height (Fig. 21B); hind trochanter with a small projection (Fig. 47A).

Specimens examined: IRAN: Khuzestan: Shush, $32^{\circ} 06^{\prime} \mathrm{N}, 48^{\circ} 26^{\prime} \mathrm{E}, 68 \mathrm{~m}$ a.s.1., 11.iii-10.v.2015, E. Gilasian, Malaise trap, JSS52231, JSS $52203(1 \hat{0}$,, , CNC).

Distribution: Israel, Iran (De Meyer, 1995) (Fig. 53).

Note: Based on DNA barcoding, T. jubata is very similar to T. bistounensis sp. nov., differing by $1.9 \%$ (pairwise divergence) (Supplementary Table 1).

\section{Tomosvaryella kiansiae Motamedinia \& Skevington sp. nov.}

Figs 22A-D, 53, 67E-F

Diagnosis: This species can be recognized by the shape of surstyli in dorsal view, right surstylus rectangular-shaped and left surstylus roughly club-shaped (Fig. 22A); left surstylus with apicoventral projection in lateral view (Fig. $22 \mathrm{C}$ ); long phallic guide, straight dorsally, wavy ventrally in lateral view (Fig. 22C-D).

Description: MALE: Body length (excluding antennae): $2.6 \mathrm{~mm}$. Head. Face dark, silver-gray pollinose. Scape and pedicel dark; pedicel with a pair of short upper setae and 1-2 short lower setae; flagellum light brown, tip paler than base, tapering and gray pollinose $(\mathrm{LF}: \mathrm{WF}=2.6)$; arista dark, with thickened base. Eyes converging but not meeting and separated by less than diameter of frontal facets. Frons dark, silver-gray pollinose, vertex dark, lacking pollinosity, bearing an elevated ocellar triangle; vertex dark, lacking pollinosity; occiput dark, gray pollinose. Thorax. Pleura, prescutum, scutum and scutellum dark. Pleura gray pollinose. Postpronotal lobe yellow, weakly gray pollinose and with 2-3 light brown postpronotal setae along upper margin. Prescutum and scutum narrowly gray pollinose, with two uniseriate dorsocentral rows of setae and some supra-alar setae. Scutellum gray pollinose, with about 2-3 thin short setae along posterior margin (up to $0.03 \mathrm{~mm}$ ). Subscutellum gray pollinose. Wing. Length: 2.5 $\mathrm{mm}$. LW:MWW $=2.5$. Wing almost entirely covered in microtrichia. $\mathrm{M}_{1}$ gently undulating. Halter length: $0.33 \mathrm{~mm}$. Base and stem brown, knob paler than base. Legs. Coxae dark, gray pollinose. Mid coxa with 2-3 light brown setae on apical margin. Trochanters dark, smooth. Femora dark brown, slightly light brown at apex, gray pollinose. Fore femur bearing two smaller anteroventral spines in basal third, Fore and hind femora with 1-2 wrinkled indentations in basal. Tibiae dark brown, distinctly light brown in basal third, gray pollinose with one wrinkled indentation in middle, hind tibia with some light brown setae in apical third. Tarsi light brown and paler than tibiae, gray polli- 
nose, with some light brown setae dorsally. Pulvilli yellow. Claws light brown with black tips. Abdomen. Ground color dark, gray pollinose. Tergite 1 with six to eight strong lateral setae. Tergites $1-5$ with scattered brown setae. Syntergosternite 8 dark, brown pollinose. Genitalia. Genital capsule in dorsal view: epandrium brown, wider than long (MLE:MWE $=0.71$ ). Surstyli brown and asymmetrical, right surstylus rectangular-shaped and left surstylus roughly club-shaped, wider than right one, tip of left surstylus rounded (Fig. 22A). Genital capsule in ventral view:
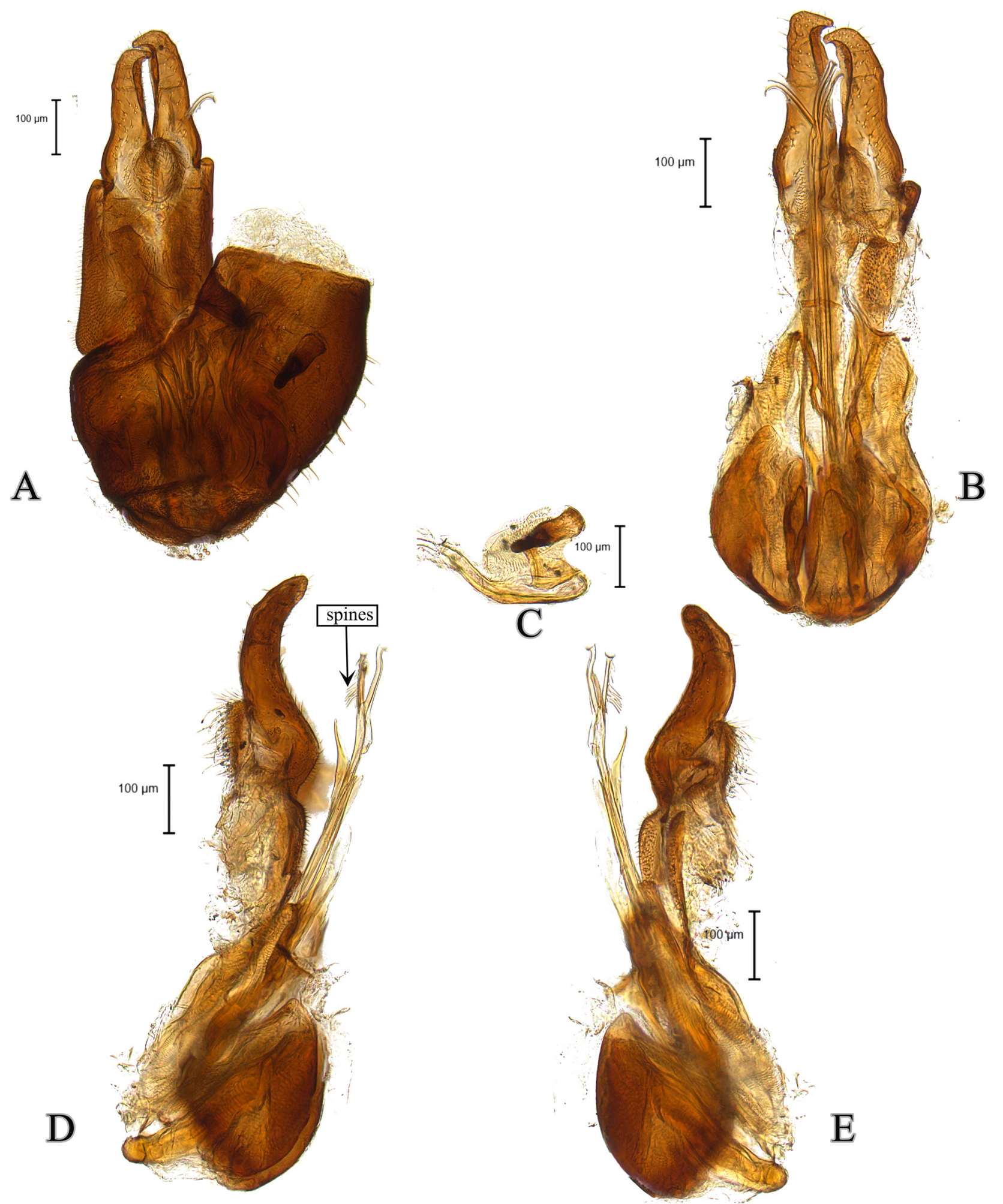

FIGURE 20. Male genitalia of Tomosvaryella israelensis, paratype (JSS52378, CNC) A) dorsal view, B) ventral view, C) ejaculatory apodeme, D, E) lateral view. 

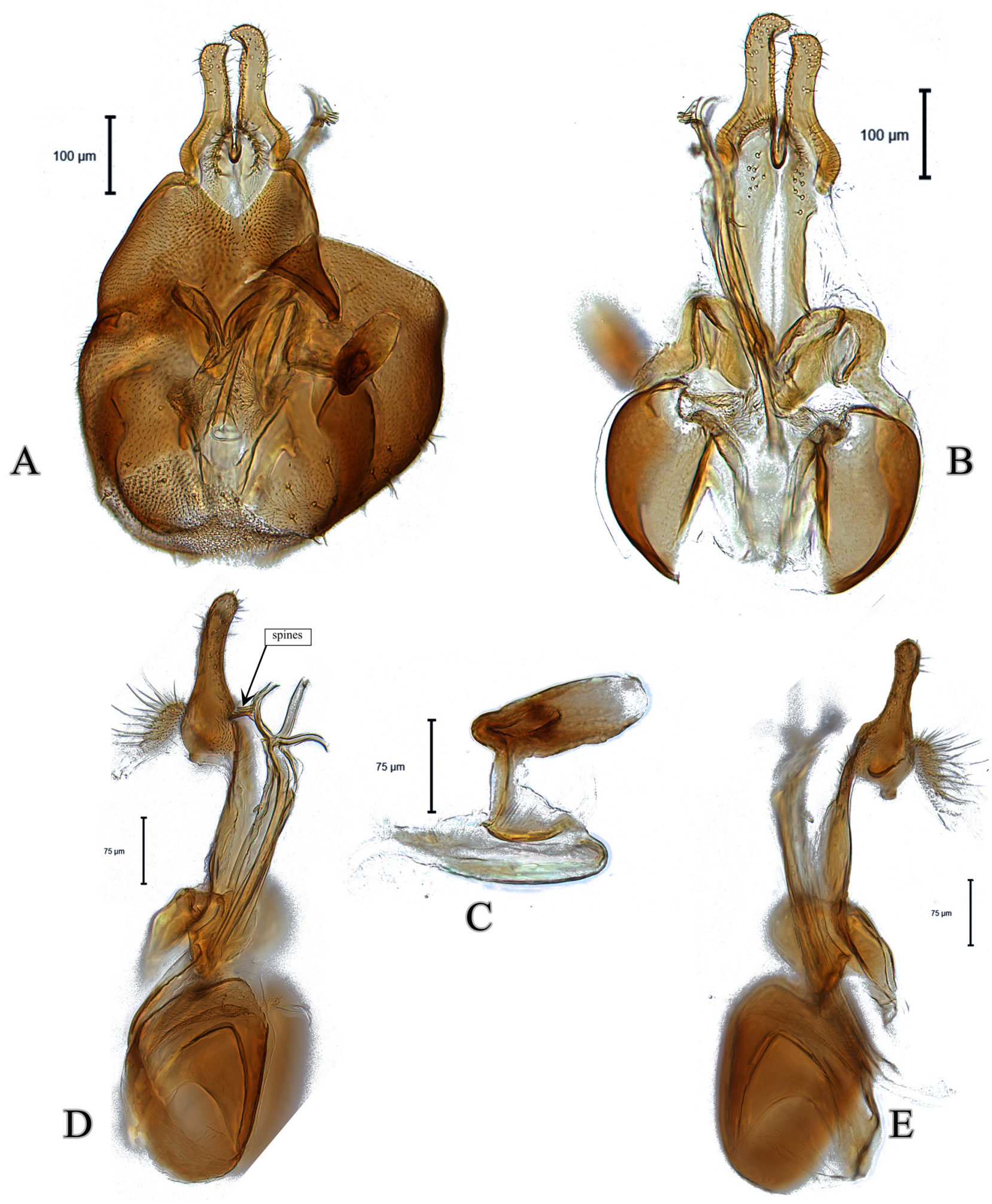

FIGURE 21. Male genitalia of Tomosvaryella jubata (JSS52231, CNC) A) dorsal view, B) ventral view, C) ejaculatory apodeme, D, E) lateral view. 

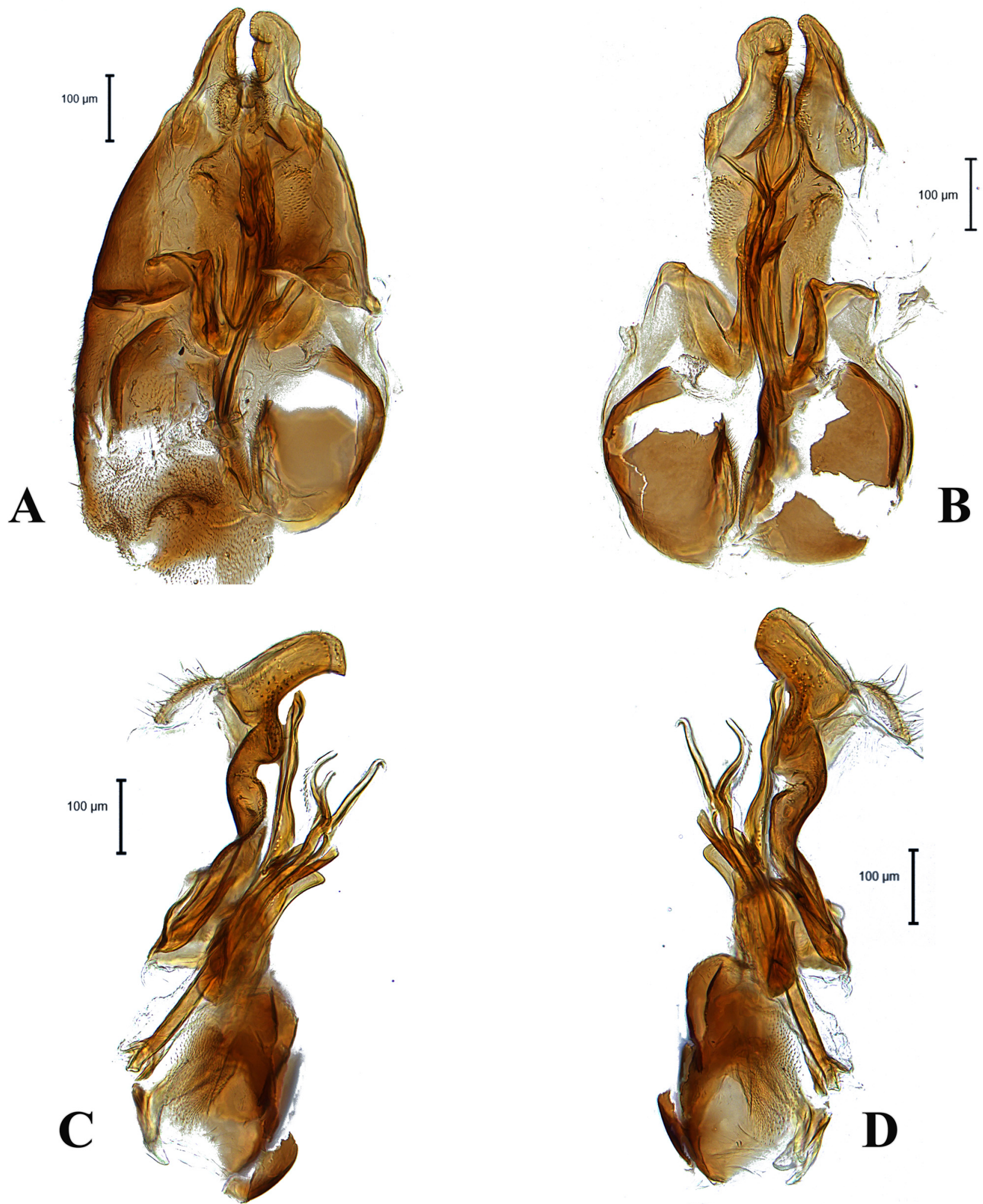

FIGURE 22. Male genitalia of Tomosvaryella kiansiae sp. nov., holotype (JSS51921, CNC) A) dorsal view, B) ventral view, C, D) lateral view.

gonopods equal in height, rather broad and almost symmetrical (Fig. 22B); phallic guide strong and long, reaches in middle of surstyli, subepandrial sclerite wide, rather rectangular-shaped (Fig. 22B). Genital capsule in lateral view: both surstyli rectangular-shaped, bent towards sternite (Fig. 22C-D); left surstylus with apicoventral projection (Fig. 22C); phallic guide thin and long, straight dorsally, wavy ventrally (Fig. 22C-D); phallus trifid with three ejaculatory ducts, one bearing small teeth along basal two thirds (Fig. 22C-D). FEMALE: unknown. 
Etymology: The specific epithet refers to "Kiansi", the historical name of a Hamoun wetland, from where the specimens were collected. The name is formed as a feminine noun in the genitive case.

Specimens examined: HOLOTYPE: IRAN: Sistan \& Baluchestan: Zabol, 31 ${ }^{\circ} 07^{\prime} \mathrm{N}, 61^{\circ} 28^{\prime} \mathrm{E}, 481 \mathrm{~m}$ a.s.l.,

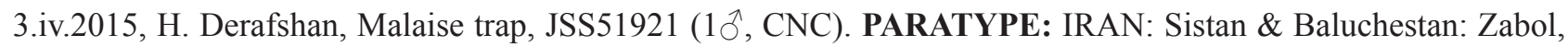
$31^{\circ} 12^{\prime} \mathrm{N}, 61^{\circ} 20^{\prime} \mathrm{E}, 14 . \mathrm{iv} .2014$, H. Derafshan, sweep net, JSS51828 (1 $\left.{ }^{\lambda}, \mathrm{CNC}\right)$.

Distribution: Iran (Fig. 53).

\section{Tomosvaryella kuthyi Aczél, 1944}

Figs 23A-D, 57

Diagnosis: This species can be recognized by elongated surstyli and epandrium in dorsal view (Fig. 23A); long subepandrial sclerite mostly covered by dense hair in ventral view (Fig. 23B); unequal gonopods, left is higher than right one in ventral view (Fig. 23B); both surstyli normally curved in lateral view (Fig. 23C-D). Based on the shape of the surstyli in dorsal view, this species is related to the kuthyi species group, Tomosvaryella cyprusensis sp. nov., T. emaratensis sp. nov., T. freidbergi, $T$. hispanica, $T$. israelensis and $T$. parakuthyi. It differs from these species by the shape of surstyli in lateral view, slightly narrow, being smoothly curved (Fig. 23C-D). See diagnosis of $T$. emaratensis sp. nov. and T. cyprusensis sp. nov. for more details.

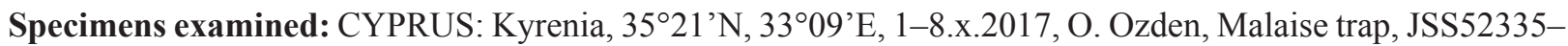
6, JSS52338-9 (4ð’, CNC); 19-25.v.2017, O. Ozden, Malaise trap, JSS52326 (1へ, CNC); 22-29.x.2017, O. Ozden,

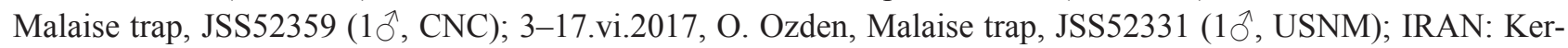
manshah: Dodan, $35^{\circ} 00^{\prime} \mathrm{N}, 4^{\circ} 12^{\prime} \mathrm{E}$, $1011 \mathrm{~m}$ a.s.l., Garden, 20.v.2016, M. Zardouei, Malaise trap, JSS52176

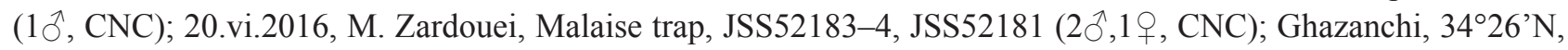

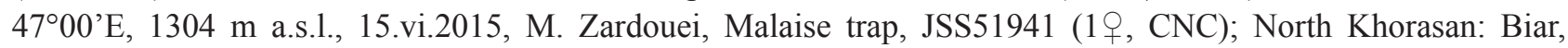

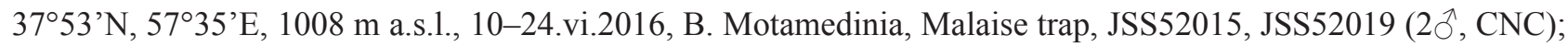

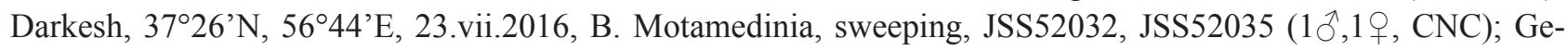
lian, $37^{\circ} 15^{\prime} \mathrm{N}, 57^{\circ} 55^{\prime} \mathrm{E}, 1283 \mathrm{~m}$ a.s.1., 8-22.vii.2016, B. Motamedinia, Malaise trap, JSS51994, JSS51986 (2 ${ }^{\AA}$, CNC, USNM); Sistan \& Baluchestan: Zabol, $31^{\circ} 07^{\prime} \mathrm{N}, 61^{\circ} 28^{\prime} \mathrm{E}, 481 \mathrm{~m}$ a.s.1., 6.vi.2016, H. Derafshan, sweep

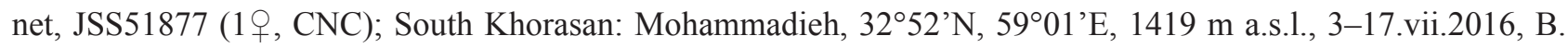
Motamedinia, funnel Malaise trap, JSS51974 (1 ${ }^{\top}$, CNC); Salmanefarsi, 32³0’N, 59¹3’E, 2.vi.2016, B. Mota-

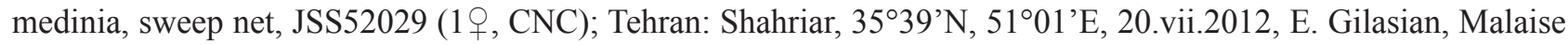
trap, JSS52219 (19, CNC); ISRAEL: Arava Valley, $0.2 \mathrm{~km}$ N. Hazeva Field School, small wadi, 3046’N, 35¹4'E, -116 m a.s.l., 30.iii.1995, M. E. Irwin, Malaise trap, JSS52062 (10ิ, TAU); Arava Valley, Iddan, wadi running east of date palm orchard, $30^{\circ} 48^{\prime} \mathrm{N}, 35^{\circ} 16^{\prime} \mathrm{E},-110 \mathrm{~m}$ a.s.l., 23.iii.1995, M. E. Irwin, Malaise trap, JSS51814 (1 $\hat{\delta}^{\lambda}$, TAU); Arava Valley, Iddan, Small wadi, 2.4 km. W. of hwy. 90 at km 149, 3042’N, 35¹1'E, -60 m a.s.1., 16.iv.1995, M. E Irwin, hand net, JSS51727 (1ð, TAU); B. S. Hazeva, 13.iii.1998, S. Alfi, JSS51795 (10^, TAU); Deir Sha-

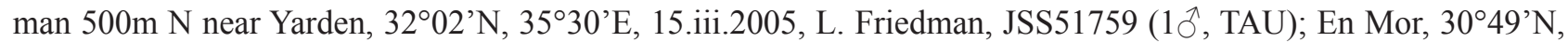

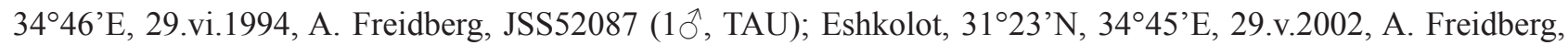

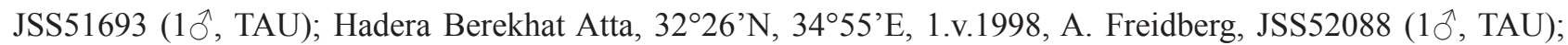

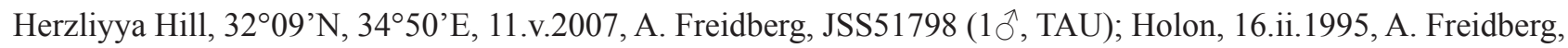

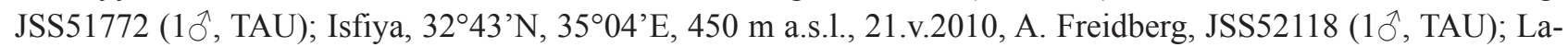
trun, $31^{\circ} 49^{\prime} \mathrm{N}, 34^{\circ} 58^{\prime} \mathrm{E}, 10$. iii.2004, L. Friedman, JSS52119 (10, TAU); Maagar Bental, 7.v.2007, L. Friedman,

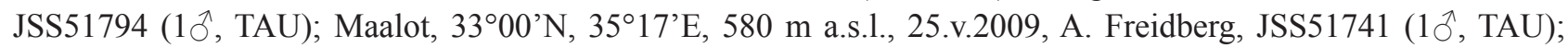

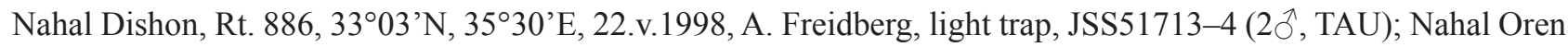

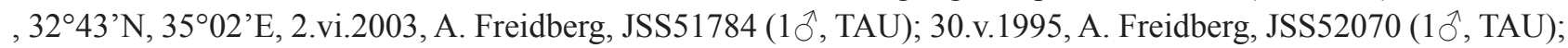
Nahal Oren, river bed, $32^{\circ} 43^{\prime} \mathrm{N}, 35^{\circ} 02^{\prime}$ E, 14.v.2002, A. Freidberg, JSS51712 (1 $0^{\wedge}$, TAU); Nahal Qidron, $31^{\circ} 42^{\prime}$ N, $35^{\circ} 20^{\prime} \mathrm{E}$, 7.vi.1996, A. freidberg, JSS52074-5 (20, TAU); Nahal Tavor, south facing slope, $32^{\circ} 39^{\prime} \mathrm{N}, 35^{\circ} 27^{\prime} \mathrm{E}$,

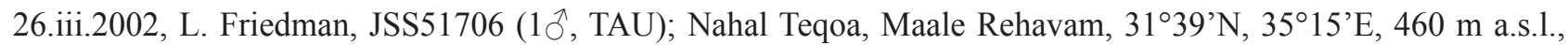

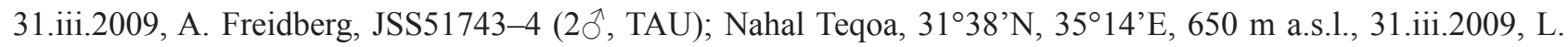

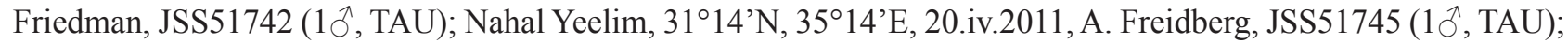
Nahal Yitav spill, $31^{\circ} 55^{\prime} \mathrm{N}, 35^{\circ} 31^{\prime} \mathrm{E}, 16 . i i i .2005$, I. Zonstein, JSS51778 (10, TAU); L. Friedman, JSS51779-80

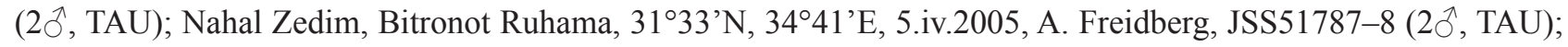




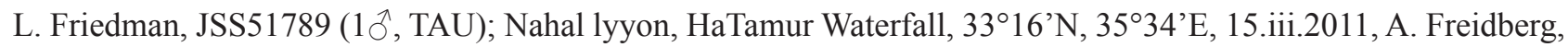

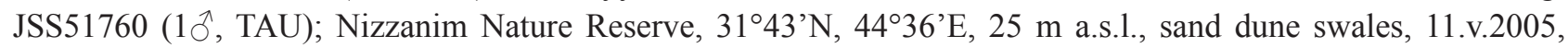
M.E. Irwin, hand net, CNCD157658 (1 ${ }^{\wedge}$, CNC); Nizzanim, D. Dunes, $31^{\circ} 45^{\prime} \mathrm{N}, 34^{\circ} 38^{\prime} \mathrm{E}, 6.1 \mathrm{iv} .2009$, A. Freidberg,

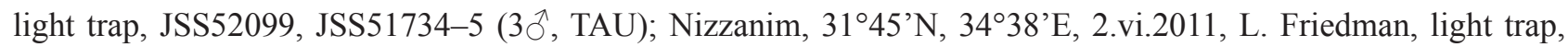

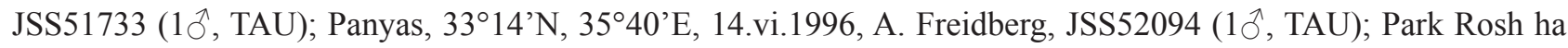

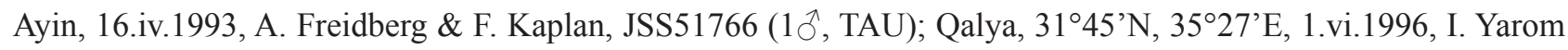

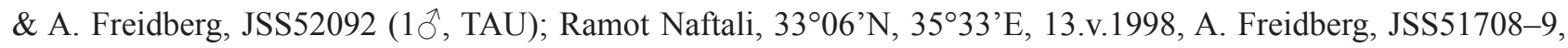

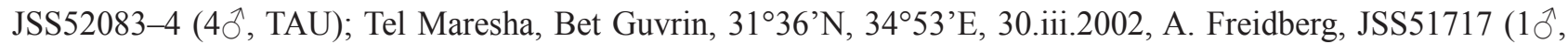

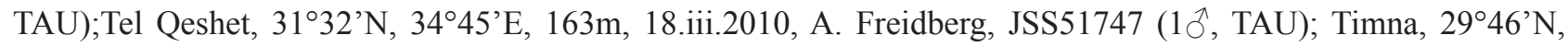

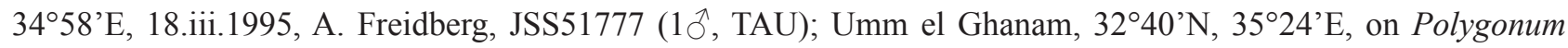
arenastrum, 26.v.2005, L. Friedman, Malaise trap, JSS51793 (1 ${ }^{\AA}$, TAU); Wadi Ahmar near Yarden, $32^{\circ} 01^{\prime} \mathrm{N}$,

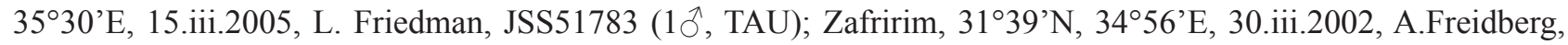

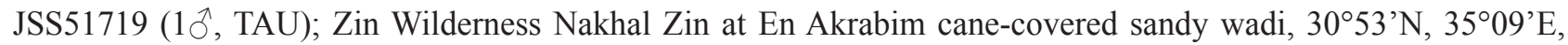
-61 m a.s.1., 7.iv.1995, M. E. Irwin, Malaise trap, JSS51701 (10๊, TAU); Zomet Mezada, 31.v.1998, A. Freidberg,

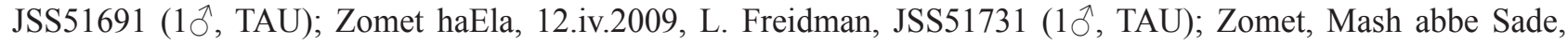

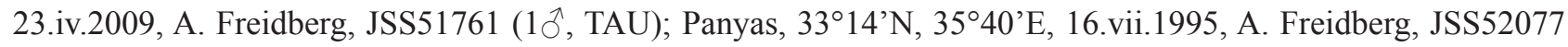
(1 $0^{\lambda}$, TAU); UNITED ARAB EMIRATES: Wadi Wurayah, $25^{\circ} 24^{\prime} \mathrm{N}, 56^{\circ} 17^{\prime} \mathrm{E}, 11-18 . v .2007$, Malaise trap, A. van

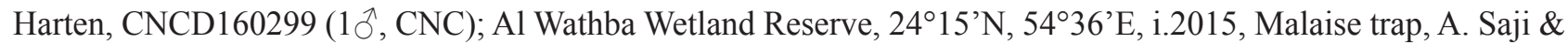
A. van Harten, CNC470760 (1 $\left.0^{\prime}, \mathrm{CNC}\right)$; Fujairah, $25^{\circ} 04^{\prime} \mathrm{N}, 56^{\circ} 12^{\prime} \mathrm{E}$, 19.iv.-02.v.2005, light trap, A. van Harten,

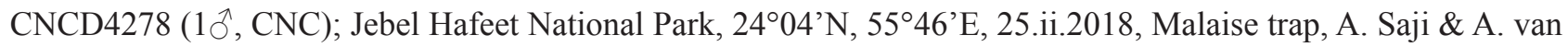
Harten, JSS52263 (10, EAD).

Distribution: Cyprus, Greece, Iran, Israel, Malta, Morocco, Turkey, United Arab Emirates, West and Central Europe (Földvári \& De Meyer, 1999; Kehlmaier et al. 2019; Skevington 2020) (Fig. 57).

Note: DNA barcodes of T. kuthyi and T. freidbergi are similar. See the notes under T. freidbergi.

\section{Tomosvaryella minima (Becker, 1897)}

Figs $24 \mathrm{~A}-\mathrm{D}, 58$

Pipunculus minimus Becker, 1897.—syn. Földvári \& De Meyer (1999): p. 320.

Diagnosis: This species can be recognized by the shape of surstyli in dorsal view, constricted in middle (Fig. 24A), broadened in basal third in lateral view (Fig. 24C-D); epandrium longer than wide in dorsal view (Fig. 24A); subepandrial sclerite long and broad in ventral view (Fig. 24B); gonopods equal in height (Fig. 24B); phallic guide long, curved to abdominal sternite in lateral view (Fig. 24C-D).

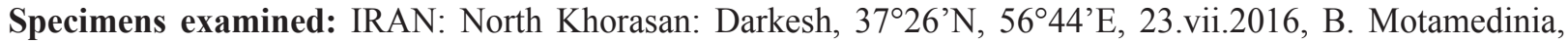

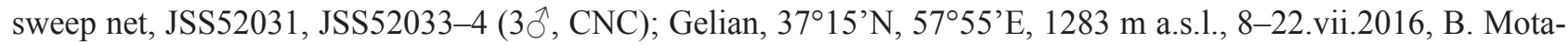

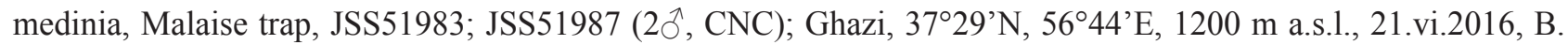

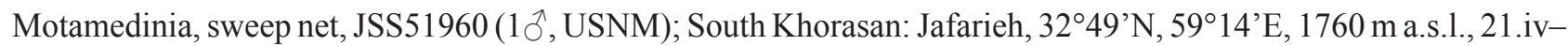

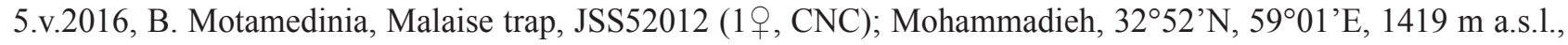

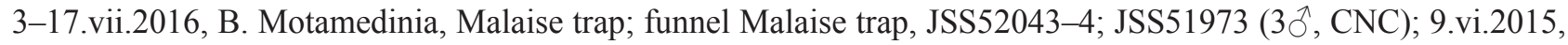

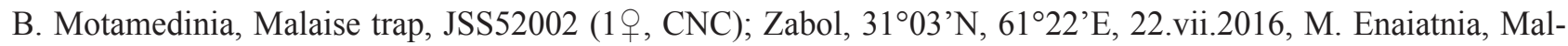
aise trap, JSS52145 (1 ${ }^{\jmath}$, CNC); ISRAEL: Be'er Sheva, $31^{\circ} 15^{\prime}$ N, 34ํำ'E, 9.vii.2001, A. Freidberg, JSS52079

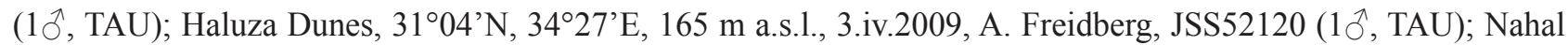
Lavan Rt. 10, 3051'N, 34³6’E, 17.iv.1998, A. Freidberg, JSS51723, JSS52089, JSS52091 (30^, TAU); Negev, 1

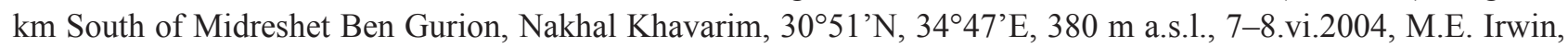
Malaise trap, CNCD135039 (1へ, CNC).

Distribution: Belgium, Czech Republic, Denmark, France, Germany, Great Britain, Hungary, Iran, Israel, Italy, Latvia, Mongolia, Morocco, Netherlands, Poland, Romania, Russia, Slovakia, Spain, Sweden, Switzerland (Skevington 2020) (Fig. 58). 

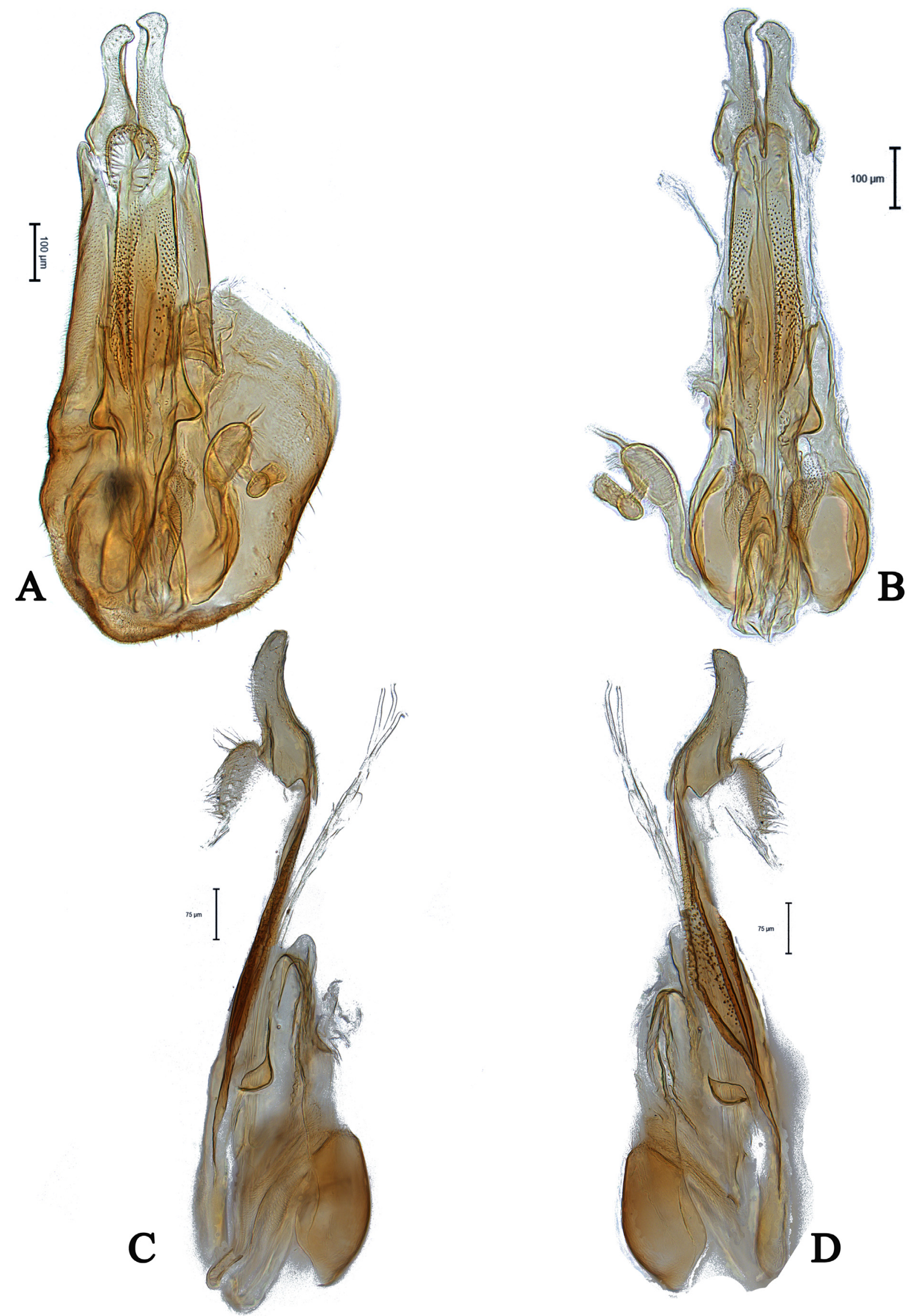

FIGURE 23. Male genitalia of Tomosvaryella kuthyi (JSS52019, CNC) A) A) dorsal view, B) ventral view, C, D) lateral view. 

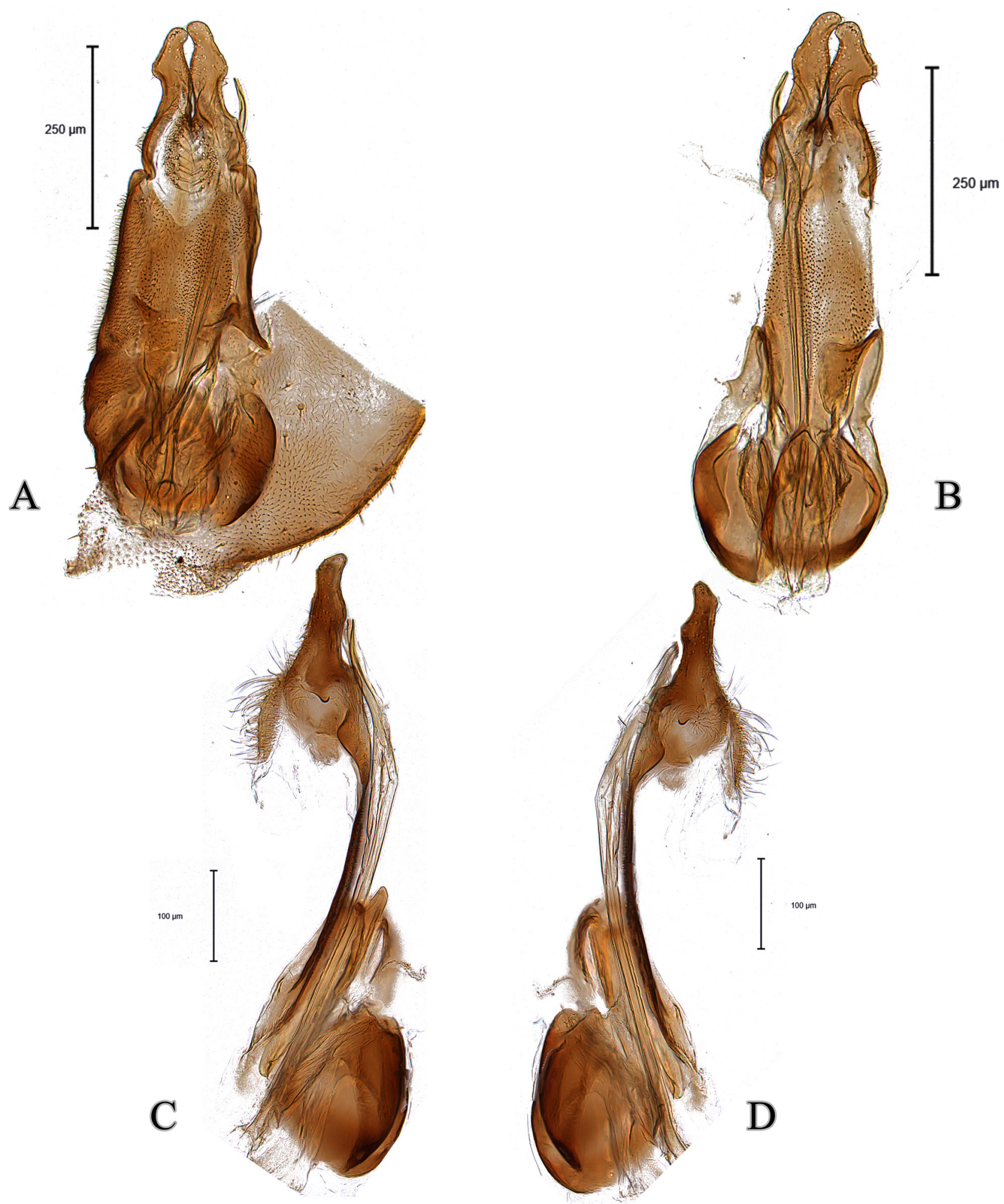

FIGURE 24. Male genitalia of Tomosvaryella minima (JSS52091, TAU) A) dorsal view, B) ventral view, C, D) lateral view.

Note: Based on DNA barcodes, T. minima is most similar to T. minuscula (3.6\% pairwise divergence) (Supplementary Table 1). 


\section{Tomosvaryella minuscula (Collin, 1956)}

Fig. 56

Alloneura minuscula Collin, 1956.—-syn. De Meyer (1996) : p. 90.

Tomosvaryella magyarica Földvári \& De Meyer, 1999.—syn. Kehlamier (2008): p. 37.

Diagnosis: Following Földvári \& De Meyer (1999), this species can be recognized by the apically divided phallic guide in lateral view; slightly broadened and elongated surstyli; phallus with three ejaculatory ducts, one bearing some long spines in lateral view; epandrium wider than long (Földvári \& De Meyer, 1999: fig. 13A-F).

Distribution: Czech Republic, Finland, Germany, Hungary, Iran, Slovakia, Sweden, Switzerland (Majnon-Jahromi et al. 2018; Skevington 2020) (Fig. 56).

\section{Tomosvaryella mutata (Becker, 1897)}

Fig. 58

Diagnosis: Following Földvári \& De Meyer (1999), this species can be recognized by the shape of surstyli in dorsal view, broadened at base, constricted before apex; both surstyli bent in middle in lateral view; epandrium wider than long in dorsal view; short phallic guide, broadened at base; phallus with three ejaculatory ducts, one bearing some small teeth in basal half (Földvári \& De Meyer, 1999: fig. 15A-D).

Distribution: Egypt, France, Hungary, Israel, Japan, Morocco, Romania, Spain, Syria (Skevington 2020) (Fig. 58).

Note: Földvári \& De Meyer (1999) mentioned that there is some variation in the male genitalia features of this species from Israel (and Hungary) and this might be a species complex.

\section{Tomosvaryella nigronitida (Collin, 1958)}

Fig. 53

Distribution: Croatia, Israel (De Meyer, 1995; Skevington 2020) (Fig. 53).

Notes: This species was described based on a female, and the male sex is unknown. The female can be identified by the black halter and long piercer reaching the first abdominal sternite (De Meyer, 1995). It may be synonymous with T. cilifemorata (Földvári \& De Meyer (1999).

\section{Tomosvaryella nimroozensis Motamedinia \& Skevington sp. nov.}

Figs 25A-F, 56, 68A-B

Diagnosis: This species can be recognized by the asymmetrical surstyli in dorsal view, broadened in basal, left surstylus knobbed apically, right surstylus narrowed in apical half (Fig. 25A); gonopods equal in height in ventral view (Fig. 25B); small phallic guide in lateral view (Fig. 25D).

Description: MALE: Body length (excluding antennae): $3.9 \mathrm{~mm}$. Head. Scape, pedicel, flagellum, arista dark brown. Pedicel gray pollinose in apical half, with three upper setae and 1-2 lower setae. Flagellum gray pollinose and tapering $(\mathrm{LF}: \mathrm{WF}=3.0)$; arista dark, with thickened base. Eyes meeting for a distance of 6-8 facets. Frons dark silver-gray pollinose. Vertex black, lacking pollinosity. Occiput dark and gray pollinose with scattered short black setae. Thorax. Postpronotal lobe light yellow, gray pollinose with 4-6 yellowish setae along the upper margin (up to $0.02 \mathrm{~mm}$ ). Prescutum, scutum and scutellum black. Scutum with two uniseriate rows of intra-alar setae. Scutellum with 14-16 thin short setae along lateral margin (up to $0.02 \mathrm{~mm}$ ). Subscutellum black, gray pollinose. Pleura black but dark brown on pteropleuron, hypopleuron and sternopleuron. Wing. Length: $3.85 \mathrm{~mm}$. LW:MWW=5.13. Wing almost entirely covered with microtrichia. Cross-vein $\mathrm{r}-\mathrm{m}$ reaches $\mathrm{dm}$ at the middle. $\mathrm{M}_{1}$ strongly undulating in middle. Halter length: $0.4 \mathrm{~mm}$. Whitish, narrowly brown at base. Legs. Coxae dark brown, gray pollinose. Mid coxa with four dark anterior setae. Trochanters brown, smooth. Femora dark with light brown apices, gray pollinose. Mid and hind femora bearing two rows of small spines in apical half and with one wrinkled indentation at the base. 

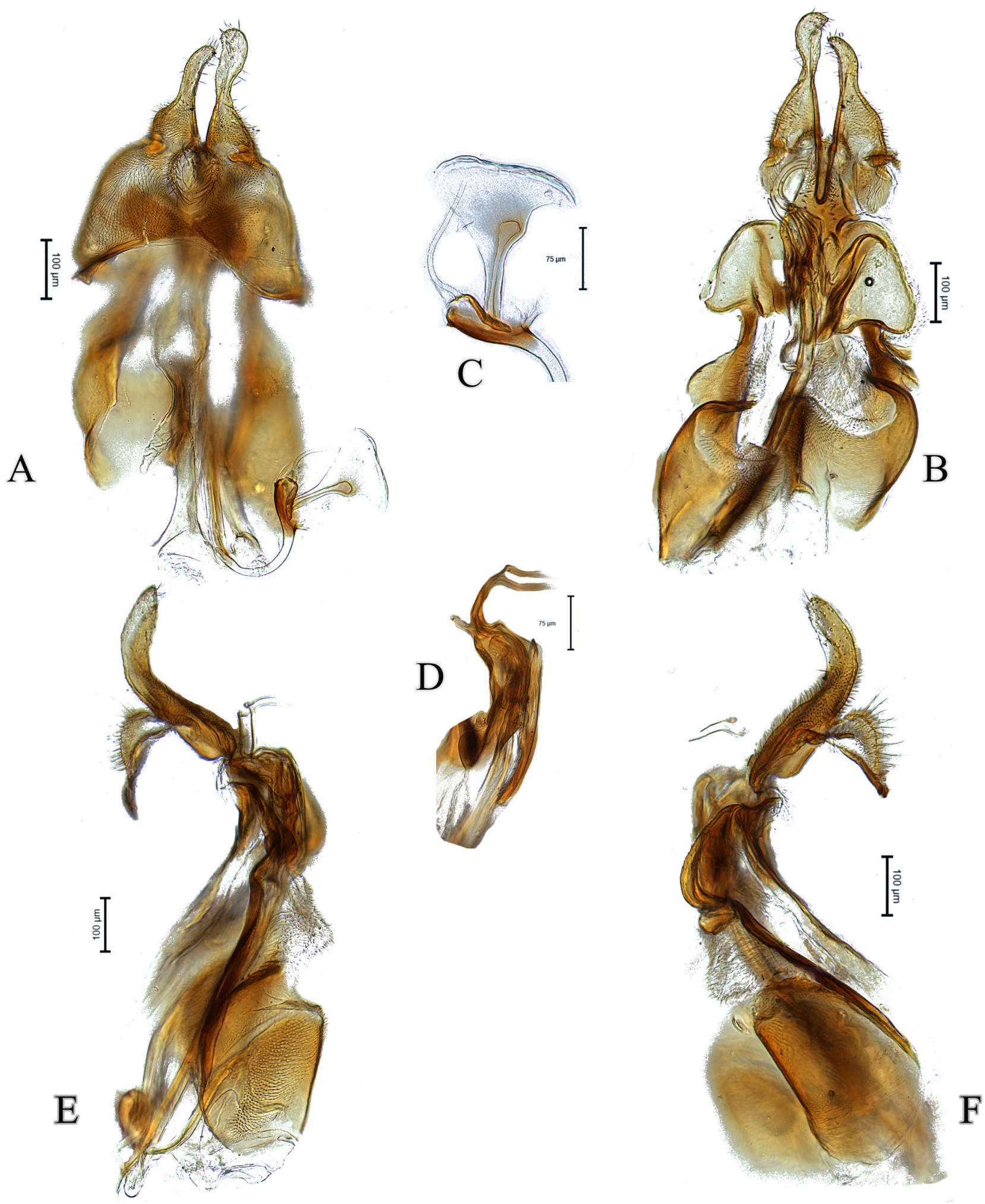

FIGURE 25. Male genitalia of Tomosvaryella nimroozensis sp. nov., holotype (JSS51819, CNC) A) dorsal view, B) ventral view, C) ejaculatory apodeme, D) phallus in lateral view E, F) lateral view.

Tibiae brown but dark at middle, with two ventral rows of short setae on anterior and three rows on posterior side. Hind tibia with 1-2 wrinkled indentations in middle. Tarsi light brown with scattered brown setae at anterior margin, basitarsi longer than other tarsomeres. Pulvilli yellow. Claws light brown with black tips. Abdomen. Ground color dark. Tergite 1 densely gray pollinose, with $8-10$ dark lateral setae (up to $0.11 \mathrm{~mm}$ ). Tergites $2-5$ gray pollinose, with scattered brown setae. Sternites light brown laterally and dark brown centrally, gray pollinose. Genitalia. 
Genital capsule in dorsal view: epandrium and surstyli brown, gray pollinose. Epandrium wider than long (MLE: MWE $=0.5$ ). Surstyli asymmetrical, elongated (Fig. 25A). Both surstyli broad at base, base of left surstylus triangular-shaped, base of right surstylus square-shaped, left surstylus entirely constricted at middle and knobbed apically, right surstylus narrowed in apical half, left surstylus higher than right one (Fig. 25A). Genital capsule in ventral view: gonopods wide, equal in height (Fig. 25B). Subepandrial sclerite small (Fig. 25B). Genital capsule in lateral view: both surstyli bent in middle towards sternite (Fig. 25E-F). Phallic guide short, phallus with three ejaculatory ducts (Fig. 25D). Ejaculatory apodeme rather spade-shaped (Fig. 25C). FEMALE: unknown.

Etymology: The specific epithet refers to Nimrooz, from where the holotype was collected.

Specimen examined: HOLOTYPE: IRAN: Sistan \& Baluchestan : Zabol, 31 ${ }^{\circ} 03^{\prime} \mathrm{N}, 61^{\circ} 22^{\prime} \mathrm{E}$, 7.iv.2016, M. Enaiatnia, Malaise trap, JSS51819 (10̂, CNC).

Distribution: Iran (Fig. 56).

Notes: T. nimroozensis sp. nov. is not genetically similar to any other known Tomosvaryella species. Tomosvaryella pilosiventris is closest to T. nimroozensis $\mathbf{s p . ~ n o v}$. with $12.2 \%$ pairwise difference (Supplementary Table 1).

\section{Tomosvaryella nodosa De Meyer, 1995}

Figs 26A-D, 27I, 47C, 59

Diagnosis: This species can be recognized by a small projection in hind trochanter (Fig. 47C); epandrium wider than long in dorsal view (Fig. 26A); syntergosternite 8 slightly rounded in dorsal view (Fig. 26A); ejaculatory ducts coiled (Fig. 26C-D); gonopods equal in height (Fig. 26B); hypandrium slightly rounded, wider than gonopods in ventral view (Fig. 26B). Based on the shape of surstyli in dorsal and lateral view, this species resembles T. pruinosa Kozánek, 1992. Tomosvaryella pruinosa lacks the small projection in hind trochanter. In addition, there is a gap between the surstyli and cerci of T. nodosa in lateral view (Fig. 26C-D). Meanwhile, It is similar to T. hamounensis sp. nov. See the diagnosis notes under T. hamounensis sp. nov. for more details.

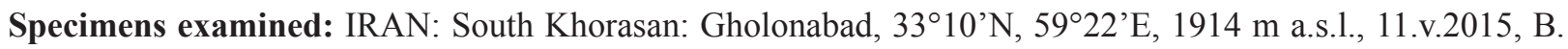

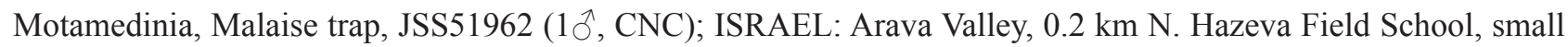

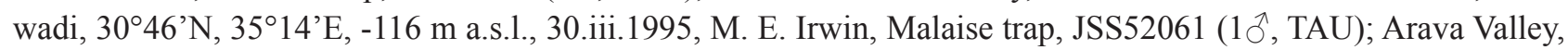
Iddan, wadi running east of date palm orchard, $30^{\circ} 48^{\prime} \mathrm{N}, 35^{\circ} 16^{\prime} \mathrm{E},-110 \mathrm{~m}$ a.s.1., 16.iv.1995, M. E. Irwin, Malaise trap, JSS52052 (1ठ, TAU); 17.iii.1995, M. E. Irwin, Malaise trap, JSS52054 (1ð, TAU); 24.iii.1995, M. E. Irwin, Malaise trap, JSS51699 (10ิ, TAU); 31.iii.1995, M. E. Irwin, Malaise trap, JSS52053 (10ิ, TAU); Arava Valley,

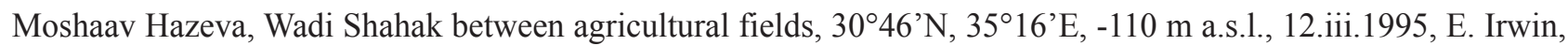
Malaise trap, JSS51622 (1ð̊, TAU); 15.iii.1995, M. E. Irwin, Malaise trap, JSS52060 (1ð̊, TAU); 19.iii.1995, M. E Irwin, Malaise trap, JSS51730 (1 $\widehat{\jmath}$, TAU); Arava Valley, Shizaf Nature Reserve, Hazeva, north of water treatment plant low sandy hummocks in small wadi, $30^{\circ} 46^{\prime} \mathrm{N}, 35^{\circ} 15^{\prime} \mathrm{E},-80 \mathrm{~m}$ a.s.1., 16.iv.1995, M. E. Irwin, JSS51698 (1 $\mathrm{O}^{\top}$,

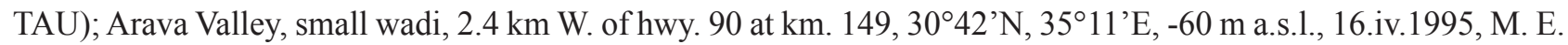

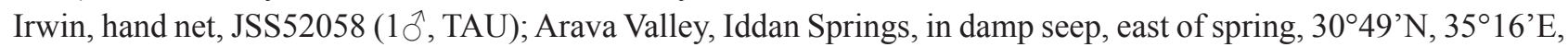

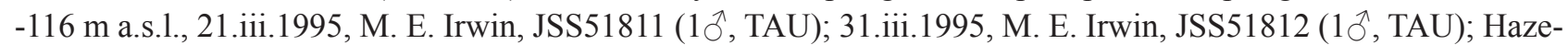

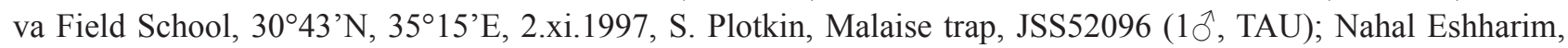

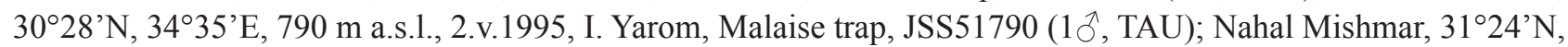
35²0’E, 11.iv.1994, A. Freidberg \& F. Kaplan, JSS51746 (10^, TAU); B. S. Hazeva, 13.iii.1998, S. Alfi, JSS51771

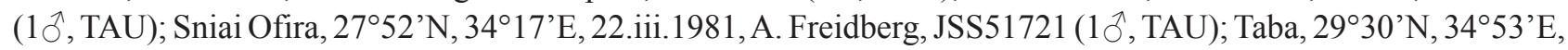
14.v.2010, A. Freidberg, JSS51764 (10̂, TAU); Zin Wilderness Nakhal Zin at En Akrabim cane-covered sandy wadi, $30^{\circ} 53^{\prime} \mathrm{N}, 35^{\circ} 09^{\prime} \mathrm{E},-61 \mathrm{~m}$ a.s.1., 7.iv.1995, M. E. Irwin, Malaise trap, JSS51700 (1 ${ }^{\curvearrowright}$, TAU); UNITED ARAB EMIRATES: Abu Dhabi: Al Wathba Wetland Reserve, $2^{\circ} 15^{\prime} \mathrm{N}, 5^{\circ} 37^{\prime} \mathrm{E}$, i.2015, A. Saji \& A. van Harten, Malaise trap, CNC470786, CNC470791, CNC470801 (30े, CNC); ii.2015, A. Saji \& A. van Harten, Malaise trap, CNC470524, CNC470585, CNC470508, CNC470473, CNC470465, CNC470545, CNC470448-9 CNC470498 (4へิ, 5우, CNC); iii.2015, A. Saji \& A. van Harten, Malaise trap, CNC470669, CNC470688, CNC470648 (20ิ, 1ㅇ, CNC); ix.2013,

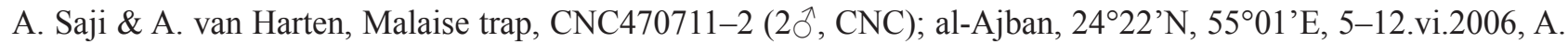

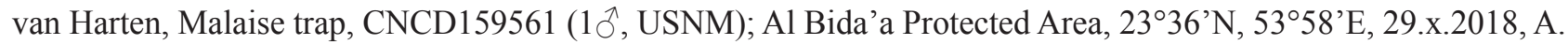

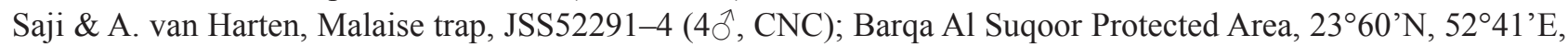


29.iii.2018, A. Saji \& A. van Harten, Malaise trap, JSS52280-1 (1ðð, 1ㅇ, CNC); 29.x.2018, A. Saji \& A. van Harten,

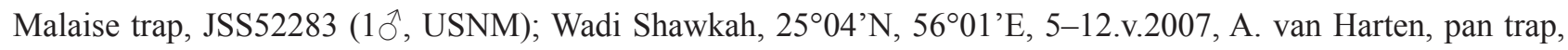

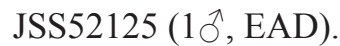
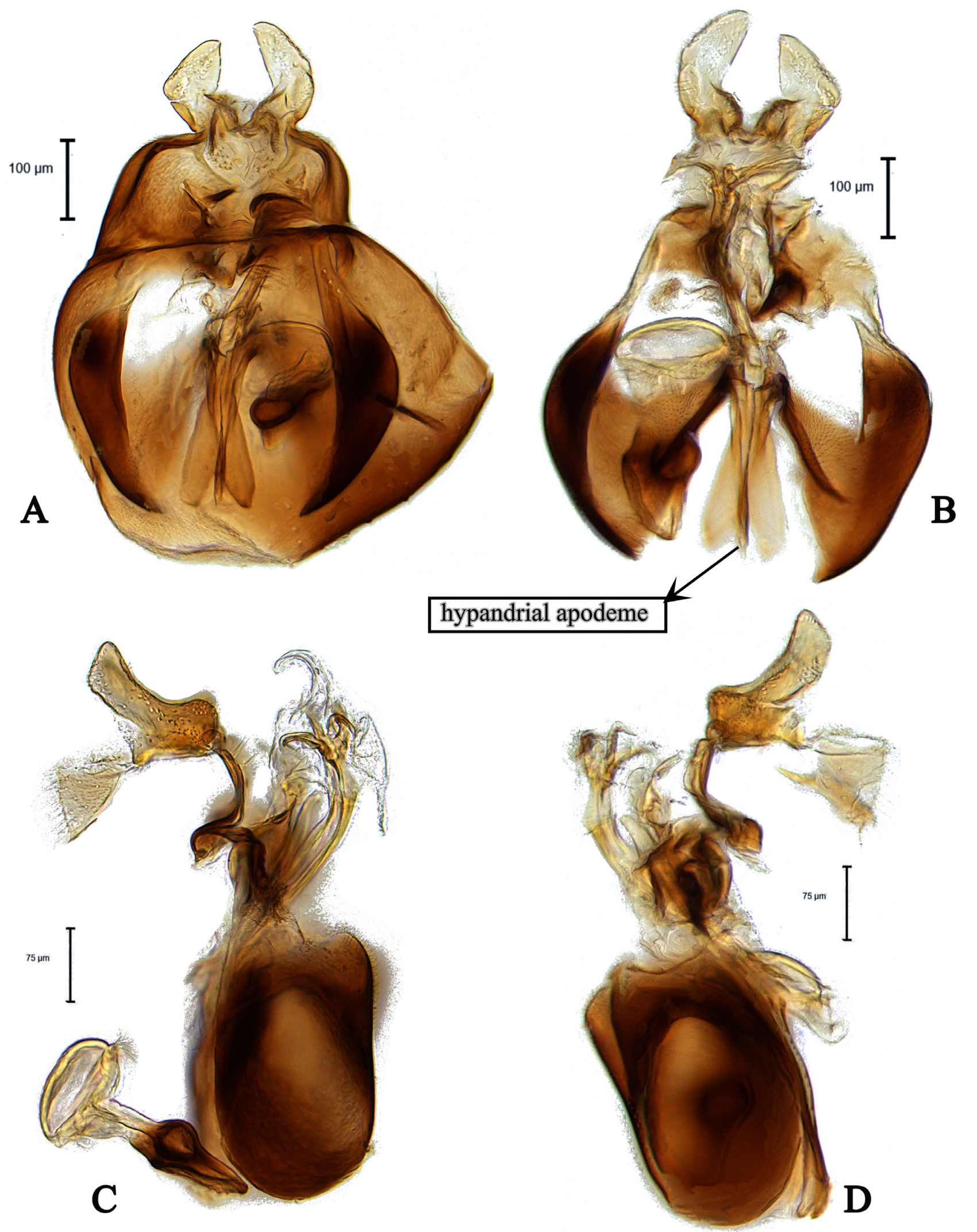

FIGURE 26. Male genitalia of Tomosvaryella nodosa (CNC470508, CNC) A) dorsal view, B) ventral view, C, D) lateral view. 
Distribution: Egypt, Iran, Israel, United Arab Emirates (Skevington 2020) (Fig. 59).

Note: Based on DNA barcodes, T. nodosa is similar to T. pruinosa, differing by $4.2 \%$. (pairwise divergence) (Supplementary Table 1).

\section{Tomosvaryella oshidae Motamedinia \& Skevington sp. nov.}

Figs 27G, 28A-E, 59, 68C-D

Diagnosis: The male of this species can be recognized by the shape of surstyli in dorsal view, broad basically, constricted in apical third (Fig. 28A); large gonopods in ventral view (Fig. 28B); broad phallic guide; ejaculatory ducts strictly bent into phallic guide in lateral view (Fig. 28C). The female can be recognized by long ovipositor, curved and reaching the mid coxa (Fig. 27G).

Description: MALE: Body length (excluding antennae): $4.5 \mathrm{~mm}$. Head. Scape, pedicel, flagellum and arista dark. Pedicel with three upper dark setae; flagellum light brown, gray pollinose and tapering (LF:WF $=1.7)$. Eyes meeting for a distance of 13-14 facets. Frons silver-gray pollinose; vertex shining; occiput gray pollinose with scattered light brown setae. Thorax. Postpronotal lobe light brown with pale setae along the upper margin (up to $0.01 \mathrm{~mm}$ ). Prescutum and scutum black, light brown pollinose; Scutum with two dark uniseriate rows of intra-alar setae. Scutellum black, silver-gray pollinose, with 12 setae along posterior margin. Subscutellum black, pleura dark brown. Wing. Wing length: $2.4 \mathrm{~mm}$. LW:MWW $=3.4$. Wing almost entirely covered with microtrichia. $\mathrm{M}_{1}$ strongly undulating in middle. Halter length: $0.5 \mathrm{~mm}$. Brown to yellowish, narrowly black at base. Legs. Coxae and trochanters black, gray pollinose, mid coxa with three black anterior setae; hind trochanter with scattered short pale bristle. Femora dark brown with narrow yellow apices, silver pollinose and 5-8 ventral spines towards apex. All femora with one wrinkled indentation in basal. Tibiae light brown at base, gray pollinose, with two rows of short black setae on anterior and three rows on posterior side. Hind tibia with one wrinkled indentation in middle. Tibiae without distal spines. Tarsi light brown, distitarsi dark, claws light brown with black tips. Abdomen. Ground color brown, tergite 1 covered by densely silver-gray pollinose, with eight short dark lateral setae, tergite $2-5$ with weak silvergray pollinose and with scattered brown setae. Sternites white-yellow laterally with dark mid-line centrally, gray pollinose. Genitalia. Genital capsule in dorsal view: surstyli asymmetrical, both with broad base and constricted in apical third but base of the right boarder than left one, left surstyli knobbed apically, right surstyli curved toward left one apically (Fig. 28A), epandrium wider than long. Genital capsule in ventral view: gonopods large, broadened, equal in height (Fig. 28B). Genital capsule in lateral view: both surstyli broadened at base, strictly bent in apical third towards sternite (Fig. 28D-E); phallic guide broad, pointed; phallus wavy, bent into phallic guide (Fig. 28C).

FEMALE: Body length (excluding antennae): $3.6 \mathrm{~mm}$. Head. Eyes separated. Frons silver-gray pollinose, concaved shortly after ocelli to lower third of frons. Occiput gray pollinose. Pedicel with four upper dark setae and one lower setae. Thorax. Postpronotal lobe light yellow, gray pollinose, with 4-5 light brown setae along the upper margin (up to $0.01 \mathrm{~mm}$ ). Prescutum and scutum, scutellum black, light brown pollinose in dorsocentral area. Wing. Length: $3.5 \mathrm{~mm}$. LW:MWW = 3.8. Legs. Hind trochanter with 6-8 light brown setae. All femora bearing one wrinkled indentation in basal. Fore femur more widened. Hind trochanter with two wrinkled indentations in middle. Distitarsi with long brown setae at anterior margin. Pulvilli broadened and leaf-shaped; claws long, twice the length of distitarsi. Abdomen. Tergites 1-6 gray pollinose with scattered short light brown setae. Ovipositor. Base of ovipositor dark brown, gray pollinose dorsally, with some scattered short pale setae. Viewed laterally (Fig. $27 \mathrm{G}$ ), base of piercer curved, piercer long and angled between proximal and distal part and reached mid coxa. LP: $\mathrm{LB}=2.5$. LDP:LPP $=4.0$.

Etymology: The specific epithet refers to Oshida, the old name of Khaje mountain and a female name in mythology, from where the holotype specimen was collected.

Specimens examined: HOLOTYPE: IRAN: Sistan \& Baluchestan: Zabol, 31 ${ }^{\circ} 07^{\prime} \mathrm{N}, 61^{\circ} 28^{\prime} \mathrm{E}, 481 \mathrm{~m}$ a.s.1., 6.vi.2016, H. Derafshan, sweep net, JSS51818 (10 , CNC); PARATYPE: IRAN: South Khorasan: Mohammadieh, $32^{\circ} 52^{\prime} \mathrm{N}, 59^{\circ} 01^{\prime} \mathrm{E}, 1419 \mathrm{~m}$ a.s.1., 3-17.vii.2016, B. Motamedinia, funnel Malaise trap, JSS51976 (1 , , CNC).

Distribution: Iran (Fig. 59).

Note: Based on DNA barcodes, T. oshidae sp. nov. is genetically most similar to T. pseudophanes, with $11.1 \%$ pairwise difference. The male and female sequenced differ by only $0.17 \%$ (Supplementary Table 1 ). 

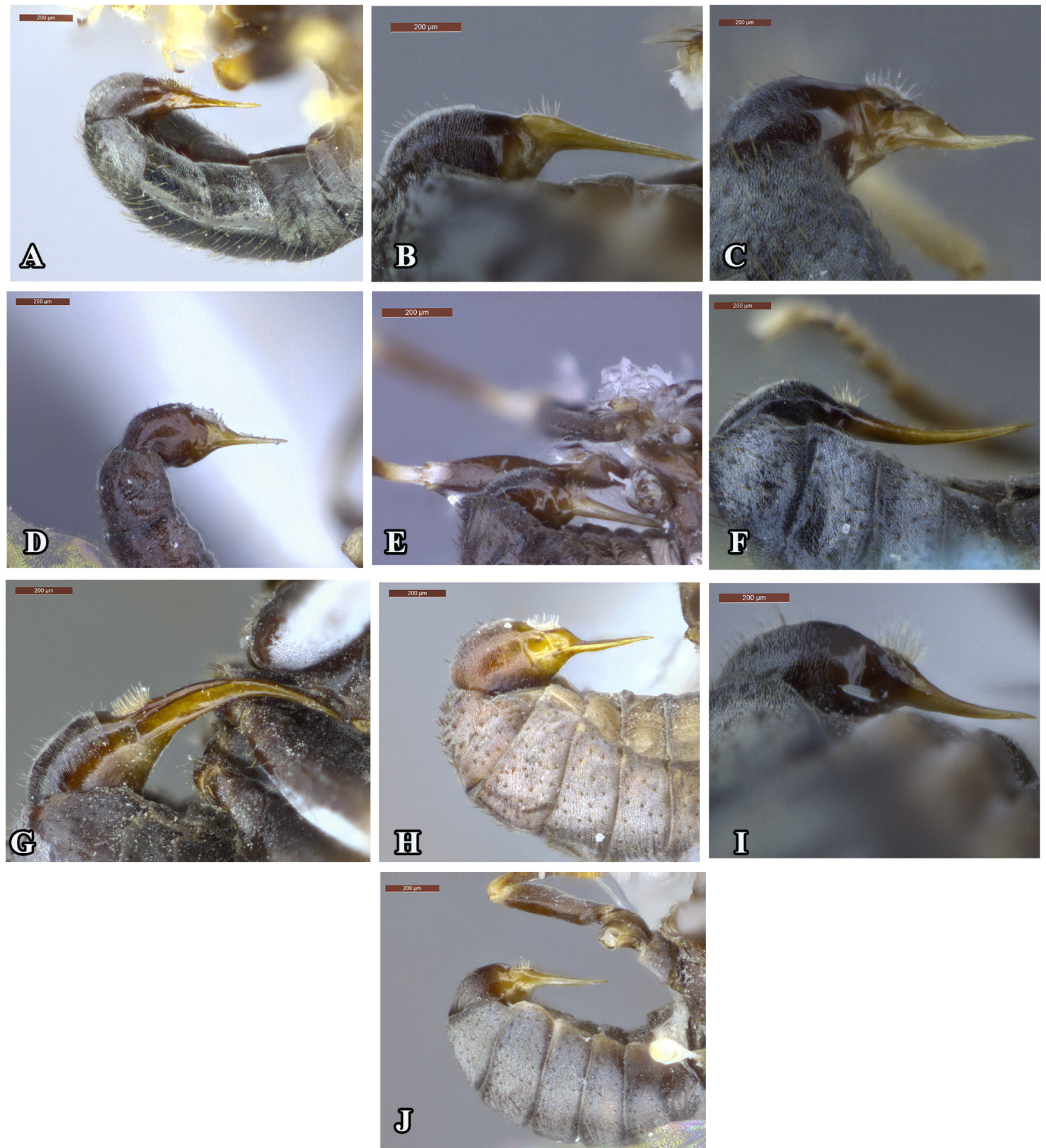

FIGURE 27. Ovipositors in lateral view A) Tomosvaryella ampliasa sp. nov., paratype (JSS43959, TAU), B) Tomosvaryella pilosiventris (JSS51961, CNC), C) Tomosvaryella pruinosa (CNC470591, CNC), D) Tomosvaryella spinula sp. nov., paratype (JSS51820, CNC), E) Tomosvaryella emaratensis sp. nov., paratype (CNCD137556, CNC), F) Tomosvaryella parakuthyi (CNC470514, CNC), G) Tomosvaryella oshidae sp. nov., paratype (JSS51976, CNC), H) Tomosvaryella soziana sp. nov., paratype (JSS52205, CNC), I) Tomosvaryella nodosa (CNC470648, CNC), J) T. hamounensis sp. nov., paratype (JSS52178, CNC). 

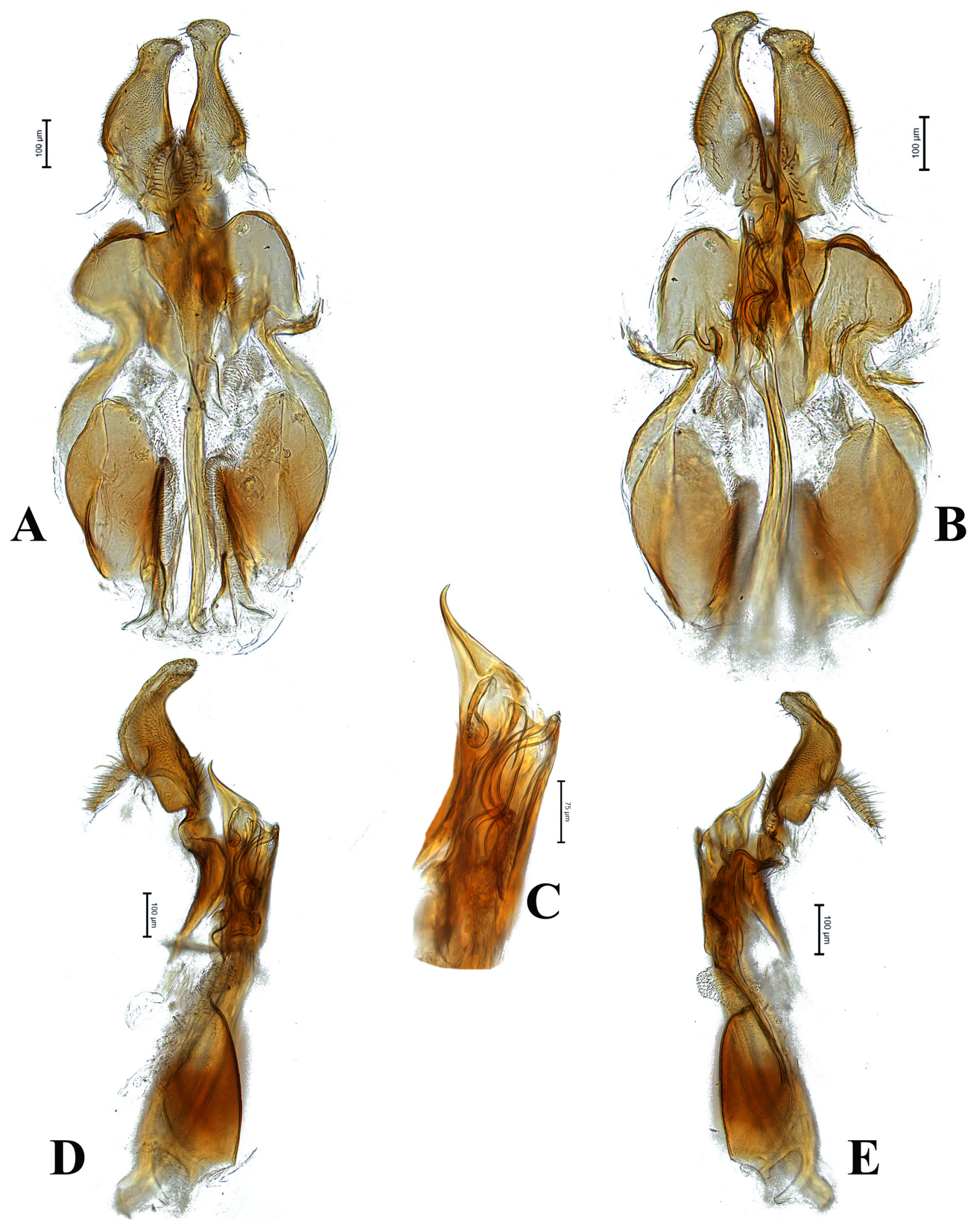

FIGURE 28. Male genitalia of Tomosvaryella oshidae sp. nov., holotype (JSS51818, CNC) A) dorsal view, B) ventral view, C) phallic guide and phallus in lateral view, D, E) lateral view. 


\section{Tomosvaryella osteodes Motamedinia \& Skevington sp. nov.}

Figs 29A-E, 58, 68E-F

Diagnosis: This species can be recognized by the asymmetrical shape of surstyli in dorsal view, both long, left surstylus bone-shaped and longer than right one (Fig. 29A); unequal gonopods, right one with a projection towards phallic guide (Fig. 29B); strong and straight phallus, three short ejaculatory ducts, one bearing some teeth; membranous sheaths bearing saw-like teeth (Fig. 29B, D-E).
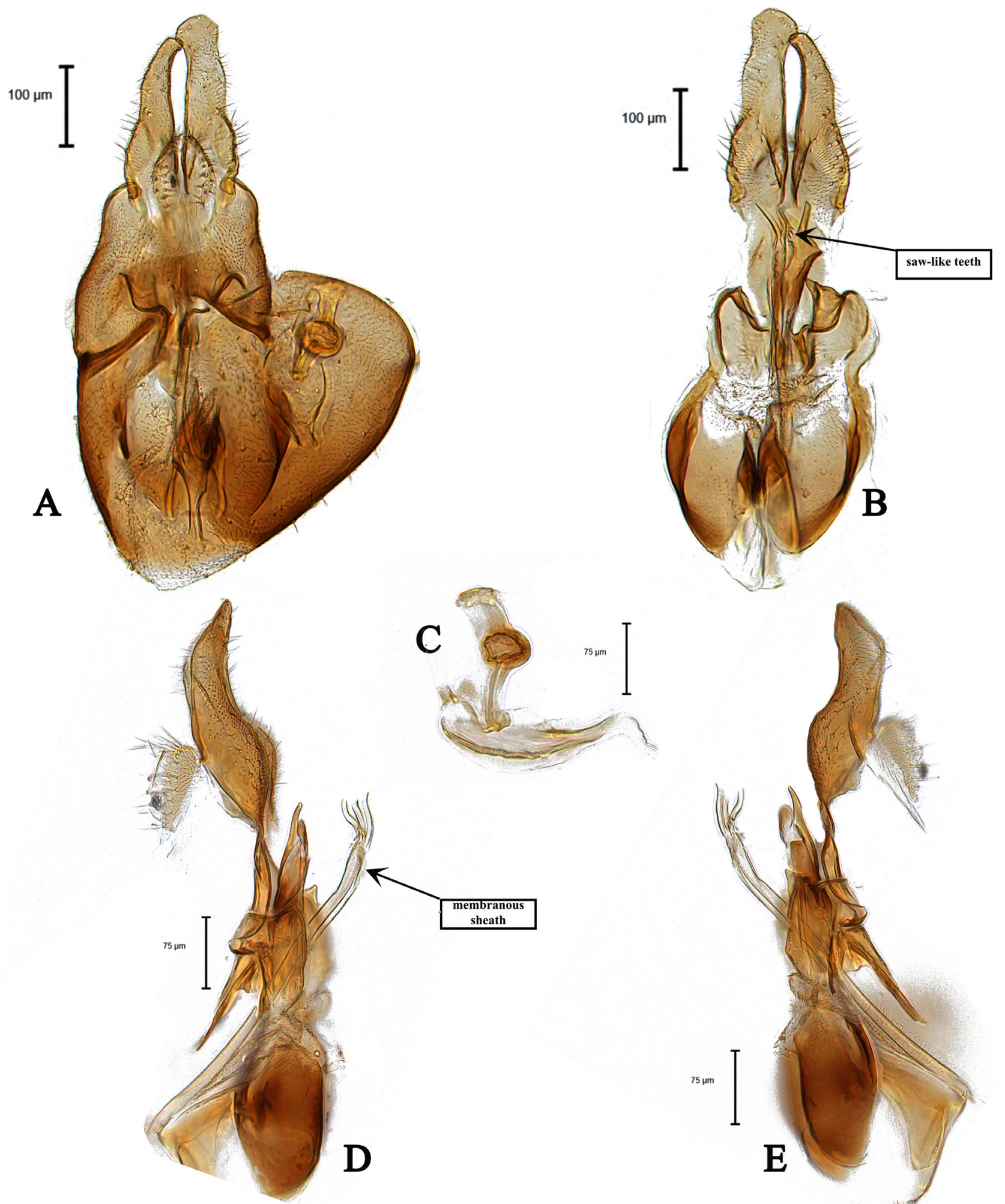

FIGURE 29. Male genitalia of Tomosvaryella osteodes sp. nov., holotype (CNCD175298, CNC) A) dorsal view, B) ventral view, C) ejaculatory apodeme, D, E) lateral view. 
Description: MALE: Body length: $2.1 \mathrm{~mm}$. Head. Frons silver-gray pollinose. Eyes meeting for a distance of five facets. Pedicel with 1-2 small dorsal setae; flagellum tapering, distinctly paler than pedicel (LF:WF $=2.3$ ). Postpronotal lobe pale, gray pollinose. Prescutum and scutum brown, silver-gray pollinose, with some patches of small supra-alar setae behind postpronotal lobes. Scutellum brown, silver-gray pollinose. Subscutellum darker than pleura. Wing. Wing length: $2.6 \mathrm{~mm}$. LW:MWW $=2.4$. Wing almost entirely covered with microtrichia except at wing base. Cross-vein $\mathrm{r}-\mathrm{m}$ reaching cell $\mathrm{dm}$ at the middle. Halter length $0.4 \mathrm{~mm}$., yellow, narrowly brown at base. Legs. Light brown. Trochanters black, smooth. Femora with posteroventral and anteroventral row of 3-8 black spines on apical half. Tibiae with two rows of short brown setae on anterior and three rows on posterior side. Distitarsi darker that tarsi; pulvilli shorter than distitarsi. Claws white with black tips. Abdomen. Ground color brown, gray pollinose; tergite 1 with four brown lateral setae, tergites normally covered with short but scattered brown hairs. Syntergosternite 8 brown. Genitalia. Genital capsule in dorsal view: epandrium and surstyli dark brown, epandrium wider than long (MLE:MWE $=0.8$ ). Surstyli long and asymmetrical. Left surstylus slightly larger than right surstylus, bone-shaped. Right surstylus broadened at base and narrowed at apex, curved toward left surstylus in apical third (Fig. 29A). Genital capsule in ventral view: subepandrial sclerite wide, gonopods unequal; right with a projection curved towards phallic guide, lobes of hypandrium sclerotized, giving it the shape of an inverted triangle (Fig. 29B). Phallus strong and straight, with three short ejaculatory ducts, one bearing some saw-like teeth along its side (Fig. 29B). Genital capsule in lateral view: membranous sheath bearing saw-like teeth (Fig. 29D-E). Phallic guide thickened at base. Ejaculatory apodeme tube-like with a bulb in its middle (Fig. 29C). FEMALE: unknown.

Etymology: The specific epithet derived from the Greek "osteodes" (=bone like), referring to the shape of left surstylus.

Specimen examined: HOLOTYPE: UNITED ARAB EMIRATES: Wadi Wurayah, $25^{\circ} 24^{\prime} \mathrm{N}, 56^{\circ} 17^{\prime} \mathrm{E}$, 25.ii.2007, sweep net, F. Menzel \& A. Stark, CNCD175298 (10ึ, CNC).

Distribution: United Arab Emirates (Fig. 58).

Note: Based on DNA barcodes, this species is most similar to T. sylvatica, differing by $8.5 \%$ (pairwise divergence) (Supplementary Table 1).

\section{Tomosvaryella parakuthyi De Meyer, 1995}

Figs 27F, 30A-D, 60

Diagnosis: This species can be recognized by elongated surstyli and epandrium in dorsal view (Fig. 30A); unequal gonopods, left is higher than right one in ventral view (Fig. 30B); both surstyli slightly straight, bent towards sternite in apical third in lateral view (Fig. 30C-D). Based on the shape of surstyli in dorsal view, this species resembles species in the kuthyi group (Tomosvaryella cyprusensis sp. nov., T. emaratensis sp. nov., T. freidbergi, T. hispanica, T. israelensis, T. kuthyi). It differs by the shape of surstyli in lateral view, bent towards sternite in apical third (Fig. 30C-D). See diagnosis of T. emaratensis sp. nov. and T. cyprusensis sp. nov. for more details.

Specimens examined: HOLOTYPE: ISRAEL: Sinai Ofira, 22iii.1981, A. Freidberg, JSS52379 (1§, TAU); PARATYPE: ISRAEL: Sinai, $20 \mathrm{Km}$ N. Dahab, 12.iii.1982, A. Freidberg, JSS52380 (1 $\hat{\jmath}$, TAU); Other specimens examined: IRAN: Kermanshah: Dodan, $35^{\circ} 00^{\prime} \mathrm{N}, 46^{\circ} 12^{\prime} \mathrm{E}, 1011 \mathrm{~m}$ a.s.l., Garden, 20.vi.2016, M. Zardouei, Malaise trap, JSS52186 (10ิ, CNC); 5.vii.2016, M. Zardouei, funnel Malaise trap, JSS51951 (10ิ, CNC); North Khorasan: Kohnekand, $37^{\circ} 51^{\prime} \mathrm{N}, 5^{\circ} 31^{\prime} \mathrm{E}, 1200 \mathrm{~m}$ a.s.1., 13-27.vi.2016, B. Motamedinia, Malaise trap, JSS51823

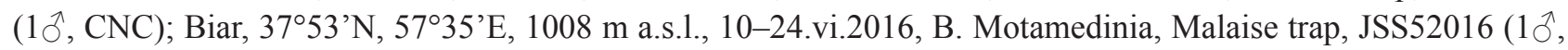
CNC); Sistan \& Baluchestan: Rask, $26^{\circ} 16^{\prime} \mathrm{N}, 6^{\circ} 25^{\prime} \mathrm{E}, 139 \mathrm{~m}$ a.s.l., 12.vi-14.vii.2016, M. Ghaforimoghadam, Malaise trap, JSS52146 (1 $\left.0^{\top}, \mathrm{CNC}\right)$; ISRAEL: Arava Valley, Iddan, wadi running east of date palm orchard, $30^{\circ} 48^{\prime} \mathrm{N}$, 35¹6’E, -110 m a.s.l., 21.iii.1995, M. E. Irwin, Malaise trap, JSS51813 (10ึ, TAU); 24.iii.1995, M. E. Irwin,

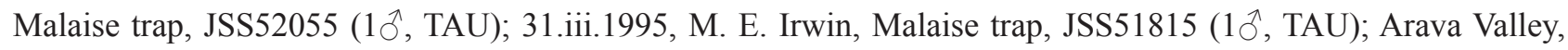
Shizaf Nature Reserve, Hazeva, north of water treatment plant low sandy hummocks in small wadi, 30 $46^{\circ} \mathrm{N}$,

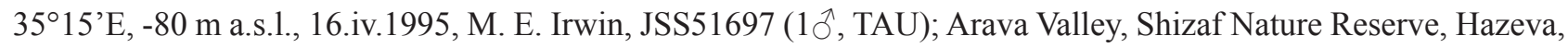
north of water treatment plant, low sandy hummocks in small wadi, $30^{\circ} 46^{\prime} \mathrm{N}, 35^{\circ} 15^{\prime} \mathrm{E},-80 \mathrm{~m}$ a.s.1., 3.iv. 1995 , M. E. Irwin, JSS52057 (10, TAU); Arava Valley, small wadi, $2.4 \mathrm{~km}$. W. of hwy. 90 at km 149, 30² $42^{\prime} \mathrm{N}, 35^{\circ} 11^{\prime} \mathrm{E}$, -60 m a.s.l., 16.iv.1995, M. E. Irwin, hand net, JSS51696 (1 ${ }^{\wedge}$, TAU); Arava Valley, En Yahav Makhteshim Res., 

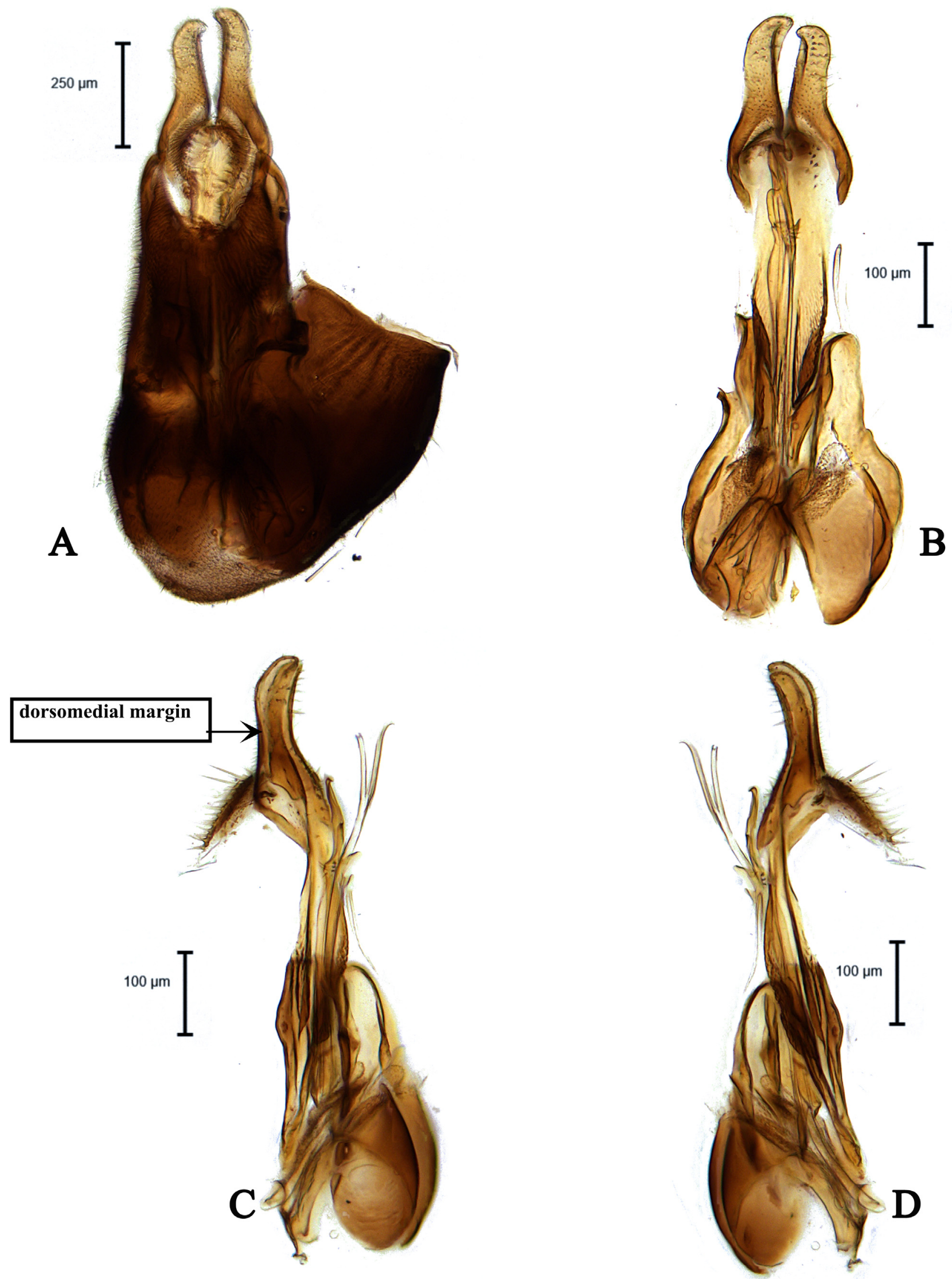

FIGURE 30. Male genitalia of Tomosvaryella parakuthyi (CNC470694, CNC) A) dorsal view, B) ventral view, C, D) lateral view. 


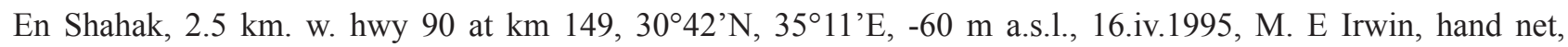
JSS51729 (1 $\hat{\jmath}$, TAU); 23.iii.1995, M. E Irwin, Malaise trap, JSS51728 (1 $\hat{\jmath}$, TAU); Arava Valley, Iddan, in damp

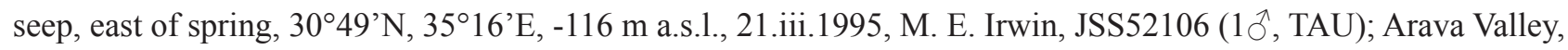
Iddan, wadi running east to date palm orchard, $30^{\circ} 48^{\prime} \mathrm{N}, 35^{\circ} 16^{\prime} \mathrm{E},-110 \mathrm{~m}$ a.s.1., 17.iii.1995, M. E Irwin, Malaise

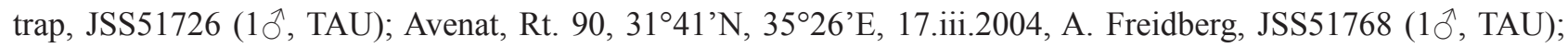

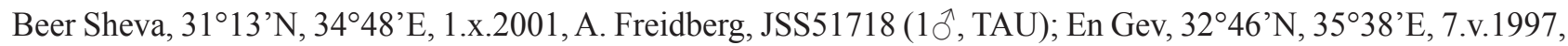

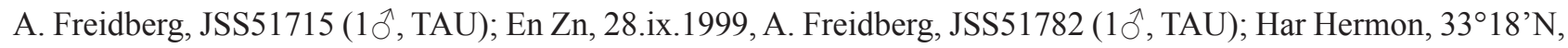

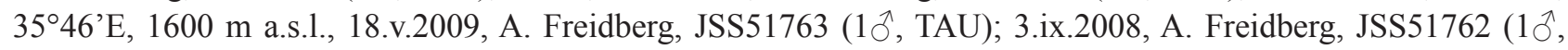

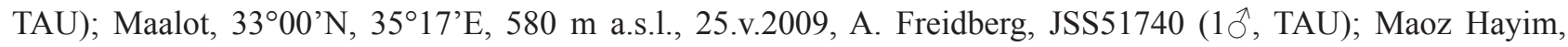

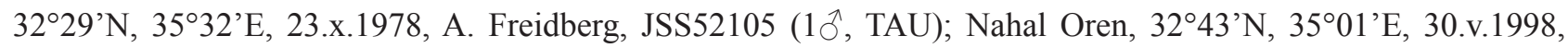

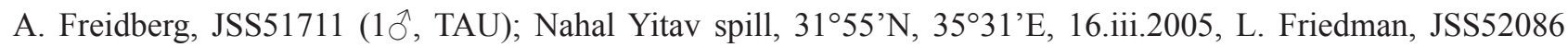

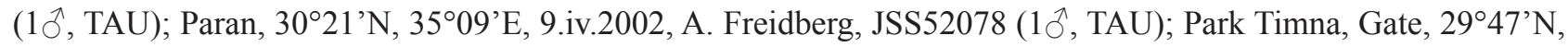

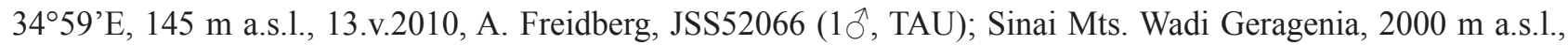
16.vii.1974, A. Freidberg, JSS52116 (1ð̄, TAU); Zin Wilderness Nakhal Zin at En Akrabim cane covered sandy wadi, $30^{\circ} 53^{\prime} \mathrm{N}, 35^{\circ} 09^{\prime} \mathrm{E}$, $-61 \mathrm{~m}$ a.s.1., 21.iii.1995, M. E. Irwin, Malaise trap, JSS52063 (1 $0^{\wedge}$, TAU); Nahal Eshharim, $30^{\circ} 28^{\prime} \mathrm{N} 34^{\circ} 35^{\prime} \mathrm{E}, 790 \mathrm{~m}$ a.s.l., 2.v.1995, I. Yarom, Malaise trap, JSS51792 (10, TAU); Nahal Parsa, 31 ${ }^{\circ} 13^{\prime} \mathrm{N}$ 3520'E, 13.iv.2009, A. Freidberg, JSS52082 (10, TAU); UNITED ARAB EMIRATES: Abu Dhabi: Al Wathba Wetland Reserve, $2^{\circ} 15^{\prime} \mathrm{N}, 54^{\circ} 37^{\prime} \mathrm{E}$, i.2015, A. Saji \& A. van Harten, Malaise trap, CNC465506, CNC47073637, CNC470740-41, CNC470748-9, CNC470753-4, CNC470769, CNC470771, CNC470774, CNC470779-80, CNC470782-3, CNC470788, CNC470792, CNC470797-8, CNC470806 (21ð, CNC); ii.2015, A. Saji \& A. van Harten, Malaise trap, CNC465507, CNC470450, CNC470452, CNC470454, CNC470457-9, CNC470461-2, CNC470464, CNC470466-8, CNC470474, CNC470478, CNC470481, CNC470484-7, CNC470490, CNC470495, CNC470496, CNC470499, CNC470501, CNC470506, CNC470509, CNC470511, CNC470513-5, CNC470519-20, CNC470522, CNC470527-30, CNC470533, CNC470535, CNC470541, CNC470547, CNC470553-6, CNC470560, CNC470562, CNC470566, CNC470568-9, CNC470571, CNC470573-5, CNC470577, CNC470580, CNC470584, CNC470590, CNC470592, CNC470598, CNC470601-2 (62ð̊, 1 \&, CNC); iii.2015, A. Saji \& A. van Harten, Malaise trap, CNC470623-4, CNC470636-8, CNC470640, CNC470653, CNC470666, CNC470672, CNC470693-4, CNC470698, CNC470634, CNC470621, CNC470701 (14ð̊, 1 9 , CNC); iv.2013, A. Saji \& A. van Harten, Malaise trap, CNC470731, CNC470733 (2ð̂, USNM); iv.2015, A. Saji \& A. van Harten, Malaise trap, CNC470833-4,

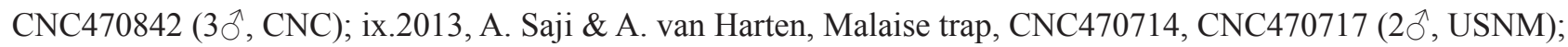
Wadi Wurayah farm, $25^{\circ} 14^{\prime} \mathrm{N}, 56^{\circ} 11^{\prime} \mathrm{E}, 19 . \mathrm{iv}-19 . v .2009$, A. van Harten, Malaise trap, CNCD137557 (1 $\left.{ }^{\lambda}, \mathrm{CNC}\right)$;

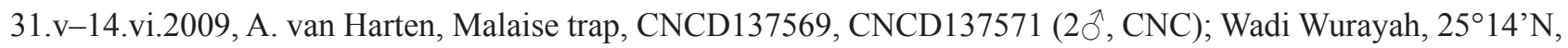
56 ${ }^{\circ} 10^{\prime} \mathrm{E}, 11-18 . v .2007$, A. van Harten, Malaise trap, CNCD160298 (1 $\left.{ }^{\top}, \mathrm{CNC}\right)$; near ad-Dhaid, $25^{\circ} 13^{\prime} \mathrm{N}, 55^{\circ} 35^{\prime} \mathrm{E}$,

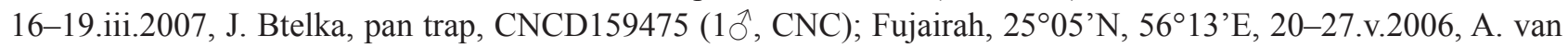
Harten, light trap, CNCD160289 (10̂, CNC); 14-25.i.2006, A. van Harten, white \& yellow pan trap, CNCD8961-2

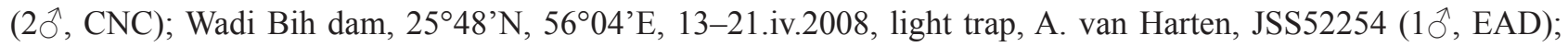
Houbara Protected Area, $24^{\circ} 05^{\prime} \mathrm{N}, 52^{\circ} 58^{\prime} \mathrm{E}$, 15.iii.2017, Malaise trap, A. Saji \& A. van Harten, JSS52272 (1 $\widehat{O}^{\wedge}$, EAD); Wadi Maidaq, $24^{\circ} 10^{\prime} \mathrm{N}, 5^{\circ} 04^{\prime} \mathrm{E}, 3-17 . i i .2008$, A. van Harten, pan trap, JSS52256 (1 $\left.\mathrm{O}^{\top}, \mathrm{CNC}\right)$; Al-Ajban, $24^{\circ} 21^{\prime} \mathrm{N}, 55^{\circ} 00^{\prime} \mathrm{E}, \mathrm{A}$. van Harten, Malaise trap, CNCD159295 (1ㅇ, CNC); YEMEN: $12 \mathrm{~km}$ NW of Manakhah,

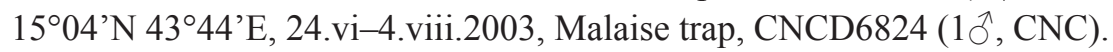

Distribution: Canary Island, Cyprus, Egypt, Iran, Israel, North Africa, United Arab Emirates, Yemen (Kehlmaier \& Majnon Jahromi, 2015; De Meyer, 1995; De Meyer et al. 2000) (Fig. 60).

Note: DNA barcodes of T. parakuthyi are most similar to T. kuthyi, differing by $2.3 \%$ (pairwise divergence) (Supplementary Table 1).

\section{Tomosvaryella pilosiventris (Becker, 1900)}

Figs 27B, 31A-E, 47E, 61

Tomosvaryella glabrum (Adams, 1905).—-syn. Kehlmaier et al. (2019): p. 54. Tomosvaryella tecta De Meyer, 1993.—syn. De Meyer et al. (2000): p. 148.

Diagnosis: This species can be recognized by the asymmetrical and irregular-shaped surstyli in dorsal view (Fig. 
31A); epandrium wider than long in dorsal view (Fig. 31A); phallus trifid (Fig. 31D-E). The surstyli shape is similar to T. subvirescens (Loew, 1872). It differs from this species by the shape of left surstylus in dorsal view, wrinkled and wavy-shaped (Fig. 31A) and triangular-shaped projections on the hind trochanter (Fig. 47E).
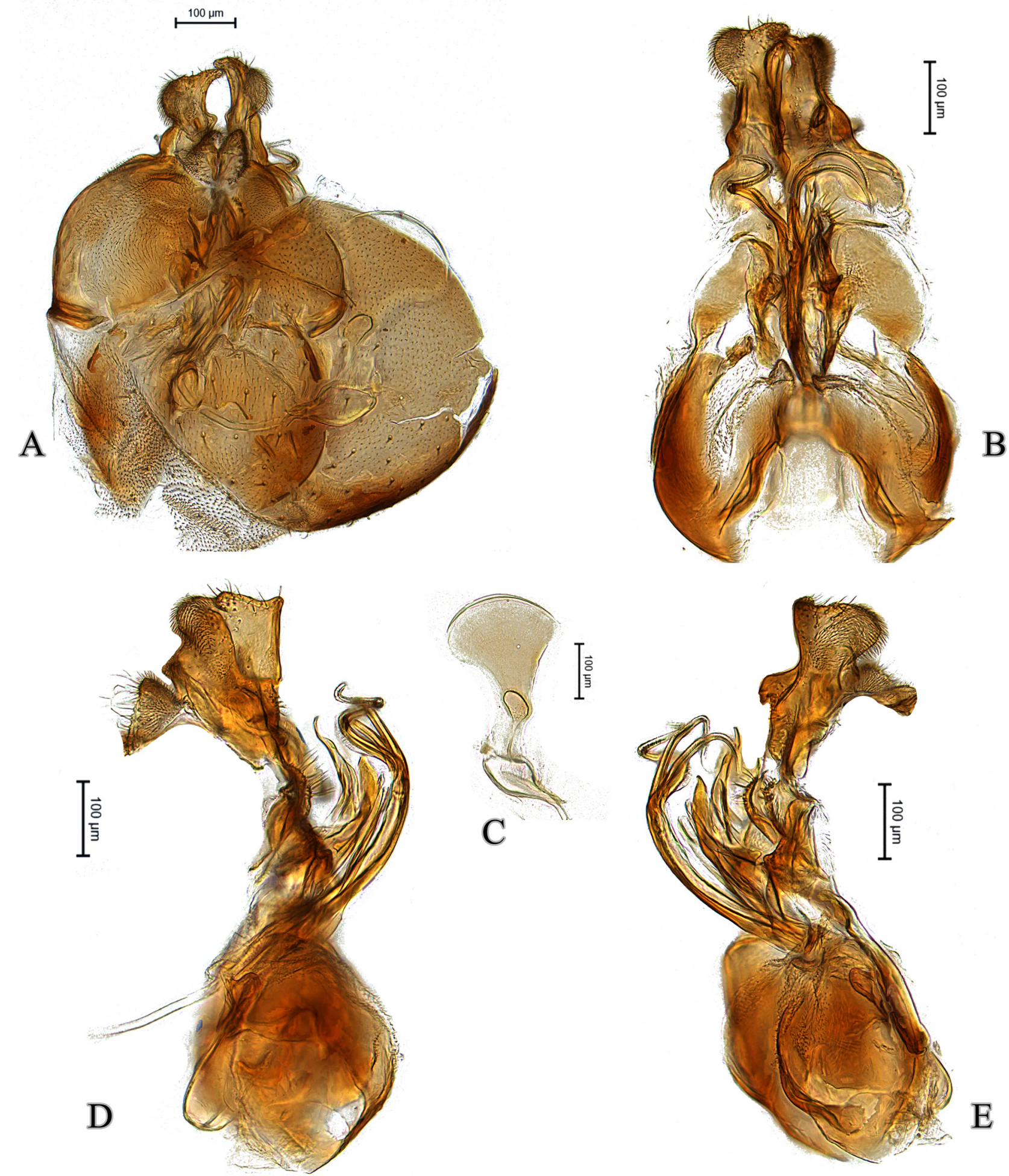

FIGURE 31. Male genitalia of Tomosvaryella pilosiventris (JSS52065, TAU) A) dorsal view, B) ventral view, C) ejaculatory apodeme, D, E) lateral view.

Specimens examined: IRAN: Kermanshah: Ghazanchi, $34^{\circ} 26^{\prime} \mathrm{N}, 4^{\circ} 00^{\prime} \mathrm{E}, 1304 \mathrm{~m}$ a.s.l., 1.vii.2015, M. Zard-

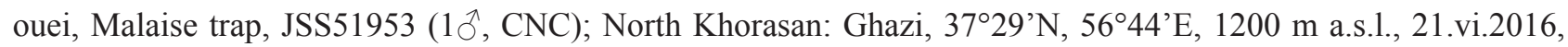

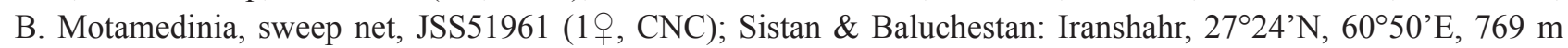


a.s.1., 2-12.v.2016, M. Ghaforimoghadam, Malaise trap, JSS52165 (1ㅇ, CNC); Zabol, 31 ${ }^{\circ} 07^{\prime} \mathrm{N}, 61^{\circ} 28^{\prime} \mathrm{E}, 481 \mathrm{~m}$ a.s.l., 6.vi.2016, H. Derafshan, sweep net, JSS51875-6 (2, CNC); South Khorasan: Mohammadieh, 3252’N, 5901'E, 1419 m a.s.l., 3-17.vii.2016, B. Motamedinia, funnel Malaise trap, JSS51975 (1ㅇ, CNC); Salmanefar-

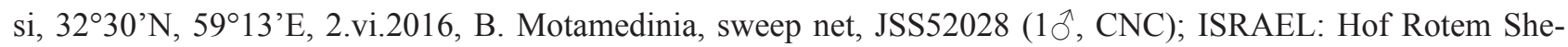

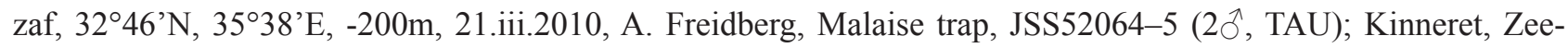

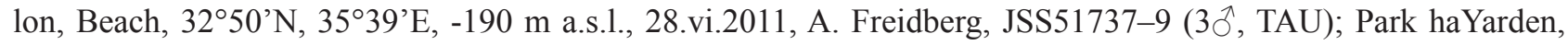
$32^{\circ} 50^{\prime} \mathrm{N}, 35^{\circ} 39^{\prime} \mathrm{E}$, $-192 \mathrm{~m}$ a.s.1., 28.vi.2011, L. Bodner, JSS43963 (1ㅇ, TAU); RT. 90, nr. En Admon, 3101'N, 35²2'E, 11.iv.1994, A. Freidberg \& F. Kaplan, JSS51748-9 (20, TAU); UNITED ARAB EMIRATES: Bithnah, $25^{\circ} 06^{\prime} \mathrm{N}, 56^{\circ} 08^{\prime} \mathrm{E}, 16 . x i-26 . x i i .2006$, A. van Harten, Malaise trap, JSS52242 (10, CNC); 19.x-16.xi.2006, A. van

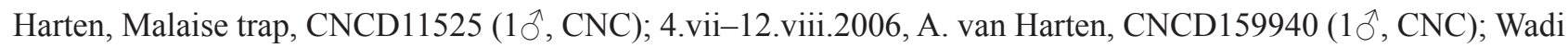
Maidaq, $25^{\circ} 11^{\prime} \mathrm{N}, 5^{\circ} 04^{\prime} \mathrm{E}, 26 . x \mathrm{ii} .2006-20 . i \mathrm{i} .2007$, A. van Harten, Malaise trap, JSS52252 (1 $\left.\mathrm{O}^{\top}, \mathrm{CNC}\right)$; 27.vi29.vii.2006, A. van Harten, Malaise trap, CNCD159304 (1 ${ }^{`}$, CNC); Wadi Safad, $25^{\circ} 07^{\prime} \mathrm{N}, 56^{\circ} 11^{\prime} \mathrm{E}$, 26.xii.20052.i.2006, A. van Harten, yellow \& white pan traps, CNCD8965, CNCD8971 (2 $\left.{ }^{\wedge}, \mathrm{CNC}\right)$; Wadi Shawkah, $25^{\circ} 04^{\prime} \mathrm{N}$,

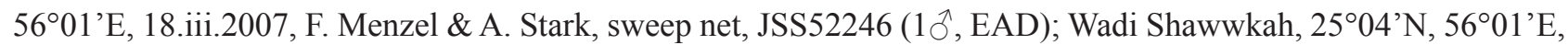

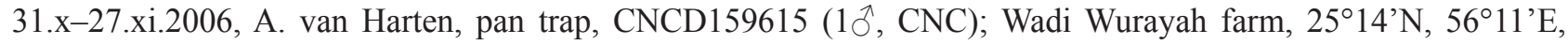
19.iv-19.v.2009, A. van Harten, Malaise trap, CNCD137547 (1 9 , CNC); near ad-Dhaid, $25^{\circ} 13^{\prime} \mathrm{N}, 5^{\circ} 35^{\prime} \mathrm{E}, 16-$ 19.iii.2007, J. Btelka, pan trap, CNCD159474 (1ð̋, USNM).

Distribution: Egypt, Iran, Israel, Kenya, South Africa, Spain (Canary Islands), Syria, Turkey, United Arab Emirates, West Bank, Zimbabwe (Kehlmaier et al. 2019; Skevington 2020) (Fig. 61).

Notes: DNA barcodes of $T$. pilosiventris overlap with $T$. subvirescens $(0.3-1.9 \%$ pairwise divergence). Despite this, the genitalia of these species are rather different. This is thus likely a case of recently diverged species, as seen in many other taxa (e.g. Skevington et al. 2007, Young et al. 2016, Motamedinia et al. 2020). There is always a possibility that it is a single species with polymorphic genitalia, so future genetic work may shed light on this issue.

\section{Tomosvaryella pistacia Majnon-Jahromi \& Kehlmaier, 2017}

Figs 32A-E, 59

Diagnosis: This species can be recognized by the shape of surstyli, broadened at base and gradually tapering toward apices in dorsal view (Fig. 32A), both surstyli bent by $90^{\circ}$ towards abdominal sternite in lateral view (Fig. 32D-E); epandrium small and wider than long in dorsal view (Fig. 32A); phallic guide short, broadened at base; phallus with three ejaculatory ducts, one bearing some small teeth in basal half(Fig. 32D); gonopods and hypandrium symmetrical in ventral view (Fig. 32B). The shape of the surstyli and small epandrium in dorsal view are similar to $T$. congoana Hardy, 1950 (for illustration see De Meyer, 1993: fig. 10), T. debruyni De Meyer, 1995 (for illustration see De Meyer, 1995: fig. 11) and T. mutata (for illustration see Földvári \& De Meyer, 1999: 15A-D). It differs from $T$. congoana and $T$. debruyni by the shape of surstyli in lateral view, which is bent by $90^{\circ}$ towards the abdominal sternites and differs from T. mutata by the shape of the right surstylus in dorsal view. It is also similar to T. angulata Majnon-Jahromi et al. 2017, as the surstyli of both species are bent by $90^{\circ}$ towards the abdominal sternite in lateral view and both have a small epandrium in dorsal view. It differs from T. angulata by the lack of distinct and distally-knobbed surstyli in dorsal view (Fig. 32B). Moreover, this species is closely related to T. argyrata and T. argyratoides. See the diagnosis notes under T. argyrata for more details.

Specimens examined: CYPRUS: Kyrenia, $35^{\circ} 21^{\prime} \mathrm{N}, 33^{\circ} 09^{\prime} \mathrm{E}, 1-8 . x .2017$, O. Ozden, Malaise trap, JSS52304

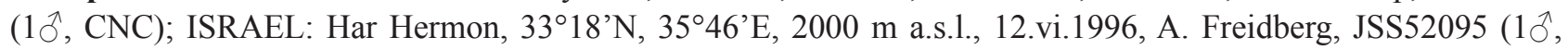
TAU).

Distribution: Cyprus, Iran, Israel (Skevington 2020) (Fig. 59).

\section{Tomosvaryella propinqua (Becker, 1913)}

Fig. 60

Distribution: Iran (Skevington 2020) (Fig. 60).

Notes: This species has been recorded by Becker (1913) from Iran (Sistan \& Baluchestan) but has not been 
completely illustrated yet. Type material (one male and one female) are currently on loan to Sergey Kuznetzov and unavailable. Majnon-Jahromi et al. (2018) mentioned its distribution in Alborz, Iran but it has been reported only in Siatan \& Baluchestan province so far.

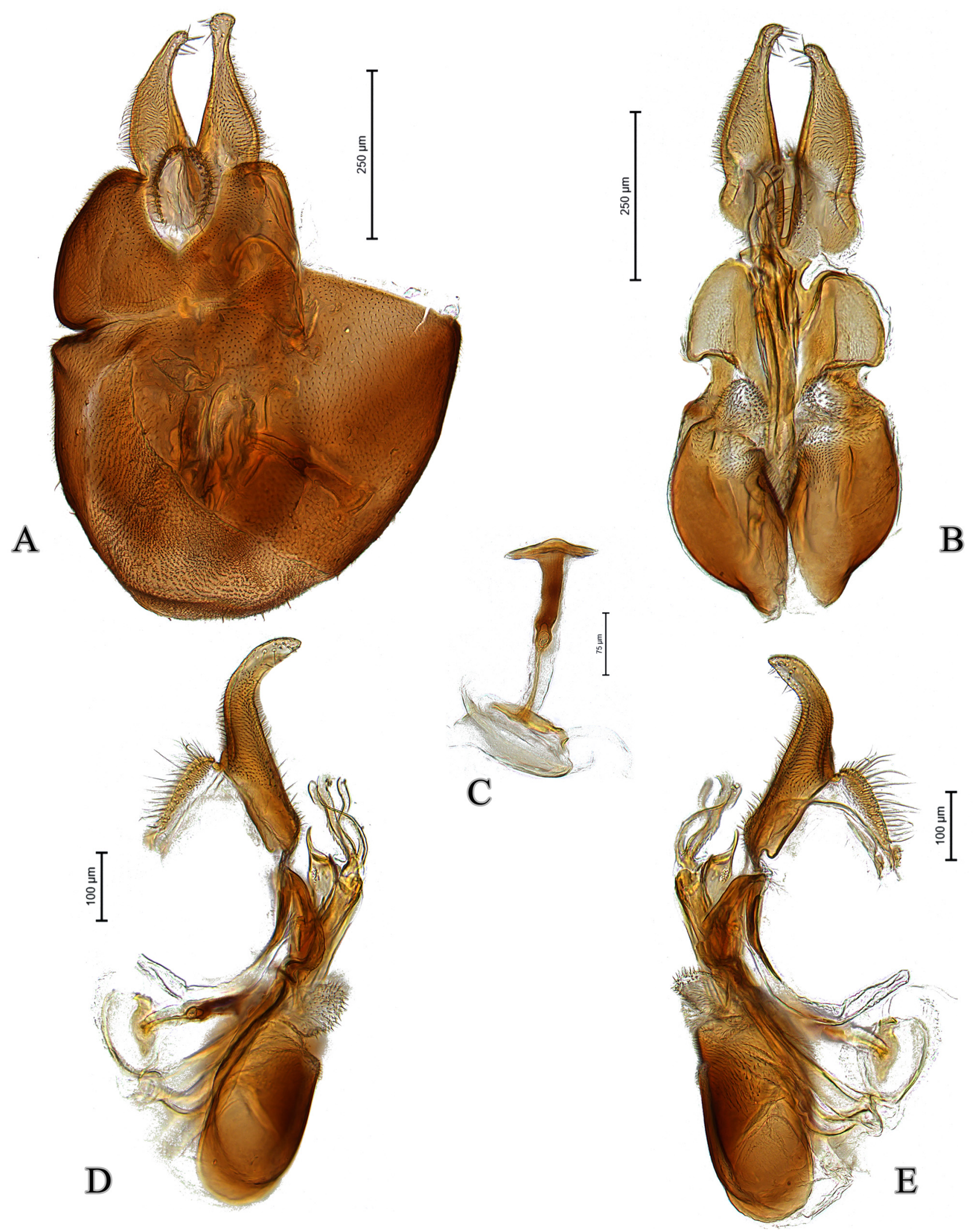

FIGURE 32. Male genitalia of Tomosvaryella pistacia (JSS52095, TAU) A) dorsal view, B) ventral view, C) ejaculatory apodeme, D, E) lateral view. 
Tomosvaryella pruinosa Kozánek, 1992

Figs 27C, 33A-E, 62

Diagnosis: This species can be recognized by the shape of surstyli in lateral view; both bean-shaped (Fig. 33D-E); epandrium wider than long in dorsal view (Fig. 33A); coiled ejaculatory ducts (Fig. 33D-E); gonopods equal in height (Fig. 33B); rounded hypandrium with distinct hypandrial apodeme in ventral view (Fig. 33B). This species is closely related to T. nodosa and T. hamounensis sp. nov. See the diagnosis notes under T. nodosa and T. hamounensis sp. nov. for more details.
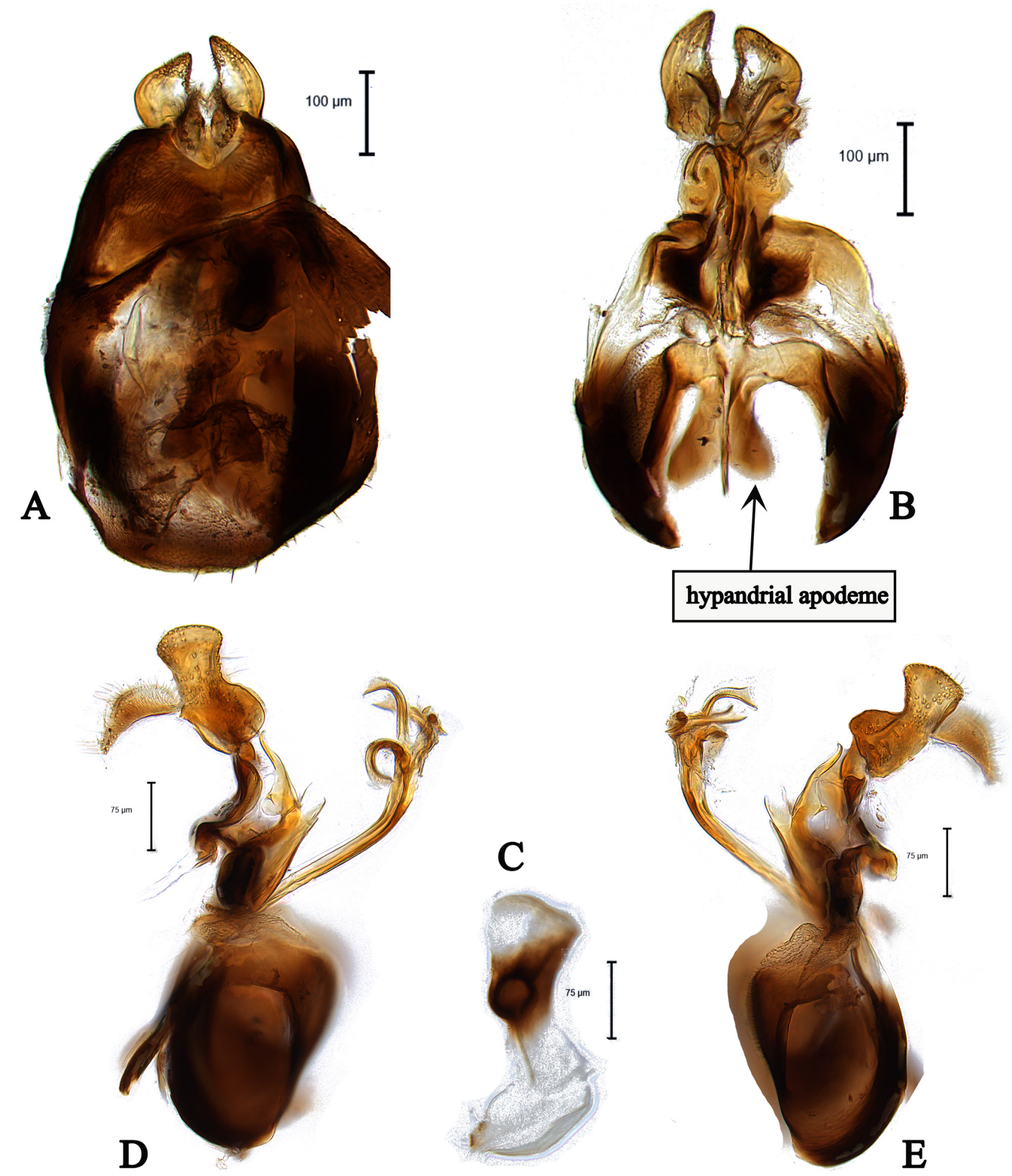

FIGURE 33. Male genitalia of Tomosvaryella pruinosa (CNC470682, CNC) A) dorsal view, B) ventral view, C) ejaculatory apodeme, D, E) lateral view. 


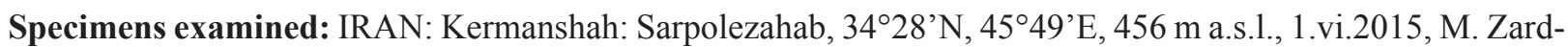
ouei, Malaise trap, JSS51831; JSS51834 (20, CNC); 456 m a.s.l., 14.v.2016, M. Zardouei, Malaise trap, JSS52235 (1, CNC); Sistan \& Baluchestan: Zabol, Dostmohammad, $31^{\circ} 09^{\prime} \mathrm{N}, 61^{\circ} 43^{\prime} \mathrm{E}, 470 \mathrm{~m}$ a.s.1., 13.ix.2016, M. Enaiat-

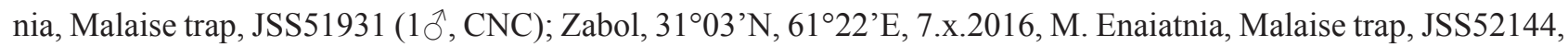
JSS52155, JSS52174 (3 ${ }^{\lambda}$, CNC); South Khorasan: Mohammadieh, 32 ${ }^{\circ} 52^{\prime} \mathrm{N}, 59^{\circ} 01^{\prime} \mathrm{E}, 1419 \mathrm{~m}$ a.s.l., 15.iv.2015, B. Motamedinia, Malaise trap, JSS52050 (10, CNC); ISRAEL: Arava Valley, Iddan Springs, in damp seep, east

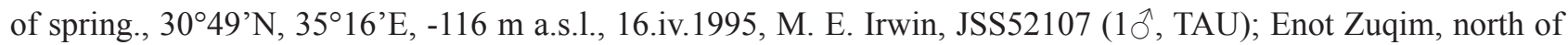

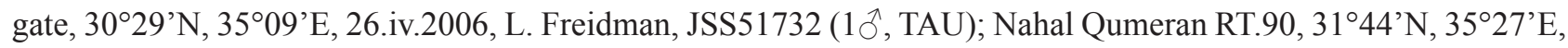

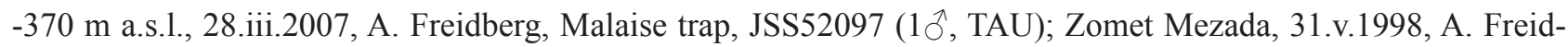
berg, JSS51695; JSS51724 (2ð, TAU); UNITED ARAB EMIRATES: Abu Dhabi, Al Wathba Wetland Reserve, $24^{\circ} 15^{\prime}$ N, 54³6'E, i.2015, A. Saji \& A. van Harten, Malaise trap, CNC470750 (1 ${ }^{\top}$, EAD); ii.2015, A. Saji \& A. van Harten, Malaise trap, CNC470517, CNC470597, CNC470475, CNC470591 (2ð̂, 2 + , CNC); iii.2015, A. Saji \& A. van Harten, Malaise trap, CNC470682 (1へ̂, CNC); iv.2015, A. Saji \& A. van Harten, Malaise trap, CNC470828,

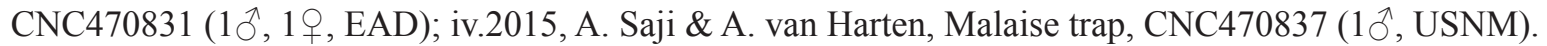

Distribution: Iran, Israel, Mongolia, United Arab Emirates (Kozánek, 1992, Skevington 2020) (Fig. 62).

Note: Based on DNA barcodes, T. pruinosa is genetically closest to T. urdaensis, differing by $0.6 \%$ (pairwise divergence) (Supplementary Table 1).

\section{Tomosvaryella pusilla De Meyer, 1995}

Figs 34A-E, 63

Diagnosis: This species can be recognized by the shape of surstyli in dorsal view, broadened at base and middle, the middle covered by dense setae dorsomedially (Fig. 34A); epandrium wider than long in dorsal view (Fig. 34A); phallic guide strong, straight and tapering apically in lateral view, with one strong spine dorsomedially (Fig. 34DE); phallus with three ejaculatory ducts, longer one divided into two branch, smaller one with two or three small spines in lateral view (Fig. 34D-E); symmetrical gonopods, wider than hypandrium in ventral view (Fig. 34B).

Specimens examined: IRAN: Sistan \& Baluchestan: Nikshahr, Pip, 26³7’ N, 6007’'E, 17.vi-19.vii.2016, M.

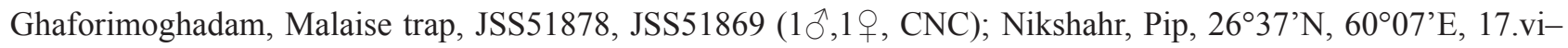

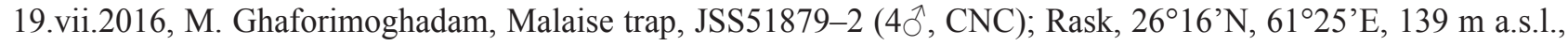
10.vi-14.vii.2016, M. Ghaforimoghadam, Malaise trap, JSS52163, JSS52171 (20’, CNC ISRAEL: En Mor, 3049’N, 34²6’E, 4.vi.2000, A. Freidberg, JSS51692, JSS52073 (20, TAU); UNITED ARAB EMIRATES: Wadi Bih dam, $25^{\circ} 29^{\prime} \mathrm{N}, 56^{\circ} 02^{\prime} \mathrm{E}, 19$. .ii-8.iii.2009, A. van Harten, Malaise trap, CNCD175304 (1 $\mathrm{O}^{\Uparrow}$, USNM); Wadi Wurayah farm, $25^{\circ} 14^{\prime} \mathrm{N}, 5^{\circ} 11^{\prime} \mathrm{E}, 31 . \mathrm{v}-14 . v i .2009$, A. van Harten, Malaise trap, CNCD137566, CNCD137572-3, CNCD137577,

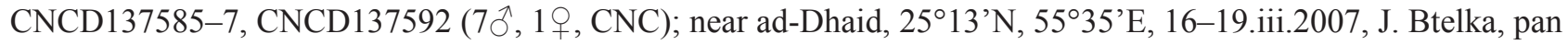
trap, CNCD159485 (1へ̂, EAD).

Distribution: Egypt, Iran, Israel, United Arab Emirates (Skevington 2020) (Fig. 63).

Notes: Based on DNA barcodes, this species is genetically closest to T. jubata, differing by $5.1 \%$ (pairwise divergence) (Supplementary Table 1).

\section{Tomosvaryella saudiensis Motamedinia \& Skevington sp. nov.}

Figs 35A-E, 46C, 54, 69A-B

Diagnosis: This species can be recognized by one distinct thorn-like projection and two small ones on the hind trochanter (Fig. 46C); elongated surstyli, broadened in basal two thirds in dorsal view (Fig. 35A), rather curved in lateral view (Fig. 35D-E); long phallic guide; phallus with three ejaculatory ducts, one with a downward projection in lateral view (Fig. 35D-E).

Description: MALE: Body length (excluding antennae): $2.7 \mathrm{~mm}$. Head. Face dark, light pollinose. Scape and pedicel dark; pedicel with a pair of short upper setae; flagellum light brown, tip paler than base, tapering and gray-light brown pollinose (LF:WF $=2.4)$; arista dark brown, with thickened base. Eyes meeting for a distance of 6-7 facets. Frons dark, light brown pollinose, vertex dark, lacking pollinosity, bearing an elevated ocellar triangle; 


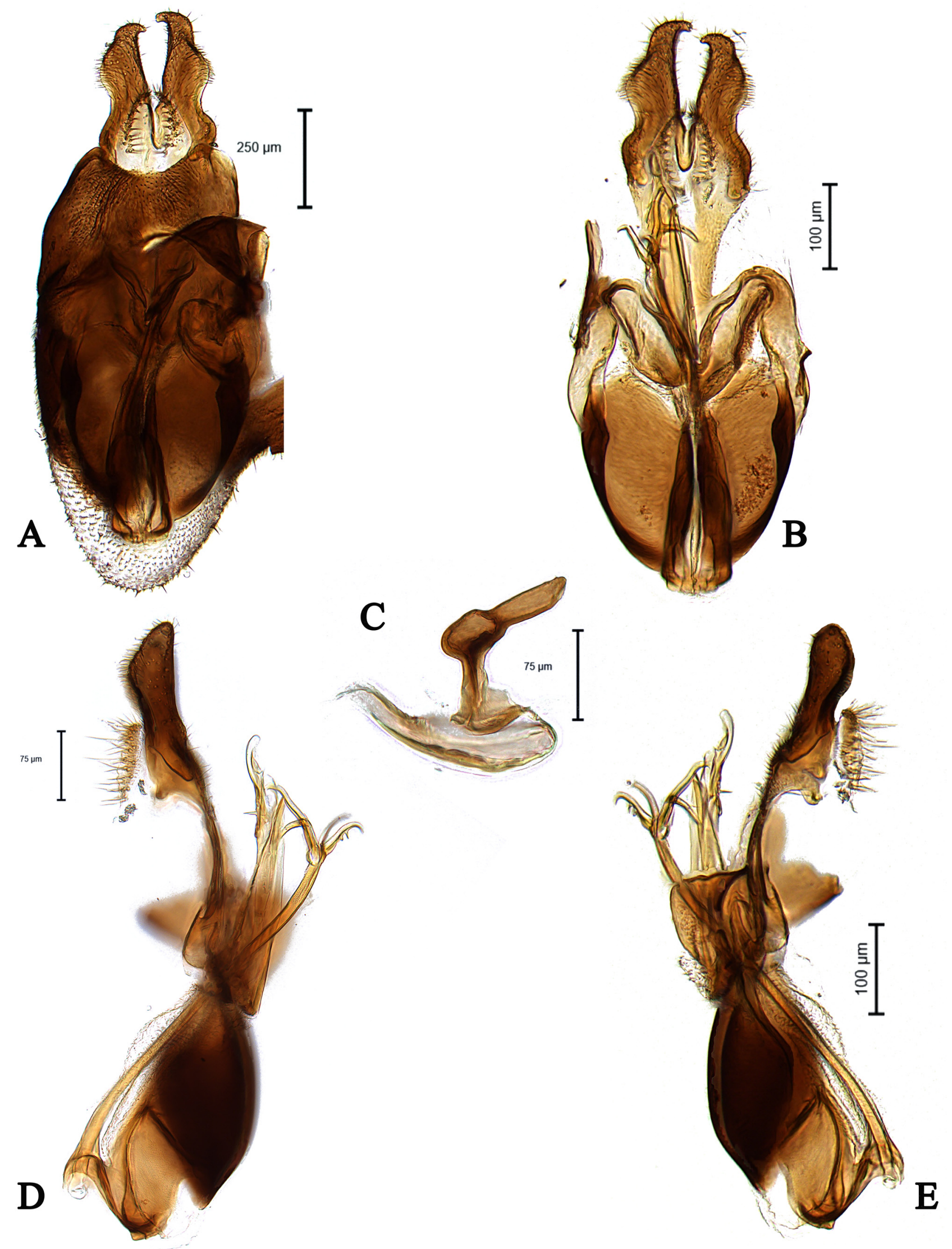

FIGURE 34. Male genitalia of Tomosvaryella pusilla (CNCD137566, CNC) A) dorsal view, B) ventral view, C) ejaculatory apodeme, D, E) lateral view. 


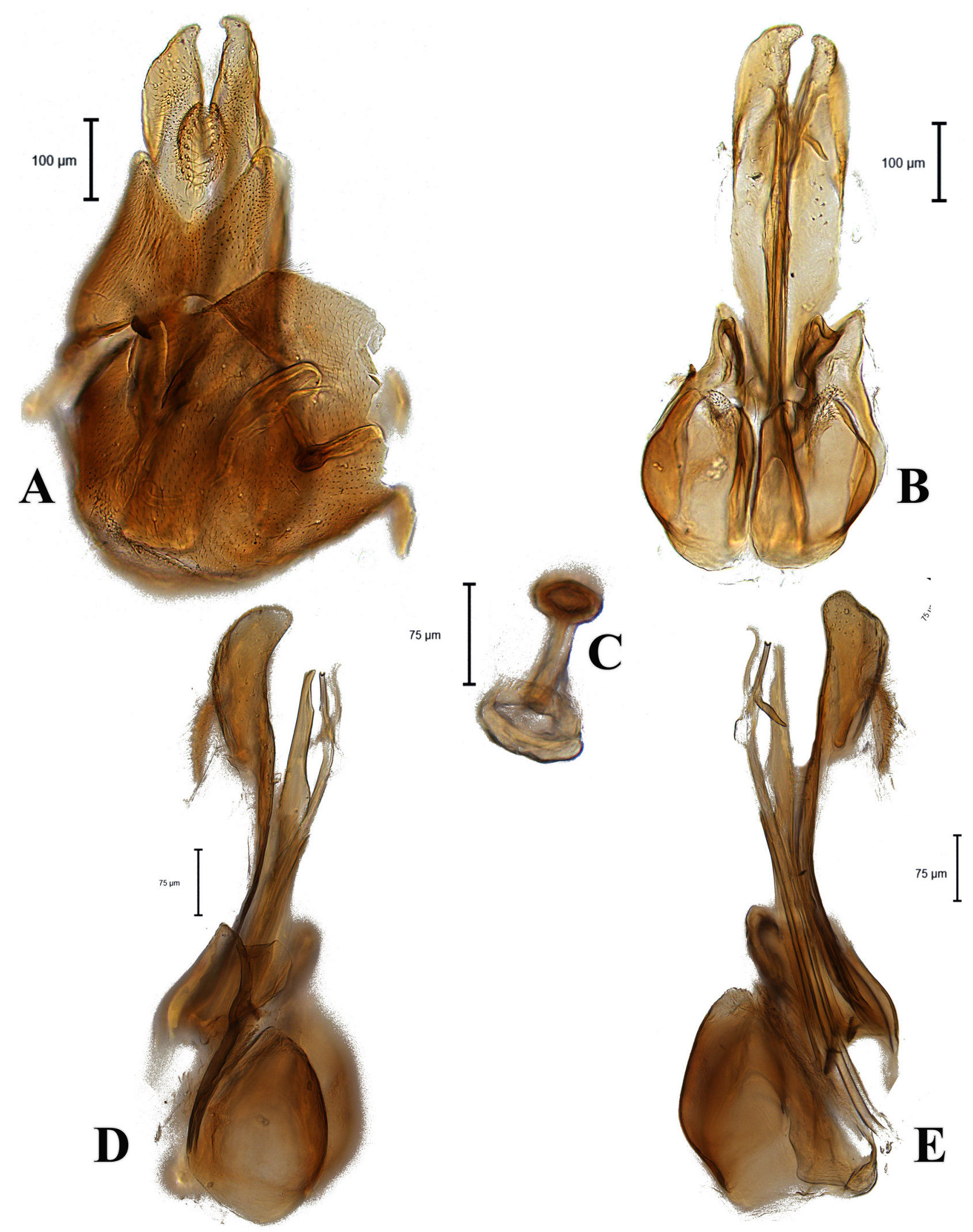

FIGURE 35. Male genitalia of Tomosvaryella saudiensis sp. nov., holotype (CNCD147709, CNC) A) dorsal view, B) ventral view, C) ejaculatory apodeme, D, E) lateral view.

vertex dark, lacking pollinosity; occiput dark, gray pollinose with scattered short dark setae. Thorax. Pleura, prescutum, scutum and scutellum brown. Pleura gray pollinose. Postpronotal lobe yellow, weakly gray pollinose and with 2-3 light brown along upper margin. Prescutum and scutum narrowly light brown pollinose, with some setae along 
anterior margin of prescutum area and some supra-alar setae. Scutellum light brown pollinose on anterior margin, with about 2-3 thin short setae along posterior margin (up to $0.03 \mathrm{~mm}$ ). Subscutellum gray pollinose. Wing. Length: $2.1 \mathrm{~mm}$. LW:MWW = 3.6. Wing almost entirely covered in microtrichia. $\mathrm{M}_{1}$ gently undulating. Halter length: 0.25 $\mathrm{mm}$. Base brown, knob paler than base. Legs. Coxae dark brown, gray pollinose. Mid coxa with 2-3 light brown setae on apical margin. Trochanters dark, gray pollinose. Hind trochanter with a long $(0.08 \mathrm{~mm})$ thorn-like projection on basal margin and two smaller one on apical margin (Fig. 46C). Femora dark brown, slightly light brown at apex, gray pollinose. Hind femur with one wrinkled indentation in basal. Tibiae light brown, distinctly dark brown in middle, gray pollinose with one wrinkled indentation in middle. Tarsi light brown and paler than tibiae, gray pollinose, with some light brown setae dorsally. Pulvilli yellow. Claws light brown with black tips. Abdomen. Ground color dark brown, light brown pollinose. Tergite 1 with three to four strong lateral setae. Genitalia. Genital capsule in dorsal view: epandrium brown, slightly longer than wide (MLE:MWE =1.1). Surstyli brown and rather symmetrical, elongated and rather broadened in basal two thirds, curved to each other at apex (Fig. 35A). Genital capsule in ventral view: gonopods equal in height, right broader than left one (Fig. 35B); subepandrial sclerite elongated, rather rectangular-shaped (Fig. 35B). Genital capsule in lateral view: both surstyli weakly concave (Fig. 35D-E); phallic guide thin and long, (Fig. 35D-E); phallus with three ejaculatory ducts, one with a downward projection (Fig. 35D-E). Ejaculatory apodeme cylindrical-shaped (Fig. 35C). FEMALE: unknown.

Etymology: The specific epithet refers to Saudi Arabia, from where the specimen was collected.

Specimen examined: HOLOTYPE: SAUDI ARABIA: Hada Al Asham Valle, $\sim 125 \mathrm{~km}$ Northeast of Jeddah,

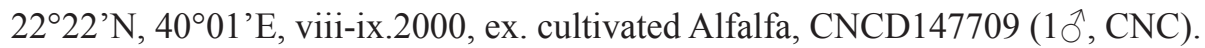

Distribution: Saudi Arabia (Fig. 54).

Note: Based on DNA barcodes, this species is genetically most similar to T. jubata, differing by $4.0 \%$ (pairwise divergence) (Supplementary Table 1).

\section{Tomosvaryella sedomensis De Meyer, 1995}

Fig. 63

Diagnosis: Following De Meyer (1995), this species can be recognized by the asymmetrical surstyli in dorsal view, left is higher than right one, left surstylus protruded in ventromedial margin; separated eyes; epandrium as long as wide; phallus with three ejaculatory ducts, one with some small spines (De Meyer, 1995: fig. 21a-f).

Distribution: Israel (De Meyer, 1995) (Fig. 63).

\section{Tomosvaryella soziana Motamedinia \& Skevington sp. nov.}

Figs 27H, 36A-E, 56, 69C-D

Diagnosis: This species can be recognized by its asymmetrical surstyli in dorsal view, left surstylus slightly rectangular-shaped, right surstylus slightly triangular-shaped (Fig. 36A), left surstylus with ventromedial triangularshaped projection in lateral view (Fig. 36D); ejaculatory ducts long and different-sized, one bearing saw-like teeth along its side (Fig. 36D-E); long phallic guide with a distinct membranous sheath basally (Figs 36D-E).

Description: MALE: Body length (excluding antennae): $2.7 \mathrm{~mm}$. Head. Scape dark brown, pedicel brown, flagellum light brown. Pedicel with a pair of short upper setae and a single short lower bristle; flagellum tapering and gray-white pollinose (LF:WF $=3.0$ ); arista dark, with thickened base. Eyes converging but not meeting and separated by less than diameter of frontal facets. Frons dark silver-gray pollinose. Vertex black, lacking pollinosity. Occiput dark and gray pollinose. Thorax. Postpronotal lobe light yellow, gray pollinose with 5-6 yellowish setae along the upper margin (up to $0.03 \mathrm{~mm}$ ). Prescutum, scutum, scutellum black. Scutum with two uniseriate rows of intra-alar setae and two uniseriate rows of dorsocentral setae. Scutellum with 1-2 thin short setae along lateral margin (up to $0.03 \mathrm{~mm}$ ). Subscutellum black, gray pollinose. Pleura black but dark brown on pteropleuron, hypopleuron and sternopleuron. Wing. Length: $2.5 \mathrm{~mm}$. LW:MWW $=2.5$. Wing almost entirely covered with microtrichia. Crossvein $\mathrm{r}-\mathrm{m}$ reaches $\mathrm{dm}$ at the middle. $\mathrm{M}_{1}$ strongly undulating in middle. Halter length: $0.3 \mathrm{~mm}$. Whitish, narrowly brown at base. Legs. Coxae dark but mid coxa brown, gray pollinose. Mid coxa with two light brown anterior setae. Trochanters brown, smooth. Femora dark with light brown apices, gray pollinose. Hind femur bearing two rows of 
small spines in apical half with 1-2 wrinkled indentations at base. Tibiae brown but dark at the middle, with two ventral rows of short setae on anterior and three rows on posterior side. Hind tibia with 1-2 wrinkled indentations in middle. Tarsi light brown with scattered brown setae at anterior margin, basitarsi longer than other tarsomeres. Pulvilli yellow. Claws light brown with black tips. Abdomen. Ground color dark. Tergite 1 gray pollinose, with 5-6 dark lateral setae (up to $0.11 \mathrm{~mm}$ ). Tergites $2-5$ with scattered brown setae. Tergite 5 slightly longer than tergite 4 and almost symmetrical in dorsal view (LT35:WT5 $=1.3$, WT5:LT5 $=2.0$, T5R:T5L $=1.0$ ). Sternites light brown laterally and dark brown centrally, gray pollinose. Syntergosternite 8 dark. Membranous area ovate in caudal view.
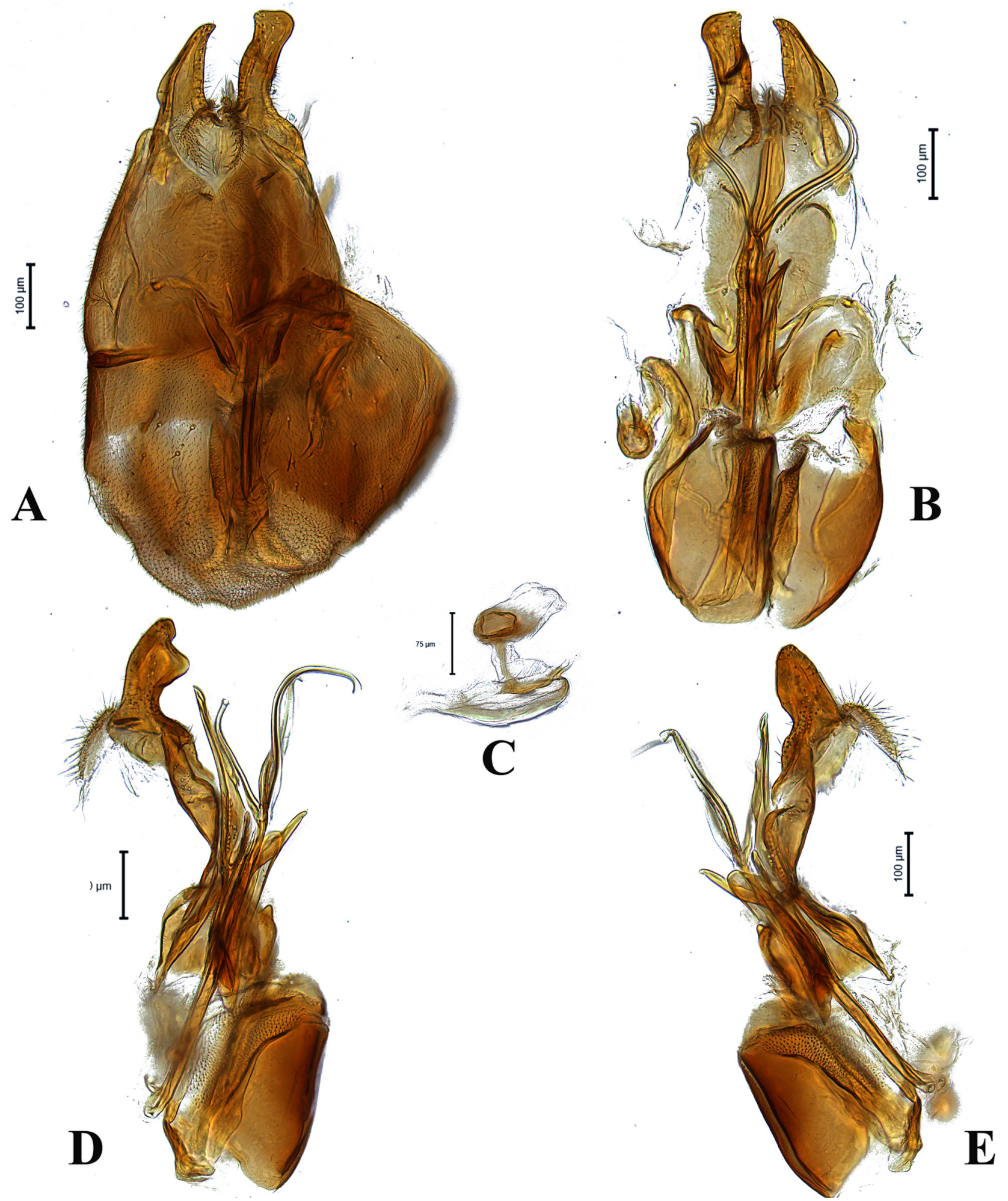

FIGURE 36. Male genitalia of Tomosvaryella soziana sp. nov., holotype (JSS52193, CNC) A) dorsal view, B) ventral view, C) ejaculatory apodeme, D, E) lateral view. 
Genitalia. Genital capsule in dorsal view: epandrium and surstyli light brown, gray pollinose. Epandrium wider than long (MLE:MWE = 0.90). Surstyli entirely asymmetrical. Left surstylus slightly rectangular-shaped and rather larger than left one, right surstylus slightly triangular-shaped and curved to left one (Fig. 36A). Genital capsule in ventral view: gonopods equal in height, right wider than left one, left more sclerotized than right one (Fig. 36B). Phallus with different-sized ejaculatory ducts, one bearing saw-like teeth along its side (Fig. 36B). Phallic guide strong, straight with small projection at the base, pointed towards right surstylus (Fig. 36B). Genital capsule in lateral view: left surstylus with distinct ventromedial projection (Fig. 36D). Phallic guide strong, elongated, with a distinct membranous sheath basally (Fig. 36D-E). Ejaculatory apodeme tube-like, bent, with a bulb in its middle (Fig. 36C).

FEMALE: Body length (excluding antennae): $2.75 \mathrm{~mm}$. Head. Eyes separated. Frons silver-gray pollinose except ocellar triangle, widened in middle (MWF: $0.1 \mathrm{~mm}$; MWF:WFA =2.4). Occiput gray pollinose. Thorax. Postpronotal lobe light yellow, gray pollinose with 2-3 light brown setae along the upper margin (up to $0.03 \mathrm{~mm}$ ). Prescutum and scutum, scutellum black, gray pollinose with scattered setae at anterior supra-alar area. Wing. Length: $2.5 \mathrm{~mm}$. LW:MWW = 3.3. Legs. Mid coxa with 2-3 black anterior setae. Mid femur bearing two small ventral rows of dark peg-like spines in the apical third. Distitarsi with long brown setae at anterior margin. Pulvilli smaller than distitarsi. Abdomen. Tergites 1-6 gray pollinose with scattered brown setae. Ovipositor. Base of ovipositor dark brown, gray pollinose, dorsally with some scattered brown setae. Viewed laterally (Fig. 27H), base of piercer curved, piercer straight, as long as the base. $\mathrm{LP}: \mathrm{LB}=1.0$.

Etymology: The specific epithet refers to the historical name of Khuzestan, from where the specimens were collected.

Specimens examined: HOLOTYPE: IRAN: Khuzestan: Shush, $32^{\circ} 06^{\prime} \mathrm{N}, 48^{\circ} 26^{\prime} \mathrm{E}, 68 \mathrm{~m}$ a.s.1., 11.iii10.v.2015, E. Gilasian, Malaise trap, JSS52193 (1へ, CNC); PARATYPE: IRAN: Khuzestan: Shush, same data as holotype, JSS52205 (1+, CNC).

Distribution: Iran (Fig. 56).

Note: Based on DNA barcoding, this species is genetically similar to T. spinula $\mathbf{s p . ~ n o v . , ~ d i f f e r i n g ~ b y ~} 1.8 \%$ (pairwise divergence). The male and female are genetically identical (Supplementary Table 1).

\section{Tomosvaryella spinula Motamedinia \& Skevington sp. nov.}

Figs 27D, 37A-D, 47F, 63, 69E-F

Diagnosis: This species can be recognized by the elongated surstyli in dorsal view, constricted in basal third and curved to each other (Fig. 37A); epandrium longer than wide (Fig. 37A); gonopods elongated with a small projection (Fig. 37D); phallus with three short ejaculatory ducts, one with a finger-like projection and a feather-like projection, another one with a small spine in its middle in lateral view (Fig. 37B-C); hind trochanter with two distinct projections (Fig. 47F).

Description: MALE: Body length (excluding antennae): $2.5 \mathrm{~mm}$. Head. Scape and arista dark, pedicel and flagellum light brown. Pedicel with one or two short upper pale setae; flagellum tapering and gray-white pollinose $(\mathrm{LF}: \mathrm{WF}=2.4)$. Eyes meeting for a distance of 6-8 facets. Frons dark, silver-gray pollinose. Vertex black, lacking pollinosity. Occiput dark and gray pollinose with scattered pale setae. Thorax. Postpronotal lobe light yellow, gray pollinose with 3-4 short setae along the upper margin (up to $0.02 \mathrm{~mm}$ ). Prescutum, scutum, scutellum black. Scutum with two uniseriate rows of intra-alar setae and two uniseriate rows of dorsocentral setae. Scutellum with 3-4 thin short setae along lateral margin (up to $0.01 \mathrm{~mm}$ ). Subscutellum black, gray pollinose. Pleura brown. Wing. Length: $2.5 \mathrm{~mm}$. LW:MWW = 3.3. Wing almost entirely covered with microtrichia. Cross-vein $\mathrm{r}-\mathrm{m}$ reaches $\mathrm{dm}$ at the middle. $\mathrm{M}_{1}$ moderately undulating in middle. Halter length: $0.33 \mathrm{~mm}$. Whitish, narrowly brown at base. Legs. Fore and mid coxae light brown, hind coxa brown, gray pollinose. Mid coxa with three dark anterior setae. Trochanters brown, gray pollinose. Hind trochanter with two distinct projections, longer one $(0.08 \mathrm{~mm})$ is thorn-like and located on basal margin with two short setae at its apex and wider one located on apical margin (Fig. 47F). Femora brown with light brown apices, gray pollinose. All femora with one wrinkled indentations at base. Tibiae brown but light brown in basal third, with two ventral rows of short setae on anterior and three rows on posterior side. Hind tibia with 1-2 wrinkled indentations in middle. Tarsi light brown with scattered brown setae at anterior margin, basitarsi lighter than other tarsomeres. Pulvilli yellow. Claws light brown with black tips. Abdomen. Ground color 
dark brown. Tergite 1 densely gray pollinose, with $4-5$ light brown lateral setae (up to $0.11 \mathrm{~mm}$ ). Tergite $2-5$ gray pollinose, with scattered brown setae. Sternites light brown laterally and dark brown centrally. Genitalia. Genital capsule in dorsal view: epandrium and surstyli brown, gray pollinose. Epandrium longer than wide (MLE:MWE = 1.14). Surstyli rather symmetrical. Both surstyli elongated, restricted in basal third, curved to each other at apex, left is higher than right one (Fig. 37A). Genital capsule in ventral view: gonopods elongated and equal in height with a small projection (Fig. 37D). Subepandrial sclerite elongated (Fig. 37D). Genital capsule in lateral view: both surstyli bent towards sternite, right is broader than left one (Fig. 37B-C). Phallic guide strong, phallus with three ejaculatory ducts, one with finger-like projection and feather-like projection, another one with a small spine in its middle (Fig. 37B-C). FEMALE: Body length (excluding antennae): $2.7 \mathrm{~mm}$. Head. Eyes separated, pedicel without short setae. Frons gray pollinose. Occiput gray pollinose with scattered dark setae. Thorax. As in male. Wing. Length: $2.2 \mathrm{~mm}$. LW:MWW = 2.09. Legs. As in males except for smooth hind trochanter. Abdomen. As in males. Ovipositor. Base of ovipositor dark brown with some gray pollinosity. Viewed laterally (Fig. 27D), piercer short and straight. LP:LB $=1.8$. LDP:LPP $=3.0$.
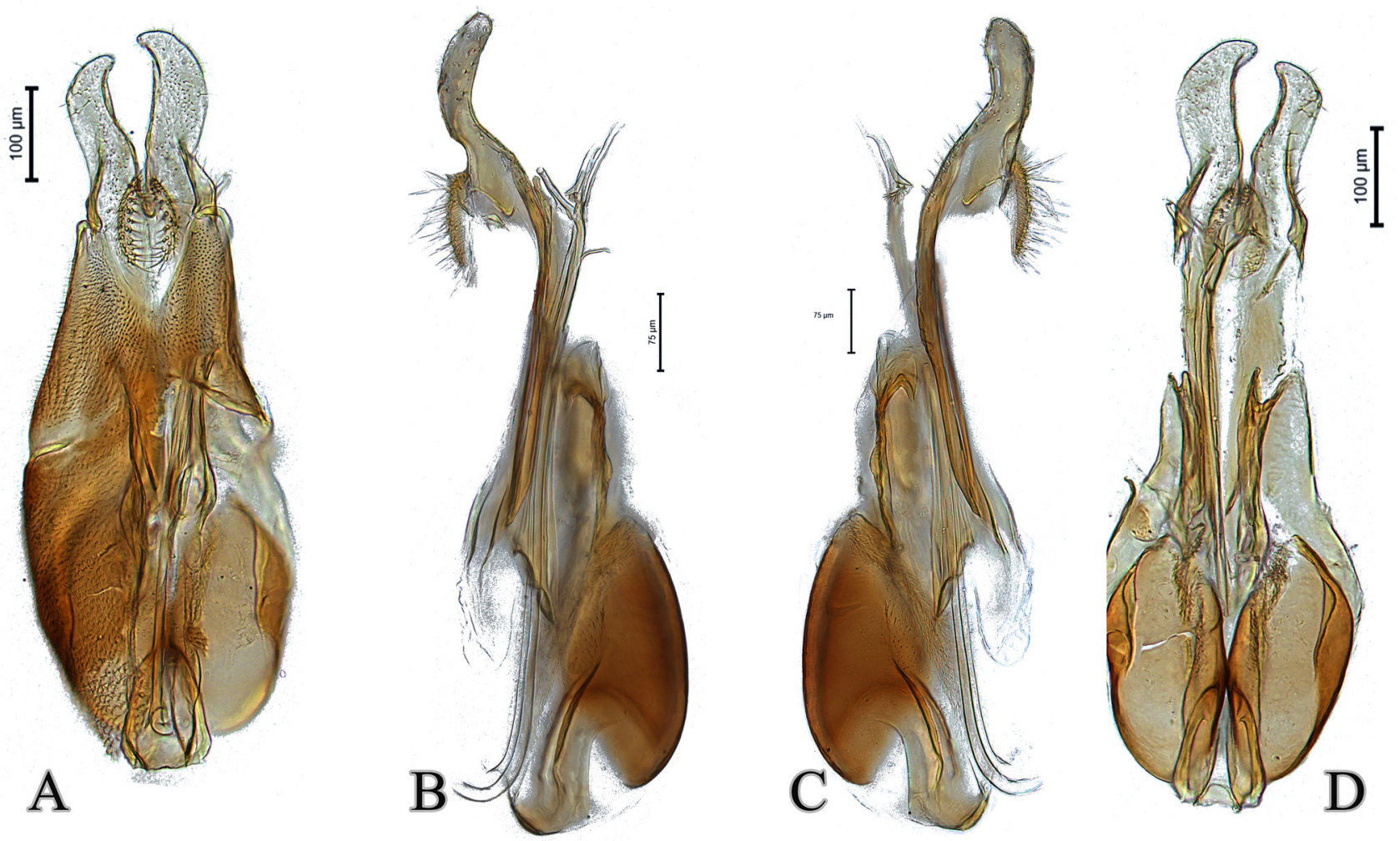

FIGURE 37. Male genitalia of Tomosvaryella spinula sp. nov., holotype (JSS51924, CNC) A) dorsal view, B, C) lateral view, D) ventral view.

Etymology: The specific name is derived from the Latin word spinula, meaning thorn, referring to the thornlike projection on its hind trochanter.

Specimens examined: HOLOTYPE: IRAN: Zabol, $31^{\circ} 03^{\prime} \mathrm{N}, 61^{\circ} 22^{\prime} \mathrm{E}, 470 \mathrm{~m}$ a.s.1., 4.vii.2016, M. Enaiatnia,

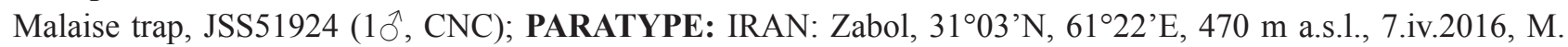
Enaiatnia, Malaise trap, JSS51820 (1, CNC).

Distribution: Iran (Fig. 63).

Note: Based on DNA barcodes, this species is genetically similar to T. soziana $\mathbf{s p . ~ n o v . , ~ d i f f e r i n g ~ b y ~} 1.8 \%$ (pairwise divergence). The male and female differ by $0.0 \%$ (Supplementary Table 1 ).

\section{Tomosvaryella subsylvatica Kazerani, Khaghaninia \& Kehlmaier, 2017}

Fig. 62

Diagnosis: Following Kazerani et al. (2017), this species can be recognized by the elongated surstyli in dorsal view, 
broadened in basal fourth, narrowed moderately apically; epandrium longer than wide; phallus with three ejaculatory ducts without projection (Kazerani et al. 2017: fig. 3A-D). Based on the shape of phallus in lateral view and surstyli in dorsal view, this species resembles T. sylvatica. It differs by the shape of surstyli in lateral view, being pointed apically; the hind trochanter with three small spines; the $\mathrm{r}-\mathrm{m}$ cross-vein reaching cell $\mathrm{dm}$ before its middle.

Distribution: Iran (Kazerani et al. 2017; Skevington 2020) (Fig. 62).

\section{Tomosvaryella subtransvaalensis Motamedinia \& Skevington sp. nov.}

Figs 38A-E, 54, 70A-B

Diagnosis: This species can be recognized by the shape of surstyli in dorsal view, elongated and constricted in middle (Fig. 38A); wide epandrium in dorsal view (Fig. 38A); asymmetrical gonopod and hypandrium in ventral view (Fig. 38B); ejaculatory apodeme funnel-shaped (Fig. 38C). Based on the shape of surstyli, this species resembles T. transvaalensis De Meyer, 1993 (Fig. 42A-E). The shape of surstyli is slightly different in lateral view, in $T$. transvaalensis, straight in medial, narrowed in apical third (Fig. 42D-E) and T. subtransvaalensis has a hypandrial apodeme in ventral view (Fig. 38B).

Description: MALE: Body length (excluding antennae): $4.6 \mathrm{~mm}$. Head. Scape dark, pedicel dark brown, flagellum brown; pedicel with three short upper setae; flagellum tapering (LF:WF $=3.0)$; arista dark. Eyes meeting for a distance of 8-9 facets. Frons silver-gray pollinose. Vertex black, lacking pollinosity. Occiput dark and gray pollinose in lower half. Thorax. Postpronotal lobe light yellow, gray pollinose with 4-6 small setae along the upper margin (up to $0.03 \mathrm{~mm}$ ). Prescutum and scutum black, with a row of supra-alar setae. Scutellum black, silver-gray pollinose, with about $12-14$ short dark setae along posterior margin (up to $0.03 \mathrm{~mm}$ ). Subscutellum and pleura dark. Wing. Length: $4.1 \mathrm{~mm}$. LW:MWW = 4.0. Wing almost entirely covered with microtrichia. Cross-vein $\mathrm{r}-\mathrm{m}$ reaching cell $\mathrm{dm}$ at the middle. $\mathrm{M}_{1}$ strongly undulating in middle. Halter length: $0.37 \mathrm{~mm}$. Yellowish, dark brown at base. Legs. Dark but narrowly yellow at apex of femora, base of tibiae. Trochanters black, smooth. Femora partly gray pollinose. All femora bearing two rows of dark, peg-like anteroventral spines in apical half. Hind femur with one wrinkled indentation in basal quarter. Tibiae with two rows of short setae on anterior and three rows on posterior side. Hind tibia with one wrinkled indentation in the middle. Tarsi brown, gray pollinose. Pulvilli shorter than distitarsi. Claws brown with black tips. Abdomen. Ground color dark. Tergite 1 entirely gray pollinose with 8-9 short black lateral setae (up to $0.1 \mathrm{~mm}$ ). Tergites $2-5$ with scattered short dark setae. Sternites brown laterally and dark centrally, gray pollinose. Genitalia. Genital capsule in dorsal view: epandrium and surstyli dark brown, gray pollinose. Epandrium wider than long (MLE:MWE =0.3), left side more extended than right one. Surstyli rather symmetrical, elongated, constricted in middle (Fig. 38A). Genital capsule in ventral view: gonopods rather large and unequal in height, left slightly higher than right one; hypandrium unequal in height, left is higher than right one (Fig. 38B). Genital capsule in lateral view: surstyli curved towards sternite (Fig. 38D-E). Phallic guide short, strong, pointed apically (Fig. 38D-E); phallus with two long and one short ejaculatory ducts (Fig. 38D-E). Ejaculatory apodeme funnel-shaped (Fig. 38C). FEMALE: unknown.

Etymology: The specific name is derived from the Latin preposition 'sub' meaning near, referring to this species close relation to T. transvaalensis De Meyer, 1993.

Specimens examined: HOLOTYPE: ISRAEL: Rehovot, 31ํ5’N, 34²48’E, 2.i.1999, Y. Nussbaum, JSS51765

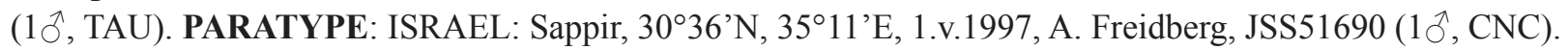

Distribution: Israel (Fig. 54).

Notes: Based on DNA barcoding, this species is genetically most similar to T. inopinata, differing by $5.3 \%$ (pairwise divergence). Note that T. transvaalensis has not been sequenced.

\section{Tomosvaryella subvirescens (Loew, 1872)}

Figs 39A-E, 46D, 64

Pipunculus subvirescens Loew, 1872.—syn. De Meyer (1996): p. 95.

Diagnosis: This species can be recognized by the shape of surstyli in dorsal view, right surstylus quadratic-shaped with small inner projection, left surstylus elongated, rather rectangular-shaped, longer than right one (Fig. 39A); ep- 
andrium wider than long, slightly ovate-shaped (Fig. 39A); phallus trifid with wavy ejaculatory ducts (Fig. 39D-E); asymmetrical gonopods in ventral view, right higher than left one (Fig. 39B); hypandrium ovate-shaped with distinct hypandrial apodeme in ventral view (Fig. 39B).
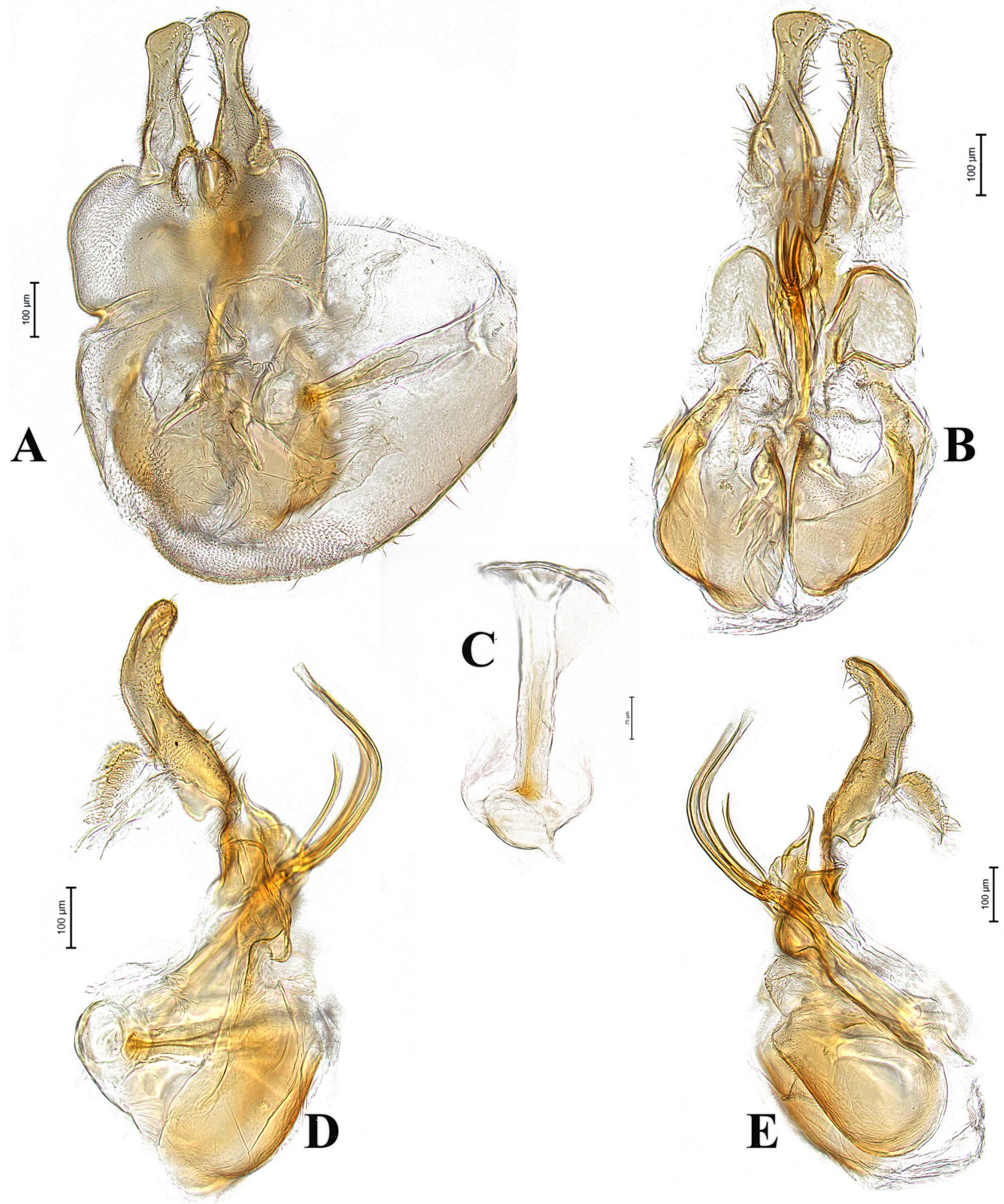

FIGURE 38. Male genitalia of Tomosvaryella subtransvaalensis sp. nov., holotype (JSS51765, TAU) A) dorsal view, B) ventral view, C) ejaculatory apodeme, D, E) lateral view. 

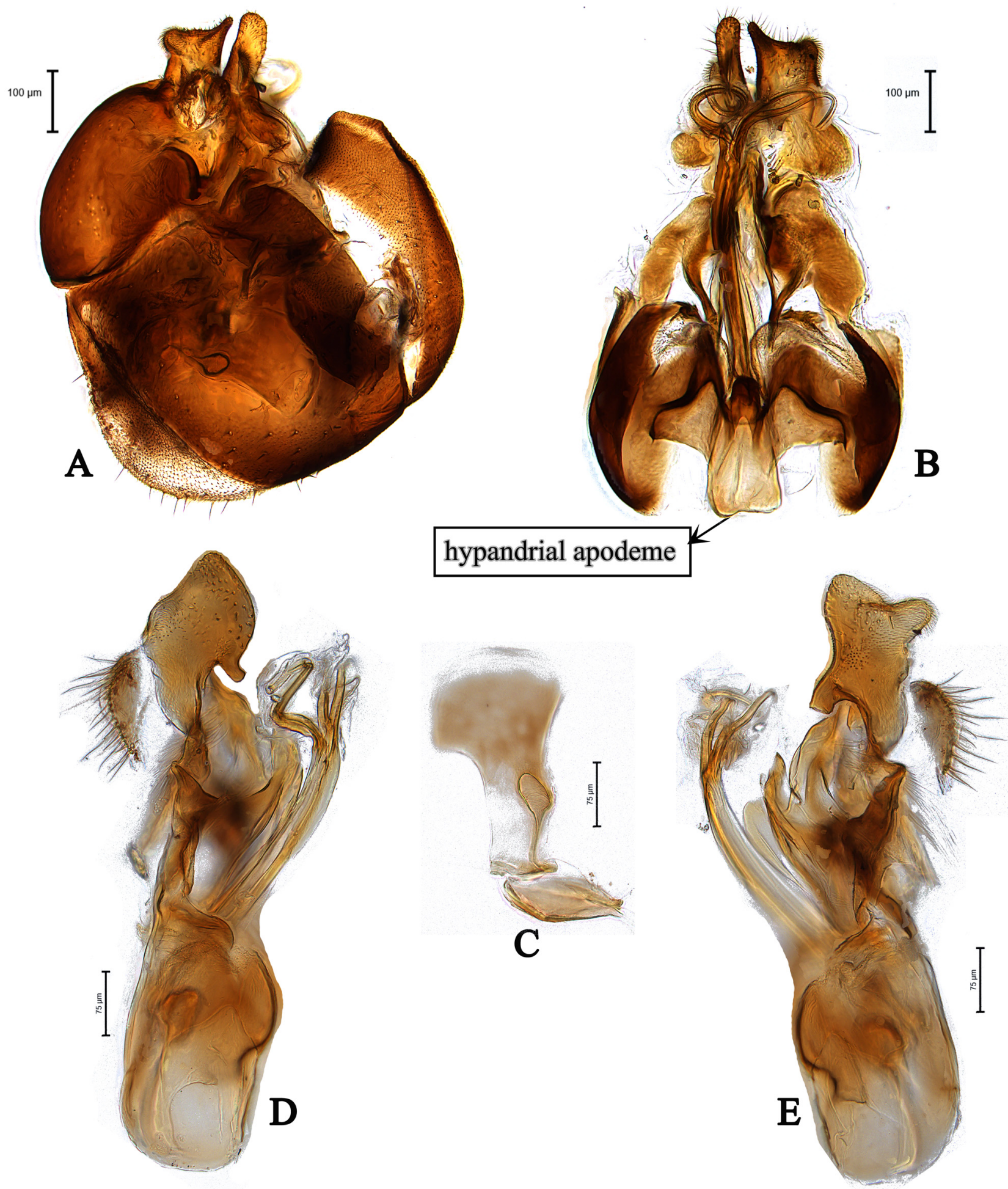

FIGURE 39. Male genitalia of Tomosvaryella subvirescens (CNCD174944, CNC) A) dorsal view, B) ventral view, C) ejaculatory apodeme, D, E) lateral view.

Specimens examined: IRAN: Sistan \& Baluchestan: Saravan, $27^{\circ} 25^{\prime} \mathrm{N}, 62^{\circ} 17^{\prime} \mathrm{E}, 12 . v .2013$, F. Hamzavi, pan

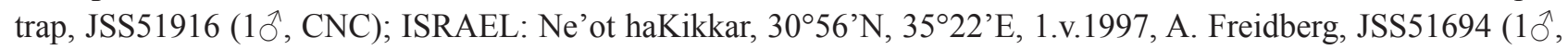

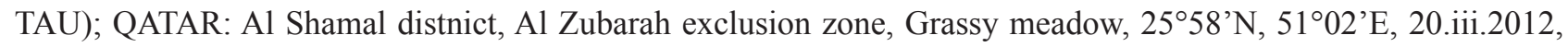
K. P. Puliafico \& A. M. Jensen, yellow \& white pan traps, JSS52318-9 (2へ,, CNC); UNITED ARAB EMIRATES:

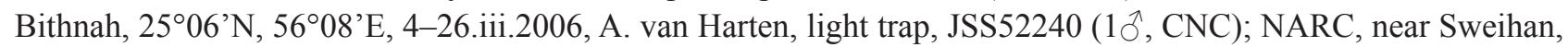

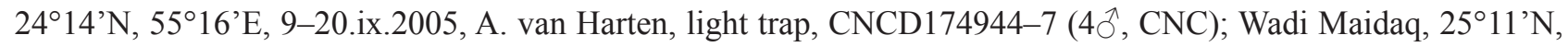




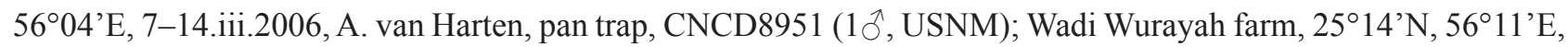
17-24.iii.2009, A. van Harten, Malaise trap; CNCD137124-5, CNCD137128 (3 Jै, CNC); 19.iv-19.v.2009, A. van Harten, Malaise trap, CNCD137532, CNCD137534, CNCD137536, CNCD137538, CNCD137540, CNCD137545, CNCD137552 (7ð̄, CNC); 24-30.iii.2009, A. van Harten, Malaise trap, CNCD136930, CNCD136932 (20, CNC);

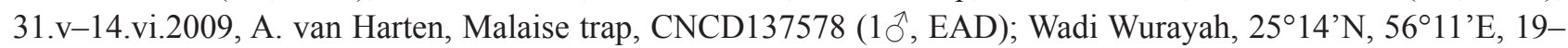

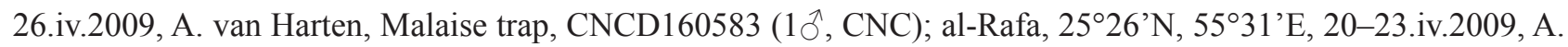

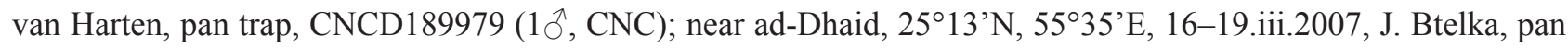
trap, CNCD159476, CNCD159478-9,CNCD159483-4, CNCD159486, CNCD159488 (7ð̄, CNC).

Distribution: Bahamas, Belize, Bermuda, Brazil, Canada, Chile, Colombia, Costa Rica, Cuba, Dominica, Egypt, Gabon, Iran, Israel, Jamaica, Mexico, Mozambique, Namibia, Nicaragua, Panama, Peru, Puerto Rico, Qatar, Thailand, the United States, United Arab Emirates (Skevington 2020) (Fig. 64).

Note: DNA barcodes of T. subvirescens overlap with T. pilosiventris. See the notes under T. pilosiventris.

\section{Tomosvaryella susa Motamedinia \& Skevington sp. nov.}

Figs 40A-D, 61, 70C-D

Diagnosis: This species can be recognized by the shape of surstyli in dorsal view, broadened at base and rather triangular-shaped (Fig. 40A); broadened gonopods, right wider than left one with small projection in ventral view (Fig. 40B); short ejaculatory ducts, one bearing some saw-like teeth in basal half in lateral view (Fig. 40C-D).

Description: MALE: Body length (excluding antennae): $3.1 \mathrm{~mm}$. Head. Scape, pedicel and arista dark. Pedicel with 2-3 upper setae and a single lower bristle; flagellum light brown, gray pollinose and long tapering (LF: WF = 3.0). Eyes converging but not meeting and separated by less than diameter of frontal facets. Frons silver-gray pollinose, vertex dark and shine, lacking pollinosity, bearing an elevated ocellar triangle. Occiput dark, gray pollinose with scattered brown setae. Thorax. Postpronotal lobe light brown. Prescutum and scutum black, silver-gray and brown pollinose, with scattered setae at anterior supra-alar area and uniseriate rows of intra-alar setae. Scutellum black, silver-gray pollinose, with about 14 brown setae along posterior margin (up to $0.08 \mathrm{~mm}$ ). Subscutellum and pleura black; pleuron light brown. Wing. Wing length: $3.1 \mathrm{~mm}$., LW:MWW = 3.0. Wing almost entirely covered with microtrichia. $\mathrm{M}_{1}$ strongly undulating in middle. Halter length: $0.37 \mathrm{~mm}$. light brown, narrowly black at base. Legs. Coxae black, trochanters light brown, smooth. Femora dark brown with narrow but distinct pale base and apices, silver pollinose. Femora without ventral spines. Mid and hind femora with one wrinkled indentation in basal. Tibiae brown at middle, gray pollinose, with two rows of short brown setae on anterior and three rows on posterior side. Mid and hind tibiae with one or two wrinkled indentations in middle. Tarsi light brown. Abdomen. Ground color dark brown, tergite 1 silver gray pollinose with a patch of light brown setae (15-17) laterally extending along posterior margin, tergites $2-5$ with relatively long brown setae. Sternites white-yellow laterally and brown centrally, gray pollinose. Genitalia. Genital capsule in dorsal view: epandrium and surstyli brown, gray pollinose. Epandrium wider than long (MLE:MWE = 0.74). Surstyli symmetrical, broadened at base, rather triangular-shaped (Fig. 40A). Genital capsule in ventral view: gonopods broadened and slightly equal in height, right wider than left one with a small projection, subepandrial sclerite wide basically, phallic guide strong, slightly straight (Fig. 40B). Genital capsule in lateral view: surstyli longer than wide, slightly straight, broadened at apex (Figs 40C-D). Phallic guide strong, pointed apically (Fig. 40C); phallus with three ejaculatory ducts, one bearing some saw-like teeth in basal half (Fig. 40C-D). FEMALE: unknown.

Etymology: The specific epithet refers to "Susa", the historical name of Shush, from where the specimen was collected. The name is a noun in apposition.

Specimen examined: HOLOTYPE: IRAN: Khuzestan: Shush, 3206’ N, 48²6’'E, 68 m a.s.1., 11.iii-10.v.2015, E. Gilasian, Malaise trap, JSS52217 (1ð̋, CNC).

Distribution: Iran (Fig. 61).

Notes: Tomosvaryella susa sp. nov. is genetically very close to T. ampliasa sp. nov., differing by $0.8-1.2 \%$ (pairwise divergence) (Supplementary Table 1). 

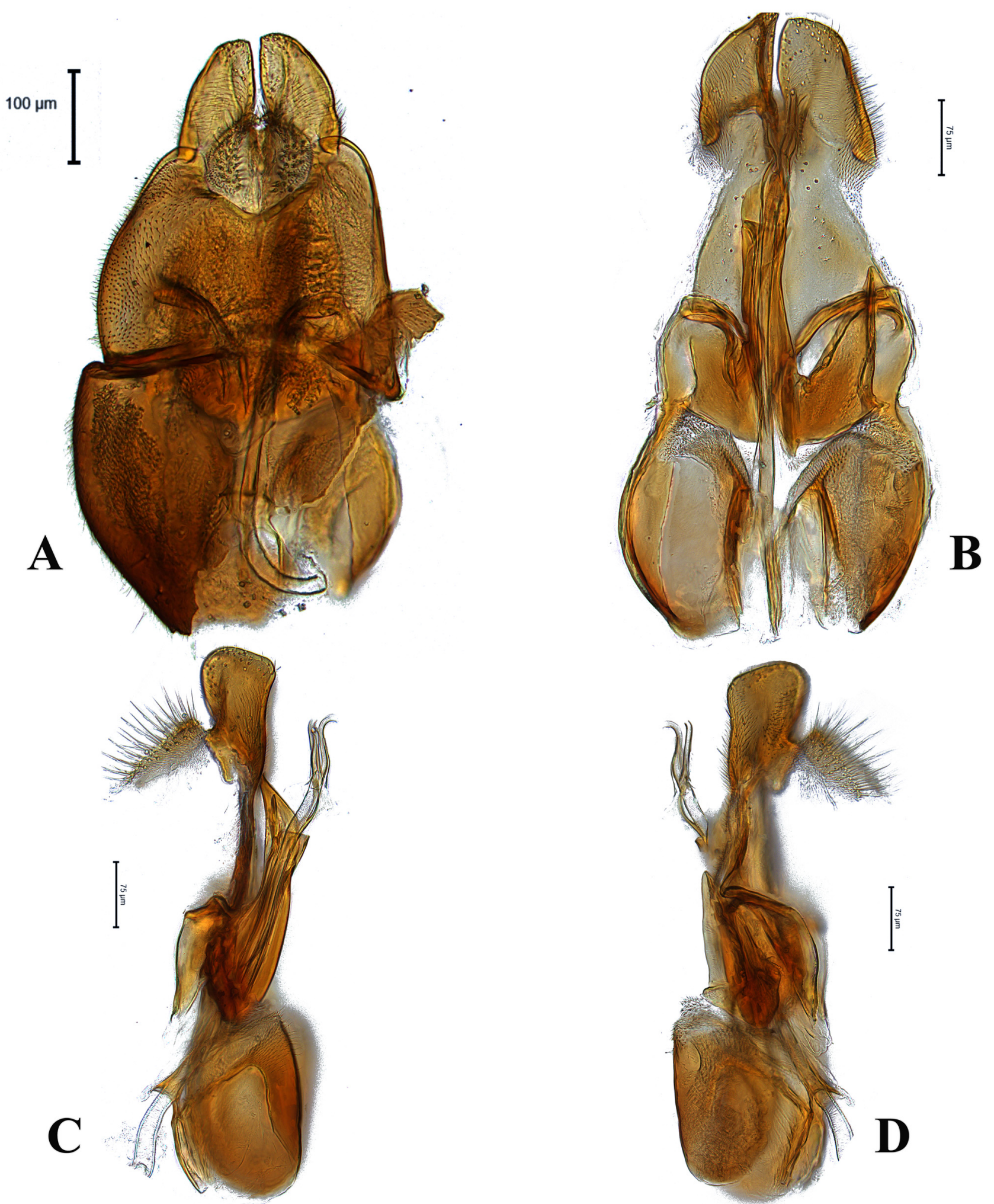

FIGURE 40. Male genitalia of Tomosvaryella susa sp. nov., holotype (JSS52217, CNC) A) dorsal view, B) ventral view, C, D) lateral view.

\section{Tomosvaryella teligera Kuznetzov, 1994}

Figs 41A-E, 48C, 64

Diagnosis: This species can be recognized by the distinct frontal prominence (Fig. 48C); shape of surstyli in dorsal 
view, both broadened in basal half, moderately narrowed to apical half, curved to each other at apex; left surstylus slightly longer than right one (Fig. 41A), gonopods slightly equal in height, right with rounded projection towards phallic guide (Fig. 41B).
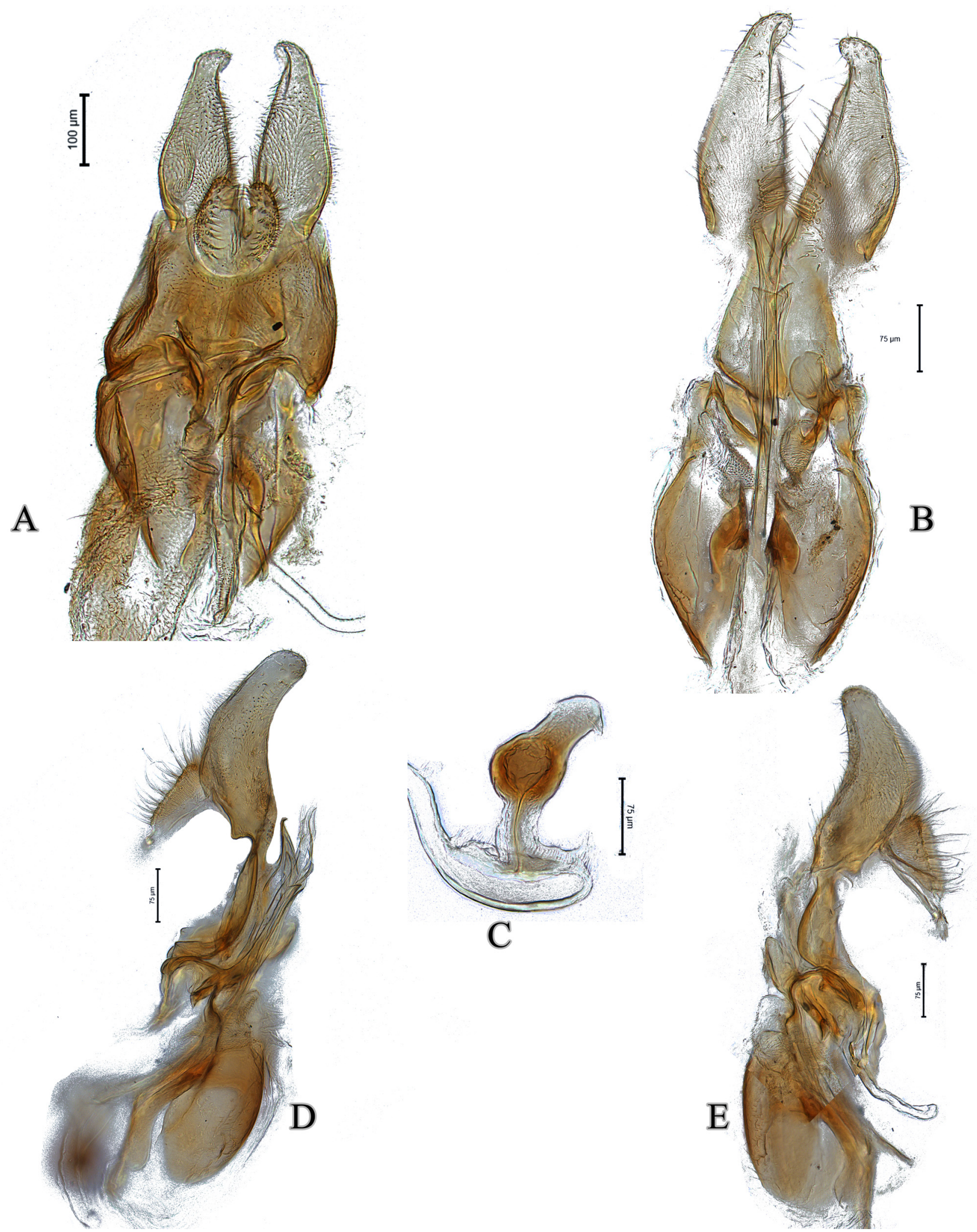

FIGURE 41. Male genitalia of Tomosvaryella teligera (JSS51936, CNC) A) dorsal view, B) ventral view, C) ejaculatory apodeme, D, E) lateral view. 
Specimens examined: IRAN: Kermanshah: Dodan, $35^{\circ} 00^{\prime} \mathrm{N}, 46^{\circ} 12^{\prime} \mathrm{E}, 1011 \mathrm{~m}$ a.s.l., Garden, 5.vii.2016, M. Zardouei, funnel Malaise trap, JSS51938 (1 $0^{\top}$, CNC); Sarpolezahab, 34² $28^{\prime} \mathrm{N}, 45^{\circ} 49^{\prime} \mathrm{E}, 456 \mathrm{~m}$ a.s.1., 14.v.2015, M. Zardouei, Malaise trap, JSS51936-7 (2へ, CNC).

Distribution: Iran, Kazakhstan (Kuznetzov 1994; Skevington 2020) (Fig. 64).

Note: Based on DNA barcoding, this species is genetically similar to T. ellipiensis sp. nov., differing by $5.7 \%$ (pairwise divergence) (Supplementary Table 1).
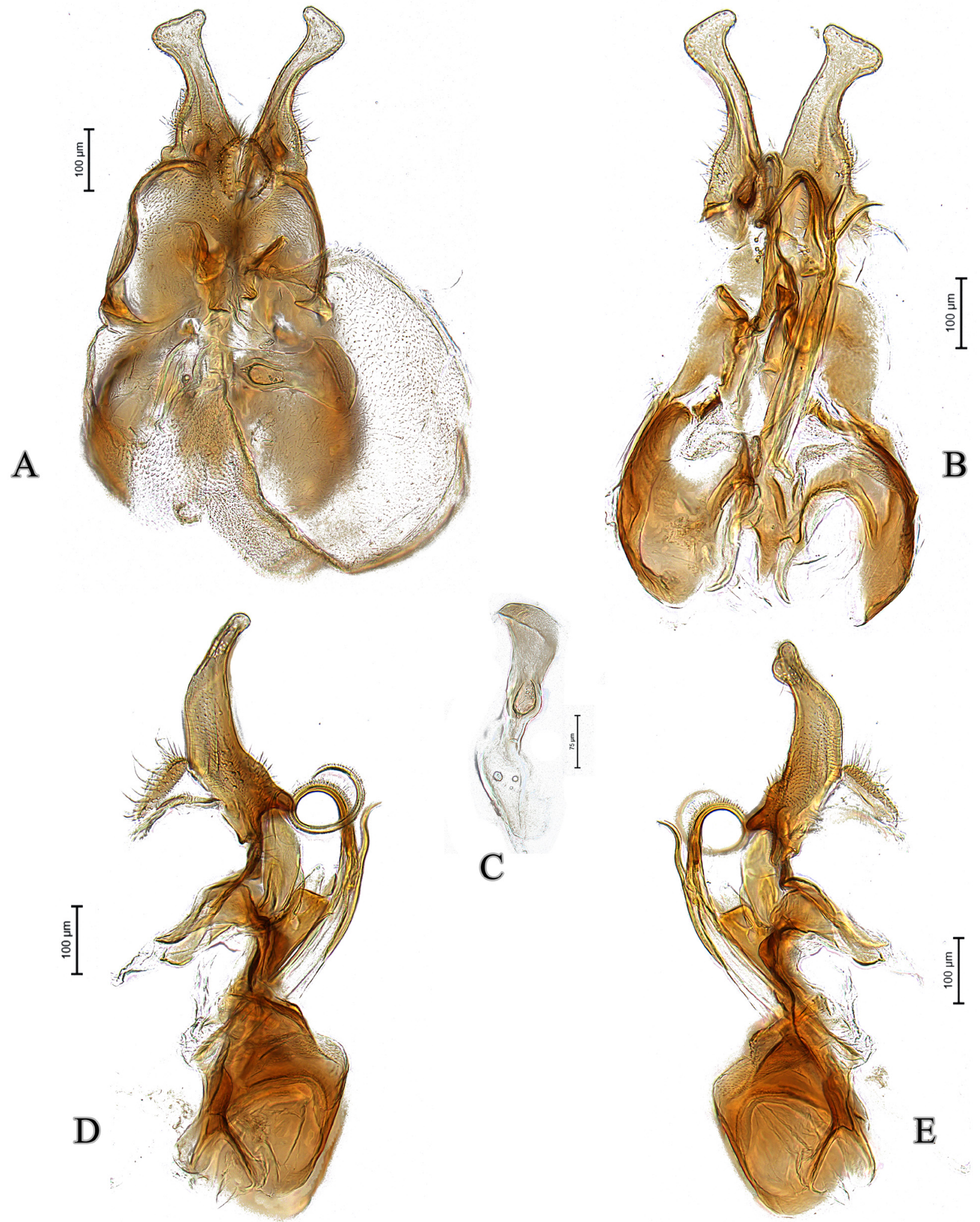

FIGURE 42. Male genitalia of Tomosvaryella transvaalensis (JSS52093, CNC) A) dorsal view, B) ventral view, C) ejaculatory apodeme, D, E) lateral view. 


\section{Tomosvaryella transvaalensis De Meyer, 1993}

Figs 42A-E, 64

Diagnosis: This species can be recognized by the shape of surstyli in dorsal view, constricted in middle, knobshaped apically (Fig. 42A); epandrium wider than long in dorsal view (Fig. 42A); phallus with three ejaculatory ducts, one longer, coiled, bearing small setae in lateral view (Fig. 42D-E); gonopods equal in height (Fig. 42B), hypandrium ovate-shaped with distinct hypandrial apodeme in ventral view (Fig. 42B).

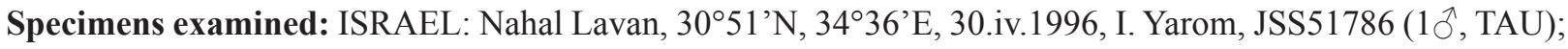

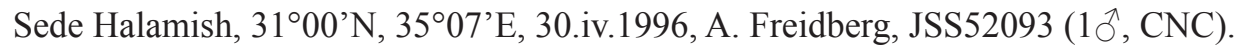

Distribution: Israel, South Africa (Fig. 64).

Note: This sort of disjunct distribution raises some questions. Could this be a crypic pair of species? Is the gap caused by collecting bias? These questions can only be answered by more field work to try to fill gaps, and molecular work to test existing species concepts. We attempted to sequence these specimens but failed. More work is needed.

\section{Tomosvaryella trichotibialis De Meyer, 1995}

Fig. 62

Diagnosis: Following De Meyer (1995), this species can be recognized by the rectangular-shaped surstyli in dorsal view, slightly broadened at base; epandrium as long as wide; straight ejaculatory ducts; hind tibia with long setae apically (De Meyer, 1995: fig. 22a-f).

Distribution: Israel, Morocco, Spain (Skevington 2020) (Fig. 62).

\section{Tomosvaryella unicorna Motamedinia \& Skevington sp. nov.}

Figs 43A-E, 48B, 63, 70E-F

Diagnosis: This species can be recognized by a distinct horn-like prominence in the middle of frons (Fig. 48B); shape of surstyli more elongated in dorsal view (Fig. 43A), rather curved in lateral view (Fig. 43D-E).

Description: MALE: Body length (excluding antennae): $3.5 \mathrm{~mm}$. Head. Scape, pedicel and arista dark brown, flagellum light brown. Pedicel with a pair of short upper pale setae; flagellum tapering and gray-white pollinose $(\mathrm{LF}: \mathrm{WF}=2.2)$. Eyes converging but not meeting and separated by less than diameter of frontal facets. Frons dark silver-gray pollinose, with a distinct prominence in middle (Fig. 48B). Vertex black, lacking pollinosity. Occiput dark and gray pollinose. Thorax. Postpronotal lobe light yellow, gray pollinose with 6-7 yellowish setae along the upper margin (up to $0.04 \mathrm{~mm}$ ). Prescutum, scutum, scutellum black. Scutum with two uniseriate rows of intra-alar setae and two uniseriate rows of dorsocentral setae. Scutellum with 1-2 thin short setae along lateral margin (up to $0.01 \mathrm{~mm}$ ). Subscutellum black, gray pollinose. Pleura brown. Wing. Length: $3.2 \mathrm{~mm}$. LW:MWW = 5.08. Wing almost entirely covered with microtrichia. Cross-vein $\mathrm{r}-\mathrm{m}$ reaches $\mathrm{dm}$ at the middle. $\mathrm{M}_{1}$ moderately undulating in middle. Halter length: $0.37 \mathrm{~mm}$. Whitish, narrowly brown at base. Legs. Coxae dark brown, gray pollinose. Mid coxa with two dark anterior setae. Trochanters dark brown, smooth. Femora brown with light brown apices, gray pollinose. All femora with 1-2 wrinkled indentations at base. Tibiae brown but light brown in basal half, with two ventral rows of short setae on anterior and three rows on posterior side. Hind tibia with 1-2 wrinkled indentations in middle. Tarsi light brown with scattered brown setae at anterior margin, basitarsi lighter than other tarsomeres. Pulvilli yellow. Claws light brown with black tips. Abdomen. Ground color dark brown. Tergite 1 densely gray pollinose, with 4-5 brown lateral setae (up to $0.11 \mathrm{~mm}$ ). Tergites 2 densely gray pollinose in anterior margin, Tergite 3-5 gray pollinose, with scattered brown setae. Sternites light brown laterally and dark brown centrally, gray pollinose. Genitalia. Genital capsule in dorsal view: epandrium and surstyli light brown, gray pollinose. Epandrium wider than long (MLE:MWE $=0.60$ ). Surstyli symmetrical. Both surstyli more elongated, longer than epandrium (Fig. 43A). Left surstylus gently bent in basal third (Fig. 43A). Genital capsule in ventral view: gonopods equal in height (Fig. 43B). Subepandrial sclerite rectangular-shaped (Fig. 43B). Genital capsule in lateral view: both surstyli long, weakly concave (Fig. 43D-E). Phallic guide strong, phallus with three small ejaculatory ducts (Fig. 43D-E). Ejaculatory apodeme tube-like, bent, with a bulb in its middle (Fig. 43C). FEMALE: unknown. 

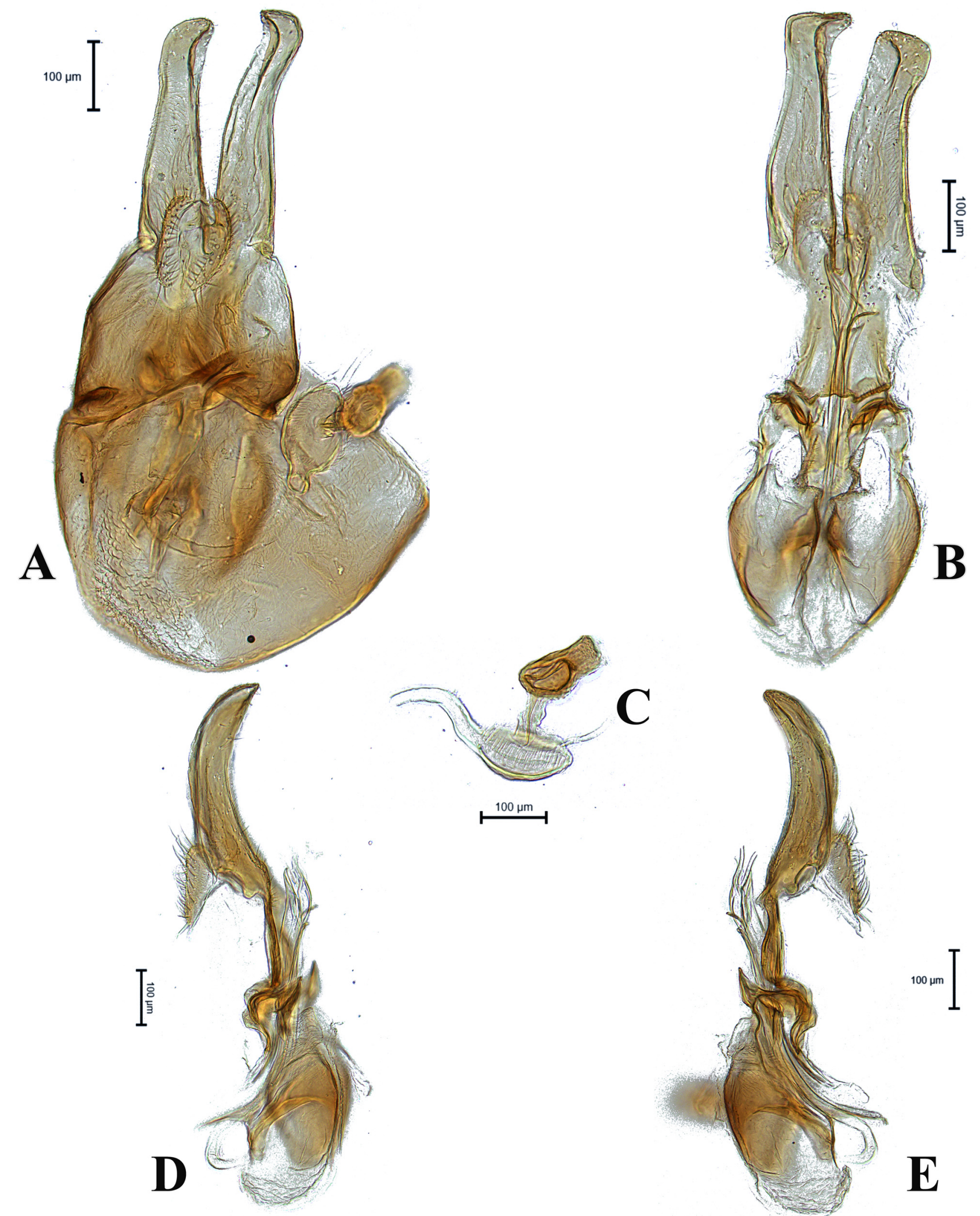

FIGURE 43. Male genitalia of Tomosvaryella unicorna sp. nov., holotype (JSS51821, CNC) A) dorsal view, B) ventral view, C) ejaculatory apodeme, D, E) lateral view.

Etymology: The specific name is derived from the mythical unicorn, in reference to the horn-like prominence on the frons.

Specimen examined: HOLOTYPE: IRAN: Kermanshah: Dagasyave, $35^{\circ} 01^{\prime} \mathrm{N}, 46^{\circ} 07^{\prime} \mathrm{E}, 810 \mathrm{~m}$ a.s.l., 7.vi.2016, M. Zardouei, Malaise trap, JSS51821 (1ð̄, CNC). 
Distribution: Iran (Fig. 63).

Note: Based on DNA barcodes, this species is genetically similar to T. debruyni, differing by $7.4 \%$ (pairwise divergence) (Supplementary Table 1).

\section{Tomosvaryella urdaensis Kuznetzov, 1994}

Fig. 60

Diagnosis: Following Kuznetzov (1994), this species can be recognized by the shape of surstyli in dorsal view, broadened and angled at base, pointed at apices (Majnon-Jahromi et al. 2017b: Fig. 19); both surstyli rounded apically, with a distinct posteroventral projection before its apex in lateral view (Kuznetzov, 1994: Figs 302-303). Tomosvaryella urdaensis appears to be closely related to T. gazliensis (Fig. 15A-D). See diagnosis of T. gazliensis for more details.

Distribution: Iran, Kazakhstan (Skevington 2020) (Fig. 60).

\section{Tomosvaryella vicina (Becker, 1900)}

Figs 44A-F, 64

Diagnosis: This species can be recognized by the shape of surstyli in lateral view, with extended dorsomedial lobe, lobe of right surstylus larger than left one (Fig. 44E-F), both surstyli slightly flatted apically in dorsal view (Fig. 44A-B); phallic guide straight, divided apically with plumose projection shortly before apex in lateral view (Fig. 44E-F); subepandrial sclerite quadratic-shaped in ventral view (Fig. 44C); gonopods equal in height, right wider than left one in ventral view (Fig. 44C).

Specimens examined: IRAN: Sistan \& Baluchestan: Zabol, 31 ${ }^{\circ} 02^{\prime} \mathrm{N}, 61^{\circ} 32^{\prime} \mathrm{E}, 470 \mathrm{~m}$ a.s.1., 24.v.2016, M.

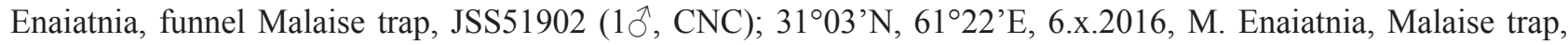

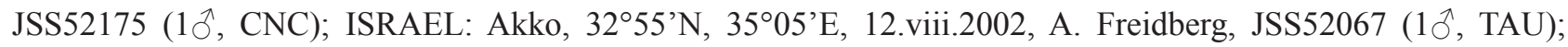

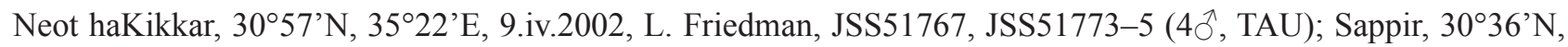
$35^{\circ} 11^{\prime}$ E, 1.v.1997, A. Freidberg, JSS51720 (10̄, TAU).

Distribution: Congo, Egypt, Iran, Israel, Madagascar (Skevington 2020) (Fig. 64).

Note: Based on DNA barcoding, this species is genetically similar to T. hamata, differing by $5.3 \%$ (pairwise divergence) (Supplementary Table 1).

\section{Tomosvaryella yemenensis Motamedinia \& Skevington sp. nov.}

Figs 45A-E, 47D, 55, 71A-B

Diagnosis: This species can be recognized by the shape of surstyli in dorsal view, symmetrical, broadened at base and rather rectangular-shaped (Fig. 45A); epandrium longer than wide (Fig. 45A); long phallic guide with distinct projection before apex, pointing upwards in lateral view (Fig. 45D-E); hind tibia with three to four long dark posterodorsal setae at apices (Fig. 47D).

Description: MALE: Body length (excluding antennae): $3.05 \mathrm{~mm}$. Head. Scape, pedicel and arista dark. Pedicel with three short upper setae and a single lower bristle; flagellum brown, gray pollinose and tapering (LF:WF = 2.4). Eyes meeting for a distance of 12-13 facets. Frons silver-gray pollinose, vertex dark and shine, lacking pollinosity, bearing an elevated ocellar triangle. Occiput dark, gray pollinose with scattered dark seate. Thorax. Postpronotal lobe light brown, with 2-3 short light brown setae along the upper margin (up to $0.01 \mathrm{~mm}$ ). Prescutum and scutum black, silver-gray and brown pollinose, with scattered setae at anterior supra-alar area and uniseriate rows of intra-alar setae. Scutellum black, silver-gray pollinose, with about 10 short dark setae along posterior margin (up to $0.04 \mathrm{~mm}$ ). Subscutellum black and pleura brown. Wing. Wing length: $3.1 \mathrm{~mm}$., LW:MWW = 3.4. Wing almost entirely covered with microtrichia. Halter length: $0.3 \mathrm{~mm}$., light brown, narrowly black at base. Legs. Dark brown, trochanters smooth, femora and tibiae with narrow but distinct pale base and apices, silver pollinose. Fore and mid femora with two rows of dark, peg-like anteroventral spines in apical half. Mid and hind femora with one wrinkled indentation in basal. Hind femur with two wrinkled indentation in basal. Tibiae with two rows of short brown setae 
on anterior and three rows on posterior side. Hind tibia with one or two wrinkled indentations in middle and with three to four long dark posterodorsal setae (up to $0.16 \mathrm{~mm}$ ) at apices (Fig. 47D). Tarsi light brown, distitarsi brown. Abdomen. Ground color dark, tergite 1 silver gray pollinose with a patch of dark setae (5-6) laterally, tergites 4-5 gray pollinose dorsolaterally, slightly extending dorsally along anterior margin. Sternites light brown laterally and brown centrally, gray pollinose. Genitalia. Genital capsule in dorsal view: epandrium and surstyli brown, gray pollinose. Epandrium longer than wide (MLE:MWE $=1.16$ ). Surstyli symmetrical, slightly broadened at base, rectangular-shaped (Fig. 45A). Genital capsule in ventral view: gonopods long and equal in height, phallic guide strong,

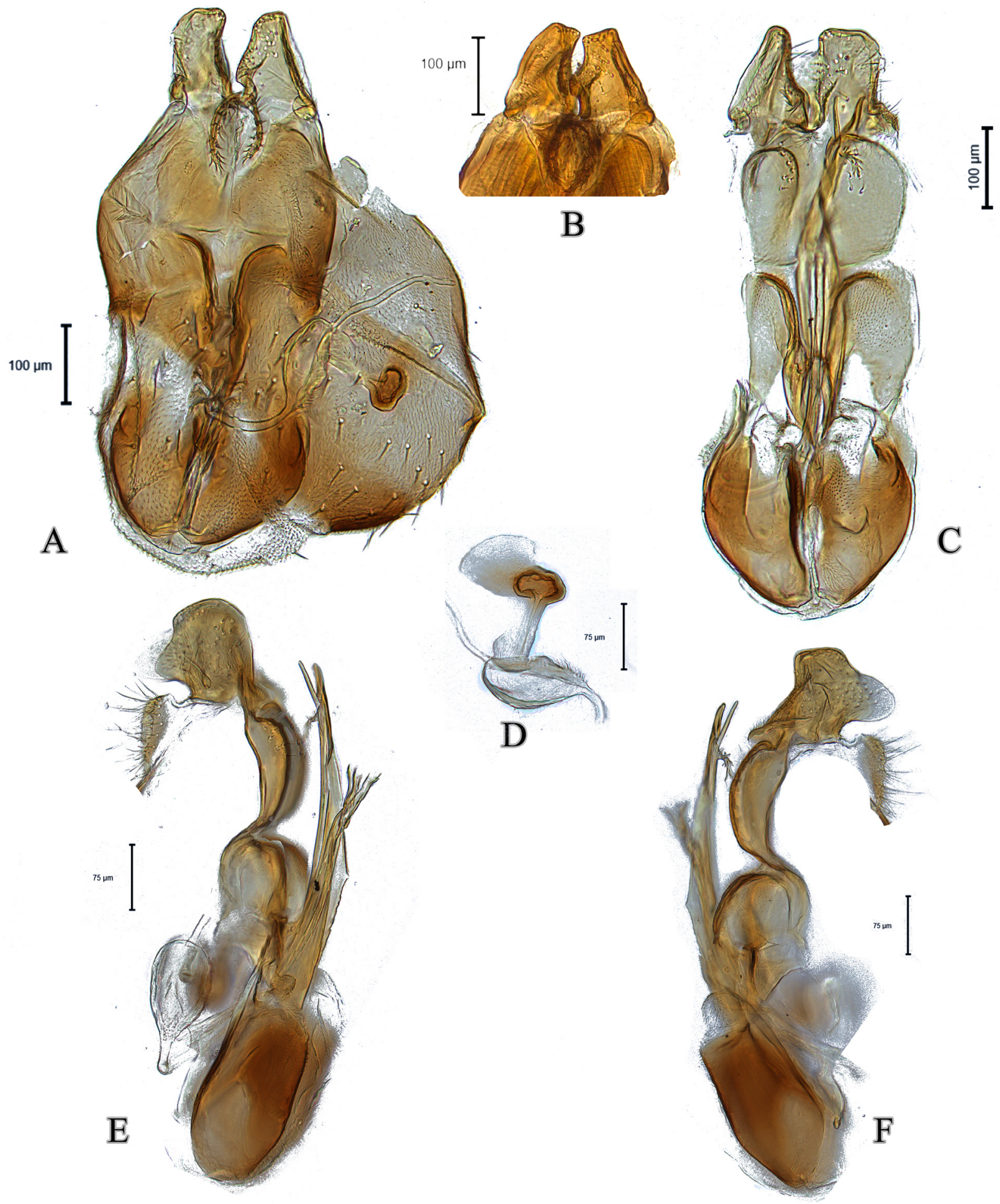

FIGURE 44. Male genitalia of Tomosvaryella vicina (JSS51902, CNC) A) dorsal view, B) surstyli dorsal view, C) ventral view, D) ejaculatory apodeme, E, F) lateral view. 


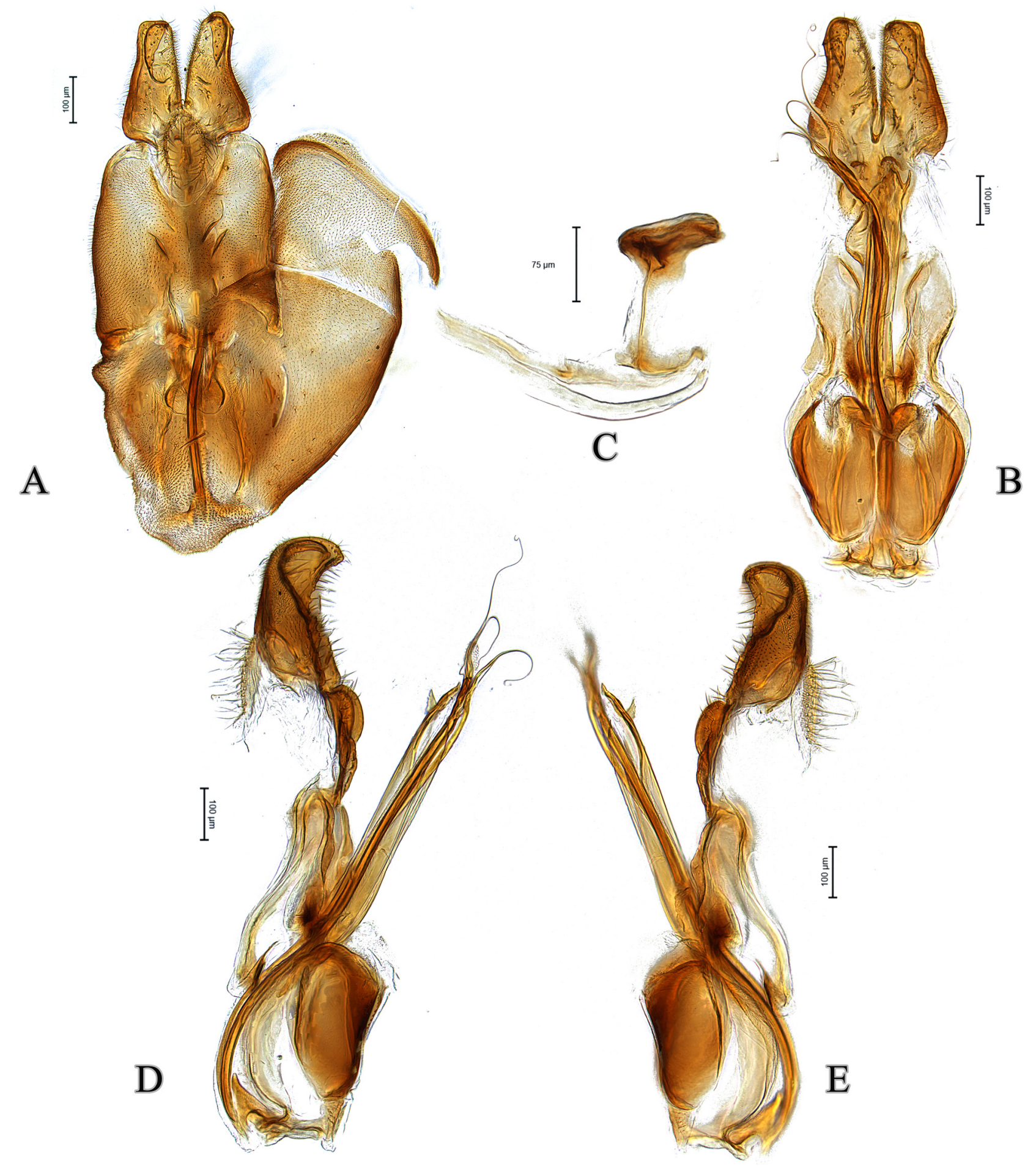

FIGURE 45. Male genitalia of Tomosvaryella yemenensis sp. nov., holotype (CNCD9082, CNC) A) dorsal view, B) ventral view, C) ejaculatory apodeme, D, E) lateral view.

straight, with a finger-like projection in right side before its apex (Fig. 45B). Genital capsule in lateral view: surstyli slightly straight in basal two thirds, curved towards sternite in apical third (Fig. 45D-E). Phallic guide long, with a distinct projection pointed upwards towards surstyli (Fig. 45D-E); phallus with three narrow ejaculatory ducts, twisted apically (Fig. 45D). FEMALE: unknown.

Etymology: The specific epithet refers to Yemen, from where the type series was collected.

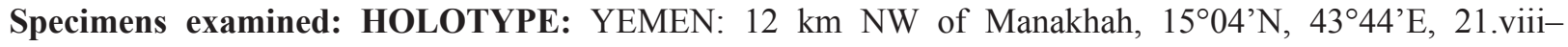


28.x.2002, A. van Harten, Malaise trap, CNCD9082 (1 $\hat{\jmath}$, CNC); PARATYPES: YEMEN: Same data as holotype,

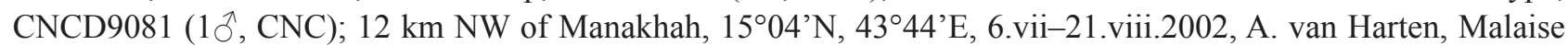
trap, CNCD9079 (10, CNC).

Distribution: Yemen (Fig. 55).

Note: Based on DNA barcodes, this species is genetically most similar to T. pilosiventris, differing by $10.3 \%$ (pairwise divergence) (Supplementary Table 1).
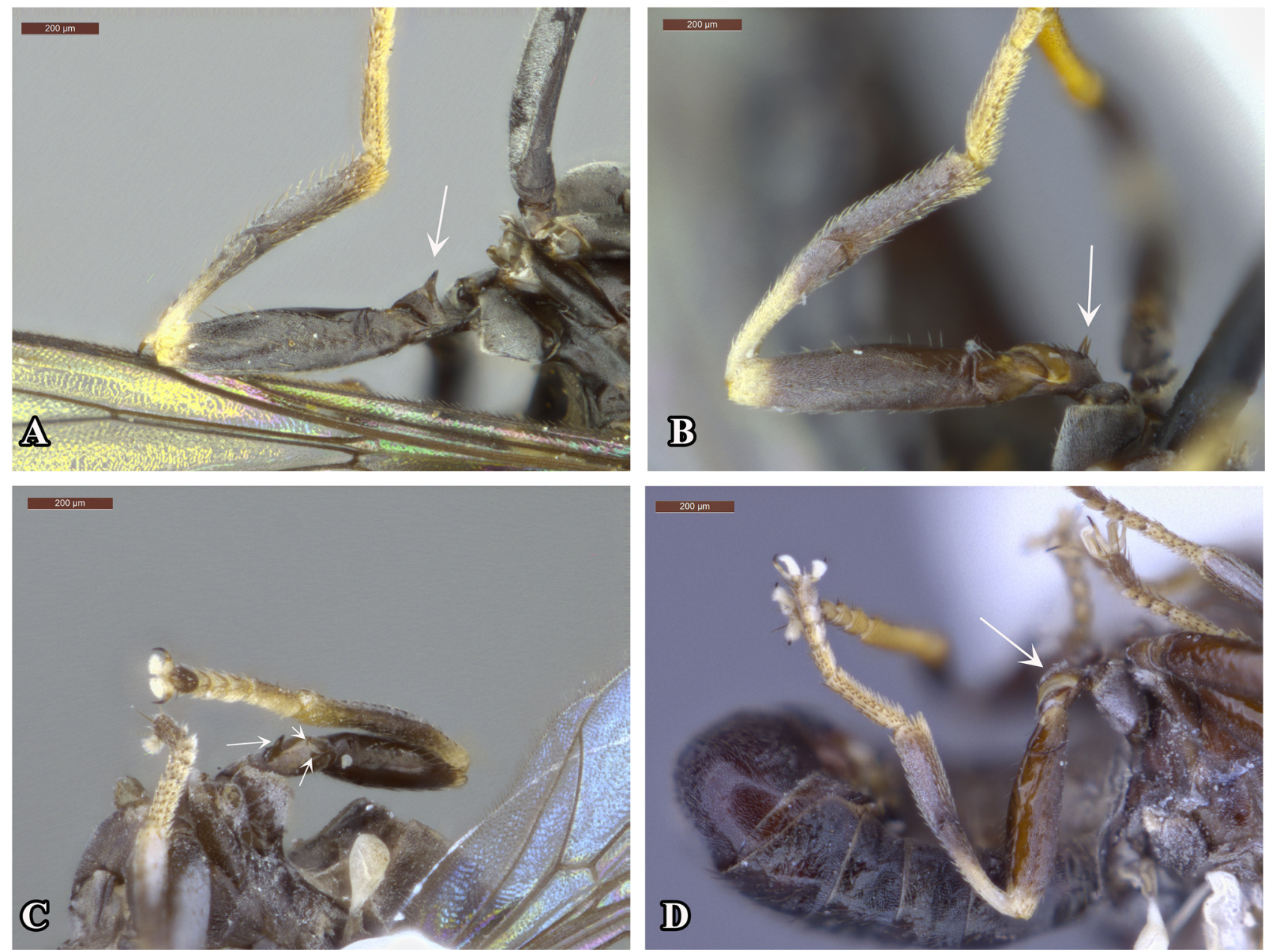

FIGURE 46. Hind leg of Tomosvaryella species in lateral view A) T. acantha sp. nov., holotype (JSS51689, TAU), B) T. littoralis (CNCD214212, CNC), C) T. saudiensis sp. nov., holotype (CNCD147709, CNC), D) T. subvirescens (JSS52318, CNC). 

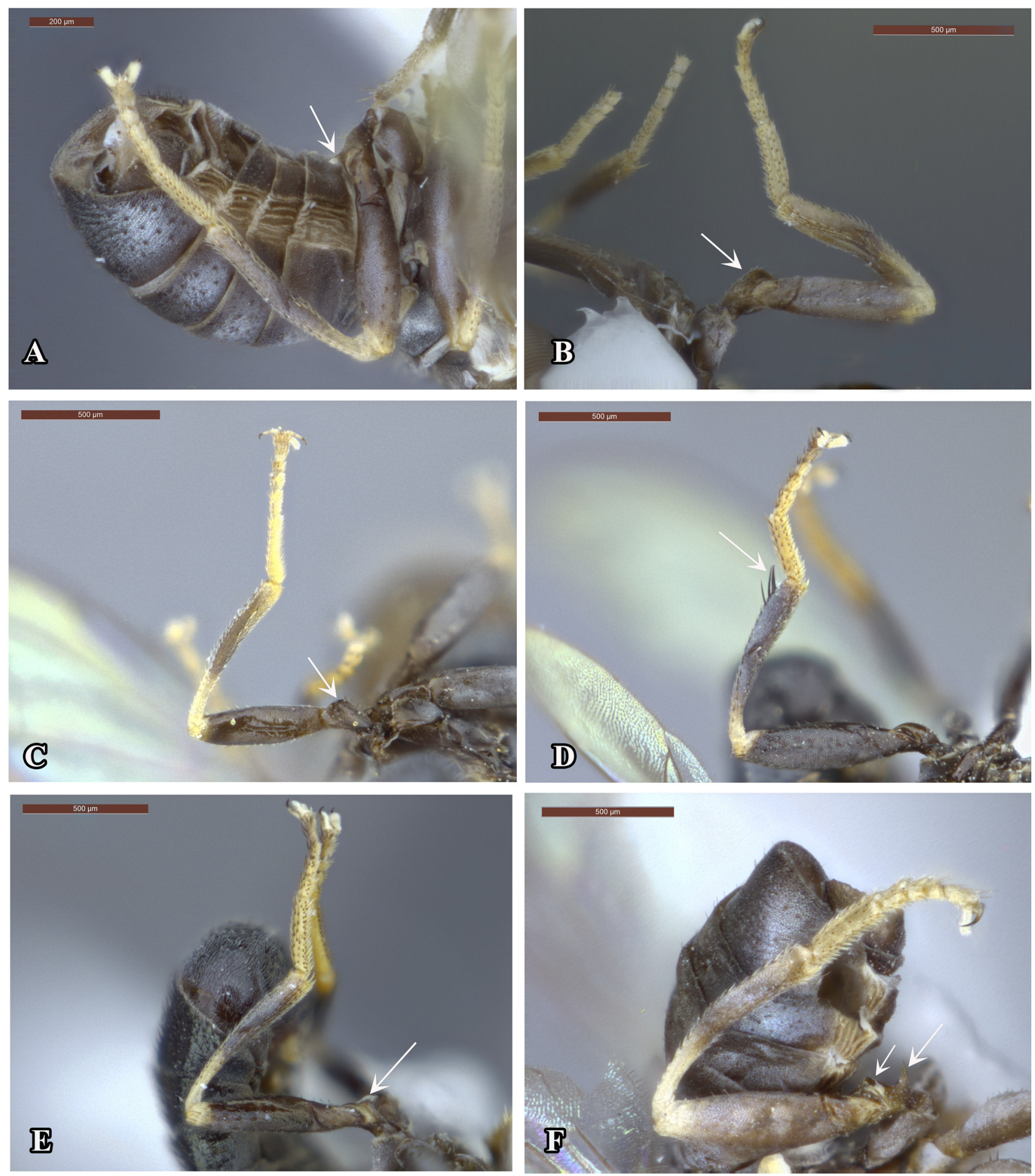

FIGURE 47. Hind leg of Tomosvaryella species in lateral view A) T. jubata (JSS52231, CNC), B) T. hamounensis sp. nov., paratype (JSS51816, CNC), C) T. nodosa (JSS51746, TAU), D) T. yemenensis sp. nov., paratype (CNCD9079, CNC), E) T. pilosiventris (JSS52252, CNC), F) T. spinula sp. nov., holotype (JSS51924, CNC). 

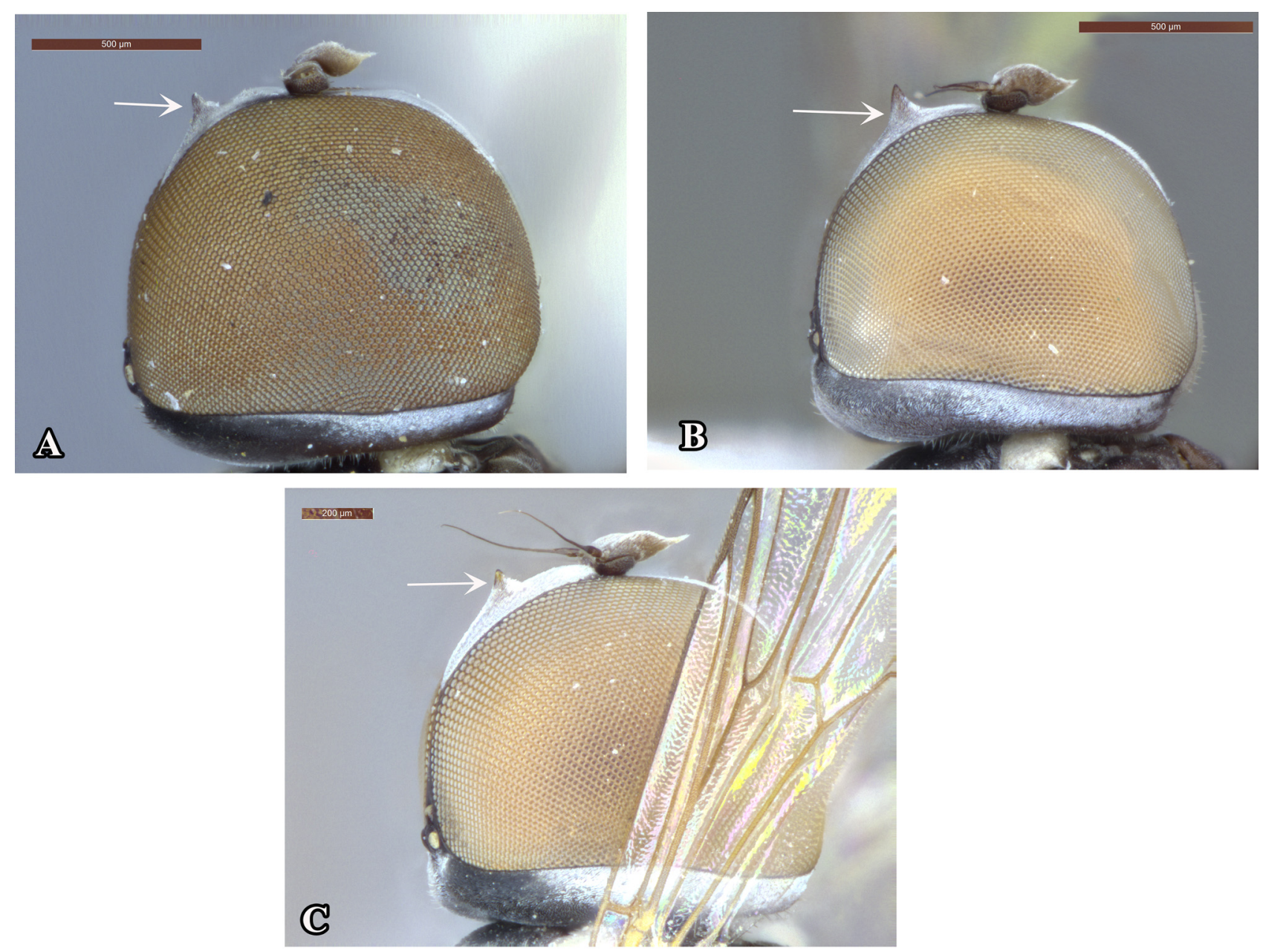

FIGURE 48. Compound eye of Tomosvaryella species in lateral view A) T. debruyni (JSS51736, TAU), B) T. unicorna sp. nov., holotype (JSS51821, CNC), C) T. teligera (JSS51938, CNC).

TABLE 2. Tomosvaryella specimens sequenced for this study

\begin{tabular}{llll}
\hline Species & Sample ID & COI GenBank & $\begin{array}{l}\text { ITS2 GenBank } \\
\text { number }\end{array}$ \\
\hline Tomosvaryella acantha & & MW377952 & - \\
Tomosvaryella ampliasa sp. nov. & JSS51689 & MW377953 & - \\
Tomosvaryella ampliasa sp. nov. & JSS51800 & MW377954 & - \\
Tomosvaryella anahitae sp. nov. & JSS43959 & MW377955 & - \\
Tomosvaryella angulata & JSS51946 & MW377956 & - \\
Tomosvaryella angulata & JSS52190 & MW377958 & - \\
Tomosvaryella angulata & JSS52192 & MW377957 & - \\
Tomosvaryella argyratoides & JSS51917 & MW377959 & - \\
Tomosvaryella argyratoides & JSS51799 & MW377961 & - \\
Tomosvaryella argyratoides & JSS51797 & MW377960 & - \\
Tomosvaryella bistounensis sp. nov. & JSS51796 & MW377963 & - \\
Tomosvaryella bistounensis sp. nov. & JSS51935 & MW377962 & - \\
Tomosvaryella coquilletti & JSS51939 & MW377965 & - \\
Tomosvaryella coquilletti & JSS51844 & MW377964 & MW377966 \\
Tomosvaryella debruyni & JSS51716 & MW6 & MW6
\end{tabular}

......continued on the next page 
TABLE 2. (Continued)

\begin{tabular}{|c|c|c|c|}
\hline Species & Sample ID & $\begin{array}{l}\text { COI GenBank } \\
\text { number }\end{array}$ & $\begin{array}{l}\text { ITS2 GenBank } \\
\text { number }\end{array}$ \\
\hline Tomosvaryella docta & JSS51827 & MW377968 & - \\
\hline Tomosvaryella docta & JSS52189 & MW377969 & - \\
\hline Tomosvaryella docta & JSS51907 & MW377970 & - \\
\hline Tomosvaryella docta & JSS51933 & MW377967 & - \\
\hline Tomosvaryella docta & CNC470645 & MW377971 & - \\
\hline Tomosvaryella ellipiensis $\mathbf{s p .}$ nov. & JSS51945 & MW377972 & - \\
\hline Tomosvaryella emaratensis sp. nov. & CNCD137556 & MW377949 & - \\
\hline Tomosvaryella freidbergi & JSS52177 & MW377974 & - \\
\hline Tomosvaryella freidbergi & JSS52000 & MW377973 & MW378046 \\
\hline Tomosvaryella geniculata & JSS52230 & MW377976 & - \\
\hline Tomosvaryella geniculata & JSS52048 & MW377980 & - \\
\hline Tomosvaryella geniculata & JSS51998 & MW377975 & - \\
\hline Tomosvaryella geniculata & JSS51824 & MW377978 & - \\
\hline Tomosvaryella geniculata & JSS52042 & MW377979 & - \\
\hline Tomosvaryella geniculata & JSS52007 & MW377977 & - \\
\hline Tomosvaryella hamounensis sp. nov. & JSS51896 & MW377987 & - \\
\hline Tomosvaryella hamounensis sp. nov. & JSS51894 & MW377986 & - \\
\hline Tomosvaryella hamounensis sp. nov. & JSS51816 & MW377981 & - \\
\hline Tomosvaryella hamounensis sp. nov. & JSS52178 & MW377985 & - \\
\hline Tomosvaryella hamounensis sp. nov. & JSS52170 & MW377984 & - \\
\hline Tomosvaryella hamounensis sp. nov. & JSS52166 & MW377982 & - \\
\hline Tomosvaryella hamounensis sp. nov. & JSS52164 & MW377983 & - \\
\hline Tomosvaryella inopinata & CNCD8963 & MW377988 & - \\
\hline Tomosvaryella jubata & JSS52231 & MW377989 & - \\
\hline Tomosvaryella jubata & JSS52203 & MW377990 & - \\
\hline Tomosvaryella kuthyi & JSS51877 & MW377999 & - \\
\hline Tomosvaryella kuthyi & JSS52219 & MW377992 & - \\
\hline Tomosvaryella kuthyi & JSS52184 & MW377993 & - \\
\hline Tomosvaryella kuthyi & JSS52181 & MW377997 & - \\
\hline Tomosvaryella kuthyi & JSS52176 & MW377991 & - \\
\hline Tomosvaryella kuthyi & JSS51798 & MW378000 & - \\
\hline Tomosvaryella kuthyi & JSS51941 & MW377998 & - \\
\hline Tomosvaryella kuthyi & JSS52035 & MW377996 & MW378047 \\
\hline Tomosvaryella kuthyi & JSS52029 & MW377994 & - \\
\hline Tomosvaryella kuthyi & JSS51974 & MW377995 & - \\
\hline Tomosvaryella minima & JSS52031 & MW378001 & - \\
\hline Tomosvaryella minima & JSS52012 & MW378002 & - \\
\hline Tomosvaryella minima & JSS52002 & MW378003 & - \\
\hline Tomosvaryella nimroozensis sp. nov. & JSS51819 & MW378004 & - \\
\hline Tomosvaryella nodosa & JSS51962 & MW378006 & - \\
\hline Tomosvaryella nodosa & CNC470688 & MW378007 & - \\
\hline Tomosvaryella nodosa & CNC470473 & MW378008 & - \\
\hline
\end{tabular}


TABLE 2. (Continued)

\begin{tabular}{|c|c|c|c|}
\hline Species & Sample ID & $\begin{array}{l}\text { COI GenBank } \\
\text { number }\end{array}$ & $\begin{array}{l}\text { ITS2 GenBank } \\
\text { number }\end{array}$ \\
\hline Tomosvaryella nodosa & CNC470648 & MW378009 & - \\
\hline Tomosvaryella nodosa & CNC470508 & MW378005 & - \\
\hline Tomosvaryella oshidae sp. nov. & JSS51818 & MW378011 & - \\
\hline Tomosvaryella oshidae sp. nov. & JSS51976 & MW378010 & - \\
\hline Tomosvaryella osteodes $\mathbf{s p . ~ n o v . ~}$ & CNCD175298 & MW378036 & - \\
\hline Tomosvaryella parakuthyi & JSS52082 & MW378014 & - \\
\hline Tomosvaryella parakuthyi & CNC470474 & - & MW378050 \\
\hline Tomosvaryella parakuthyi & $\mathrm{CNC} 470634$ & MW378015 & MW378051 \\
\hline Tomosvaryella parakuthyi & CNC470528 & - & MW378048 \\
\hline Tomosvaryella parakuthyi & CNC470514 & MW378013 & - \\
\hline Tomosvaryella parakuthyi & $\mathrm{CNC} 470481$ & - & MW378049 \\
\hline Tomosvaryella parakuthyi & $\mathrm{CNC} 470621$ & MW378012 & - \\
\hline Tomosvaryella pilosiventris & JSS51875 & MW378017 & - \\
\hline Tomosvaryella pilosiventris & JSS43963 & MW378023 & - \\
\hline Tomosvaryella pilosiventris & JSS52165 & MW378018 & - \\
\hline Tomosvaryella pilosiventris & JSS51953 & MW378022 & - \\
\hline Tomosvaryella pilosiventris & JSS52028 & MW378016 & - \\
\hline Tomosvaryella pilosiventris & JSS51975 & MW378020 & - \\
\hline Tomosvaryella pilosiventris & JSS51961 & MW378021 & - \\
\hline Tomosvaryella pilosiventris & CNCD137547 & MW378019 & - \\
\hline Tomosvaryella pruinosa & JSS51831 & MW378024 & - \\
\hline Tomosvaryella pruinosa & JSS52235 & MW378027 & - \\
\hline Tomosvaryella pruinosa & JSS51732 & MW378026 & - \\
\hline Tomosvaryella pruinosa & JSS52050 & MW378025 & - \\
\hline Tomosvaryella pruinosa & CNC470828 & MW377951 & - \\
\hline Tomosvaryella pruinosa & CNC470591 & MW377950 & - \\
\hline Tomosvaryella pruinosa & $\mathrm{CNC} 470831$ & MW377947 & - \\
\hline Tomosvaryella pruinosa & CNC470475 & MW377948 & - \\
\hline Tomosvaryella pusilla & JSS51869 & MW378029 & - \\
\hline Tomosvaryella pusilla & JSS52171 & MW378028 & - \\
\hline Tomosvaryella pusilla & CNCD137592 & MW378033 & - \\
\hline Tomosvaryella saudiensis sp. nov. & CNCD147709 & MW378030 & - \\
\hline Tomosvaryella soziana $\mathbf{s p . ~ n o v . ~}$ & JSS52205 & MW378032 & - \\
\hline Tomosvaryella soziana $\mathbf{s p . ~ n o v . ~}$ & JSS52193 & MW378031 & - \\
\hline Tomosvaryella spinula $\mathbf{s p . ~ n o v . ~}$ & JSS51820 & MW378035 & - \\
\hline Tomosvaryella spinula $\mathbf{s p . ~ n o v . ~}$ & JSS51924 & MW378034 & - \\
\hline Tomosvaryella subtransvaalensis $\mathbf{s p . ~ n o v . ~}$ & JSS51690 & MW378037 & - \\
\hline Tomosvaryella subvirescens & JSS51916 & MW378039 & - \\
\hline Tomosvaryella subvirescens & CNCD137125 & MW378038 & - \\
\hline Tomosvaryella susa $\mathbf{s p . ~ n o v . ~}$ & JSS52217 & MW378040 & - \\
\hline Tomosvaryella teligera & JSS51936 & MW378041 & - \\
\hline Tomosvaryella teligera & JSS51938 & MW378042 & - \\
\hline
\end{tabular}


TABLE 2. (Continued)

\begin{tabular}{llll}
\hline Species & Sample ID & COI GenBank & $\begin{array}{l}\text { ITS2 GenBank } \\
\text { number }\end{array}$ \\
\hline Tomosvaryella unicorna sp. nov. & JSS51821 & MW378043 & - \\
Tomosvaryella vicina & JSS52175 & MW378044 & - \\
Tomosvaryella yemenensis sp. nov. & CNCD9081 & MW378045 & - \\
\hline
\end{tabular}

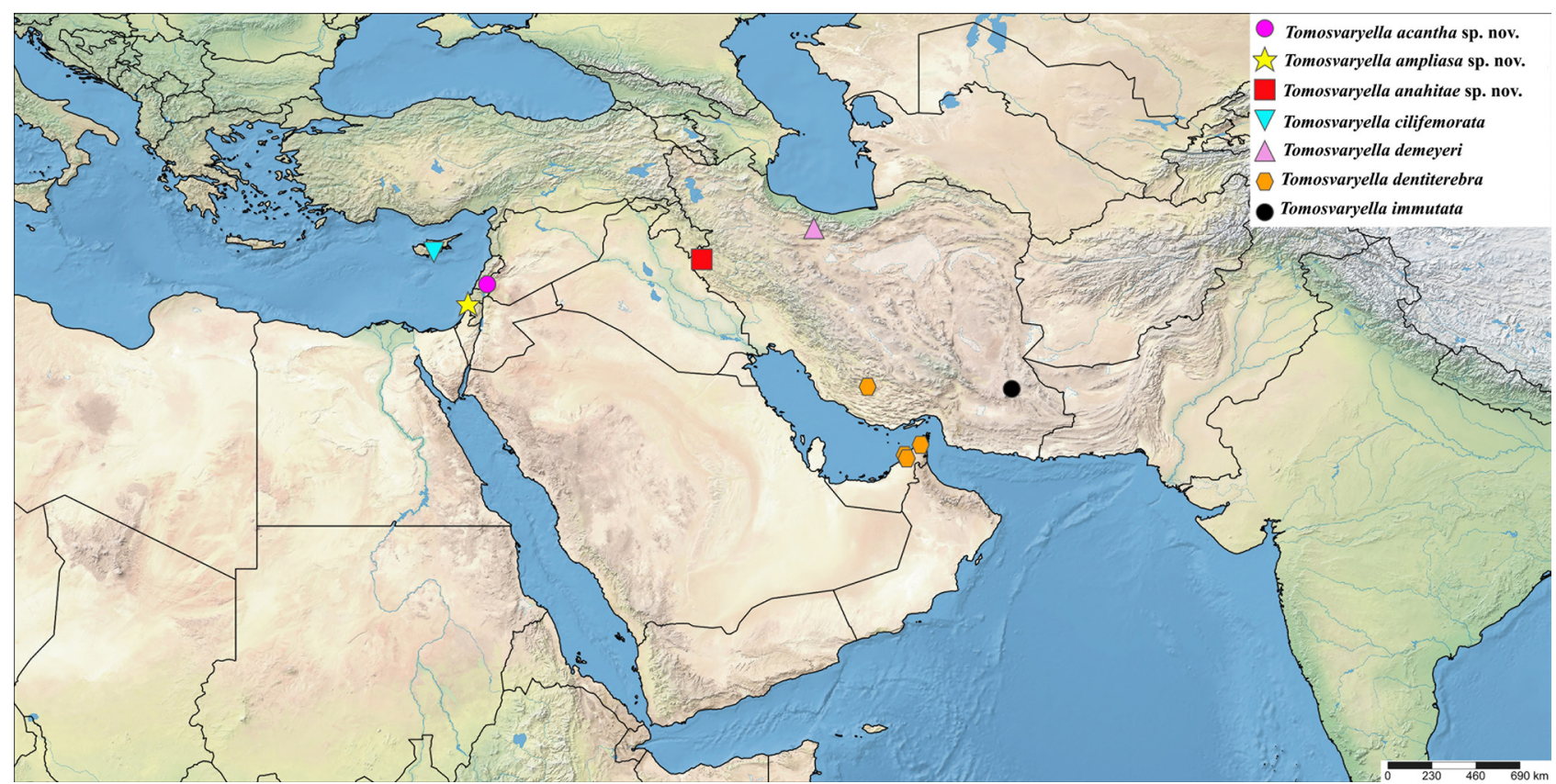

FIGURE 49. Distribution of Tomosvaryella acantha sp. nov., T. ampliasa sp. nov., T. anahitae sp. nov., T. cilifemorata, T. demeyeri, T. dentiterebra, T. immutata in the Middle East.

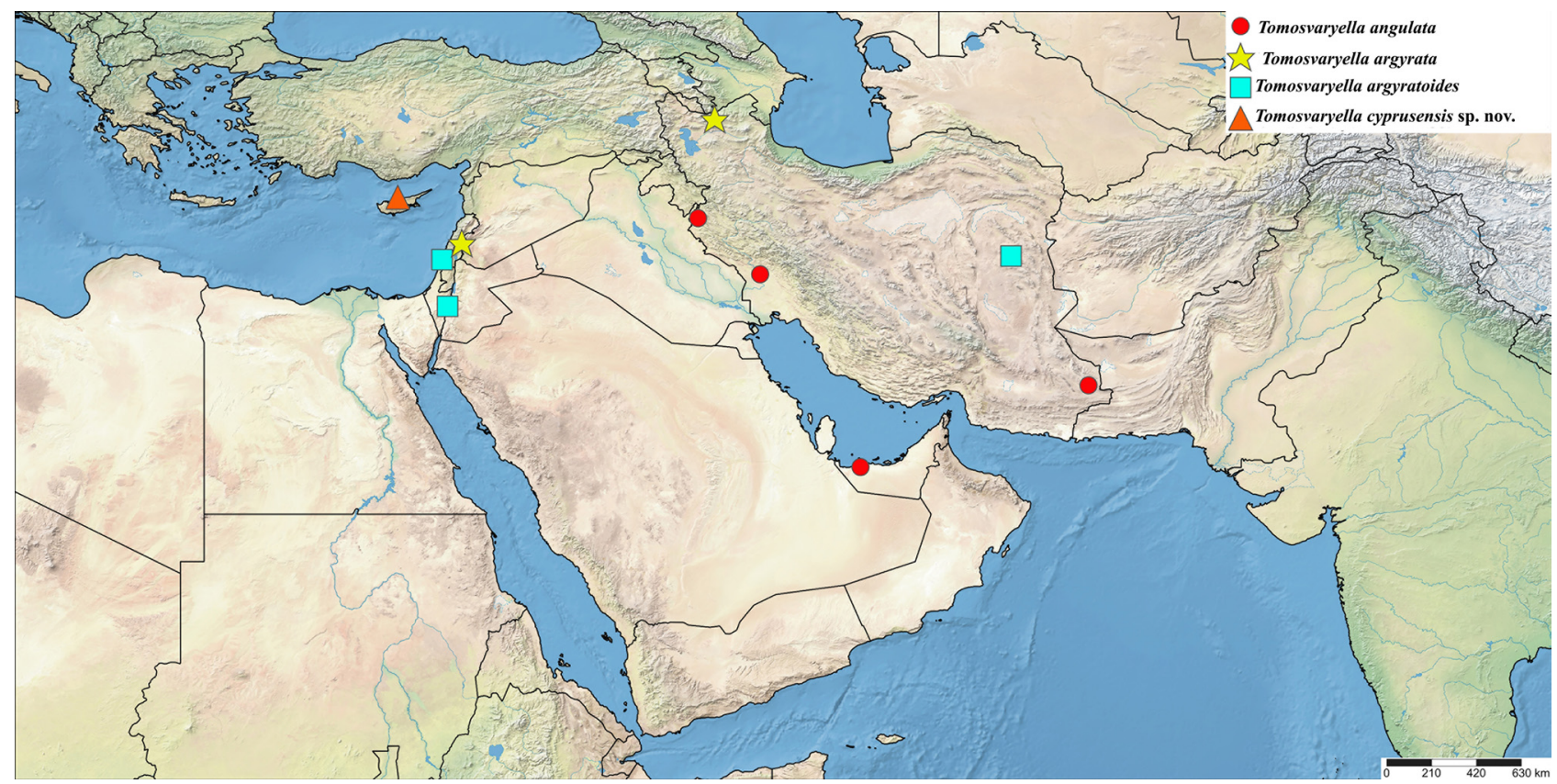

FIGURE 50. Distribution of Tomosvaryella angulata, T. argyrata, T. argyratoides, T. cyprusensis sp. nov. in the Middle East. 


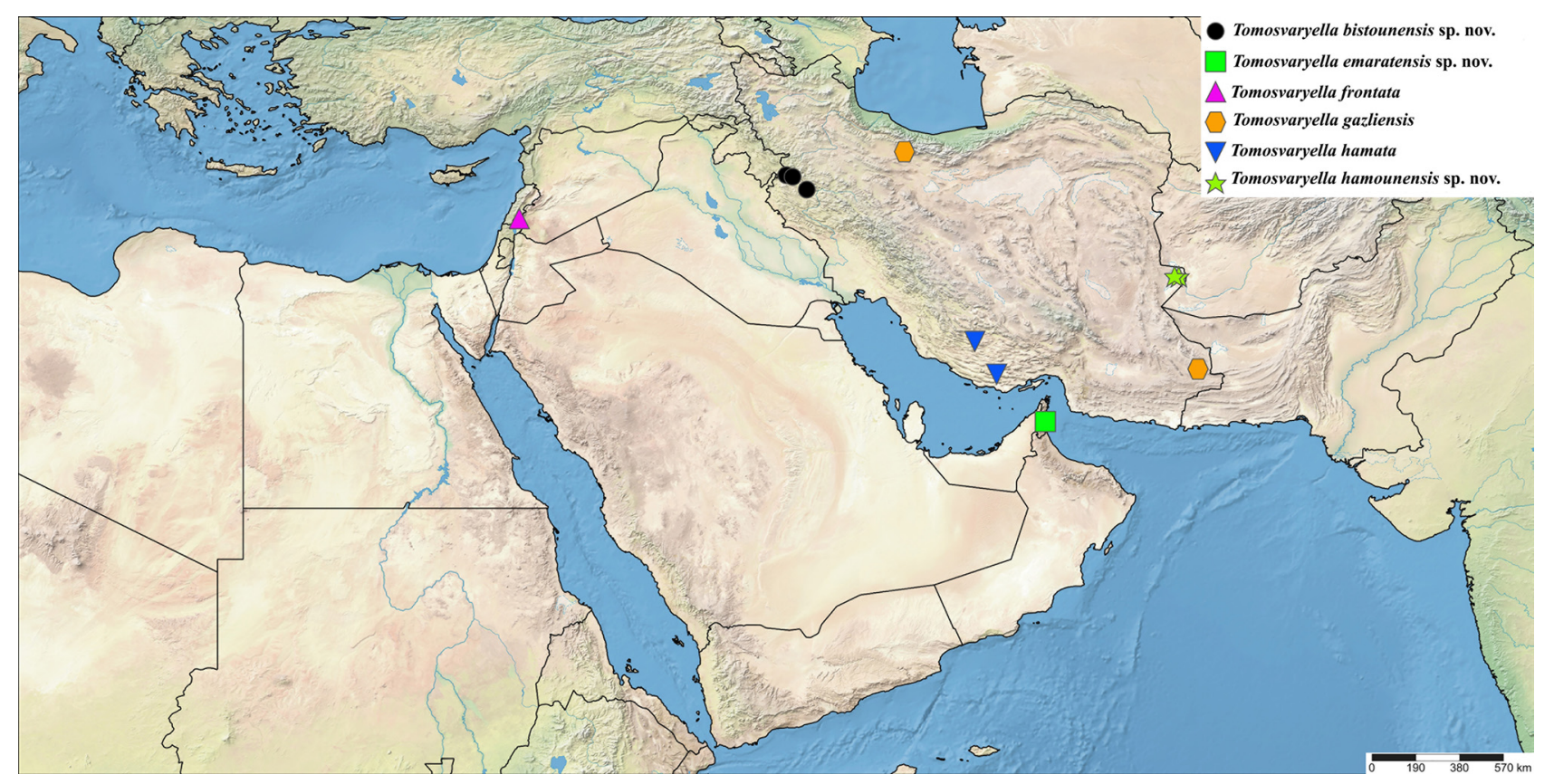

FIGURE 51. Distribution of Tomosvaryella bistounensis sp. nov., T. emaratensis sp. nov., T. frontata, T. gazliensis, T. hamata, T. hamounensis sp. nov. in the Middle East.

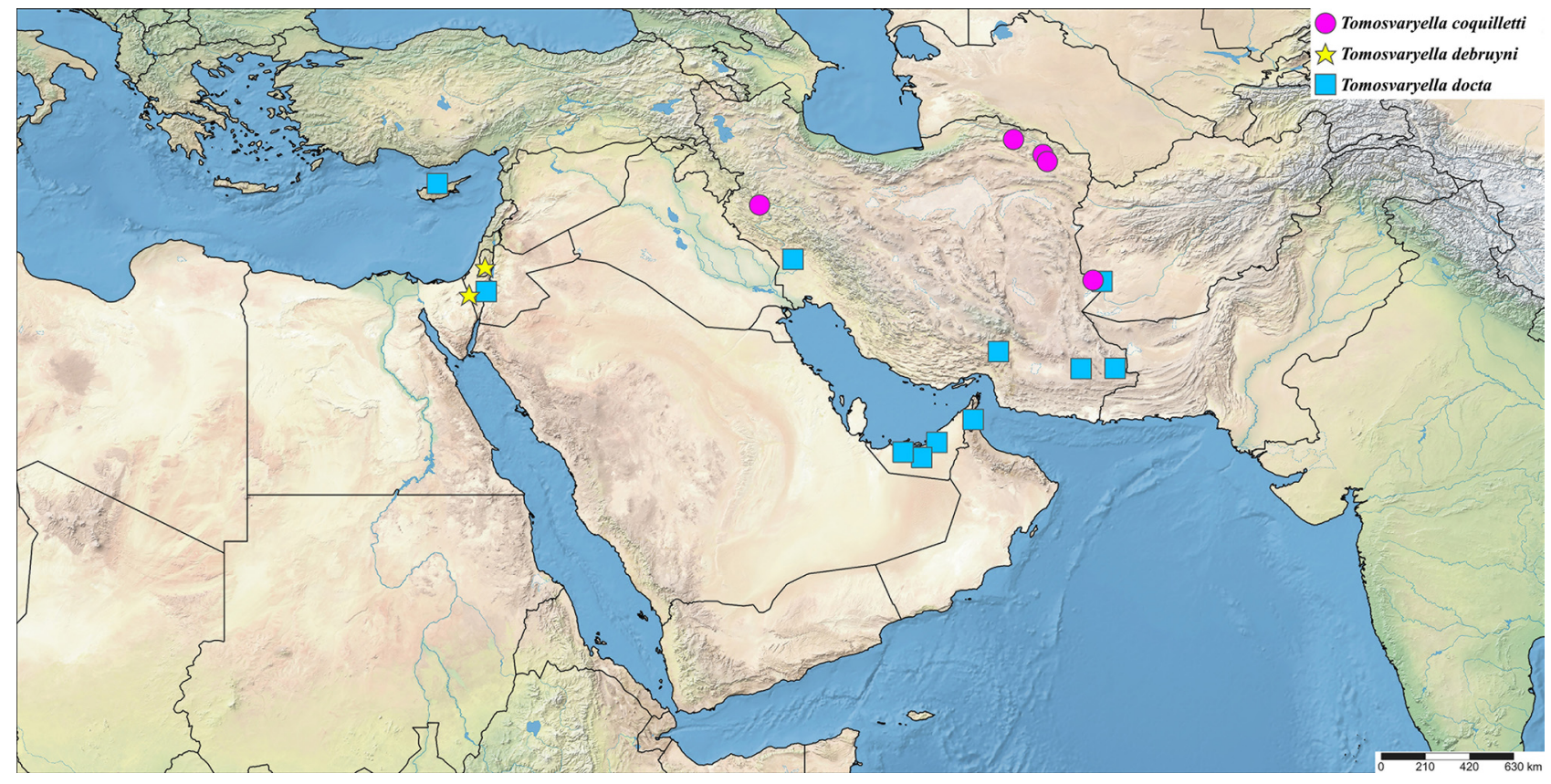

FIGURE 52. Distribution of Tomosvaryella coquilletti, T. debruyni, T. docta in the Middle East. 


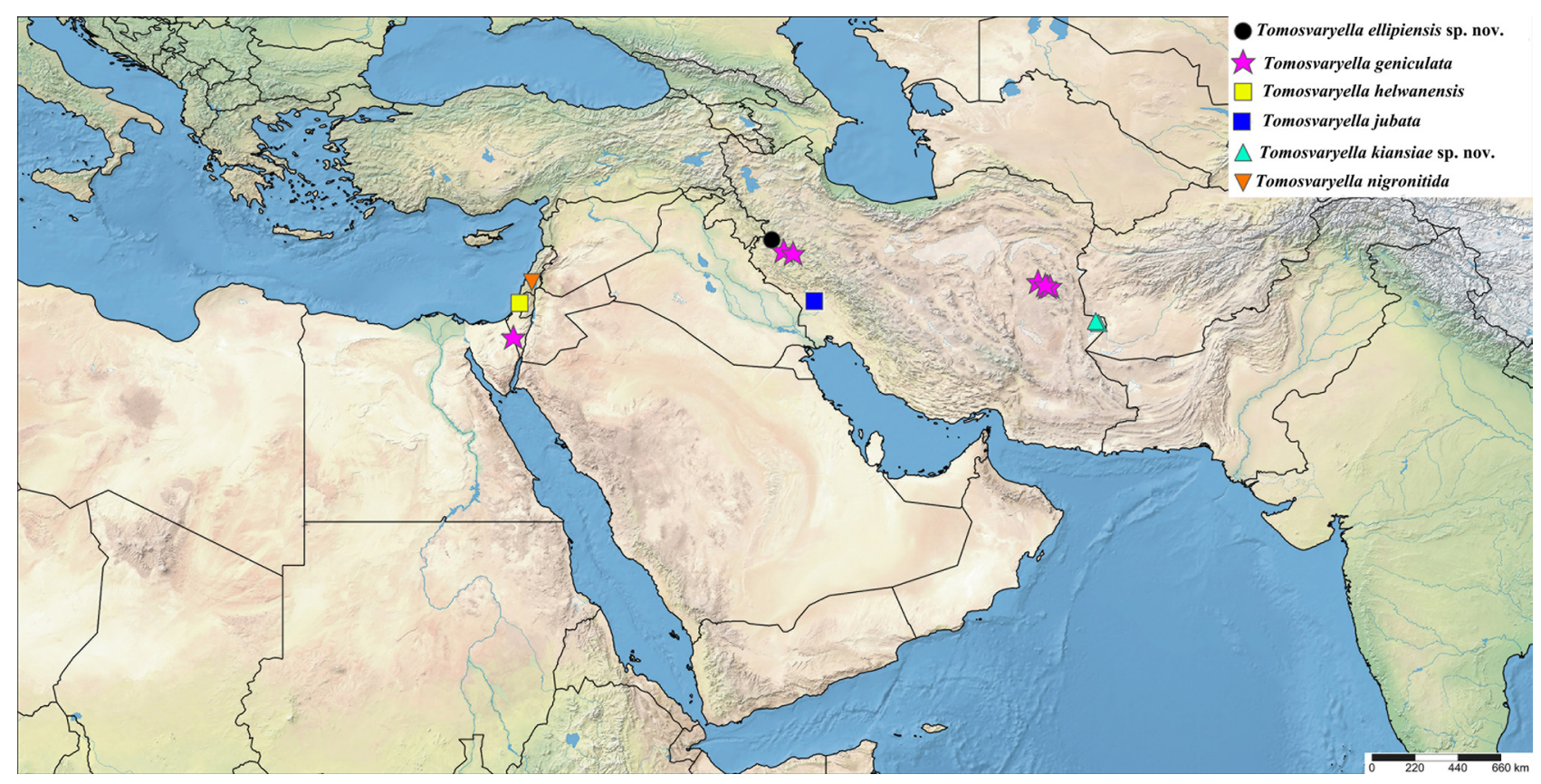

FIGURE 53. Distribution of Tomosvaryella ellipiensis sp. nov., T. geniculata, T. helwanensis, T. jubata, T. kiansiae sp. nov., T. nigronitida in the Middle East.

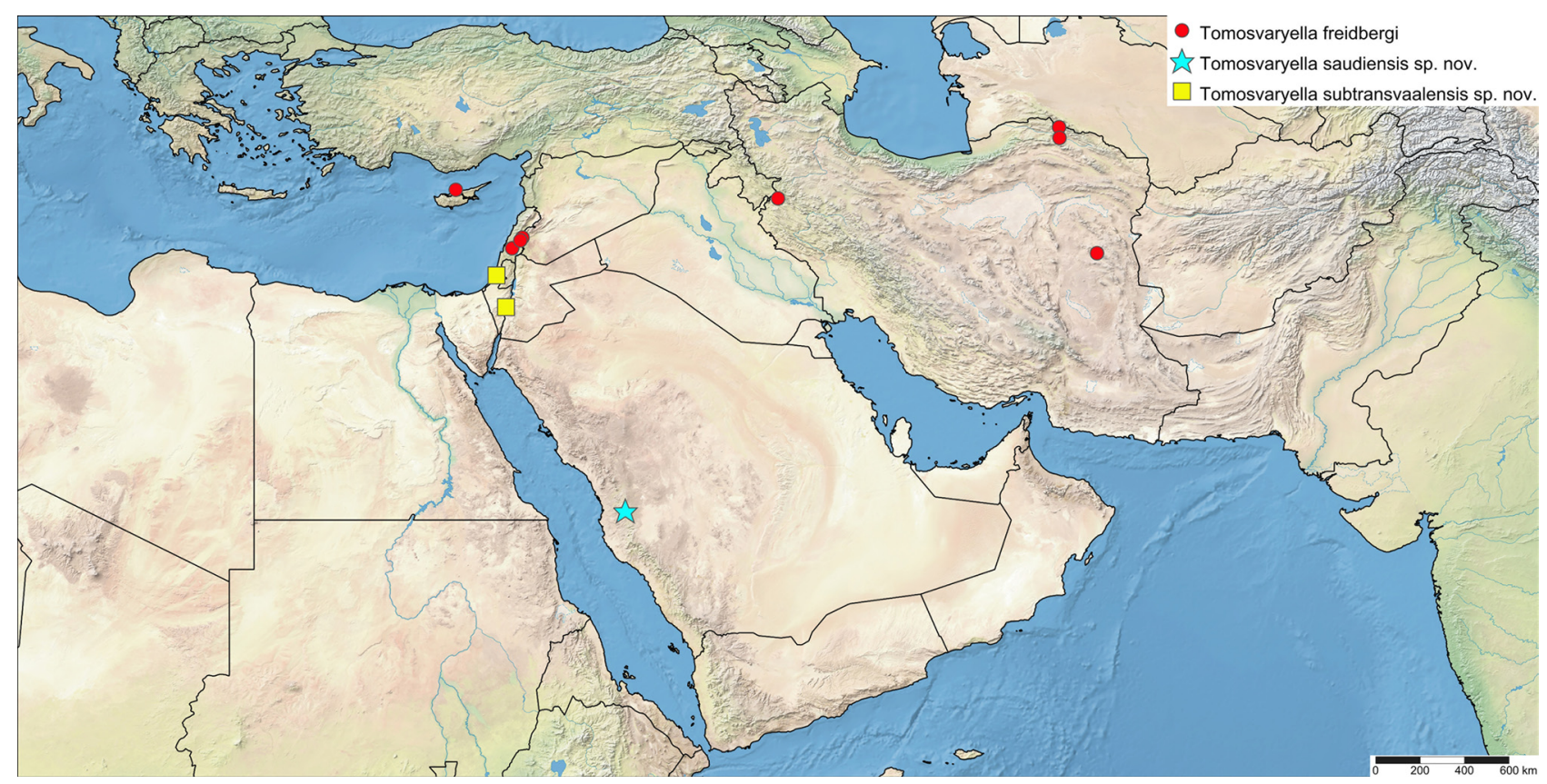

FIGURE 54. Distribution of Tomosvaryella freidbergi, T. saudiensis sp. nov., T. subtransvaalensis sp. nov. in the Middle East. 


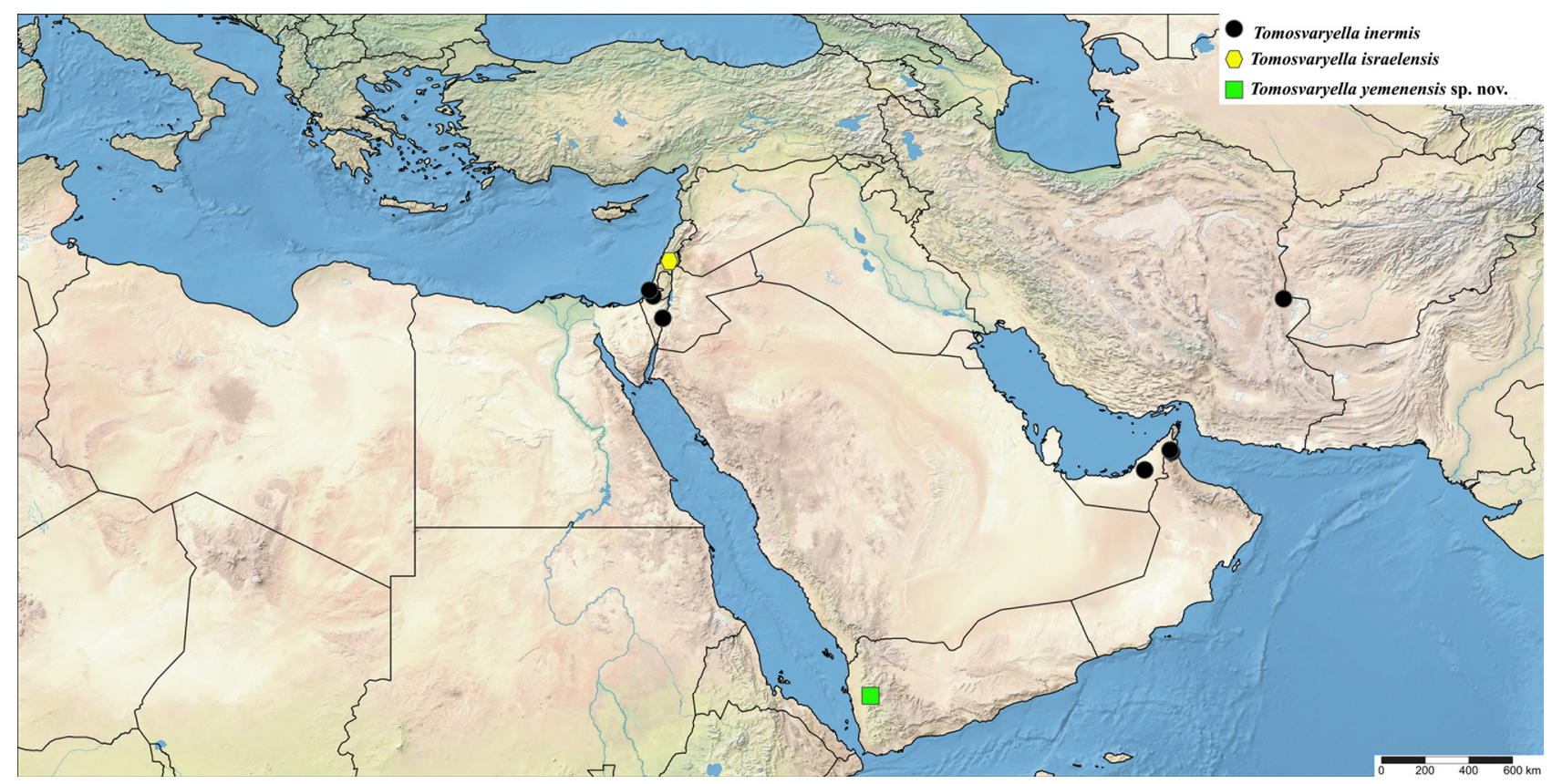

FIGURE 55. Distribution of Tomosvaryella inermis, T. israelensis, T. yemenensis sp. nov. in the Middle East.

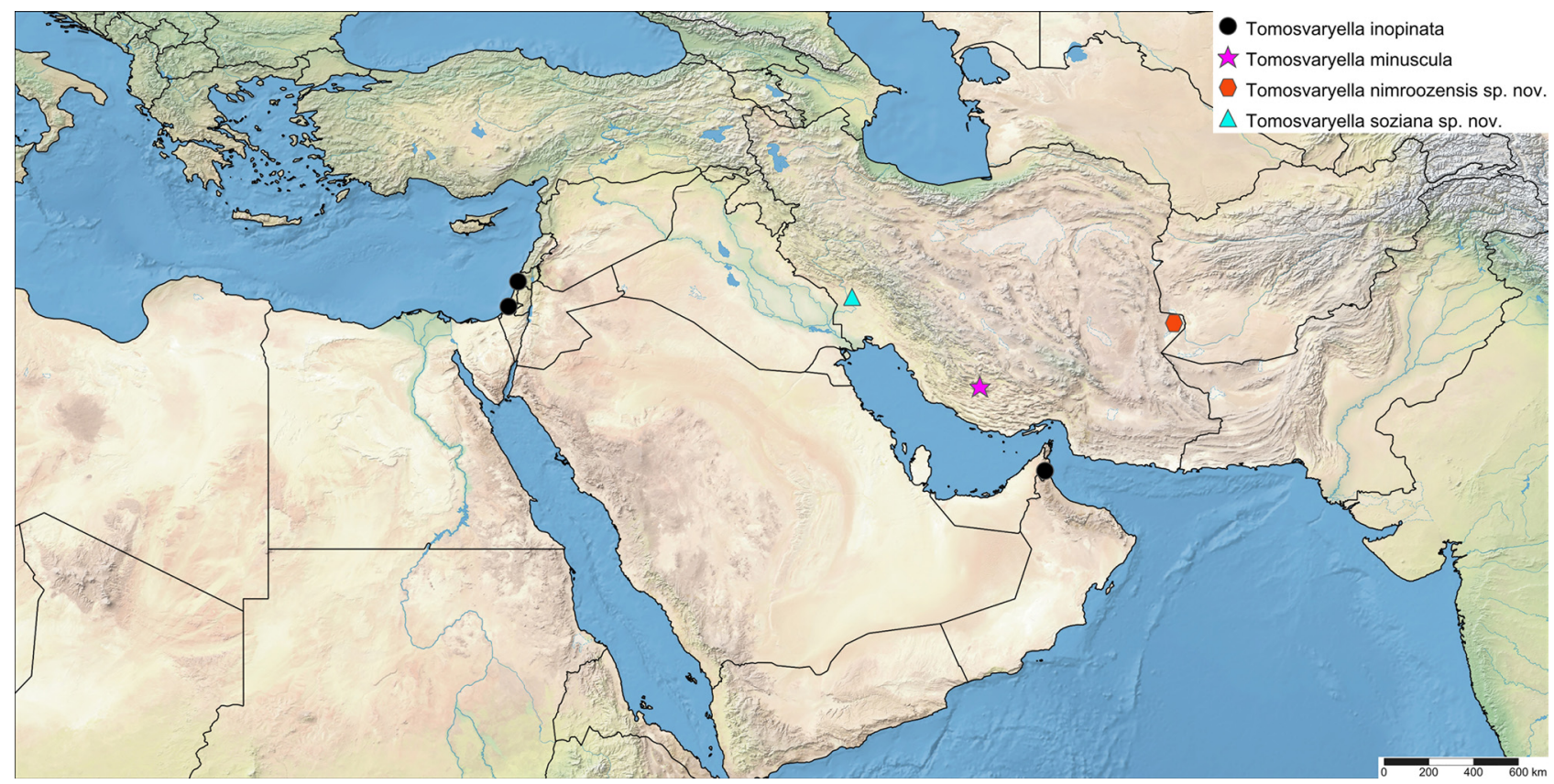

FIGURE 56. Distribution of Tomosvaryella inopinata, T. minuscula, T. nimroozensis sp. nov., T. soziana $\mathbf{s p .}$ nov. in the Middle East. 


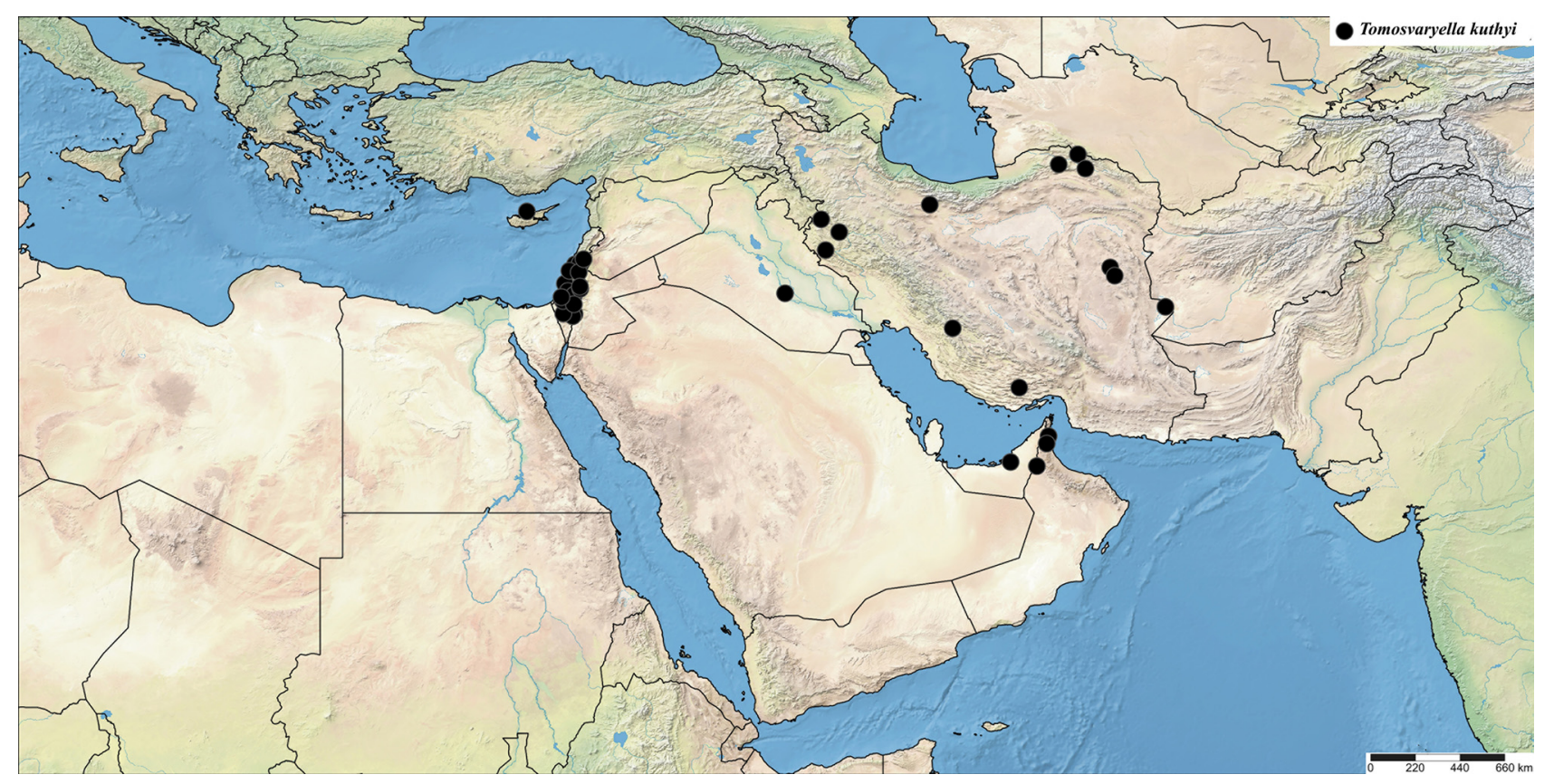

FIGURE 57. Distribution of Tomosvaryella kuthyi in the Middle East.

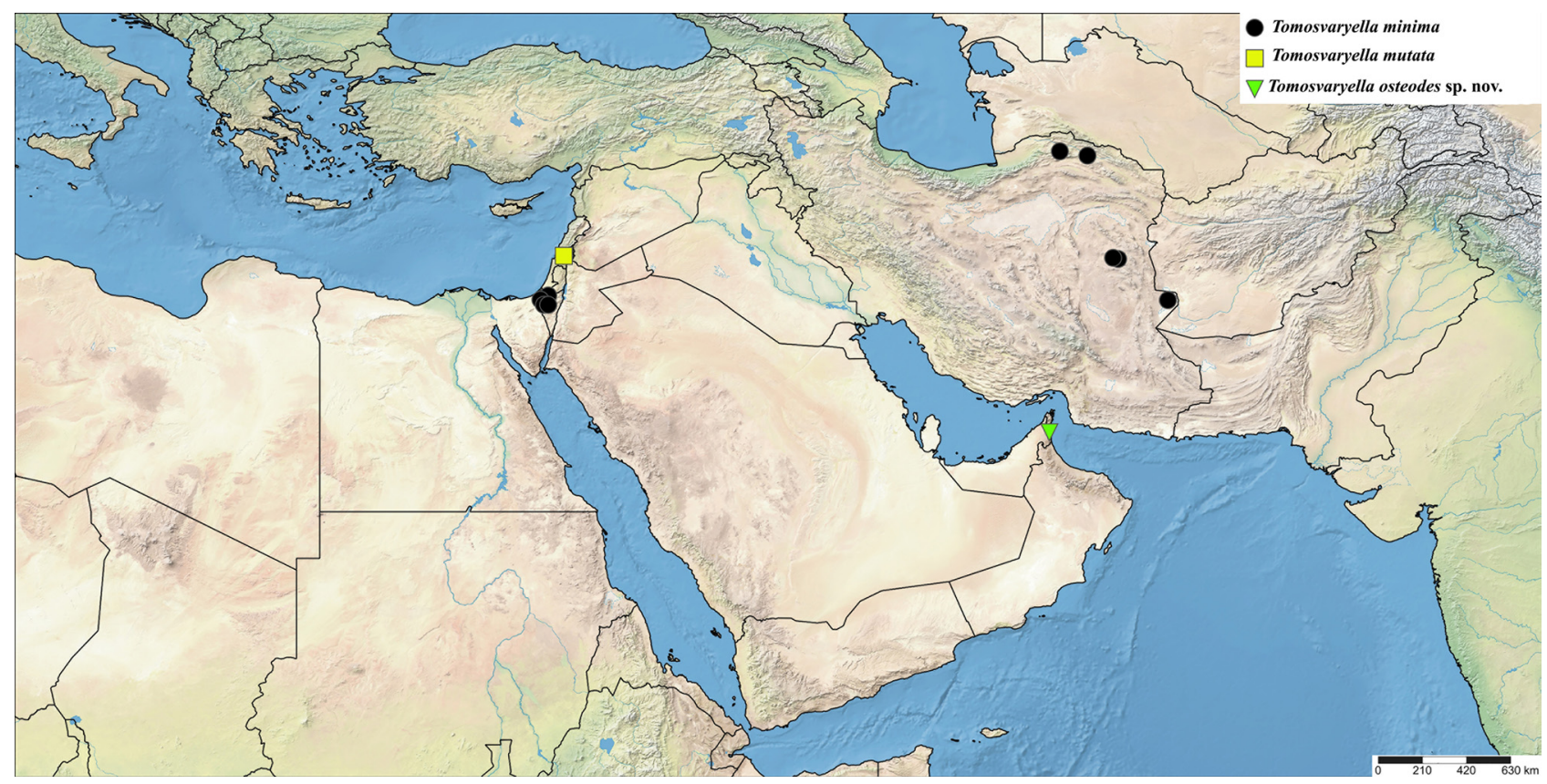

FIGURE 58. Distribution of Tomosvaryella minima, T. mutata, T. osteodes sp. nov. in the Middle East. 


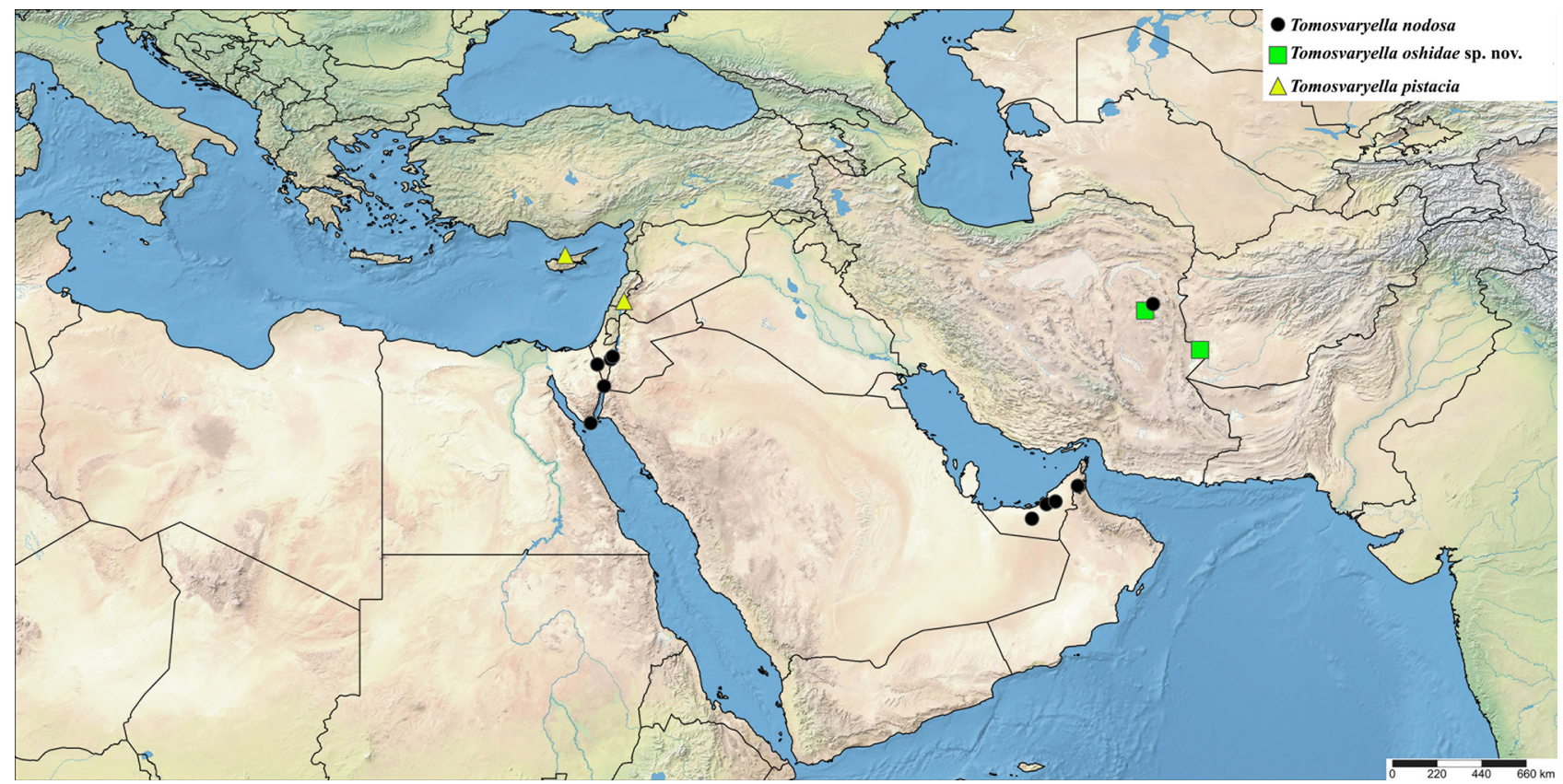

FIGURE 59. Distribution of Tomosvaryella nodosa, T. oshidae sp. nov., T. pistacia in the Middle East.

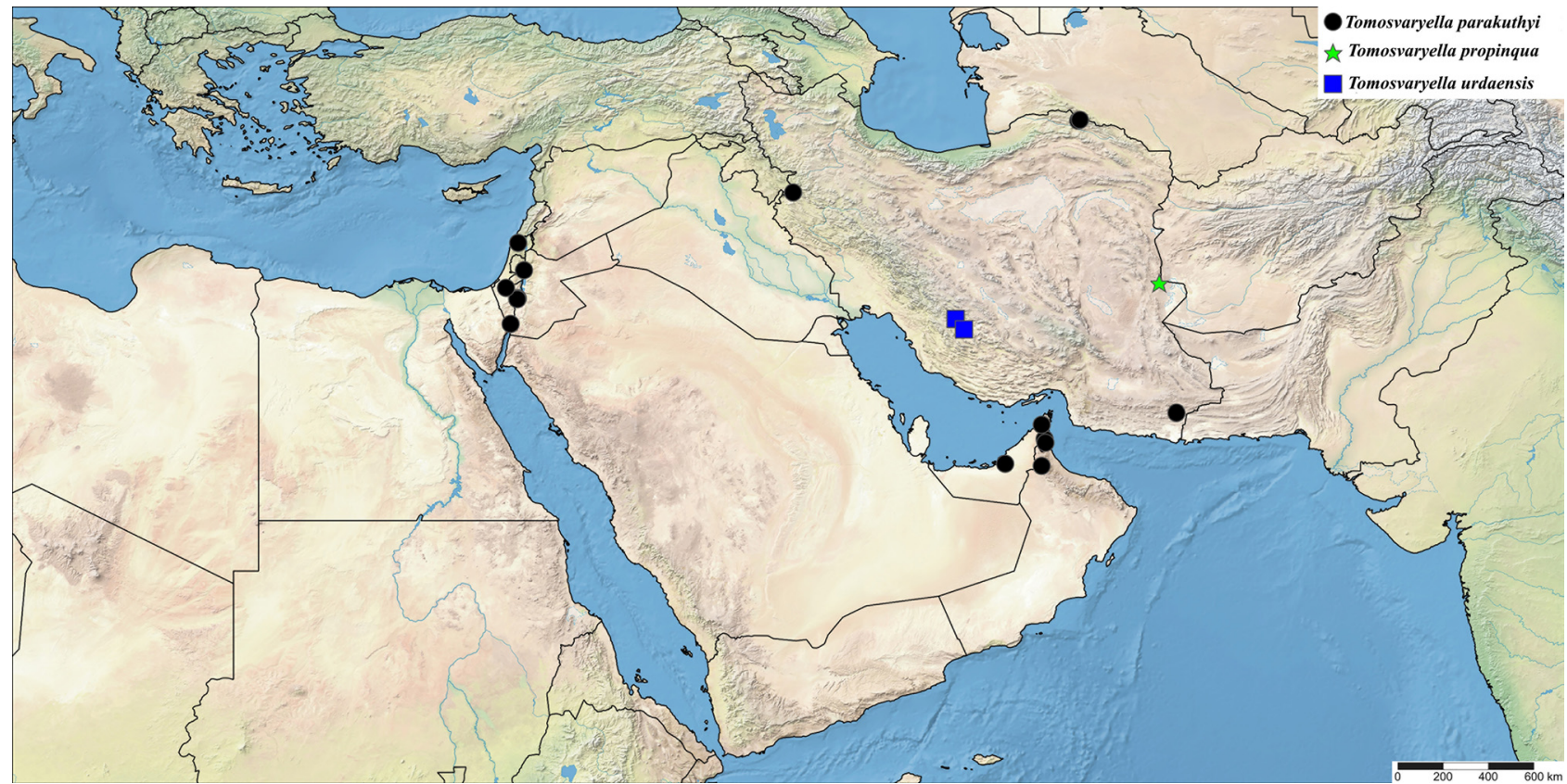

FIGURE 60. Distribution of Tomosvaryella parakuthyi, T. propinqua, T. urdaensis in the Middle East. 


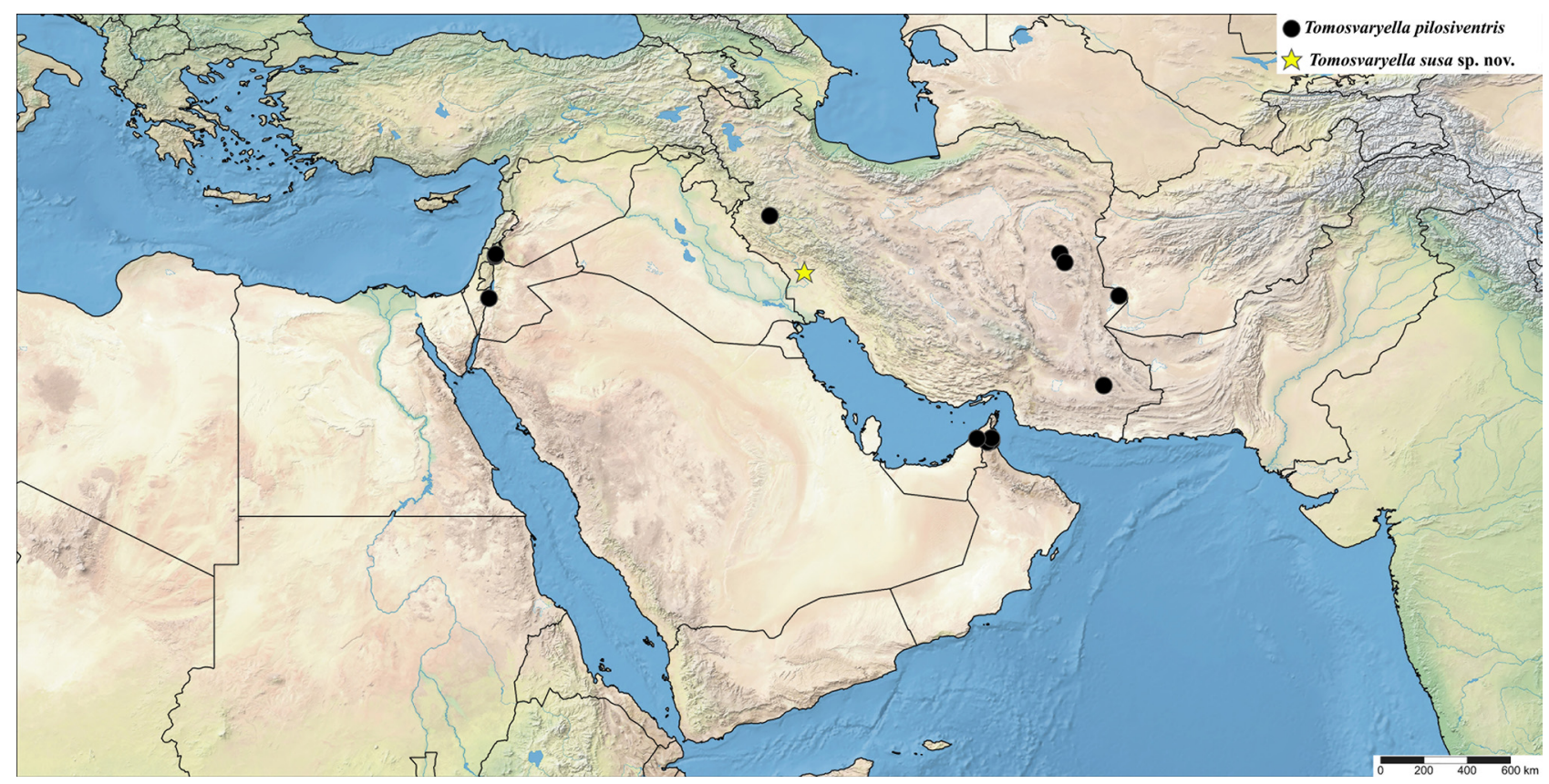

FIGURE 61. Distribution of Tomosvaryella pilosiventris, T. susa sp. nov. in the Middle East.

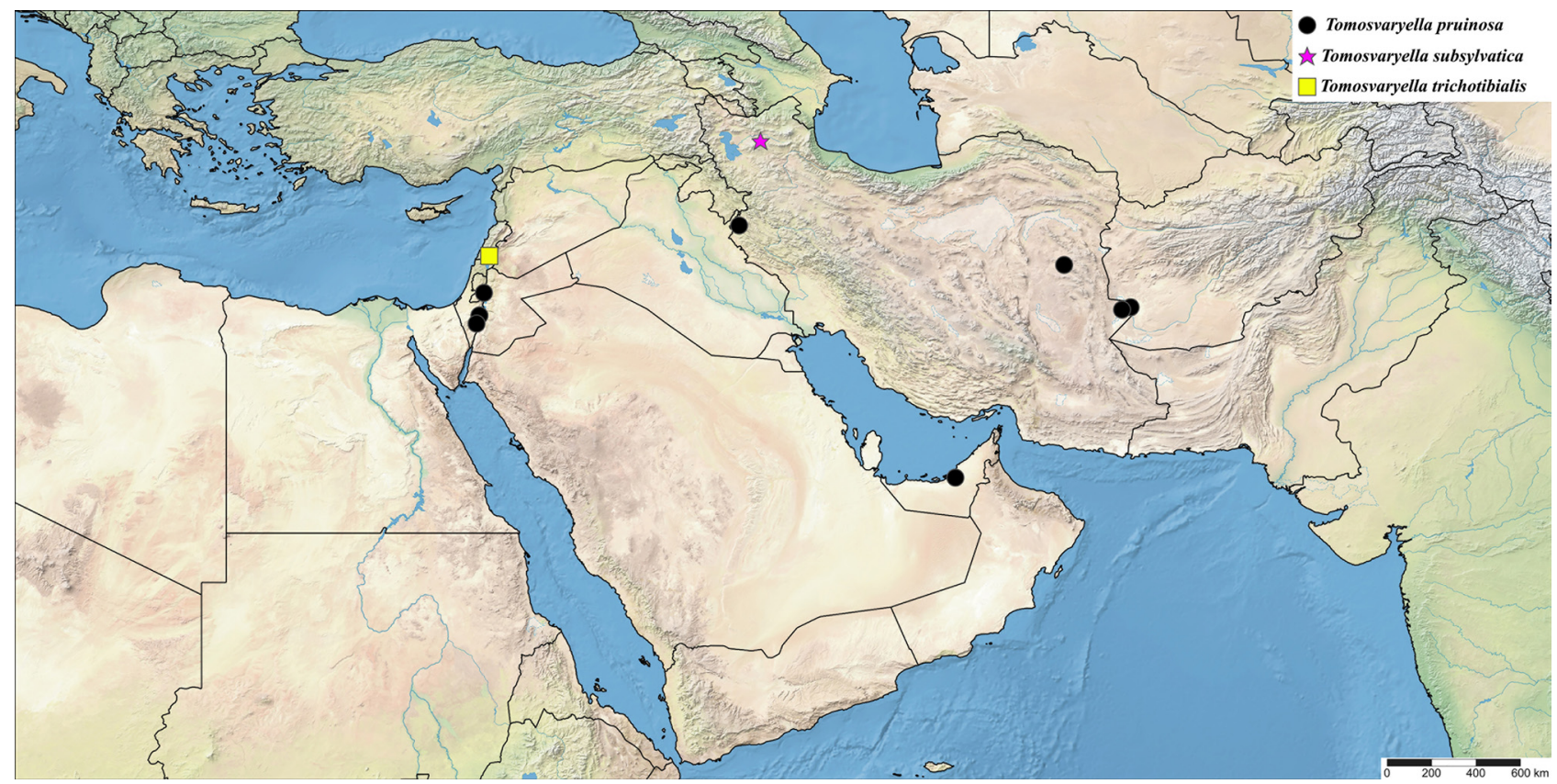

FIGURE 62. Distribution of Tomosvaryella pruinosa, T. subsylvatica, T. trichotibialis in the Middle East. 


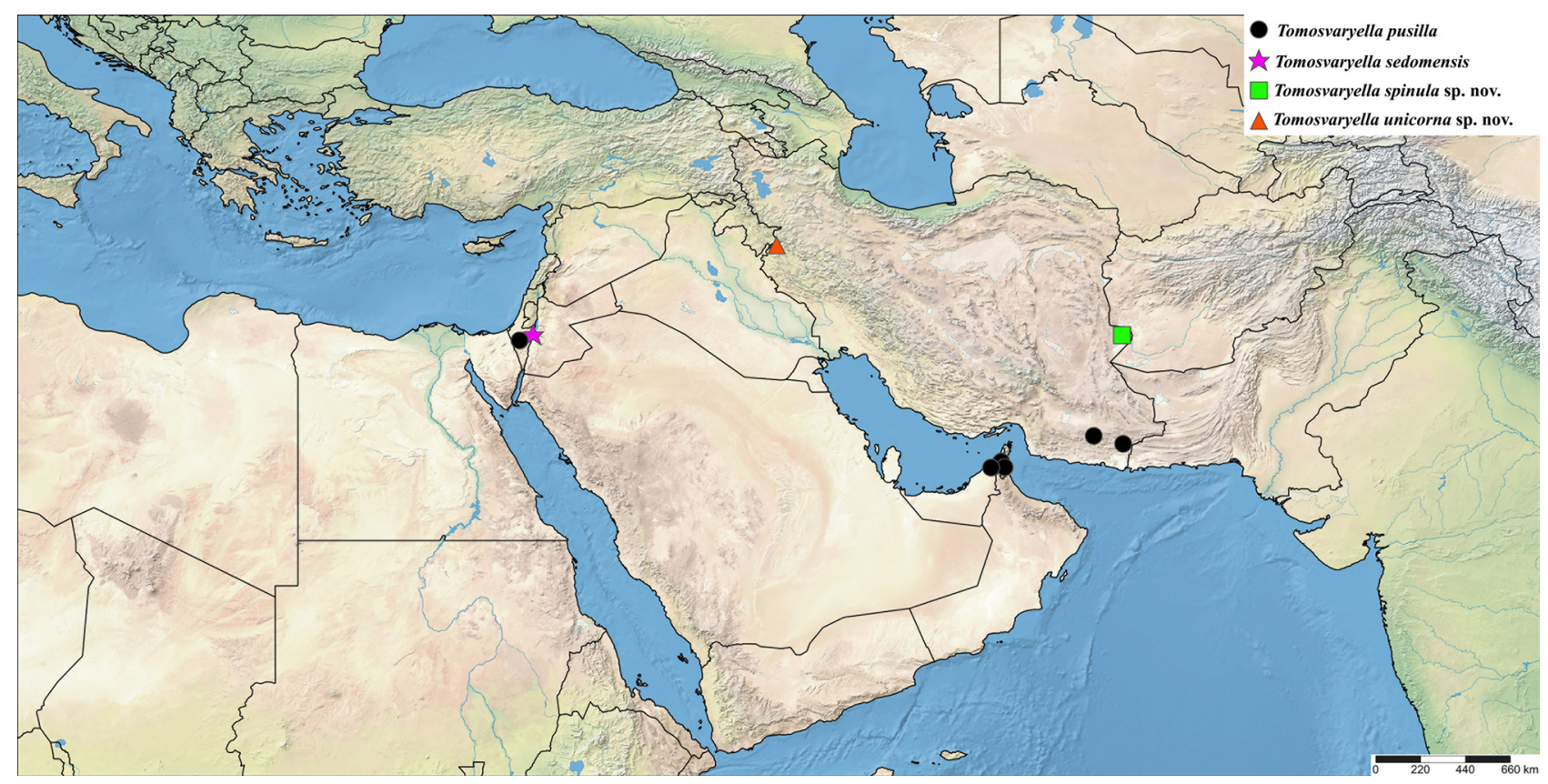

FIGURE 63. Distribution of Tomosvaryella pusilla, T. sedomensis, T. spinula sp. nov., T. unicorna sp. nov. in the Middle East.

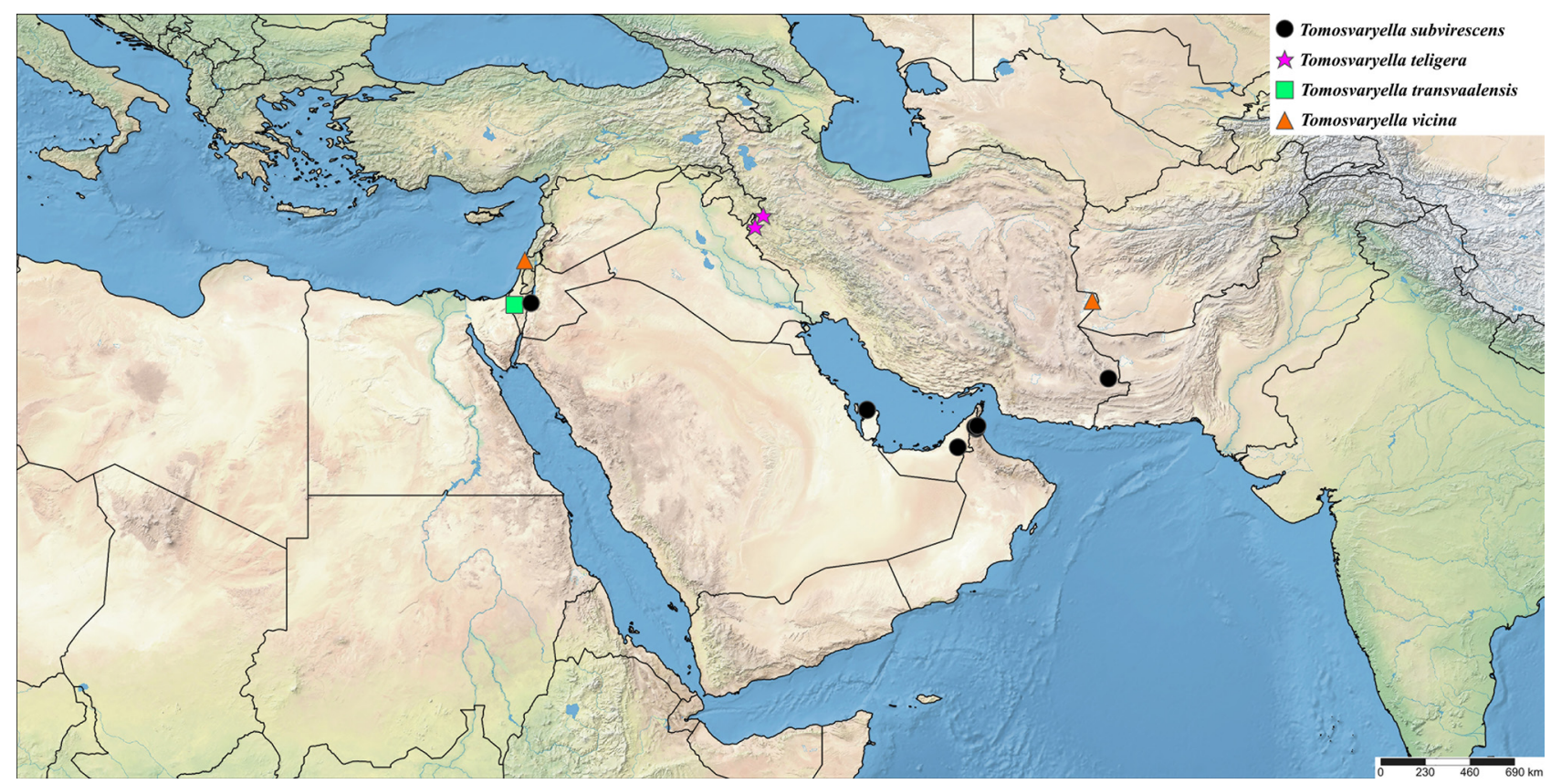

FIGURE 64. Distribution of Tomosvaryella subvirescens, T. teligera, T. transvaalensis, T. vicina in the Middle East. 

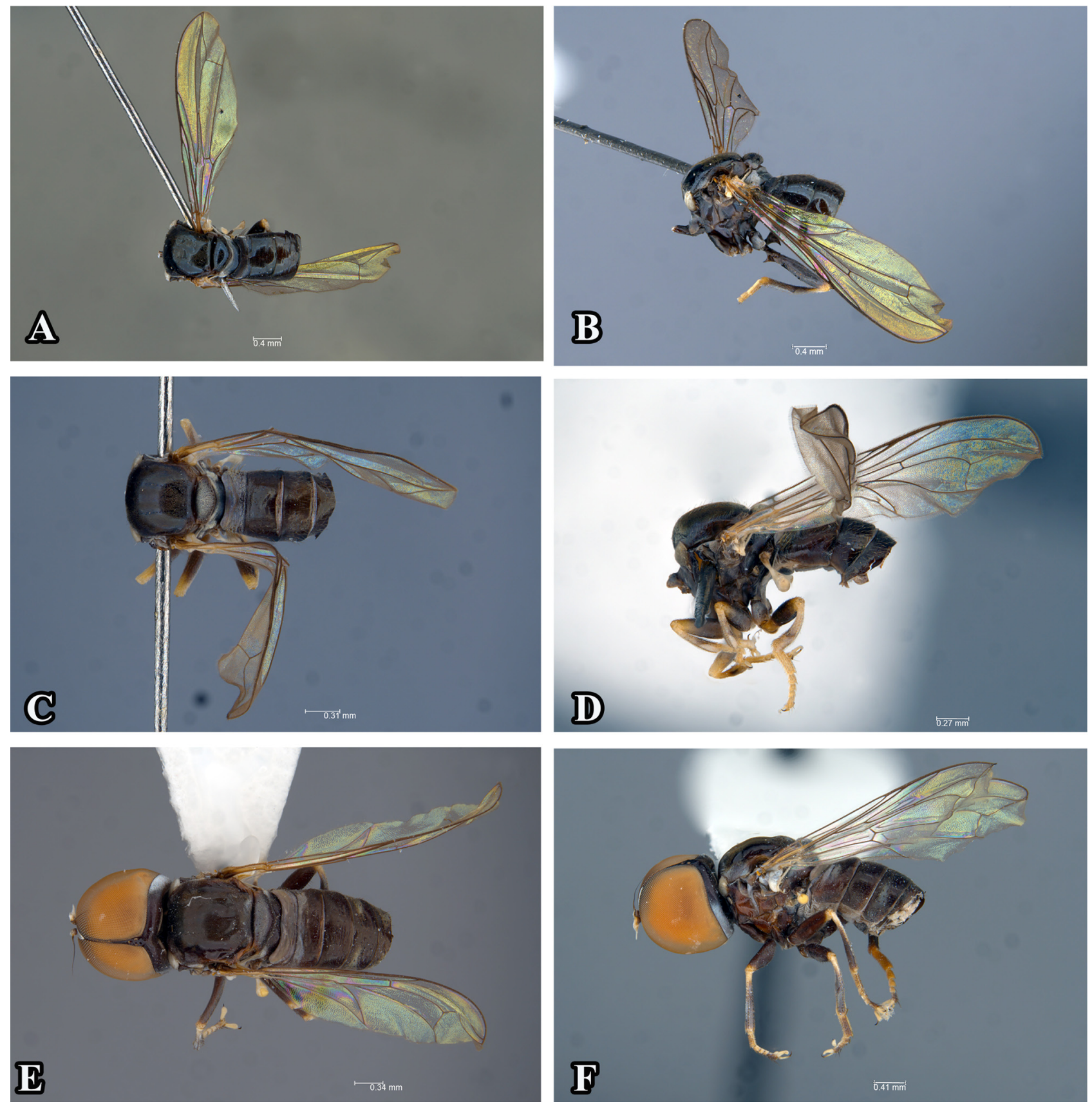

FIGURE 65. Male habitus of Tomosvaryella species A-B) T. acantha sp. nov., holotype (JSS51689, TAU) A) in dorsal view B) in lateral view, C-D) T. ampliasa sp. nov., holotype (JSS51800, TAU) C) in dorsal view D) in lateral view, E-F) T. anahitae sp. nov., holotype (JSS51946, CNC) E) in dorsal view F) in lateral view. 

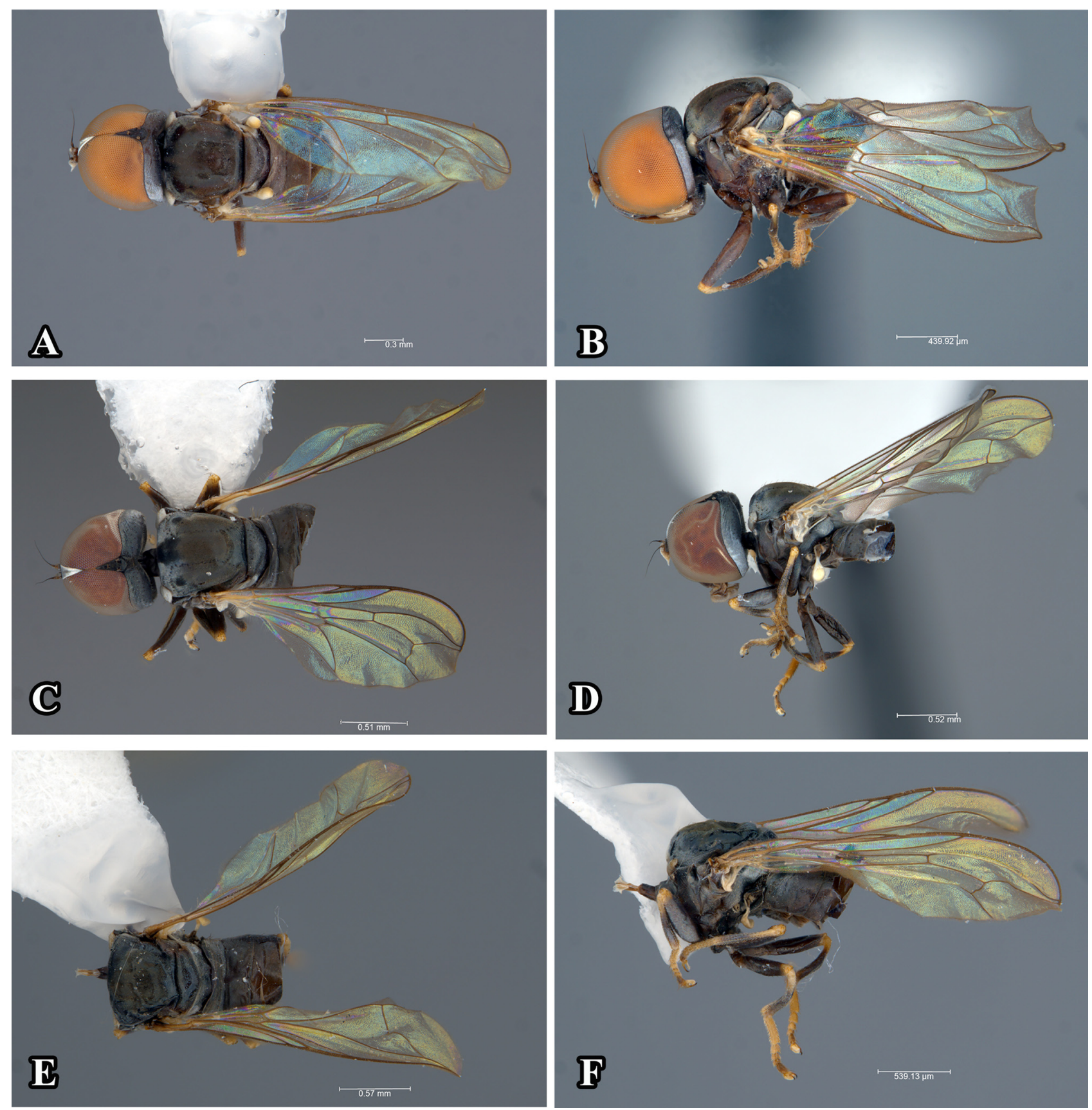

FIGURE 66. Male habitus of Tomosvaryella species A-B) T. bistounensis sp. nov., holotype (JSS51939, CNC) A) in dorsal view B) in lateral view, C-D) T. cyprusensis sp. nov., paratype (JSS52349, CNC) C) in dorsal view D) in lateral view, E-F) $T$. ellipiensis sp. nov., holotype (JSS51945, CNC): E) in dorsal view F) in lateral view. 

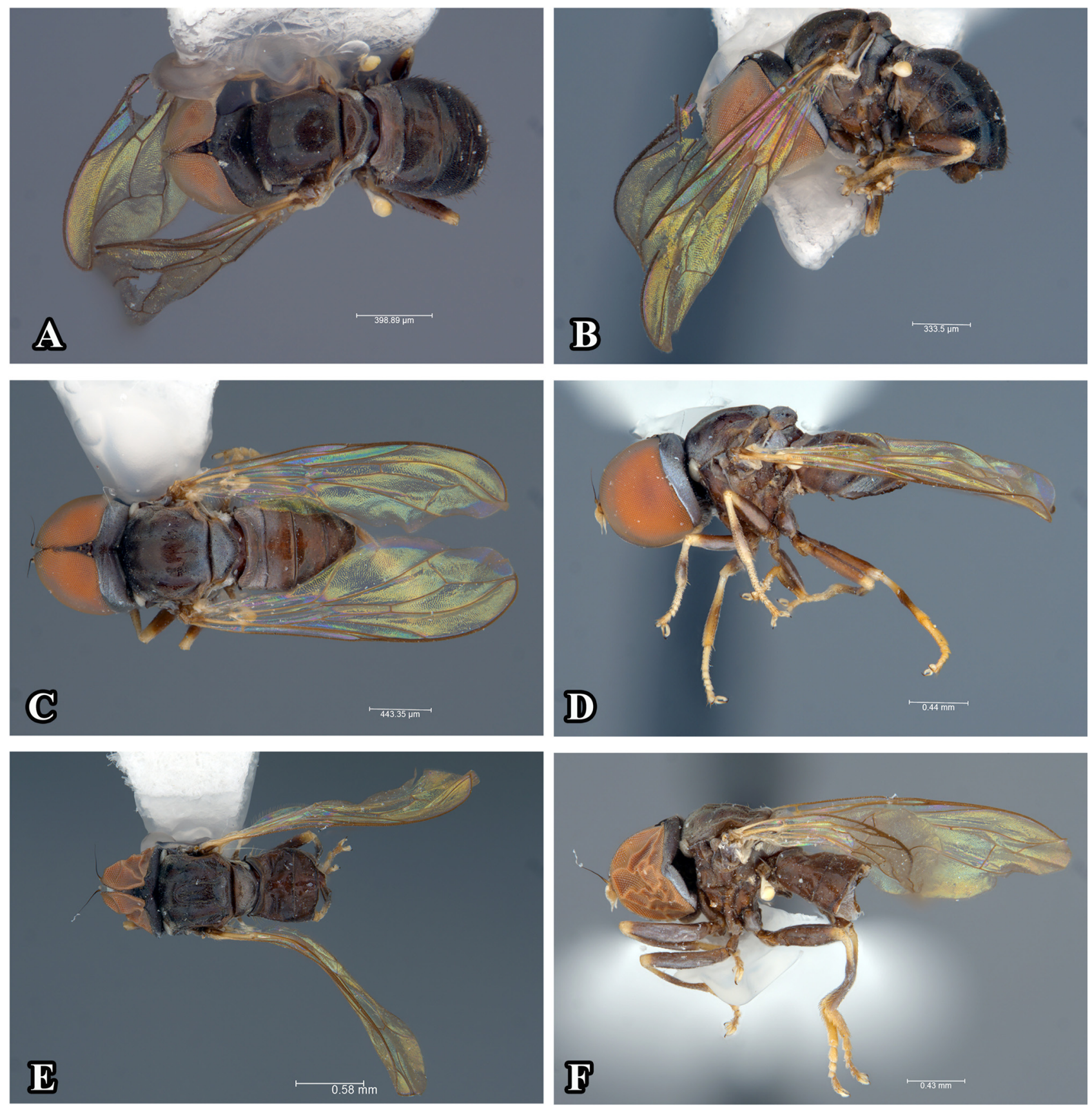

FIGURE 67. Male habitus of Tomosvaryella species A-B) T. emaratensis sp. nov., holotype (CNCD137568, CNC) A) in dorsal view B) in lateral view, C-D) T. hamounensis sp. nov., holotype (JSS51893, CNC) C) in dorsal view D) in lateral view, E-F) T. kiansiae sp. nov., holotype (JSS51921, CNC) E) in dorsal view F) in lateral view. 

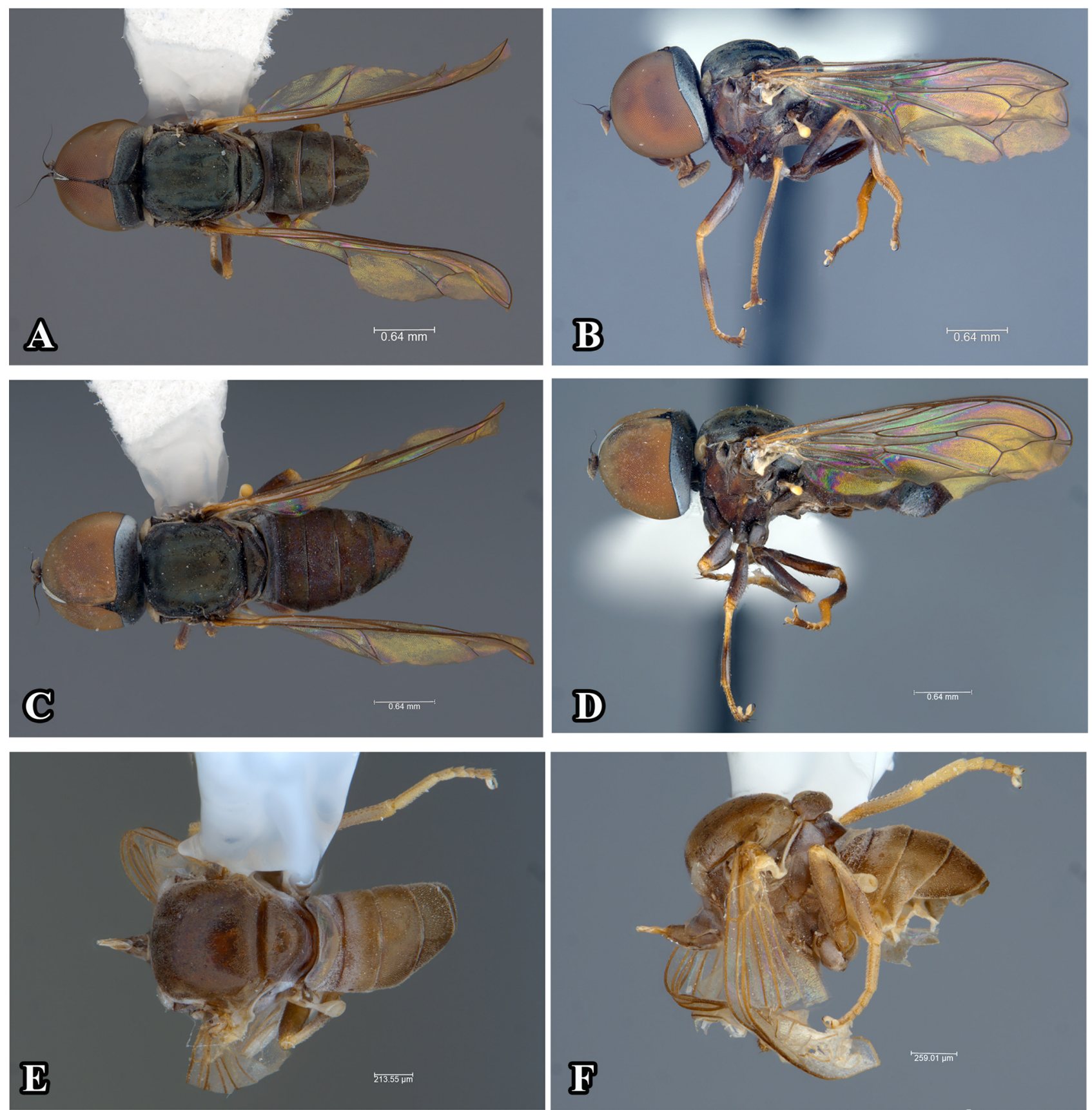

FIGURE 68. Male habitus of Tomosvaryella species A-B) T. nimroozensis sp. nov., holotype (JSS51819, CNC) A) in dorsal view B) in lateral view, C-D) T. oshidae sp. nov., holotype (JSS51818, CNC) C) in dorsal view D) in lateral view, E-F) T. osteodes sp. nov., holotype (CNCD175298, CNC) E) in dorsal view F) in lateral view. 

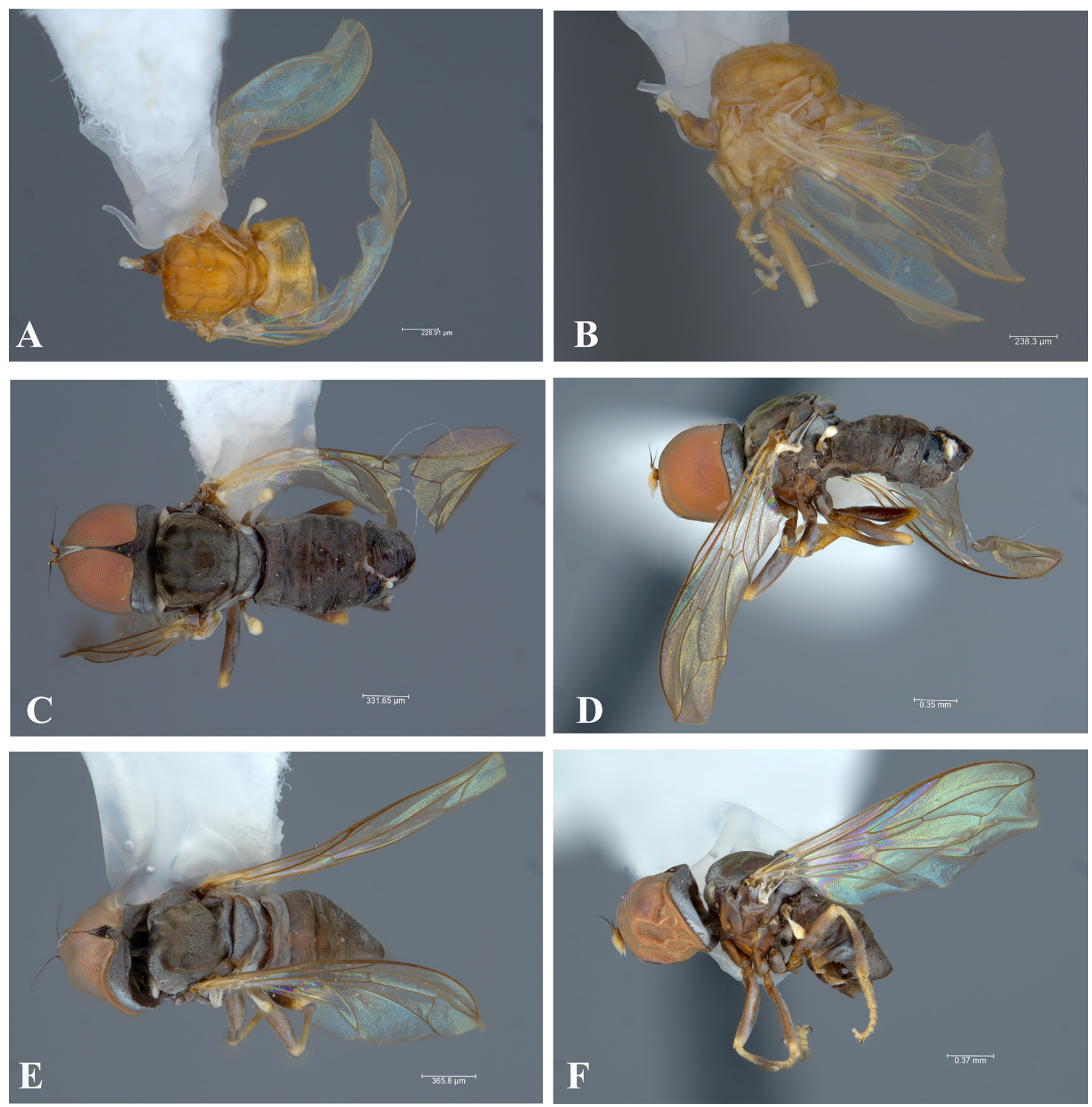

FIGURE 69. Male habitus of Tomosvaryella species A-B) T. saudiensis sp. nov., holotype (CNCD147709, CNC) A) in dorsal view B) in lateral view, C-D) T. soziana sp. nov., holotype (JSS52193, CNC) C) in dorsal view D) in lateral view, E-F) $T$. spinula sp. nov., holotype (JSS51924, CNC) E) in dorsal view F) in lateral view. 

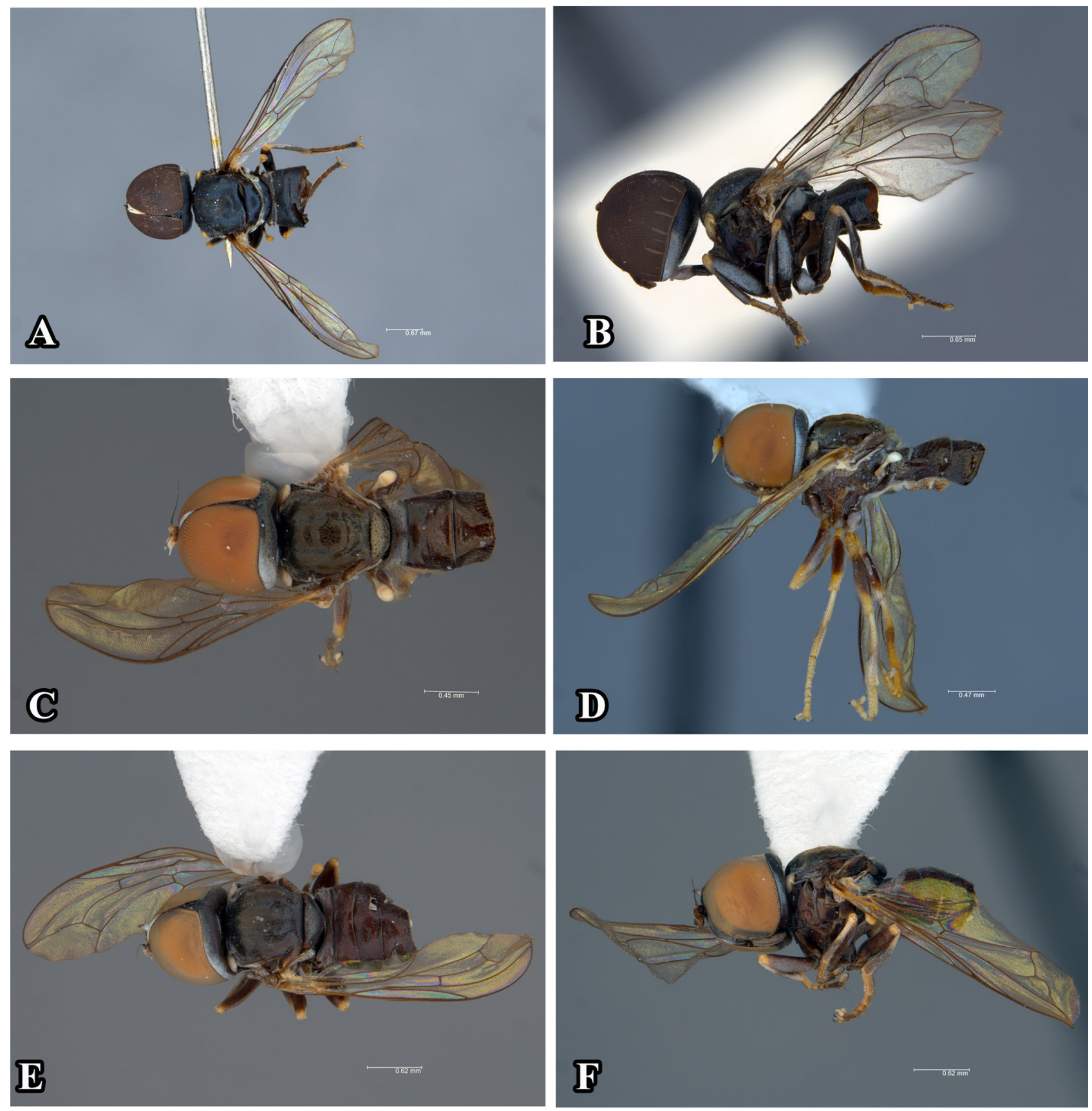

FIGURE 70. Male habitus of Tomosvaryella species A-B) T. subtransvaalensis sp. nov., holotype (JSS51765, TAU) A) in dorsal view B) in lateral view, C-D) T. susa sp. nov., holotype (JSS52217, CNC) C) in dorsal view D) in lateral view, E-F) $T$. unicorna sp. nov., holotype (JSS51821, CNC) E) in dorsal view F) in lateral view. 

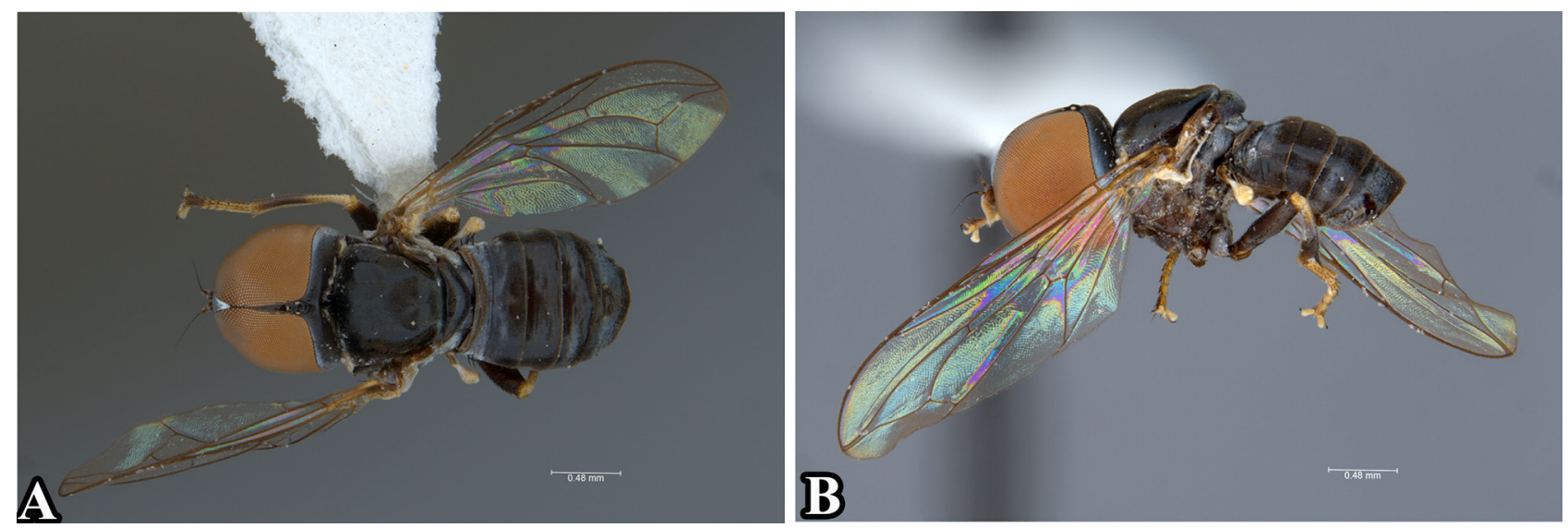

FIGURE 71. Male habitus of Tomosvaryella yemenensis sp. nov., holotype (CNCD9082, CNC) A) in dorsal view B) in lateral view.

\section{Discussion}

Among 59 Middle Eastern Tomosvaryella species revised here by comparing morphplogy, the T. kuthyi group, including T. emaratensis sp. nov., T. cyprusensis sp. nov., T. hispanica, T. freidbergi, T. israelensis, T. kuthyi and $T$. parakuthyi, has proven the most problematic. These species present few differential morphological characters, so more molecular and ecological work is needed to clarify if they are a single species with polymorphic genitalia or different species.

Based on the uncorrected pairwise genetic distances of mitochondrial cytochrome oxidase subunit I (COI) sequences among the Middle Eastern Tomosvaryella species presented in Supplementary Table 1, there are three clusters of overlapping sequences (with no barcoding gap) and clearly closely related species that we refer to as species groups. The first cluster including T. freidbergi and T. kuthyi belong to the T. kuthyi group as discussed by Földvári and De Meyer (1999) and differ by only $0.0-1.5 \%$. Similarly, a second cluster including T. pilosiventris and T. subvirescens differed by $0.3-1.9 \%$ and a third cluster including T. gazliensis, T. pruinosa and T. urdaensis differed by $0.0-0.6 \%$.

In our experience, ITS2 sequences are difficult to obtain from degraded material. It is much more difficult to obtain this marker than it is to sequence mitochondrial genes like COI. We have found that material must be ten years old or younger to have any reasonable chance of success when sequencing ITS2. Because of this, we only obtained six sequences for three species, T. freidbergi, T. kuthyi and T. parakuthyi to further test the morphological species concepts. Unfortunately, the divergence within ITS2 was similar to that seen in COI, suggesting that the species within this group are oversplit. Despite this, we have not synonymized these species as the morphological differences are consistent with that seen in closely related species supported by both morphology and DNA. More genetic work and sampling within these species groups are thus required. It is recommended that species in these problematic species groups are collected into $95 \%$ ethanol and retained in a freezer until enough specimens are available for a thorough analysis

\section{Acknowledgments}

We wish to thank C. Kehlmaier, N. Dorchin and the late A. Freidberg for the loan of specimens from Israel to the CNC. Special thanks to E. Rakhshani from Zabol University for his ongoing collaboration and support and to Tony van Harten for his incredible work sampling these flies in the UAE. Cyprus specimens come from a research project by André van Eck (Tilburg, Netherlands) and Ö. Özden (Lapta, Cyprus), supported by the Department of Landscape Architecture of the Near East University (Nicosia, Cyprus) who provided the collecting permit and financial support from the Dutch Uyttenboogaart-Eliasen foundation (ref. nr. SUB.2016.12.13). We are indebted to M. ParchamiAraghi, E. Gilasian, H. Derafshan, M. Zardouei, M. Ghaforimoghadam, F. Hamzavi, H. Davari, M. Arabzadeh, 
M. Enaiatnia and K. Ghahari for collecting and providing the specimens from Iran. Funding for the project was provided by an Agriculture and Agri-Food Canada A-base grant to J.H. Skevington.

\section{References}

Aczél, M.L. (1939) Das system der familie Dorylaidae. Dorylaiden-Studien I. Zoologischer Anzeiger, 125, 15-23.

Aczél, M.L. (1944) Die gattung Tomosvaryella Acz. (Dipt.). (Dorylaiden-Studien VIII). Annales Historico-Naturales Musei Nationalis Hungarici, 37, 75-130.

Adams, C.F. (1905) Diptera Africana, I. Kansas University Science Bulletin, 3, 149-208. https://doi.org/10.5962/bhl.part.8100

Ale-Rocha, R. \& Rafael, J.A. (1995) Tomosvaryella Aczél do México, América Central e Antilhas (Diptera, Pipunculidae). Revista Brasileira de Zoologia, 12, 407-427. https://doi.org/10.1590/S0101-81751995000200017

Ale-Rocha, R. (1996) Revisão das espécies de Tomosvaryella Aczél da América do Sul (Diptera, Pipunculidae). Revista Brasileira de Entomologia, 40, 165-187.

Becker, T. (1897) Dipterologische Studien V. Pipunculidae. Berliner Entomologische Zeitschrift, 42, 25-100. https://doi.org/10.1002/mmnd.18970420108

Becker, T. (1900) Dipterologische Studien V. Pipunculidae. Erste Fortsetzung. Berliner Entomologische Zeitschrift, 45, 215252. https://doi.org/10.1002/mmnd.47919000308

Becker, T. (1907) Die Ergebnisse meiner dipterologischen Frühjahrsreise nach Algier und Tunis, 1906. (Forts. aus 1906). Zeitschrift für Systematische Hymenopterologie und Dipterologie, 7, 225-256. https://doi.org/10.5962/bhl.title.9280

Becker, T. (1913) Persische Dipteren von den Expeditionen des Herrn N. Zarudny 1898 und 1901. Annuaire du Musée Zoologique de l'Académie Impériale des Sciences de St. Petersbourg, 17, 503-654.

Collin, J.E. (1949) Results of the Armstrong College Expedition to Siwa Oasis (Libyan Desert), 1935, under the leadership of Prof. J. Omer-Cooper. Diptera Empididae, Dolichopodidae, Aschiza and Acalypterae. Bulletin de la Société Fouad 1er d'Entomologie, 33, 175-225.

Collin, J.E. (1956) Scandinavian Pipunculidae. 1. On the species of Pipunculus in the collection of Fallén at Stockholm and Zetterstedt, and others at Lund. Opuscula Entomologica, 21, 149-169.

Collin, J.E. (1958) Pipunculidae collected by Mr. Ralph L. Coe in Jugoslavia in 1955, with descriptions of two new species. Entomologist, 91, 96-99.

De Meyer, M. (1993) A revision of the Afrotropical species of Tomosvaryella Aczél, 1939(Diptera: Pipunculidae). Annals of the Natal Museum, 34, 43-101.

De Meyer, M. (1995) The pipunculid flies of Israel and the Sinai (Insecta, Diptera, Pipunculidae). Spixiana, 18, $283-319$.

De Meyer, M. (1996) World catalogue of Pipunculidae (Diptera). Studiedocumenten van het Koninklijk Belgisch Instituut voor Natuurwetenschappen, 86, 1-127.

De Meyer, M. (1997) Contribution to the Pipunculidae fauna of Spain: (Diptera). Beiträge zur Entomologie, 47, 421-450.

De Meyer, M., Földvári, M. \& Báez, M. (2000) The Pipunculidae (Diptera) fauna of the Canary Islands and Madeira. Bulletin de l'Institut Royal des Sciences Naturelles de Belgique, Entomologie, 136, 144-152.

Földvári, M. \& De Meyer, M. (1999) Revision of central and west European Tomosvaryella Aczél species (Diptera, Pipunculidae). Acta Zoologica Academiae Scientiarum Hungaricae, 45, 299-334.

Folmer, O., Black, M., Hoeh, W., Lutz, R. \& Vrijenhoek, R. (1994) DNA primers for amplification of mitochondrial cytochrome c oxidase subunit I from diverse metazoan invertebrates. Molecular Marine Biology and Biotechnology, 3, $294-299$.

Gibson, J.F., Kelso, S., Jackson, M.D., Kits, J.H., Miranda, G.F.G. \& Skevington, J.H. (2011) Diptera-Specific Polymerase Chain Reaction Amplification Primers of Use in Molecular Phylogenetic Research. Annals of the Entomological Society of America, 104, 976-997. https://doi.org/10.1603/an10153

Hardy, D.E. (1943) A revision of Nearctic Dorilaidae (Pipunculidae). University of Kansas Science Bulletin, 29, 1-231.

Hardy, D.E. (1967) Redescription of Tomosvaryella frontata (Diptera: Pipunculidae). Annals of the Entomological Society of America, 60, 116-118. https://doi.org/10.1093/aesa/60.1.116

Kazerani, F., Khaghaninia, S. \& Kehlmaier, C. (2017) Additions to the Pipunculidae fauna of Iran with the description of a new Tomosvaryella (Insecta: Diptera). Zoology in the Middle East, 63, 147-153. https://doi.org/10.1080/09397140.2017.1315856

Kehlmaier, C. (2005) Taxonomic revision of European Eudorylini (Insecta, Diptera, Pipunculidae). Verhandlungen des Naturwissenschaftlichen Vereins in Hamburg, Neue Folge, 41, 45-353.

Kehlmaier, C. (2008) Finnish Pipunculidae (Diptera) studies Part I: Taxonomic notes on Cephalops Fallén, 1810, Pipunculus Latreille, 1802 and Tomosvaryella Aczél, 1939. Zootaxa, 1672 (1), 1-42. 
https://doi.org/10.11646/zootaxa.1672.1.1

Kehlmaier, C. \& Majnon Jahromi, B. (2014) On the presence of Pipunculidae (Diptera) in Iran. Studia dipterologica, 21, 29-36.

Kehlmaier, C., Gibbs, D.J. \& Withers, P. (2019) New records of big-headed flies (Diptera: Pipunculidae) from the Mediterranean Basin. Bonn Zoological Bulletin, 68 (1), 31-60

Kertész, K. (1907) Vier neue Pipunculus-arten. [Four new Pipunculus species]. Annales Historico-Naturales Musei Nationalis Hungarici, 5, 579-583.

Kozánek, M. (1992) Contribution to the pipunculid fauna of Mongolia (Diptera: Pipunculidae). Akitu, Kyoto Entomological Society, New Series, 131, 1-16.

Kumar, S., Stecher, G. \& Tamura, K. (2016) MEGA7: Molecular Evolutionary Genetics Analysis version 7.0 for bigger datasets. Molecular Biology and Evolution, 33 (7), 1870-1874. https://doi.org/10.1093/molbev/msw054

Kuznetzov, S.Y. (1993) A new Tomosvaryella Aczél from Egypt, with redescription of T. disjuncta (Becker) (Diptera, Pipunculidae). Dipterological Research, 4, 151-162.

Kuznetzov, S.Y. (1994) New Palaearctic species of Tomosvaryella Aczél (Diptera, Pipunculidae) with a redescription of T. rondanii (Collin). Dipterological Research, 5, 107-207.

Littlefield, R. (2018) Zerene Stacker. Available from: http://zerenesystems.com/cms/stacker (accessed 28 June 2021)

Loew, H. (1872) Diptera Americae septentrionalis indigena. Centuria decima. Berliner Entomologische Zeitschrift, 16, 49124. https://doi.org/10.1002/mmnd.18720160110

Maddison, W.P. \& Maddison, D.R. (2018) Mesquite: a modular system for evolutionary analysis. Version 3.51. Available from http://www.mesquiteproject.org (accessed 28 June 2021)

Majnon-Jahromi, B., Gheibi, M., Fallahzadeh, M., Kehlmaier, C. \& Hesami, S. (2017a) A checklist of the genus Tomosvaryella Aczél (Diptera: Pipunculidae) from the Middle East with the description of a new species. Zoology in the Middle East, 63, $336-347$. https://doi.org/10.1080/09397140.2017.1349240

Majnon-Jahromi, B., Gheibi, M., Fallahzadeh, M., Kehlmaier, C. \& Hesami, S. (2017b) Pipunculidae (Diptera) from southern Iran, including two new species of the genus Tomosvaryella Aczél. Zootaxa, 4273 (4), 488-500. https://doi.org/10.11646/zootaxa.4273.4.2

Majnon-Jahromi, B.M., Gheibi, M., Fallahzadeh, M., Kehlmaier, C. \& Hesami, S. (2018) An annotated list of the big-headed flies (Diptera: Pipunculidae) of Iran with notes on the material collected by window traps in Fars province. Far Eastern Entomologist, 367, 10-20. https://doi.org/10.25221/fee.367.2

Meigen, J.W. (1824) Systematische Beschreibung der bekannten europäischen zweiflügligen Insekten. Vol. 4. Vierter Theil. Schultz-Wundermann, Hamm, XII + 428 pp., tabs 33-41.

Motamedinia, B., Skevington, J.H. \& Kelso, S. (2019) Revision of Claraeola (Diptera, Pipunculidae) in the Middle East based on morphology and DNA barcodes. Zookeys, 873, 85-111.

https://doi.org/10.3897/zookeys.873.36645

Motamedinia, B., Skevington, J.H. \& Kelso, S. (2020) Revision of Eudorylas Aczél, 1940 (Diptera, Pipunculidae) in the Middle East, with the description of four new species. Biodiversity Data Journal, 8, e53609. https://doi.org/10.3897/BDJ.8.e53609.figure14

Perkins, R.C.L. (1905) Leaf-Hoppers and their natural enemies (pt.IV. Pipunculidae). Bulletin. Division of Entomology. Hawaiian Sugar Planters Association Experiment Station, 1, 123-157.

Rafael, J.A. \& De Meyer, M. (1992) Generic classification of the family Pipunculidae (Diptera): a cladistic analysis. Journal of Natural History, 26, 637-658. https://doi.org/10.1080/00222939200770391

Ramos-Pastrana, Y. \& Rafael, J.A.J.Z. (2021) Tomosvaryella Aczél (Diptera: Pipunculidae) of Colombia, with description of two new species. Zootaxa, 4985 (1), 37-68. https://doi.org/10.11646/zootaxa.4985.1.2

Shorthouse D.P. (2010) SimpleMappr, an online tool to produce publication-quality point maps. Available from: http://www. simplemappr.net (accessed 20 April 2020)

Skevington, J.H. (2002) Phylogenetic revision of Australian members of the Allomethus genus group (Diptera: Pipunculidae). Insect Systematics and Evolution, 33, 133-161. https://doi.org/10.1163/187631202X00109

Skevington, J.H. \& Földvári, M. (2007) Revision of Fijian Tomosvaryella Aczél (Diptera: Pipunculidae). Bishop Museum Occasional Papers: Fiji Arthropods VIII, 93, 27-40.

Skevington, J.H., Kehlmaier, C. \& Ståhls, G. (2007) DNA barcoding: Mixed results for big-headed flies (Diptera: Pipunculidae). Zootaxa, 1423 (1), 1-26.

https://doi.org/10.11646/zootaxa.1423.1.1

Skevington, J.H. (2020) "Pipunculidae". Canadian National Collection of Insects, Arachnids and Nematodes database. Available from: https://cnc.agr.gc.ca/taxonomy/Taxonomy.php?id=18557 (accessed 18 October 2020) [public version of Pipun- 
culidae catalogue maintained by J.H. Skevington]

Weekers, P.H.H., De Jonckheere, J.F. \& Dumont, H.J. (2001) Phylogenetic relationship inferred from ribosomal ITS sequences and biogeographic patterns in representatives of the genus Calopteryx (Insecta: Odonata) of the West Mediterranean and adjacent West European Zone. Molecular Phylogenetics and Evolution, 20, 89-99. https://doi.org/10.1006/mpev.2001.0947

Young, A.D., Marshall, S.A. \& Skevington, J.H. (2016) Revision of Nearctic Platycheirus Lepeletier and Serville (Diptera: Syrphidae). Zootaxa, 4082 (1), 1-317.

https://doi.org/10.11646/zootaxa.4082.1.1 